\title{
6. GESCHÄFTE UND POLITIK \\ ABDELKRIMS TRAUM VON EINEM RIFSTAAT UND DER BERGBAU
}

\subsection{Abdelkrim und die Mannesmann-Brüder aus Remscheid}

Abdelkrim trachtete danach, den Rifkrieg diplomatisch zu internationalisieren, um die Chancen für eine weltweite Anerkennung seines Staates zu verbessern. Er bediente sich hierfür politischer Vermittler, die den Kontakt zwischen der "Rif-Republik« und den Regierungen vornehmlich in Europa herstellen sollten. Einige von ihnen waren gleichzeitig an Bergbaugeschäften innerhalb des Rifs beteiligt und/oder betätigten sich als Nachschublieferanten bzw. Waffenschmuggler. Abdelkrims Ziel der Anerkennung eines unabhängigen Rifstaates war untrennbar mit der Vergabe von Bergbau-Konzessionen an ausländische Kapitalgeber verbunden. Während des gesamten Rifkrieges versuchten die Khattabibrüder, den vermeintlich erzreichen Untergrund ihres Herrschaftsgebietes an finanzkräftige Interessenten aus dem Ausland zu veräußern bzw. sie gegeneinander in parallelen Verhandlungen auszuspielen. Auf diese Weise sollten europäisches Kapital, europäische Technik und eine europäische Infrastruktur im Rif aufgebaut werden. Auch so wollte Abdelkrim demnach sModernität Einzug halten lassen. Gleichzeitig erhoffte er sich mit dem Lockmittel Bergbau größere Chancen für eine internationale Anerkennung der »Rif-Republik«. Diesen Plänen lag die feste Überzeugung zugrunde, daß es im Rif große Reichtümer an Bodenschätzen gab.

Der Wettbewerb um Konzessionsrechte in Nordmarokko begann 1905, als ein regelrechtes »Bergbaufieber ${ }^{1}$ ausbrach. Der spanische Geologe Alfonso del Valle de Lersundi hatte die reichen Erzfelder vom Jebel Ouixane, vom Jebel Afra und von Beni Bou Ifrour südlich von Melilla entdeckt. Diese "Minas del Rif" genannten Gebiete spielten fortan in den spanischen Kolonialvisionen für Marokko eine maßgebende Rolle ${ }^{2}$.

\footnotetext{
${ }^{1}$ MADARIAGA, España y el Rif, S. 123.

${ }^{2}$ AZIZA, Le Rif, S. 133, S. 136f., S. 142-145; Salvador TEN, Exploitation du gisement de minerai de fer d'Ouichane Achara de la Compagnie espagnole des mines du Rif, in: Mines et geologie 4 (1961) S. 55-61, S. 55; Walter DIECKMANN, Die geologischen Verhältnisse der Umgebung von Melilla unter besonderer Berücksichtigung der Eisenerz-Lagerstätten des Gebietes von Beni-Bu-Ifrur im marokkanischen Rif, Berlin (Diss.) 1912, S. 20-22; José A. GUTIÉRREZ DE LA PAZ, La explotación de mineral de hierro en el Rif, in: De economía 16 (1951) S. 428-446, S. 433; Lluís RIUDOR I GORGAS, Expediciones, excursiones y correrias en el protectorado español en Marruecos, in: NoGUE, VILLANOVA (Hg.), España, S. 303-339, S. 309; VilLALOBOS, El sueño colonial, S. 67.
} 
Das Interesse anderer Nationen war ebenfalls geweckt worden. Seit dem Ende des 19. Jahrhunderts richtete die europäische Schwerindustrie auf ihrer Suche nach Rohstoffen - insbesondere nach phosphorarmem Eisen - ihr Augenmerk vermehrt nach Marokko ${ }^{3}$. Vor allem englische, französische, spanische und deutsche Interessenten lieferten sich einen Wettstreit um die marokkanischen Bergbaurechte. 1880 hatte der Marokko-Vertrag von Madrid allen Unterzeichnerstaaten gleichberechtigte wirtschaftliche Chancen eingeräumt. Artikel 112 des Vertrages von Algeciras von 1906 schrieb vor, daß vor der Ausbeutung von Bodenschätzen ein marokkanisches Bergbaugesetz verabschiedet werden mußte. Die rechtlichen Streitigkeiten zwischen den rivalisierenden europäischen Nationen in diesem Kampf um Bergbau-Konzessionen fanden lange Zeit kein Ende ${ }^{4}$.

Nach der Errichtung der spanischen Einflußzone Marokkos dauerte es bis zum Januar 1914, ehe zwei Erlasse des marokkanischen Sultans die Einsetzung einer internationalen Schiedskommission für bergbauliche Rechtsstreite in Marokko (Commission arbitrale de litiges minières au Maroc) mit Sitz in Paris vorschrieben. Sie hatte verbindlich über sich überlappende oder sich häufig widersprechende Ansprüche verschiedener Bergbaugruppen aus ganz Europa zu entscheiden ${ }^{5}$.

Noch 1914 urteilte die Schiedskommission über die Erteilung provisorischer Besitztitel im Umkreis von Melilla. Vier Bergbaufirmen, die Compañía española de Minas del Rif, die Compañía norte africano, die Sociedad anónima minera Setolazar und die Compañía la Alicantina erhielten die vorläufige Erlaubnis, auf ihren Besitztümern bei Melilla Erze zu schürfen und zu exportieren $^{6}$. Die vier Firmen nahmen ihre Arbeit noch während des Ersten Weltkrieges im Osten von Spanisch-Marokko auf'.

${ }^{3}$ Ulrich WENGENROTH, Auslandsinvestitionen der deutschen Schwerindustrie zur Sicherung ihrer Erzversorgung zwischen Gründerjahren und Weltwirtschaftskrise, Arbeitspapier, 15.11.1998, S. 6 u. S. 6, Anm. 8. URL: http://www.mzwtg.mwn.de/arbeitspapiere/we_erzfdi. pdf [14.5.2003]; LEONIDOFF, Der Kampf um die Eisenerze Nordafrikas, in: Wirtschaftsdienst 13 (1928) S. 1971-1974, S. 1971.

${ }^{4}$ Balfour, Deadly Embrace, S. 16; ALlan, Agadir, S. 123; MADARIAGa, España y el Rif, S. $163 f$.

${ }^{5}$ Robert RUZE, Litiges minières du Maroc. L'affaire Mannesmann, in: Revue de droit international et de législation comparée 47 (1920) S. 159-168, S. 162.

${ }^{6}$ Madariaga, España y el Rif, S. 157, S. 175f., S. 179; AZIZA, Le Rif, S. 133; LeONDOFF, Der Kampf, S. 1971; Allan, Agadir, S. 113f.; GuTIERREZ dE LA PAZ, La explotación, S. 432f., S. 444; Les richesses minières, in: BCAF 31 (1921) S. 64-66, S. 64; Minenschiedsgericht für Marokko, in: Vossische Zeitung, 17.4.1914; CADN Tanger B44: Vice-Consulate of Tetuan an RG Rabat 2.2.1918; PA-AA R16097, A28742: Botschaft Madrid an AA, 28.10.1914.

${ }^{7}$ Jacques LeVAinville, Les minerais de fer dans la zone espagnole au Maroc, in: La géographie 35 (1921) S. 169f., S. 170; LADREIT DE LACHARRIERE, Le rêve, S. 20; ESPAÑa, La actuación, S. 206f; L'exportation des minerais de Melilla, in: BCAF 29 (1919) S. 252; Claus H. MANNESMANN, Die Unternehmungen der Brüder Mannesmann in Marokko, Würzburg 
Damit war die Entscheidung über das wichtigste Bergbaugebiet in der spanischen Einflußzone bereits gefallen. Es lag außerhalb des späteren Herrschaftsbereichs Abdelkrims. Er erhob auf diese Felder auch nie Anspruch und betrachtete sie als zu Spanien gehörig ${ }^{8}$. Die Riftruppen zerstörten die Bergbaubetriebe 1921 im Zuge ihres Vormarsches auf Melilla, zogen sich im Anschluß aber wieder zurück' .

Nicht nur bei Melilla, sondern in ganz Spanisch-Marokko wurden vor dem Ersten Weltkrieg zwischen europäischem Kapital und indigenen Lokalfürsten Bergbauverträge abgeschlossen. 203 Anträge gingen bis 1914 bei der Pariser Schiedskommission ein. 102 kamen aus Spanien, 46 aus Deutschland, 27 aus Großbritannien, 21 aus Frankreich, sechs aus den Niederlanden und einer aus Italien. Bis Ende 1925 zählte die nun zuständige Bergbauverwaltung, der Servicio de minas del protectorado, gar 674 Anträge. 155 bezogen sich auf den Osten der spanischen Einflußzone, 89 auf das Ghomara-Gabiet, 51 auf den Sektor Tetuan, 131 auf das Gebiet um Larache. Insgesamt 248 Anträge - also der weitaus höchste Anteil - betrafen Bereiche im zentralen Rif $^{10}$.

Diese Petitionen bezogen sich demnach insbesondere auf Gebiete der Beni Ouriaghel, die Spanien zu dieser Zeit noch gar nicht unter Kontrolle hatte. Dort erhofften sich die Petitionäre ähnliche Erzvorkommen wie bei Melilla. Genaueres wußte allerdings niemand. Angeblich >wissenschaftliche< Berichte spanischer wie französischer Geologen stützten sich »weniger auf Mutungen als auf Vermutungen «" ${ }^{11}$, da kaum einer von ihnen sich im Rif aufgehalten, geschweige denn Probebohrungen vorgenommen hatte. Bis zum Anfang des 20. Jahrhunderts war der Norden Marokkos aus europäischer Sicht eines der am wenigsten erforschten Gebiete des afrikanischen Kontinents. Wer sich für Bergbau interessierte, war auf Berichte der einheimischen Bevölkerung angewiesen. Hartnäckig hielten sich Geschichten über sagenhafte Boden->Schätzer. Insbesondere der fast 2000 Meter hohe Jebel Hamam - eine Art >Hausberg`

(Diss.) 1931, S. 28; Mohamed el ABDELlaOuı, Nour E. CHIKHI, Explotación de los recursos naturales, in: NoGUE, VillaNova (Hg.), España, S. 509-550, S. 543; Víctor MORALES LeZCANO, El colonialismo hispanofrancés en Marruecos 1898-1927, Madrid 1976, S. 83; DERS., Las minas del Rif y el capital financiero peninsular 1906-1930, in: Moneda y crédito 135 (1975) S. 61-79, S. 74.

${ }^{8}$ RUE, Tribune, 23.6.1925; Robert GORDON-CANNING, The Riff (Leserbrief, 24.7.1925), in: Manchester Guardian, 27.7.1925.

${ }^{9}$ PA-AA R72041, L057297: Konsulat Tetuan an Botschaft Madrid, 16.8.1921; WoOLMAN, Rebels in the Rif, S. 95f.

${ }^{10}$ Madariaga, España y el Rif, S. 177; Jean-Paul TRYSTRAM, Le mineur marocain. Contribution statistique à une étude sociologique, Paris (Diss.) 1955, S. 28; Minerals of the Spanish Zone, in: Morocco, 16.4.1921.

${ }^{11}$ BEN ASSAR, Kampf um das Schatzland, S. 39. 
der Khattabis im Süden des Gebietes der Beni Ouriaghel - sollte diesen Legenden zufolge Gold, Kupfer und Silber in seinem Untergrund bergen ${ }^{12}$. Davon war Abdelkrim noch nach dem Ende des Rifkrieges fest überzeugt ${ }^{13}$.

Gerade dieser Berg, das sogenannte »Eldorado der Mineninteressenten ${ }^{14}$, fachte später die Phantasien abenteuerlustiger Spekulanten während der Herrschaft Abdelkrims an. Die Träume sollten nach dem Rifkrieg wie eine Luftblase zerplatzen. Eine kurz nach Abdelkrims Kapitulation durchgeführte Inspektionsreise von Bergbauingenieuren der Sociedad minera y metalúrgica de Pañarroya erbrachte ernüchternde Ergebnisse. Die Legende vom Reichtum des Rifs an Bodenschätzen erwies sich als Trugbild. Dies galt auch für Abdelkrims vermeintlich wichtigsten Faustpfand, den Jebel Hamam ${ }^{15}$. Bis heute gibt es im Rifgebirge keinen nennenswerten Bergbau ${ }^{16}$.

Einige Zeitgenossen vertraten die Ansicht, daß vor allem die Sicherung der Bergbaugeschäfte Abdelkrim zu seinem Widerstandskampf veranlaßt hätte ${ }^{17}$. Dies geht sicher zu weit, auch wenn sein Wunsch zur persönlichen Bereicherung nicht außer acht gelassen werden sollte. Seine Hauptantriebsfeder war die Auflehnung gegen die spanischen Invasoren. Dennoch spielte der Bergbau eine erhebliche Rolle, da für Abdelkrim die Rifbevölkerung das Recht hatte, Wirtschaftsverträge eigenverantwortlich abzuschließen. Im Laufe des Jahres 1921 erlebte er jedoch mit, wie die Pariser Schiedskommission über weite Teile des zentralen Rifs Forschungs- und Schürfrechte verteilte. Es war klar, daß über die Vergabe von Bergbaurechten nicht im Rif selbst, sondern anderswo entschieden wurde. Spanische Petitionäre behielten 1921 die Oberhand. Es handelte sich um die Salama-Gruppe (22. November 1921: Schürfrecht für den Jebel Hamam, 2580 ha), Manuel Ferrer Marín (2. Dezember 1921: Recht

${ }^{12}$ CAOM 10 APOM 295: Bericht von Robert Montagne "L'affaire riffaine - Abd el Krimu, 28.5.1937; FonTAINE, Abd el-Krim, S. 69; SHIN, La Guerte du Rif, S. 58; WoOlman, Rebels in the Rif, S. 39; DAOUD, Abdelkrim, S. 55; DuMAS, Abd-el-Krim, S. 36; Paul MOHR, Tragödie des Rif, in: Tägliche Rundschau, 8.9.1925; Mineral Riches in Morocco, in: Morocco, 6.8.1921.

${ }^{13}$ ABDELKRIM, Memoiren, S. 108.

${ }^{14}$ Edgar PröBSTER, Liquidation der Rifrepublik, in: Der Deutsche Gedanke 3 (1926) S. $922-$ 929, S. 925.

${ }^{15}$ CADN Madrid C312: Ambassade de Madrid an MAE, 22.7.1926 mit Bezug auf einen Bericht der Sociedad minera y metalúrgica de Peñarroya, 21.7.1926. Vgl. Mineral Wealth of the Riff, in: Al-Moghreb al Aksa \& Tangier Gazette, 3.7.1926.

${ }^{16}$ Bernadette MICHALSKI, The Mineral Industry of Morocco and Western Sahara. URL: http://www.minerals.usgs.gov/minerals/puts/country/9226097.pdf [7.6.2001]; NOGUÉ, VILLANOVA, La zona norte, S. 118-120.

${ }^{17}$ Pierre GHISOLFI, Abd-el-Krim, in: Tablettes marocaines, 4.10.1924; MOHR, Frankreich, S. 308f.; C. GODCHOT, Le mystère des mines du Rif, in: Revue mondiale 174 (1926) S. 247254, S. 247; LADRET DE LACHARRIERE, Le rêve, S. 163; SPENCER PRYSE, Through the Lines, S. 639; PA-AA R72041, L057338: übersetzter Artikel der Zeitung "La Acción«, 7.11.1921; PRO-FO 371, 7085, 12039, 88: Embassy of Madrid an FO, 10.11.1921 mit der Zusammenfassung eines Artikels von Ruíz Albeniz in der Zeitung »E1 Sol«, 2.11.1921. 
auf Erforschung der Eisenminen »La fama«, Beni Touzine, 900 ha, und »Elvíra«, Temsamane, 1400 ha), Carlos García Alonso (30. Mai 1921: Recht auf Erforschung von Karbon-, Blei-, Kupfer- und Bleivorkommen im westlichen Rif), Compañía minera hispano africana (30. Mai 1921: Schürfrecht für Eisenmine »Maria de la asunción«, Beni Oulichek, 1940 ha), Abraham Pinto (30. Mai 1921: Recht auf Erforschung von Bleivorkommen im westlichen Rif auf mehreren tausend Hektar), Juan Antonio Güell y López von der Compañía española de Minas del Rif (8. Juni 1921: Schürfrecht für die Eisen- und Bleimine »La trinidad«, Beni Saìd, 2000 ha) oder Andrés Teulón Bisso (2. Oktober 1921: Schürfrecht für die Eisenminen "La segunda«, Beni Ouriaghel, $300 \mathrm{ha}$, und "La cuarta«, Temsamane, $500 \mathrm{ha}$ ). Andrés Teulón Bisso und die Salamas erhielten von der Bergbauverwaltung nach dem Ende des Rifkrieges am 15. Januar 1929 Konzessionen auf dem Gebiet der Temsamane (300 ha) sowie der Beni Ouriaghel (ca. 2900 ha). Der niederländischen Firma Wm. H. Müller \& Co. wurden am 20. Juni 1921 Erforschungsrechte am Djebel Hamam sowie auf dem Gebiet der Beni Touzine/Temsamane und der Beni Mezdoui zugesprochen. Daran war der Oberhausener Gutehoffnungshütte-Konzern (GHH) zu 50\% beteiligt. Das britische Morocco Minerals Syndicate bekam für Bergbaurechte auf 2615 ha auf dem Gebiet der Beni Touzine den Zuschlag ${ }^{18}$.

Abdelkrim erkannte später weder die Entscheidungen der Pariser Schiedskommission noch sonstige von ihm nicht bestätigte Besitzrechte an ${ }^{19}$. Diese Haltung änderte sich bis zum Ende des Rifkrieges nicht. Folgerichtig hatten weder Abdelkrim noch andere Mitglieder seiner Familie jemals eine Bergbaupetition bei der Schiedskommission eingereicht ${ }^{20}$. Andererseits wurden seine späteren Konzessionsverkäufe an Europäer international nicht anerkannt ${ }^{21}$. Glücksritter in Europa sahen nach dem Ausbruch des Rifkrieges ihre Chance, durch direkte Verhandlungen mit Abdelkrim bzw. durch die Stärkung seiner Position innerhalb des Rifs doch noch ins Bergbaugeschäft einsteigen zu können - abseits der internationalen Vereinbarungen, der Schiedskommission und des Servicio de minas del protectorado. In einem international akzeptierten Rifstaat, so spekulierten sie, würde das marokkanische Bergbaugesetz keine Gültigkeit haben $^{22}$.

${ }^{18}$ Madariaga, L'Espagne et le Rif, Bd. 1, S. 195-200; GodChot, Le mystère, S. 249; Mining Titles in Morocco, in: Morocco, 21.4.1923; MORALES LEZCANO, Las minas, S. 79; Erich MASCHKE, Es entsteht ein Konzern. Paul Reusch und die GHH, Tübingen 1969, S. 81.

${ }^{19}$ SHEEAN, Riffis Fight, 12.2.1925.

${ }^{20}$ Madariaga, España y el Rif, S. 490.

${ }^{21}$ Spain's Problem in Morocco. The Riff Rebellion (Abdruck aus »Daily Telegraph«), in: Al-Moghreb al Aksa \& Tangier Gazette, 15.9.1923; Was will Abd el Krim, in: Deutsche Allgemeine Zeitung, 19.6.1925.

${ }^{22}$ LADREIT DE LACHARRIERE, Le rêve, S. 144; GODCHOT, Le mystère, S. 249. 
Schon früh beteiligte sich die Khattabi-Familie am Bergbaugeschäft. Abdelkrims Vater, Cadi Mohammed Abdelkrim el Khattabi, galt als vorausblickender Mann, der das Rif mit der Unterstützung Spaniens modernisieren und dabei noch mit Hilfe des Bergbaus Profite machen wollte. Im Zuge der Kontakte zur spanischen Festung in der Bucht von Alhucemas und nach Melilla war er mit europäischen Handelspraktiken vertraut. Sein ältester Sohn Abdelkrim arbeitete sich, seit er 1906 nach Melilla gegangen war, bis 1910 zum Beschäftigten der Zentralverwaltung (Oficina central de tropas y asuntos indigenas) hoch und hatte unmittelbar mit Anträgen über die Vergabe von Bergbau-Konzessionen zu tun ${ }^{23}$. Gespräche mit europäischen Bergbauingenieuren beeinflußten seine späteren Visionen für die wirtschaftliche Ausgestaltung des $\mathrm{Rifs}^{24}$. Schon 1907 schloß Abdelkrim in Melilla einen Bergbauvertrag mit Juan Olavarriaga y Eguilor, einem Mitbegründer der Sociedad anónima minera Setola$\mathrm{zar}, \mathbf{a b}^{25}$.

Seine Kontakte reichten bis nach Deutschland. Zu den umtriebigsten Bergbauaktivisten mit besten Kontakten zu Abdelkrim und seiner Familie gehörten sechs Brüder aus Remscheid - die Mannesmanns. Ihr marokkanisches Engagement trug wesentlich zur Hoffnung der Khattabis, durch Bergbaugeschäfte die wirtschaftliche und politische Entwicklung im Rif vorantreiben zu können, bei. Reinhard und Max Mannesmann hatten 1884 bis 1885 das Schrägwalzverfahren für die Herstellung nahtloser Stahlrohre erfunden. Der Aufsichtsrat der schon bald weitverzweigten Mannesmannröhren-Werke erzwang jedoch in einem schleichenden Prozeß zwischen 1893 und 1900 den Austritt der als Untemehmer glücklosen Brüder aus dem Vorstandsvorsitz ${ }^{26}$.

${ }^{23}$ AYACHe, Les origines, S. 178; TAHTAH, Pragmatisme 1995, S. 68; Fleming, Primo de Rivera and Abd-el-Krim, S. 60f; SHINAR, Abd al-Qadir, S. 161, S. 163; HARRIS, France, S. 66; DUMAS, Abd-el-Krim, S. 36; WOOLMAN, Rebels in the Rif, S. 77.

${ }^{24}$ FurNeAUX, Abdel Krim, S. 46; PENNELl, A Country, S. 50; SÁnCheZ PÉREZ, Abdelkrim, S. 235; SHEEAN, My Meeting, S. 849.

${ }^{25}$ TAHTAH, Pragmatisme 1995, S. 82. Beim Firmennamen Setolazar handelte es sich um ein Anagramm, das aus den Nachnamen der Firmengründer Setuain, Olavarriaga und Zárate gebildet wurde [ALLAIN, Agadir, S. 358f.].

${ }^{26}$ Ruth BrandT-MaNNESMANN, Max Mannesmann, Reinhard Mannesmann. Dokumente aus dem Leben der Erfinder, Remscheid 1964, S. 36, S. 49, S. 68; MADARIAGA, España y el Rif, S. 221-223; AlLAIN, Agadir, S. 95f;; Gisela SCHMOECKEL, Die maghrebinischen Abenteuer der Brüder Mannesmann, in: Bergischer Almanach 3 (1991) S. 7-19, S. 8; Yorck DIETRICH, Die Mannesmannröhren-Werke 1888-1920. Organisation und Unternehmensführung unter der Gründerfamilie, Bankiers und Managern, Stuttgart 1991 (Zeitschrift für Unternehmensgeschichte, Beiheft, 66), S. 39-50; Lutz HATZFELD, Mannesmann, in: Neue Deutsche Biographie, Bd. 16, Berlin 1990, S. 61-64, S. 62-64; MANNESMANN, Die Unternehmungen, "Vorrede«; Horst A. WESSEL, Die Familie Mannesmann in Marokko 1907-1914. Ein Beispiel partnerschaftlicher Wirtschaftsentwicklung, Düsseldorf 1996, S. 1; DERS., Die Techniker der Familie Mannesmann, in: Wolfhard WEBER (Hg.), Ingenieure im Ruhrgebiet, Münster 1999 (Rheinisch-westfälische Wirtschaftsbiographien, 17), S. 123-148, S. 130-133; Die Mannesmänner in Marokko, in: Deutsche Bergwerkszeitung, 20.11.1936; Eugene STALEY, 
Die Mannesmannröhren-Werke hatten demnach in der Folgezeit mit den Marokko-Aktivitäten der längst aus dem Unternehmen ausgeschiedenen Brüder nichts zu tun ${ }^{27}$.

Ein Reisebericht über alte Erzlagerstätten in Nordafrika, der von der Vermutung ausging, daß sich die Erzvorkommen Südspaniens in Nordafrika fortsetzen würden, hatte das Interesse des studierten Bergbauingenieurs Reinhard Mannesmann geweckt ${ }^{28}$. Kaum hatten sich Mannesmann und Marie-Luise (»Titak) Eigen am 6. Januar 1906 vermählt, da startete das Brautpaar seine Hochzeitsreise in Richtung Nordafrika. "Der Erze und nicht nur der schönen Landschaft zuliebe ${ }^{29}$ trafen sie Ende März 1906 in Melilla ein. Umgehend nahm Reinhard Mannesmann Bodenproben der benachbarten Erzlager von Ouixane, die im Jahr zuvor entdeckt worden waren. Zwei Monate später reiste sein Bruder Max nach Melilla nach ${ }^{30}$. Es ist nicht bekannt, wann die ersten Gespräche zwischen den Mannesmanns und der Khattabi-Familie über Bergbaugeschäfte stattfanden. Es ist sehr wahrscheinlich, daß dies in Melilla geschah, denn just im Jahre 1906 wurde der damals 24jährige Abdelkrim Redaktionsmitglied der dortigen Zeitung »El Telegrama del Rif ${ }^{31}$.

Versehen mit einem Schutzbrief des marokkanischen Sultans, reisten Reinhard, Max und "Tita« Mannesmann monatelang durch das Landesinnere Marokkos und kauften Ländereien auf ${ }^{32}$. Mit Hilfe seiner eingereisten Ingenieure aus Deutschland wurde Reinhard Mannesmann in den Folgejahren eine Art Pionier der bergbaulichen Erkundung des Rifgebirges. Zugleich war er damit der eigentliche Hauptverantwortliche für die zur Zeit des Rifkrieges kursie-

Mannesmann Mining Interests and the Franco-German Conflict over Morocco, in: Journal of Political Economy 40 (1932) S. 52-73, S. 55.

${ }^{27}$ Heinrich KOCH, 75 Jahre Mannesmann. Geschichte einer Erfindung und eines Unternehmens 1890-1965, Düsseldorf 1965, 67; ONCKEN, Panthersprung, S. 93, Anm. 97.

${ }^{28}$ SCHMOECKEL, Die maghrebinischen Abenteuer, S. 10; WESSEL, Die Techniker, S. 135; Heinrich POHL, Marokko und Mannesmann. Ein völkerrechtlicher Rückblick, in: Zeitschrift für Politik 5 (1912) S. 558-577, S. 559. Es handelte sich um den Artikel von BAUM, Die Eisenerzlagerstätten Nordwestafrikas, in: Stahl und Eisen 23 (1903) S. 713-726. Die Strategie der Mannesmanns sah eine Monopolisierung des Bergbausektors in Gesamtmarokko vor. Wir beschränken uns jedoch in unserem Zusammenhang weitgehend auf die Geschehnisse in Nordmarokko.

${ }^{29}$ HALlGARTEN, Imperialismus, Bd. 2, S. 130.

${ }^{30}$ BRANDT-ManNeSMANN, Max Mannesmann, S. 100f., S. 107; G. GoldBerG, Marokkos Eisenerze in ihrer wirtschaftlichen Bedeutung zu Deutschland, in: Zeitschrift für Kolonialpolitik, Kolonialrecht und Kolonialwirtschaft 14 (1912) S. 29-35, S. 30; POHL, Marokko, S. 559; MANNESMANN, Die Unternehmungen, S. 8, S. 28; SCHMOECKEL, Die maghrebinischen Abenteuer, S. 11; STALEY, Mannesmann, S. 55.

${ }^{31}$ WOOLMAN, Rebels in the Rif, S. 76; AYACHE, Les origines, S. 169; SHINAR, Abd al-Qadir, S. 162.

${ }^{32}$ WeSSEL, Die Familie Mannesmann, S. 2-7; SCHMOECKEL, Die maghrebinischen Abenteuer, S. 12f.; MANNESMaNN, Die Unternehmungen, S. 8-10; Wipert von BlüCHER, Am Rande der Weltgeschichte. Marokko, Schweden, Argentinien, Wiesbaden 1958, S. 62. 
rende Legende von den Erzreichtïmern speziell im Gebiet der Beni Ouriaghel. Mit der Erlaubnis von Abdelkrims Vater war der Deutsche einer der ersten, der sporadische und sozusagen roberflächliche Bodenproben entnehmen konnte $^{33}$. Cadi Mohammed Abdelkrim el Khattabi war auch in anderen Gebieten des Rifs der »Haupterwerber für Mannesmann « ${ }^{34}$.

Mit dem Motorschiff »Kaid Tita« prüften die Remscheider Brüder zunächst günstige Anlegemöglichkeiten an der Mittelmeerküste, um Erze von dort verschiffen zu können. Sie erwarben Besitztümer in der Bucht von Alhucemas und am Jebel Hamam. Hinzu kamen Eisenerz-Lagerstätten im Gebiet der Aït Ouert und der Beni Touzine, am Quellgebiet des Oued Nokour, Bleiglanzvorkommen im Ghomara-Gebiet oder Bereiche in Temsamane, Beni Saïd, Beqqioua, Beni Iteff, Beni Hozmar und Beni Bou Ifrah ${ }^{35}$. Die angeblich größte und älteste Eisenmine Nordmarokkos am Jebel Hadid östlich der Bucht von Alhucemas kaufte Max Mannesmann für 40000 Francs $^{36}$. Von 2027 aufgekauften (angeblichen) Erzlagern der Mannesmanns in Gesamtmarokko befanden sich 410 im Norden ${ }^{37}$.

Zur Absicherung gegen die englische, spanische, französische und deutsche Konkurrenz ließ sich Reinhard Mannesmann im Oktober 1906 von Sultan Abdelaziz sowie im Oktober 1908 und im März 1909 von dessen Nachfolger Moulay Abdelhafid die Bergbaurechte der entdeckten Lagerstätten bestätigen. Die Entscheidung des Letzteren wußte er durch Geldspritzen und etliche Geschenke - darunter ein sweißer، (eigentlich hellgrauer) Elefant aus dem Hamburger Tierpark Hagenbeck - zu beeinflussen. Moulay Abdelhafid nahm es mit der Erteilung von Bergbaurechten allerdings nicht so genau. Am 14. Oktober 1908 gewährte er auch einer englischen Firma Konzessionen für zum Teil die gleichen Gebiete. Die Mannesmanns kannten jedoch den geheimgehaltenen Beschluß des diplomatischen Korps von Tanger vom

${ }^{33}$ TOYNBEE, The Islamic World, S. 108; WOOLMAN, Rebels in the Rif, S. 77, S. 126; KuNZ, MŨlleR, Giftgas, S. 50; HART, The Aith Waryaghar, S. 371; HARRIS, France, S. 66; SHINAR, Abd al-Qadir, S. 161-163; FURNEAUX, Abdel Krim, S. 46; LADREIT DE LACHARRIÈRE, Le rêve, $S .99 f$.

${ }^{34}$ PA-AA R118401, L525139: Bericht "Aufzeichnung für die interfraktionelle Ausschußsitzung betr. Mannesmann«, 7.5.1926.

${ }^{35}$ MANNESMANN, Die Unternehmungen, S. 27-30; WeSSEL, Die Familie Mannesmann, S. 9; MADARIAGA, España y el Rif, S. 242; La question miniere au Maroc, in: BCAF 19 (1909) S. 186; PRO-FO 368, 2150, 18170: Vice-Consulate of Tetuan an CG Tangier, 18.1.1919, CG Tangier an FO, 23.1.1919; CADN Tanger A450: MAE an Chargé d'affaires à Tanger, 25.11.1910.

${ }^{36}$ BRANDT-MANNESMANN, Max Mannesmann, S. 139.

${ }^{37}$ PA-AA R118401, L525058: Bericht »Verzeichnis der Besitzungen der Brüder Mannesmann in Spanisch-Marokkow o.D. Vgl. Daniel RIVET, Mines et politique au Maroc 19071914, in: Revue d'histoire moderne et contemporaine 26 (1979) S. 549-578, S. 551. 
20. August 1908 nicht, der Monopolstellungen in Marokko ausschlo $B$ und besagte, daß ohne die Zustimmung des Korps keine bergrechtlichen Bestimmungen erlassen werden durften ${ }^{38}$.

Im Norden Marokkos blies den "Daltons aus Remscheid ${ }^{39}$ ein heftiger Wind entgegen. Spanien hatte sich schon kurz nach dem Vertrag von Algeciras zwischen 1907 und 1909 an die Eroberung des Gebietes südlich bis südwestlich von Melilla gemacht, um sich in diesem Bereich den Einfluß zu sichern $^{40}$. Von 1908 bis 1910 wurden drei Mannesmann-Expeditionen bei Melilla gewaltsam zurückgedrängt ${ }^{4}$. Spanische Truppen nahmen die Tötung spanischer Minenarbeiter durch Rifkabylen im Juli 1909 zum Anlaß, weitere Vorstöße nach Nador und Beni Bou Ifrour zu unternehmen. Diese besonders wertvollen Gebiete hatte Spanien nach dem Ende der Operationen im November 1909 unter Kontrolle - drei Jahre vor der Errichtung der spanischen Einflußzone $^{42}$. Die Spanier wollten klare Verhältnisse schaffen. Denn die Bergbauansprüche der Compañía española de Minas del Rif, die gute Beziehungen zur spanischen Regierung unterhielt, deckten sich in dieser Region zum Teil mit denen anderer Konkurrenten. Allein bei Nador stritten sich die Mannesmanns mit der spanischen Gesellschaft um das Vorrecht auf 47 Erzlagerstätten ${ }^{43}$.

Mit dem im Mai 1909 gegründeten Marokko-Minen-Syndikat, das die Rechte der Mannesmann Rif Companie verwertete, wollten die Brüder ihren Einfluß im Norden Marokkos mit Nachdruck wahrnehmen. Thm gehörten Russen und Österreicher wie Karl Ritter von Skoda, Graf Coudenhouve und Graf Khevenhueller sowie Franzosen wie der bekannte Spekulant Vaffier-Pollet, der in der Wirtschaftswelt bis dahin unbekannte Gontier, dessen Sohn Mitglied des Kabinettssekretariats des französischen Politikers Joseph Caillaux war, oder der frühere Pariser Polizeipräfekt Andrieux $a^{44}$. Die französische Union des mines marocaines, in der ebenfalls deutsche Interessen $(20 \%$ Anteile) vertreten waren, war der Hauptkonkurrent der Mannesmanns im Süden

${ }^{38}$ AllaIn, Agadir, S. 99f., S. 115-117; RUZÉ, Litiges, S. 160; BURKE, Prelude to Protectorate, S. 103, S. 140; Wessel, Die Familie Mannesmann, S. 7f;; BRANDT-ManNeSManN, Max Mannesmann, S. 107-109, S. 118, S. 121; MADARIAGA, España y el Rif, S. 221f.; Minen-Konzessionen in Marokko, in: Der Tag, 20.10.1909; La situation politique, in: BCAF 19 (1909) S. 389f., S. 389; SCHMOECKEL, Die maghrebinischen Abenteuer, S. 13f.; MANNESMANN, Die Unternehmungen, S. 11-16.

${ }^{39}$ RIVET, Lyautey, Bd. 1, S. 73.

${ }^{40}$ Chandler, Spain, S. 302, S. 304; AZZZA, Le Rif, S. 137, S. 149.

${ }^{41}$ BA R1501, 53103, 24: Max Mannesmann an AA, 30.4.1910.

42 Allain, Agadir, S. 81; WoOlman, Rebels in the Rif, S. 42.

${ }^{43}$ PA-AA R16065, A18847: Botschaft Madrid an AA, 16.11.1909.

44 Allain, Agadir, S. 84, S. 360; AZIZA, Le Rif, S. 134; HallgarTen, Imperialismus, Bd. 2, S. 139, Anm. 4, S. 145, Anm. 4; Die Mannesmann'schen Minenkonzessionen, in: Deutsche Marokko-Korrespondenz, 19.10.1909; PA-AA R16066, A6198: Max Mannesmann an AA, 9.4.1910; PA-AA R16070, A18819: Botschaft Madrid an AA, 7.11.1910. 
Marokkos. Sie entsprach in ihrer Zielsetzung und ihrer internationalen Zusammensetzung eher der von der deutschen Regierung favorisierten Politik des Ausgleichs in Marokko. Zwischen 1909 bis 1911 gab es daher forcierte Bemühungen, entweder eine Aufteilung der Interessensphären oder eine Fusion herbeizuführen. Eine Einigung wurde jedoch nie erzielt ${ }^{45}$. Genauso ergebnislos verliefen Verhandlungen der Mannesmanns mit der spanischen Konkurrenz Compañía española de Minas del Rif ${ }^{46}$.

Die Brüder aus Remscheid setzten auf Don Rodrigo de Figueroa y Torres alias Duque de Tovar, zu dem seit 1908 freundschaftliche Verbindungen bestanden ${ }^{47}$. Es handelte sich um den Bruder von Alvaro de Figueroa y Torres alias Conde de Romanones, der einer der einflußreichsten Politiker Spaniens und eine der Hauptfiguren in der Compañía española de Minas del Rif war. Über Tovars Einfluß erhoffte sich Reinhard Mannesmann eine bessere Position im Kampf um die Bergbaurechte in Nordmarokko. Nach schleppendem Beginn der Gespräche schlossen die Mannesmann Rif Companie und Duque de Tovar am 15. September 1910 einen Fusionsvertrag ${ }^{48}$. Die Reputation des Spaniers hätte allerdings durchaus besser sein können, wie die deutsche Bot-

${ }^{45}$ BRANDT-MANNESMANN, Max Mannesmann, S. 122f., S. 128; RIVET, Mines et politique, S. 553f.; MADARIAGA, L'Espagne et le Rif, Bd. 1, S. 268; MEYER, "Endlich eine Tat«, S. 193-195; STALEY, Mannesmann, S. 61, S. 65-69; SCHMOECKEL, Die maghrebinischen Abenteuer, S. 14; HALlgaRTEN, Imperialismus, Bd. 2, S. 211, S. 215, S. 219; ALLAIN, Agadir, S. 90-93, S. 102-104, S. 118-123, S. 358; STOECKER, NIMSCHOWSKI, Marokko, S. 216-218; MANNESMANN, Die Unternehmungen, S. 17-24; Max HAESSNER, Marokkos Handelsbeziehungen seit 1905 mit besonderer Berücksichtigung von Deutschland, Berlin 1912, S. 71-81; Aufzeichnung des Staatssekretärs des Auswärtigen Amtes Freiherrn von Schoen, 18.5.1910, in: Johannes LEPSIUS, Albrecht MENDELSSOHN-BARTHOLDY, Friedrich THIMME (Hg.), Die große Politik der europäischen Kabinette 1871-1914, Bd. 29: Die zweite Marokkokrise 1911, Berlin ${ }^{2} 1927$, S. 54f. Zur Tätigkeit Walter Rathenaus während der Verhandlungen zwischen der Union des mines marocaines und den Mannesmanns zwischen Mai bis August 1910: Hartmut POGGE VON STRANDMANN, Rathenau, die Gebrüder Mannesmann und die Vorgeschichte der zweiten Marokkokrise, in: Imanuel GEISS, Bernd J. WENDT (Hg.), Deutschland in der Weltpolitik des 19. und 20. Jahrhunderts. Fritz Fischer zum 65. Geburtstag, Düsseldorf 1973, S. 251-270, S. 255-263.

${ }^{46}$ PA-AA R16065, A18847: Botschaft Madrid an AA, 16.11.1909; PA-AA R16067, A7938: Botschaft Madrid an AA, 7.5.1910; PA-AA R16067, A8235: Botschaft Madrid an AA, 12.5.1910; PA-AA R16068, A9728: Botschaft Madrid an AA, 4.6.1910; PA-AA R16068, Al 1809: Botschaft Madrid an AA, 7.7.1910; PA-AA R16074, A6167: Botschaft Madrid an AA, 1.4.1912; PA-AA R16057, A16321: Konsulat San Sebastian an AA, 7.8.1913; CADN Madrid B466: MAE an Ambassade de Madrid, 20.9.1913.

${ }^{47}$ MANNESMANN, Die Unternehmungen, S. 16; La question minière au Maroc, in: BCAF 19 (1909) S. 186.

${ }^{48}$ PA-AA R16066, A6183: Botschaft Madrid an AA, 6.4.1910; PA-AA R16066, A6183: Botschaft Madrid an AA, 9.4.1910; PA-AA R16069, A11003: Botschaft Madrid an AA, 25.6.1910; PA-AA R16070, A18974: Botschaft Madrid an AA, 10.11.1910; PA-AA R16057, A10585: Botschaft Madrid an AA, 26.5.1914; PRO-FO 371, 930, 727, 20: CG Tangier an FO, 8.1.1910; AlLAIN, Agadir, S. 87; MADARIAGA, España y el Rif, S. 249. 
schaft aus Madrid meldete: »Der Herzog von Tovar steht nicht in dem Rufe, immer nur die lautere Wahrheit zu sagen. Auch wird behauptet, es sei ein alter Trick des Herzogs und des Grafen Romanones, daß sie einmal die zärtlichen Verwandten, ein anderes Mal die feindlichen Brüder spielten, je nachdem sie es ihren Interessen für dienlich hielten ${ }^{49}$.

1911 brach im Rif ein Aufstand aus, der bis zum Frühjahr 1912 andauerte, als der Anführer Mohammed Ameziane in einem Gefecht getötet wurde ${ }^{50}$. Im Februar 1912 erhielt Reinhard Mannesmann die Nachricht, daß ihn die Rifkabylen um die Vermittlung von Friedensgesprächen mit den Spaniern bäten. Zu dieser Zeit befand sich der Vater Abdelkrims, Cadi Mohammed Abdelkrim el Khattabi, im Exil in Tetuan. Das Hilfeersuchen zeigt also, wie hoch das Ansehen des Deutschen im Rif auch ohne dessen Einwirken war. Er wurde der erste europäische Friedensvermittler der Rifkabylen. Nachdem Reinhard Mannesmann vom spanischen König, der selbst in den Bergbau von SpanischMarokko investierte, empfangen worden war, gab Ministerpräsident José Canalejas y Méndez sein Einverständnis. Er trug dem Deutschen auf, »daß er den Rifkabylen mitteile, die spanische Regierung werde, wenn diese sich zum Frieden bereit erklärten, sie in Ruhe lassen, ihren Besitz, ihre Harems und ihre religiösen Gebräuche respektieren und nicht die Auslieferung der Waffen verlangen ${ }^{51}$. Canalejas stellte Mannesmann als Belohnung Vorrechte für die Erzausfuhr aus der Melilla-Region in Aussicht ${ }^{52}$.

Monatelang hielt sich das Ehepaar »Tita« und Reinhard Mannesmann im Rif auf. Der Deutsche führte nicht nur Friedensgespräche. Auf Einladung einer Kabyle aus der Umgebung von Tetuan besichtigte er Erzfundorte. Nach seiner Rückkehr nach Madrid wurde Reinhard Mannesmann Anfang September 1912 erneut im spanischen Königspalast empfangen. Er verdeutlichte, daß er die Anführer der Rifkabylen von der Nützlichkeit eines Friedens mit Spanien überzeugt habe. Um ein Abkommen abzuschließen, sei ein weiterer Besuch im Rif nötig ${ }^{53}$. Es kam jedoch anders. Am 27. November 1912 wurde mit der französisch-spanischen Konvention die Errichtung einer spanischen Einflußzone in Marokko vereinbart. Die Rifbevölkerung wehrte sich gegen die Eingriffe in ihr Territorium und rebellierte im darauffolgenden Jahr gegen die geplanten Beschränkungen der Selbstverwaltung ${ }^{54}$.

\footnotetext{
${ }^{49}$ PA-AA R16074, A10947: Botschaft Madrid an AA, 27.5.1913.

${ }^{\text {so }}$ WOOLMAN, Rebels in the Rif, S. 44f.

${ }^{51}$ PA-AA R16074, A3225: Botschaft Madrid an AA, 14.2.1912; PA-AA R16074, A2962: Botschaft Madrid an AA, 15.2.1912. Vgl. zu den Bergbauaktivitäten des spanischen Königs SLAVIN, Anticolonialism, S. 18; WOOLMAN, Rebels in the Rif, S. 102; CAOM 10 APOM 295: Bericht von Robert Montagne »L'affaire riffaine - Abd el Krim«, 28.5.1937.

52 PA-AA R16074, A6167: Botschaft Madrid an AA, 1.4.1912.

${ }^{53}$ PA-AA R16074, A15397: Botschaft Madrid an AA, 6.9.1912.

${ }^{54}$ BRANDT-MANNESMANN, Max Mannesmann, S. 142; WoOlman, Rebels in the Rif, S. $59 \mathrm{f}$.
} 
Diese Punkte hatte Reinhard Mannesmann im Jahr zuvor noch klären sollen. Er begriff den Ernst der Lage im Rif. Da er Beziehungen zu beiden Seiten unterhielt, war er einer der wenigen, die einen Frieden vermitteln konnten. Aus dem spanischen San Sebastian schrieb Mannesmann, ihn interessiere ")nur die Lösung der beinah unmöglichen Aufgabe, ohne Soldaten und ohne Geldausgaben diesen entsetzlichen Greueln dort unten Einhalt zu tun und unsere spanischen wie marokkanischen Freunde vor weiteren Trauerfallen zu bewahren « $^{55}$.

Reinhard Mannesmann schwebte seit längerem ein besonderes Projekt vor. Im Dezember 1911 hatte er sich in Paris mit Duque de Tovar getroffen, um mit ihm über die Errichtung eines Hafens in der Bucht von Alhucemas und die Gründung einer Import-Export-Gesellschaft zu verhandeln ${ }^{56}$. Seither hatte er Vorbereitungen für das Projekt einer Chartergesellschaft für Spanisch-Marokko getroffen. Hierzu hatte er die Zustimmung von 18 Kabylen eingeholt. Im Dezember 1913 sandte er an die spanische Regierung ein Memorandum, dessen Hauptpunkte er auch den wichtigsten Madrider Zeitungen zukommen ließ. Nach dem Vorbild der holländischen Ostindienkompanie sollte Spanien mit einer Mannesmann unterstehenden Handelsgesellschaft für das Rif und das Jebala-Gebiet (Tetuan bis Oued Kert) für die Dauer von 100 Jahren einen Pachtvertrag abschließen. Gegen die militärische Besetzung der spanischen Zone setzte Mannesmann die kaufmännische Durchdringung mit einer von deutschem, französischem und spanischem Kapital ausgestatteten Chartergesellschaft. So sollte das gepachtete Gebiet infrastrukturell erschlossen und gleichzeitig der Frieden gesichert werden: mDie Zusammenlegung des Eigentums der marokkanischen Eingeborenen mit dem ausländischen wird beide Parteien dazu anhalten, aus wirtschaftlichem Interesse und wirtschaftlicher Notwendigkeit sich gewaltsamer Maßnahmen zu enthalten und in der Nutzung des gemeinsamen Vermögens friedlich zusammenzuarbeiten “ ${ }^{57}$.

Der Plan sah nicht nur die autonome Selbstverwaltung der Kabylen, sondern auch die Entmilitarisierung der spanischen Zone bis auf einige Garnisonen in Larache, El Ksar, Tetuan, Melilla und Ceuta vor. Mannesmann behielt sich das Recht vor, mit den Rifkabylen einen Friedensvertrag abzuschließen. Der Sitz der Chartergesellschaft sollte in San Sebastian sein. Ihr Aufgabengebiet betraf die landwirtschaftliche und bergbauliche Erschließung des gepachteten Landes sowie den Neubau von Dörfern, Straßen, Eisenbahnlinien und Häfen. Die indigene Bevölkerung sollte mit modernen Methoden der Landkultivie-

\footnotetext{
${ }^{55}$ Brief Reinhard Mannesmanns, 27.7.1913, zit. aus BRANDT-MANNESMANN, Max Mannesmann, S. 142.

${ }^{36}$ PA-AA R16074, A19928: Botschaft Madrid an AA, 28.11.1911; PA-AA R16074, A21562: Botschaft Madrid an AA, 26.12.1911.

${ }^{57}$ Zit. aus BRANDT-MANNESMANN, Max Mannesmann, S. 143.
} 
rung vertraut gemacht werden. Nach dem Mannesmann-Plan sollte die Chartergesellschaft innerhalb ihres Einflußbereichs die volle administrative und polizeiliche Gewalt innehaben $^{58}$.

In der spanischen Marokko-Zeitung "Hoy« vom 3. Dezember 1913 schrieb Mannesmann: ")Dies ist der Weg - und wir glauben der einzige -, wie der Frieden, ein friedliches Leben und der rasche Aufschwung des spanischen Einflußgebietes verwirklicht werden kann “ ${ }^{39}$. Hierbei ist ihm sicher bewußt gewesen, daß eine militärische Besetzung des Rifs durch spanische Truppen seine wirtschaftlichen Pläne zunichte gemacht hätte. Erstmals tauchte in diesem Plan der Gedanke einer Autonomie für immerhin 18 verbündete Kabylen auf. Es ist nicht bekannt, um welche Kabylen es sich handelte, aber es ist auszuschließen, daß Reinhard Mannesmann ein derartiges Projekt ohne die $\mathrm{Zu}$ stimmung der Beni Ouriaghel, der wichtigsten Kabyle im Rif, und damit ohne das Einverständnis der mit ihnen geschäftlich verbundenen Khattabis geplant hätte. Zumindest eines läßt darauf schließen, daß Abdelkrim und seine Familie involviert waren. Das Grundprinzip - die von europäischem Kapital getragene infrastrukturelle Erschließung des Jebala-Gebietes und des Rifs unter Beibehaltung eines hohen Grades an Unabhängigkeit für die dortige Bevölkerung diente Abdelkrim während des Rifkrieges als Vorbild für ähnliche Verträge mit Europäern.

Reinhard Mannesmanns Vorhaben sprach Spanien indirekt die Fähigkeit ab, in seiner Einflußzone selbst für Ordnung zu sorgen, und stieß daher auf wenig Gegenliebe. Der Plan war utopisch und hätte zu keinem schlechteren Zeitpunkt angebracht werden können. Denn zu dieser Zeit war Conde de Romanones von Mannesmanns Hauptkonkurrenten Compañía española de Minas del Rif Spaniens Ministerpräsident. Er wies Mannesmann mit der Begründung ab, eine Verpachtung würde gegen den Protektoratsvertrag verstoßen ${ }^{60}$. Die spanische Presse tobte. Sie warf den Mannesmanns vor, die Rebellion im Rif angestachelt zu haben, um auf die spanische Regierung Druck auszuüben ${ }^{61}$. Die

${ }^{58}$ Les mémoires Mannesmann, in: Renseignements coloniaux et documents 23 (1913) S. 427-432 mit der französischen Übersetzung der Mannesmann-Memoranden. Vgl. zum Mannesmann-Projekt auch MADARIAGA., España y el Rif, S. 234-239; WOOLMAN, Rebels in the Rif, S. 39; GODChOT, Le mystère, S. 248; Edgar PRÖBSTER, Die Minen des Rif, in: Deutsche Allgemeine Zeitung, 21.9.1925; René de SEGONZAC, En zone espagnole. De Raîssouli à Abd el Kerim, in: Revue de Paris 32 (1925) S. 253-282, S. 277f.; PRO-FO 371, 1694, 55644: Embassy of Madrid an FO, 7.12.1913; PRO-FO 371, 2047, 13657: CG Tangier an FO, 18.3.1914 mit dem beiliegenden Bericht »Morocco, Annual Report, 1913«, S. 18.

${ }^{59}$ Zit. aus BRANDT-MANNESMANN, Max Mannesmann, S. 142.

${ }^{60}$ TOYNBEE, The Islamic World, S. 108f.; GODCHOT, Le mystère, S. 248.

${ }^{61}$ L'action espagnole au Maroc et l'affaire Mannesmann, in: BCAF 23 (1913) S. 452-458, S. 453; WoOLMAN, Rebels in the Rif, S. 77. 
republikanische Zeitung "El País« forderte Reinhard Mannesmanns Ausweisung, da er als Vertreter marokkanischer Kabylen auftrete, mit denen Spanien sich im Krieg befinde ${ }^{62}$.

Dennoch hoffte der Deutsche, mit einem Friedensangebot aus dem Rif einen Stimmungsumschwung in Spanien bewirken zu können. Im Dezember 1913 brach er »praktisch als Parlamentär ohne Auftrag ${ }^{63}$ nach Marokko auf. Über Gibraltar und Melilla wollte er die Großversammlung der Rifkabylen bei Oued Kert aufsuchen. Die spanischen Militärs, die Mannesmanns Kontakte zu den Khattabis mit Argusaugen beobachteten, hielten ihn in Melilla mit der Begründung zurück, Spanien wolle bei Friedensgesprächen ohne Vermittler agieren. Die Rif-Versammlung, die Reinhard Mannesmann ein Mandat zur Überbringung ihrer Friedensvorschläge erteilen wollte, mußte ohne ihn auskommen. Die Aktion und der Plan einer Chartergesellschaft waren gescheitert ${ }^{64}$. Noch bis zum Sommer 1914 bemühte sich Mannesmann, wie der deutsche Botschafter in Paris spottete, "seinen bekannten phantastischen Plänen der Friedensvermittlung zwischen den Spaniern und den Riff-Kabylen nachzugehen ${ }^{65}$. Mit dem Ausbruch des Ersten Weltkrieges platzten die Marokko-Träume der Mannesmanns endgültig. Ihr gesamter Besitz in Französisch-Marokko wurde entzogen, das Betreten untersagt. Diese Regelung galt nicht für die spanische Einflußzone ${ }^{66}$.

Während des Weltkrieges liefen daher die Geschäfte der Mannesmanns in Nordmarokko weiter. Sie wiesen ihren in Melilla lebenden marokkanischen Agenten Si Mohammed el Ferkhani alias »El Fraile« (der Mönch) an, im Rif Gelände aufzukaufen. Über ihn traten sie mit zahlreichen Rifchefs in Verbindung. El Ferkhani arbeitete eng mit Alberto Suárez de Lorenzana, dem Repräsentanten der holländischen Firma Wm. H. Müller \& Co., zusammen. Dieser hatte 1887 und 1888 weite Teile des Rifs - auch das Gebiet der Beni Ouriaghel - erforscht und dort zahlreiche Ländereien für Bergbauvorhaben aufgekauft $^{67}$. Einem Bericht des belgischen Konsuls von Malaga zufolge versuchten die Mannesmanns im Sommer 1916, mit den Holländern zu einer Verständi-

${ }^{62}$ PRO-FO 371, 1694, 55644: Embassy of Madrid an FO, 7.12.1913; Unwelcome Offer of a German Firm, in: Times, 6.12.1913; The Mannesmann Proposal, in: Times, 8.12.1913; Walter B. HARRIS, A Well-Known Trick, in: Times, 6.12.1913.

${ }^{63}$ BRANDT-MANNESMANN, Max Mannesmann, S. 143.

${ }^{64}$ AYACHE, Les origines, S. 191; WESSEL, Die Familie Mannesmann, S. 10.

${ }^{65}$ PA-AA R16057, A12831: Botschaft Paris an AA, 27.6.1914.

${ }^{66}$ BRANDT-MANNESMANN, Max Mannesmann, S. 145; TRYSTRAM, Le mineur, S. 28; WESSEL, Die Familie Mannesmann, S. 15.

${ }^{67}$ CADN Tanger A1319: Bericht »Note sur Si Mohammadi El Ferkhani (El Fraile)《, 5.10.1917; MaDariaga, España y el Rif, S. 147f. 
gung über die Errichtung eines Hafens in der Bucht von Alhucemas zu kommen $^{68}$. Kurz zuvor hatten sie die kleine Bucht Morro Nuevo westlich von Alhucemas erworben ${ }^{69}$.

Als Strohmann für den Erwerb von Ländereien im Rif diente der Mannesmann-Vertraute El Haj Mohammed Boumghait ${ }^{70}$. Weitere indigene Agenten in Marokko waren Abdallah ben Omar, Bouterfas ben el Hadi, Bouterfas ben Messaoud, Ahmed ben Zouggari, Ben Ali alias Sapo und - Si Mohammed Azerkane, Abdelkrims späterer Außenminister ${ }^{71}$. Noch kurz vor dem Ende des Weltkrieges warb Reinhard Mannesmann im Reichskolonialamt mit den ")Aussichten, die das Rifgebiet, wenn sie sich bewahrheiten, zu einem der aussichtsreichsten nicht nur Bergbau-, sondem Industriegebiete der Erde, zum Lande der Zukunft machen würden « ${ }^{72}$.

Kurz zuvor hatten die Mannesmanns am 5. Mai 1918 ihre vor 1908 erworbenen Bergbau-Besitzungen in Spanisch-Marokko an ihren Partner Duque de Tovar abgetreten. Es handelte sich um bei der Bergbau-Schiedskommission angemeldete Petitionen der Mannesmann Rif Companie (116E-140E, 183E: Guelia, Beni Bou Yahi, Beni Touzine, Ghomara, Beni Ouriaghel, Beni Itefft, Beni Hozmar, Beni Saìd, Beni Maaden, Beni Hamed, Kebdana, Anjera, Beni Zerkat, Beni Mecouar, Beni Jemas, M'Tioua und Jebala), vom Marokko Minen-Syndikat der Mannesmanns (141E, 144-145E: Beni Saïd), von Reinhard Mannesmann (151-153E: Temsamane, Beni Ouriaghel) sowie von Max Mannesmann (149-150E: Beni Touzine, Guelia) ${ }^{73}$. Auch vom Deutschen Franz Forscht, der allgemein als Strohmann der Mannesmanns angesehen wurde, erwarb Tovar einen über 90000 ha großen Landstrich im Westen des Rifs (Petition 148E). Dahinter stand der Gedanke der Mannesmanns, ihre Interessen vor der wieder in Paris tagenden Schiedskommission für marokkanische Bergbauangelegenheiten hinter einer spanischen Fassade zu verschleiern ${ }^{74}$.

${ }^{68}$ CADN Tanger A575: RG Rabat an CG Tanger, 22.8.1916 mit Bezug auf einen Bericht des belgischen Konsuls von Malaga, 4.7.1916.

${ }^{69}$ CADN Tanger A575: Ambassade de Madrid an CG Tanger, 28.2.1916.

${ }^{70}$ PA-AA Madrid 474-1: Vermerk, 8.8.1929; CADN Berlin B44: MAE an Ambassade de Berlin, 24.7.1913.

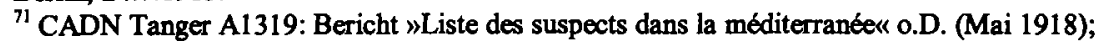
ADMAE Maroc 194, 152: Renseignement, 15.9.1921; CADN Madrid C258: MAE an Ambassade de Madrid, 12.12.1922.

${ }^{72}$ Zit. aus BEN ASSAR, Kampf um das Schatzland, S. 41.

${ }^{73}$ CADN Madrid C312: Bericht 'Sentence de la commission arbitrale conçernant les requêtes 116-141E, 144E, 145E, 146E, 149-153E, 183E«, 29.1.1920. Eine Auflistung aller deutschen an die Schiedskommission gerichteten Anträge findet sich in: PRO-FO 368, 2150 , 18170: CG Tangier an FO, 23.1.1919.

${ }^{74}$ MADARIAGA, España y el Rif, S. 247; Boletín oficial de la zona de protectorado español en Marruecos, Número 3, 10 de febrero de 1920, Madrid 1920, S. 127; PRO-FO 371, 4531, 4281, 181: Note, 29.6.1920. 
Am 29. Januar 1920 berieten die Bergbau-Schiedsrichter über die an Tovar übertragenen Mannesmann-Rechte für Spanisch-Marokko. Sie erklärten die Dekrete des früheren Sultans Moulay Abdelhafid von 1908 und 1909 für ungültig. Die zugesagte Entschädigung von 74000 Francs für entstandene Unkosten beim Erwerb von Konzessionen in der spanischen Zone wurde nie an die Mannesmanns ausgezahlt ${ }^{75}$. Tovar gab die Rechte wieder zurück. Die Mannesmanns glaubten trotzdem weiter an die Gültigkeit anderer nach 1908 erworbener Ansprüche, für die der Schiedskommission keine Petitionen vorgelegt worden waren ${ }^{76}$. In den Verhandlungen vom 16. Januar 1920 bis zum 8. Februar 1921 wurden den Mannesmanns dann alle Bergbaurechte für Französisch-Marokko aberkannt. Nach dem Tode Reinhard Mannesmanns am 20. Februar 1922 übernahmen dessen Witwe »Tita» sowie seine Brüder Carl und Alfred die Geschäfte ${ }^{77}$.

Im August 1925 erschien in der internationalen Presse die aufsehenerregende Meldung, daß der Mannesmann-Besitz in Spanisch-Marokko verkauft werden solle ${ }^{78}$. Die Erben benötigten den Erlös für ihre in eine finanzielle Schieflage geratenen Unternehmen Mannesmann Motorenwerke in Remscheid, Mannesmann-Mulag (Motoren und Lastwagen) AG in Aachen und Mannesmann Industrie und Handels AG in Berlin. Sie verlangten für ihren Besitz 20 Millionen Goldmark ${ }^{79}$.

Die Verhandlungen verliefen sehr schleppend. Besonderes Interesse zeigte die New Yorker Firma W.A. Harriman. Der amerikanische Geschäftsmann William Averell Harriman (1891-1986) - Sohn des Eisenbahn-Tycoons Ernest H. Harriman - verfügte über das Hamburger Bankhaus M.M. Warburg

${ }^{75}$ La fin des prétentions minières Mannesmann dans la zone espagnole, in: BCAF 30 (1920) S. 149f.; RUZE, Litiges, S. 167; MANNESMANN, Die Unternehmungen, S. 25; WESSEL, Die Familie Mannesmann, S. 16; SCHMOECKEL, Die maghrebinischen Abenteuer, S. 17.

${ }^{76}$ BA R43, I, 654, 56: Carl Mannesmann an AA, 6.1.1926.

${ }^{77}$ CADN Madrid C312: Bericht »Commission arbitrale des litiges miniers au Maroc, Séance«, 16.2.1920; A la Commission arbitrale des litiges miniers au Maroc, in: BCAF 30 (1920) S. 282-284; $\AA$ la Commission arbitrale des litiges miniers au Maroc, in: BCAF 31 (1921) S. 89-95.

${ }^{78}$ Verkauf des Mannesmann-Besitzes in Spanisch-Marokko, in: Berliner Lokal-Anzeiger, 8.8.1925; Mannesmann verkauft seinen Marokko-Besitz, in: Vossische Zeitung, 19.8.1925; Mannesmann verkauft seine Marokko-Konzessionen, in: Die Rote Fahne, 19.8.1925; Die Verkăufe der Brüder Mannesmann, in: Kölnische Zeitung, 20.8.1925; Edgar PRóBSTER, Die Minen, 21.9.1925; Mannesmann Deal. Morocco Mining Concessions, in: Al-Moghreb al Aksa \& Tangier Gazette, 29.8.1925; Exploiting Morocco, in: Al-Moghreb al Aksa \& Tangier Gazette, 29.8.1925; Mining Rights in the Riff. Why Mannesmanns are Selling, in: AlMoghreb al Aksa \& Tangier Gazette, 12.9.1925; Germans to Sell Vast Riff Lands, in: New York Times, 18.8.1925; Sale of Mannesmann Properties, in: Times, 19.8.1925; Les vistes allemandes sur le Riff. Les frères Mannesmann au Maroc, in: Homme Libre, 5.9.1925; Les intérêts des Mannesmann dans le Rif, in: Matin, 19.8.1925.

${ }^{79}$ BA R43, I, 654, 52: Bericht »Aufzeichnung über eine Besprechung in der Reichskanzlei«, 30.12 .1925 . 
\& Co. über beste Beziehungen nach Deutschland. Erst 1925 hatte Harriman die Konzession über die georgischen Chiaturi-Minen erworben. Weitere Interessenten waren die US-Firma J.G. White \& Co., die Mischgesellschaft Compagnie franco-américaine des métaux et minerais, C. Tennart, Sons \& Co. aus Großbritannien, die französischen Geldinstitute Banque de Paris et des PaysBas und Crédit foncier algérien sowie die Montangesellschaft Mansfeld. Da keine Einigung zustande kam, wandten sich die Mannesmanns mit der Bitte um einen Kredit an die Reichsregierung ${ }^{80}$.

Insbesondere durch die Unterstützung von Reichsaußenminister Gustav Stresemann, der zur Weimarer Zeit »noch am ehesten als politischer Vertreter eines regierungsamtlichen kolonialen Revisionismus gelten könnte ${ }^{81}$, wurde den Mannesmanns am 12. Juni 1926 ein Reichskredit in Höhe von über acht Millionen Reichsmark bewilligt ${ }^{82}$. Stresemann wollte die $» V e r s c h l e u d e r u n g$ eines wertvollen deutschen Außenbesitzes von grosser außenpolitischer und wirtschaftlicher Bedeutung «, der »vielgestaltige außenpolitische Verwertungsmöglichkeiten « offenhalte, verhindern ${ }^{83}$. Erkundigungen der Terramons Ver-

${ }^{80}$ PA-AA R118401, L525018: Carl Mannesmann an AA, 15.1.1926; PA-AA R118401, L525023: Aufzeichnung, 18.1.1926; PA-AA R118401, L525232: Vermerk, 20.7.1926; Amerikanische Erwartungen, in: Kölnische Zeitung, 27.5.1926; Die Zukunft der Mannesmannkonzessionen, in: Kölnische Zeitung, 30.5.1926; Rudy ABRAMSON, Spanning the Century. The Life of W. Averell Harriman 1891-1986, New York 1992, S. 139-144.

${ }^{81}$ GRÜNDER, Geschichte, S. 222. Vgl. Jan ESCHE, Koloniales Anspruchsdenken in Deutschland im Ersten Weltkrieg, während der Versailler Friedensverhandlungen und in der Weimarer Republik (1914 bis 1933), Hamburg (Diss.) 1989, S. 246f.; Adolf RŬGER, Richtlinien und Richtungen deutscher Kolonialpolitik 1923-1926, in: Peter HEINE, Ulrich VAN DER HEYDEN (Hg.), Studien zur Geschichte des deutschen Kolonialismus in Afrika. Festschrift zum 60. Geburtstag von Peter Sebald, Pfaffenweiler 1995, S. 453-465, S. 455-457; POGGE VON STRANDMANN, Rathenau, S. 287f.; Andrew J. CROZIER, Die Kolonialfrage während der Locamo-Verhandlungen und danach. Ein Essay über die Beziehungen zwischen GroBbritannien und Deutschland 1924-1927, in: Wolfgang MICHALKA, Marshall M. LEE (Hg.), Gustav Stresemann, Darmstadt 1982 (Wege der Forschung, 539), S. 324-349, S. 331 f., S. 343.

PA-AA R118401: Bericht "Reichstag 1924/26: Ausschuß für den Reichstagshaushalt, 161. Sitzung«, 12.6.1926, S. 1-4, S. 11. Vgl. Außenpolitik und Geschäft. Zur Hetze gegen die Mannesmanns, in: Der Tag, 6.6.1926; Kreditgarantie für den Marokkobesitz von Mannesmann, in: Düsseldorfer Nachrichten, 13.6.1926; Um die Mannesmann-Konzessionen in Marokko. Erhaltung deutschen Auslandsbesitzes, in: Düsseldorfer Nachrichten, 16.6.1926; German Concessions in Morocco. Mannesmann Credit, in: Times, 15.6.1926; TERRIER, Les "Frères de la côte» 1926, S. 301; RüCHARDT, Deutsch-spanische Beziehungen, S. 339; SePasgosarian, Freundschaft, S. 110; VIÑAS, Franco, S. 263; KUNZ, MülleR, Giftgas, S. $101 \mathrm{f}$.

${ }^{83}$ PA-AA R118401, L525139: Bericht "Aufzeichnung für die interfraktionelle Ausschußsitzung betr. Mannesmann«, 7.5.1926. Vgl. auch BA R43, I, 654, 182: AA an Reichskanzlei, 2.2.1926; Karl-Heinz MNUTH (Bearb.), Die Kabinette Luther I und II 1925-1926, Bd. 2, Boppard 1977 (Akten der Reichskanzlei, Weimarer Republik, 9), S. 1080f., Anm. 7. 
wertungsgesellschaft im Jahre 1928 führten aber zu dem Ergebnis, daß der tatsächliche Wert des Mannesmann-Besitzes in Spanisch-Marokko nicht im entferntesten ausreichte, um den Kredit abzudecken ${ }^{84}$.

Viel bewirkte die Finanzspritze für die Mannesmanns nicht. Nach einem Zwangsvergleich 1926 verkaufte die Mannesmann-Mulag AG im Jahr darauf Teile der Fabrikanlagen und stellte 1928 die Produktion gänzlich ein. 1929 ereilte die Mannesmann Motorenwerke in Remscheid das gleiche Schicksal ${ }^{85}$.

\subsection{Abdelkrim und der Baske Horacio Echevarrieta}

Während des Ersten Weltkrieges fand Abdelkrim trotz seines Gefängnisaufenthaltes in Melilla (September 1915 bis August 1916) Zeit für geschäftliche Aktivitäten. Wie wichtig ihm der Handel mit Bodenschätzen war, zeigte sich im September 1915 darin, daß in seiner Zelle 276 Briefe, die Bergbau zum Thema hatten, konfisziert wurden ${ }^{86}$. Nach seiner Entlassung war Abdelkrim als Mitarbeiter der Oficina central de tropas y asuntos indígenas in besonderem Maße mit der Bearbeitung von Bergbaugeschäften auf dem Gebiet der Beni Touzine beschäftigt. Gleichzeitig hatte er Zugang zu Dokumenten, die die eigennützigen Motive der Spanier bei ihrer geplanten Ausbeutung der Rif-Bodenschätze offenbarten. Die Khattabis bereiteten sich auf die Zukunft vor. Si M'hammed, der Bruder Abdelkrims, wurde am 28. August 1917 auf die renommierte Madrider Schule für Bergbauingenieure (escuela de ingenieros de minas) geschickt, um sich Spezialwissen anzueignen ${ }^{87}$. Abdelkrim selbst schloß am 28. Mai 1918 mit Sadia Cohen Benaïm aus Melilla einen Vertrag über die Erforschung von angeblichen Erdölfeldern (Beni Touzine) $\mathrm{ab}^{88}$. Doch schon kurze Zeit später, im Dezember 1918, rief ihn sein Vater nach Ajdir zurück, und Si M'hammed kehrte Madrid im Januar 1919 den

\footnotetext{
${ }^{84}$ PA-AA R118404, L526283: Vermerk, 12.10.1928; PA-AA R118404, L526370: Bericht »Aufzeichnung über den gegenwärtigen Stand der Mannesmann-Angelegenheit«, 8.11.1928; VIÑAS, Franco, S. 264.

${ }^{85}$ WESSEL, Die Techniker, S. 143f.

${ }^{86}$ AYACHE, Les origines, S. 194, Anm. 85, S. 323, Anm. 95; TAHTAH, Pragmatisme 1995, S. 81; MADARIAGA, España y el Rif, S. 490.

${ }^{87}$ HART, The Aith Waryaghar, S. 371; DERS., Tribe and Society, S. 40-42; PENNELL, La guerra del Rif, S. 94f.; SHINAR, Abd al-Qadir, S. 162f.; AYACHE, Les origines, S. 245, S. 249; HARRIS, France, S. 267; FlemING, Primo de Rivera and Abd-el-Krim, S. 62f.; E. KLENN-WINTERMANN, Bodenschätze im Rif und in Marokko, in: Die Umschau 29 (1925) S. 865-868, S. 866; GRAF, Abd el Krims »Freiheitskampf«, S. 299; SHEEAN, My Meeting, S. 845, S. 849, S. 852; ABDELKRIM, Memoiren, S. 49; Les événements d'octobre à novembre, in: BCAF 31 (1921) S. 355-372, S. 371.
}

${ }^{88}$ ADMAE Maroc 112, 176: Vertrag zw. Abdelkrim und Sadia Cohen Benaīm, 28.5.1918. 
Rücken, ohne sein Studium zu beenden. Bei ihnen hatte sich der Wille verstärkt, gegen die Expansion der spanischen Militärs den Widerstandskampf zu organisieren.

Die Khattabis wandten sich gegen die militärische Besetzung ihres Landes. Im Bergbau sahen sie aber 1919 bis 1921 eine letzte Möglichkeit, kriegerische Auseinandersetzungen zwischen den Rifkabylen und Spanien zu vermeiden, wobei sie einer Art von wirtschaftlichem Protektorat Spaniens unter Beibehaltung des unabhängigen Lebens der Rifbevölkerung nicht abgeneigt waren. An einer Zusammenarbeit mit spanischen Wirtschaftsleuten waren sie daher durchaus interessiert. Über seinen Freund Cándido López, den stellvertretenden Chef der Oficina central de tropas y asuntos indígenas der Festung von Alhucemas, kontaktierte Abdelkrim 1918 und 1919 die Compañía española de Minas del Rif, um sie dazu zu veranlassen, auf dem Gebiet der Beni Ouriaghel Bergbauforschungen zu betreiben. Die Spanier lehnten Verhandlungen vor einer Besetzung des Rifs durch das spanische Militär jedoch ab. Auch Gespräche über Agrarprojekte in der Alhucemas-Region mit Rafael Roda von der Compañía española de colonización verliefen im November 1919 im Sande ${ }^{89}$.

Zuvor schon hatte Si M'hammed in einem Brief vom 23. Februar 1919 an Julio Setuaín - einem Bruder von Francisco Setuaín y San Emeterio von der Sociedad anónima minera Setolazar - Ländereien an der Mündung des Oued Nokour in der Bucht von Alhucemas zum Verkauf angeboten. Er schlug eine Gesellschaft unter der Führung der Familien Ybanco und Benaïm aus der spanischen Festung in Alhucemas vor. Sie sollte das Rif mit Lebensmitteln versorgen $^{90}$. Am 30. April 1920 dann schloß Abdelkrim mit der Sociedad anónima minera Setolazar einen Assoziationsvertrag über drei Erzvorkommen im Gebiet der Beni Ouriaghel und über zwölf Areale bei den Beni Touzine ab. Der auf die Zukunft ausgerichtete Kontrakt blieb in der Schwebe, da Setolazar die Beziehungen zu den zu dieser Zeit vorrückenden spanischen Militärs nicht trüben wollte ${ }^{91}$. Dennoch schickte Don Francisco Caballero, der Geschäftsführer der Setolazar in Bilbao, 1921 eine Vorschußzahlung von 400000 Peseten an Abdelkrim. Er warnte diesen allerdings, daß er sich mit seinen Kriegsvorbereitungen in Schwierigkeiten bringe ${ }^{92}$. Ihr am 28. April 1922 erteiltes Recht

${ }^{89}$ Madariaga, España y el Rif, S. 426, S. 488-492; TaHTAH, Pragmatisme 1995, S. 82f.; PAYNE, Politics, S. 162f.; SHIN, La Guetre du Rif, S. 58; DfAZ MORLÁn, Horacio Echevarrieta, S. 128; CADN Maroc DAI 190: Bericht »Notice de renseignements sur Mohamed Abdelkrim, Chef de la harka du Riff, le Caïd d'Adjdir« o.D. (1926).

${ }^{90}$ AYACHE, Les origines, S. 323 u. S. 323, Anm. 95.

${ }^{91}$ MADARIAGA, Mohammed ben Abdelkrim, S. 28f.; Dies., España y el Rif, S. 493-495, S. 503 mit dem Text des Vertrages; BALFOUR, Deadly Embrace, S. 62; ROGER-MATHIEU, Mémoires, S. 76; KERNER, La Guerre du Rif espagnole, S. 143; DIAZ MORLAN, Horacio Echevarrieta, S. 128; PRO-FO 371, 7085, 12039, 88: Embassy of Madrid an FO, 10.11.1921 mit der Zusammenfassung eines Artikels in der Zeitung "El Sol«, 2.11.1921.

${ }^{92}$ DAOUD, Abdelkrim, S. 99; LA PORTE, La atracción del imán, S. 103. 
auf Erforschung von Bergbaufeldern (Beni Ouriaghel, Beni Touzine) nahmen Juan Olavarriaga y Eguilor, Félix Ortiz de Zárate und Francisco Setuain y San Emeterio trotz der guten Kontakte ins Rif nicht wahr ${ }^{93}$.

Eine besondere Rolle sollte jedoch der baskische Millionär Horacio Echevarrieta spielen. Er war Reeder, Eigentümer der Zeitung »El liberal« in Bilbao und überzeugter Republikaner mit besten Beziehungen zum spanischen Königshof. Die von seinem Vater gegründete Firma Echevarrieta y Larrinaga war im Besitz reichhaltiger Bergbaufelder in der Biskaya. Seit 1908 hatte Echevarrieta Ländereien in Spanisch-Marokko aufgekauft und mit Francisco Ruíz Pastor eine Gütergemeinschaft zur bergbaulichen Ausbeutung Nordafrikas gegründet. 1917 beteiligte er sich an Rechten des Franzosen Henri Letellier, die dieser am Jebel Hamam im Kerngebiet des Rifs innehatte. Echevarrieta war ein alter Vertrauter von Abdelkrims Vater. Abdelkrim selbst und sein Bruder Si M'hammed, der den Basken von seinen Studientagen in Madrid her persönlich kannte, betrachteten ihn als einen der wenigen vertrauenswürdigen Spanier. Im Frühjahr 1921 beschloß Echevarrieta, seine marokkanischen Geschäfte voranzutreiben ${ }^{94}$. Zu dieser Zeit stieß die spanische Ostarmee unter dem Kommando von General Manuel Fernández Silvestre in das Gebiet der Rifkabylen vor, während Abdelkrim um sich den Widerstand gegen die spanische Expansion formierte.

Horacio Echevarrieta stand im Verdacht, entweder der Repräsentant ${ }^{95}$ bzw. der Teilhaber ${ }^{96}$ der Brüder Mannesmann geworden zu sein oder deren Rechte im Rif gänzlich aufgekauft bzw. eine Option auf sie erworben zu haben ${ }^{97}$. Er selbst äußerte sich zu seinen angeblichen Beziehungen zu den Deutschen nur

${ }^{93}$ Madariaga, L'Espagne et le Rif, Bd. 1, S. 199f.; GoDCHOT, Le mystère, S. 249; Mining Titles in Morocco, in: Morocco, 21.4.1923.

${ }^{94}$ DÍAZ MORLÁN, Horacio Echevarrieta, S. 28, S. 101-103, S. 127f., S. 338, Anm. 212 (in seiner Biographie sind die Marokko-Aktivitäten Echevarrietas nur ein Randthema); DERS., Un ejemplo de clientelismo empresarial. La influencia política del industrial Horacio Echevarrieta, in: Historia social 36 (2000) S. 101-120, S. 101f.; DERS., Capital minero e industrialización. El grupo empresarial vizcaíno "Echevarrieta y Larrínaga« 1882-1916, in: Revista de historia industrial 9 (1996) S. 153-173, S. 154-165.; MADARIAGA, España y el Rif, S. 513; BoYd, Praetorian Politics, S. 175; SUeIro SEOANE, España, S. 141, Anm. 14; LADRET DE LAChaRRière, Le rêve, S. 102, S. 124, S. 142; PenNell, A Country, S. 114, S. 196; DAOUD, Abdelkrim, S. 83; SHAT 3H134: Ambassade de Madrid, Attaché militaire an MG, EMA, $2^{\circ}$ bureau, 2.2.1923; SHAT 3H134: Bericht „Espagne, Mines du Riff«, 27.12.1924; SHAT 3H134: MAE an MG, EMA, Section d'Afrique, 8.1.1925.

${ }^{95}$ SLAVIN, Anticolonialism, S. 48; PENNELI, A Country, S. 114; WOOLMAN, Rebels in the Rif, S. 87; SHINAR, Abd al-Qadir, S. 161; HART, Tribe and Society, S. 39. Niemand liefert jedoch einen Quellenbeleg.

${ }^{9}$ CADN Tanger C39: Tabor de police $\mathrm{N}^{\circ} 1$, Note, 18.7.1925; SHAT 3H135: EMA, $2^{e}$ bureau, SR, Renseignements, 7.9.1925; RIVET, Le commandement français, S. 107, Anm. 27.

${ }^{97}$ CADN Tanger C274: Ambassade de Madrid an MAE, 26.1.1923; CADN Tanger A425: MAE an CG Tanger, 27.10.1921 mit Bezug auf einen Bericht der spanischen Zeitung »Acción«; LADREIT DE LACHARRIÈrE, Le rêve, S. 123f.; WOOLMAN, Rebels in the Rif, S. 110. 
insoweit, als daß sie »eines Tages« zu ihm mit großem Lob über das Rifgebiet gesprochen und ihn an die großen Erzvorkommen dort erinnert hätten. Um diese Aussagen zu überprüfen, habe er im Frühjahr 1921 seinen Freund Don Antonio Got Inchausti aus Melilla gebeten, mit Abdelkrim in Verbindung zu treten $^{98}$. Got war ein ehemaliger Artillerieoffizier und Ingenieur, der jetzt als Direktor der Escuela de artes y oficios in Tetuan und als Korrespondent der Zeitung »El sol« fungierte". Zwischen dessen Mitarbeiter Mohammed Dris ben Saïd, der seit der gemeinsamen Studienzeit in Fes freundschaftliche Bande zu Abdelkrim geknüpft hatte ${ }^{100}$, und den Mannesmanns bestand allerdings ein direkter Kontakt, wie dieser dem französischen Gesandten von Tanger bei einem Gespräch in Tetuan selbst bestätigte ${ }^{101}$.

Anfang April 1921 bat Antonio Got den Militärkommandanten von Melilla, General Manuel Fernández Silvestre, um die Erlaubnis, mit Abdelkrim wegen der Ausbeutung von Bodenschätzen auf dem Gebiet der Beni Ouriaghel in Verbindung zu treten. Echevarrietas Instruktionen für Got lauteten, das im Rif geplante Bergbauprojekt aufzugeben, falls sich das Militär dagegenstellen sollte. An dem Gespräch nahm Coronel Gabriel Morales y Mendigutía - der Leiter der Oficina central de tropas y asuntos indígenas in Melilla und Abdelkrims früherer Vorgesetzter - teil. Got und Echevarrieta planten über Wirtschaftskontakte eine friedliche Durchdringung des Rifs, was die militärische Besetzung der strategisch wichtigen Bucht von Alhucemas mit einschloß. Silvestre gab zunächst seine prinzipielle Zustimmung. Am 6. April 1921 landete Got darauthin in der Bucht von Alhucemas und traf sich mit Abdelkrims Bruder Si M'hammed und dessen Onkel Si Abdeslam ben Mohammed el Khattabi. Si M'hammed bekräftigte die Gesprächsbereitschaft der ebenfalls an Bergbaugeschäften interessierten Khattabis und ihren Wunsch zu friedlichen Beziehungen mit Spanien. Mit Got als Vermittler sollten die Verhandlungen in aller Geheimhaltung ablaufen. Mehrere Wochen vergingen, bis Abdelkrim seinen Schwager Si Mohammed Azerkane nach Melilla schickte. Ihm wurde am 5. Mai 1921 die spanische Gesprächsbereitschaft signalisiert - mit dem Zusatz, daß von Abdelkrim erwartet werde, seine Truppen zu verraten. Dies war eine inakzeptable Forderung. Als Antonio Got am 16. Mai 1921 für neue Gespräche in Ajdir eintraf, teilte Abdelkrim ihm mit, daß die Rifkabylen wegen des permanenten spanischen Vormarsches sehr beunruhigt seien. Eine spanische Besetzung von Alhucemas sei unmöglich, und Silvestre dürfe den Ame-

\footnotetext{
${ }^{98}$ Díaz MORLÁN, Horacio Echevarrieta, S. 128 mit Bezug auf einen Artikel in der Zeitung "La correspondencia de Españak, 31.1.1923.

${ }^{99}$ Les événements d'octobre à novembre, in: BCAF 31 (1921) S. 371; LADREIT DE LACHARRIEkRE, Le rêve, S. 124; PA-AA R72041, L057338: übersetzter Artikel der spanischen Zeitung »La Acción«, 7.11.1921.

${ }^{100}$ BROWN, Résistance, S. 473f.; PENNELL, A Country, S. 112; TAHTAH, Pragmatisme 1995, S. 146, Anm. 3; WoOlman, Rebels in the Rif, S. 77; AYACHE, La Guerre du Rif, S. 134.

${ }^{101}$ CADN Madrid C258: MAE an Ambassade de Madrid, 12.12.1922.
} 
krane-Fluß keinesfalls überqueren. In Melilla unterrichtete Got General Silvestre von Abdelkrims Warnung, doch dieser zeigte sich uneinsichtig. Mit dem Scheitern der Pläne Echevarrietas und Gots war eine große Chance auf eine friedliche Beilegung des Konflikts vertan ${ }^{102}$.

Nach der Eröffnung der Kämpfe gab Echevarrieta seine Bergbaupläne zunächst auf. Die Tür für eine Einigung Abdelkrims mit seinen spanischen Geschäftspartnern war geschlossen. Für diese wäre die Gefahr eines Landesverrates zu hoch gewesen ${ }^{103}$. Abdelkrim und $\mathrm{Si}$ M'hammed versuchten von Mai bis Juni 1921 weiter, über ihren Freund Coronel Morales den Kontakt mit den spanischen Militärs aufrechtzuerhalten. Am 21. Juni 1921 - nach dem ersten Sieg der Riftruppen bei Ouberrane - übermittelten sie einen Brief an den Kommandanten der spanischen Festung in der Bucht von Alhucemas, Coronel Manuel Civantos. Sie bekräftigten ein letztes Mal ihre Bereitschaft zu einer friedlichen Lösung des Konflikts bis hin zu einer Anerkennung des spanischen Protektorats. Doch die Fronten waren verhärtet. In seiner Antwort warf Civantos den Beni Ouriaghel vor, ein unkultiviertes Volk zu sein, das die Regeln des Krieges niemals akzeptiert habe. Damit ging er auf die verstümmelten Toten der spanischen Besatzung von Ouberrane ein. Er forderte die Rifkämpfer zum sofortigen Rückzug auf. General Silvestre setzte seinen Vormarsch fort, der in die spanische Niederlage von Annual im Juli 1921 mündete ${ }^{104}$.

Abdelkrims Faustpfand in seinen Verhandlungen mit Spanien waren die während der Kämpfe von 1921 gefangengenommenen spanischen Soldaten und Zivilisten, die in der Nähe von Ajdir untergebracht waren. Kontaktversuche seitens der Spanier über den vom Kriegsministerium zur Festung von Alhucemas entsandten Luis Montes - er hatte zusammen mit Si M'hammed an der Madrider Bergbauschule studiert ${ }^{105}$-, über Fernández Almeyda vom spanischen Roten $\mathrm{Kreuz}^{106}$ oder über eine aus Coronel Patxot und Si Abderrah-

${ }^{102}$ DIAZ MORLÁN, Horacio Echevarrieta, S. 128f.; MADARIAGA, España y el Rif, S. 499502; AYACHE, Les origines, S. 319-329; HART, Tribe and Society, S. 41; UsBORNE, The Conquest, S. 248; WoOlman, Rebels in the Rif, S. 87; PANDO, Historia secreta, S. 101; ÁLVAREZ, The Betrothed of Death 1995, S. 78f.; HERNÁNDEZ MIR, Del desastre a la victoria, Bd. 1, S. 38-41; PRO-FO 371, 7085, 12039, 83: Embassy of Madrid an FO, 5.11.1921 mit einem Artikel Antonio Gots in der Zeitung »El Sol«, 3.11.1921; PRO-FO 371, 7085, 12039, 88: Embassy of Madrid an FO, 10.11.1921 mit der Zusammenfassung eines Artikels von Ruíz Albeniz in der Zeitung »El Sol«, 2.11.1921; CADN Tanger A425: MAE an CG Tanger, 27.10.1921 mit einem Bericht der Zeitung "La Acción« (Oktober 1921); PA-AA R72041, L057338: übersetzter Artikel der Zeitung »La Acción«, 7.11.1921.

${ }^{103}$ AYACHE, La Guerre du Rif, S. 221.

${ }^{104}$ MAdARIAGA, España y el Rif, S. 509-513; HeRnANDEZ MIR, Del desastre a la victoria, Bd. 1, S. 42-46.

${ }^{105}$ Les événements d'octobre à novembre, in: BCAF 31 (1921) S. 371; LADRETT DE LACHARRIERE, Le rêve, S. 130; DAOUD, Abdelkrim, S. 142.

${ }^{106}$ WOOLMAN, Rebels in the Rif, S. 110; FURNEAUX, Abdel Krim, S. 91; HERNANDEZ MIR, Del desastre a la victoria, Bd. 2, S. 69; LADREIT DE LACHARRIERE, Les origines, S. 227. 
man ben Abdessadik bestehende Mission wurden von Abdelkrim abgewiesen, da er sich weigerte, mit Abgesandten der spanischen Regierung oder des Hochkommissariats zu kommunizieren. Er bestand darauf, über Echevarrietas Mitarbeiter Dris ben Saïd zu verhandeln. Neben der Zahlung von vier Millionen Peseten und der Freilassung von rund 800 Rifkämpfern verlangte Abdelkrim einen Friedensvertrag inklusive der Anerkennung der Unabhängigkeit sowie deren Bestätigung durch Frankreich oder Großbritannien. Die spanische Regierung lehnte einen Rifstaat jedoch $\mathrm{ab}^{107}$.

Der im marokkanischen Petitjean lebende Franzose Maurice Banzet wurde im Februar 1922 von Spaniens Ministerpräsident José Sánchez Guerra ins Rif geschickt. Bis auf einen Punkt war die spanische Regierung zu Zugeständnissen bereit. Banzet bot Abdelkrim die geforderten vier Millionen Peseten für die Freilassung der Gefangenen und die informelle Anerkennung von dessen Herrschaft im Rif an. Doch dieser traute den Spaniern nicht und bestand darauf, daß die Abmachung von einer weiteren Nation - vorzugsweise Frankreich - bestätigt werden müßte ${ }^{108}$. Im Mai 1922 führte der Franziskanermönch Padre Revilla - der Kaplan der spanischen Fremdenlegion - zwei Gespräche mit Abdelkrim, der weiter auf seinen Bedingungen beharrte ${ }^{109}$. Diese Initiativen verliefen im Sande. Die Khattabis hatten alle Karten in der Hand. Sie hatten Zeit, zumal Spanien ihnen monatlich 50000 Peseten zahlte, damit Versorgungsgüter die Gefangenen erreichen konnten ${ }^{110}$.

Das Hauptproblem für Abdelkrim bestand darin, daß seine Zielsetzungen in der westlichen Welt, die von der Kriegsberichterstattung des spanischen bzw. später des französischen Militärs beeinflußt wurde, nicht bekannt waren. Zeitungsberichte seines französischen Beraters Daniel Bourmancé-Say und dessen Vertrauten Jean du Taillis - er war der erste Journalist, der sich während des Krieges im Rif aufhielt - hatten nur wenig Aufmerksamkeit erregt ${ }^{111}$. Im Mai 1922 lud Abdelkrim daher Pressevertreter ausdrücklich zu einem Besuch ein $^{112}$. Journalisten aus Europa und aus den USA, die das Rif bereisten, wurden in der Folgezeit ebenso wie in Tanger stationierte Presse-Korrespondenten

${ }^{107}$ SECo SerRaNo, Los comienzos, S. 624f.; Les prisonniers, in: BCAF 31 (1921) S. 418f., S. 419; BOYD, Praetorian Politics, S. 199; KHARCHICH, La France, S. 87; CADN Maroc DAI 190: Note, 21.11.1921.

${ }^{108}$ CADN Tanger A426: MAE an CG Tanger, 29.3.1922; ADMAE Maroc 194, 151: Renseignement, 9.3.1922; CADN Madrid C273: MAE an Ambassade de Madrid, 5.2.1922.

${ }^{109}$ A Greyfriar's Visit to the Rif. Abd-el-Krims Terms, in: Times, 6.6.1922; El rescate de los prisioneros, in: El Sol, 2.6.1922; OTEYZA, Abd-el-Krim, S. 118; HERNÁNDEZ MIR, Del desastre a la victoria, Bd. 2, S. 81-83; LADRETT DE LACHARRIĖRE, Le rêve, S. 138; AYACHE, La Guerre du Rif, S. 244, Anm. 32; PRO-FO 371, 8341, 171, 22: Embassy of Madrid an FO, 8.6.1922; TNLA, RD, 1, Deakin: Walter Harris an Ralph Deakin, 7.6.1922.

${ }^{110}$ PRO-FO 371, 9473, 898, 53: Embassy of Madrid an FO, 31.1.1923; PRO-FO 371, 8342, 171, 90: Embassy of Madrid an FO, 13.10.1922.

${ }^{111}$ Siehe S. 247f. u. S. 253.

${ }^{112}$ TNLA, RD, 1, Deakin: Walter Harris an Ralph Deakin, 27.5.1922. 
als Mediatoren der Rif-Propaganda funktionalisiert ${ }^{113}$. Über sie versuchte der ehemalige Redakteur der Zeitung "Telegrama del Rif», die Absichten der Rifkabylen zu verdeutlichen. Der Rifkrieg war der erste Kolonialkrieg mit einer regelrechten Gegenpropaganda der Bevölkerung, die unterworfen werden sollte ${ }^{114}$. Gleichzeitig nutzten die Rifkabylen die Presse ihrer Gegner, um Informationen über deren militärische Planungen zu erhalten ${ }^{115}$.

Im August 1922 empfing Abdelkrim über die Vermittlung von Mohammed Dris ben Saïd den Leiter der spanischen Zeitung »Libertad«, Luis de Oteyza, der sich ein Bild vom Zustand der spanischen Gefangenen machen wollte. In aufsehenerregenden Reportagen, die zwischen dem 6. bis 15 . August 1922 erschienen, sowie in dem im selben Jahr veröffentlichten Buch "Abd-el-Krim y los prisioneros « berichtete der spanische Journalist von seiner Reise. Schon am 16. November 1921 hatte die »Libertad« einen Brief Abdelkrims veröffentlicht, in dem er sich mit seinen Bedingungen für eine Freilassung direkt an die Familien der spanischen Gefangenen gewandt hatte. Es handelte sich um die erste politische Verlautbarung Abdelkrims in der europäischen Presse - und um einen Einzelfall in der spanischen Zeitungslandschaft, die in der Regel von der Kolonialpropaganda beherrscht wurde. Die »Libertad« galt als moderates und republikanisches Blatt, das dem liberalen Politiker Santiago Alba y Bonifaz, der eine Verhandlungslösung mit Abdelkrim befürwortete, nahestand $^{116}$. Einer der engsten politischen Freunde Albas war Horacio Echevarrie$\operatorname{ta}^{117}$.

Ende Juli 1922 gingen Luis de Oteyza und die ihn begleitenden Fotografen Alfonsito Sánchez und José Maria »Pepe» Díaz Casariego in der Bucht von Alhucemas an Land. Sie waren mit dem Dampfschiff »Gandía der Compañía

${ }^{113}$ L'agression des Rifains contre le Maroc français, in: BCAF 35 (1925) S. 362; HUETZ DE LEMPS, La collaboration, S. 91; HARRIS, France, S. 318f,; LADREIT DE LACHARRIERE, Le rêve, S. 255; GABRIELl, Abd-el-Krim, S. 15; Hills, Franco, S. 121; BOUTBOUQALT, La Guerre du Rif, S. 29; OVED, La gauche frangaise, Bd. 1, S. 294; SHINAR, Abd al-Qadir, S. 166f.; SHIN, La Guerre du Rif, S. 122.

${ }^{114}$ RIVET, Lyautey, Bd. 3, S. 264; LA PORTE, La atracción del imán, S. 186.

${ }^{115}$ CADN Madrid C274: MAE an Ambassade de Madrid, 17.9.1923; SHAT 3H1559: Commissariat de la sûreté régionale Oujda, Renseignements, 21.10.1923 und 22.10.1923; PROFO 371, 9470, 44, 29: CG Tangier an FO, 2.9.1923; NARA 881.00, 1057: American Agency and Consulate General of Tangier an Secretary of State, 20.5.1925.

${ }^{116}$ Maria-Rosa de MADARIAGA, Estudio introductorio, in: OTEYZA, Abd-el-Krim, S. 11-52, S. 14, S. 17-20, S. 24, S. 30; Pedro GOMEZ APARICIO, Historia del periodismo español, Bd. 3: De las guerras coloniales a la dictadura, Madrid 1974, S. 657f.; María CRUZ SEOANE, Maria D. SAZ, Historia del periodismo en España, Bd. 3: El siglo XX 1898-1936, Madrid 1996, S. 260-263, S. 359; BOUTBOUQALT, La Guerte du Rif, S. 86-91; WoOLMAN, Rebels in the Rif, S. 113; Trois journalistes espagnoles chez Abdel Krim, in: BCAF 32 (1922) S. 382-385; HERNANDEZ MIR, Del desastre a la victoria, Bd. 2, S. 63-66; CADN Tanger A426: MAE an CG Tanger, 18.11.1922; PRO-FO 371, 8356, 7395, 196: Embassy of Madrid an FO, 31.8.1922.

${ }^{117}$ DIAZ MORLÁN, Horacio Echevarrieta, S. 75-79. 
transmediterránea angekommen, das den spanischen Gefangenen im Rif regelmäßig Versorgungsgüter zukommen ließ ${ }^{118}$. Oteyza erhielt die Gelegenheit, mit seinen Landsleuten - darunter General Felipe Navarro - Gespräche zu führen. Mit Si Mohammed Azerkane und Si M'hammed debattierte er über die Ursachen ihres Bruchs mit Spanien und über den Ablauf der Kämpfe von 1921. Ein Essen am 2. August 1922 nutzte Si M'hammed für politische Erklärungen, die der spanischen Öffentlichkeit erstmals die angestrebte Bildung einer »Rif-Republik« anzeigten. Er forderte die Unabhängigkeit des Rifs zwischen Oued Kert und Tetuan außerhalb der spanischen Administration ein. Der Krieg, so führte er aus, richte sich gegen den Imperialismus Spaniens, nicht gegen die dort lebenden Arbeiter und Händler, denn im Grunde verfolge man mit dem angestrebten Fortschritt im Rif die gleichen Ziele. Die spanische Wirtschaft lud er daher ein, sich an der Ausbeutung der Reichtümer innerhalb des Rifs zu beteiligen ${ }^{119}$.

Dies untermauerte er wenige Tage später in einer handschriftlichen Notiz, die Oteyza im Original veröffentlichte. Dem Aufruf folgte jedoch niemand. Bei dieser Gelegenheit traf Luis de Oteyza auch auf Abdelkrim, den er als "Präsidenten der Rif-Republik» auswies. Dieser bekräftigte wie sein Bruder, daß er nichts gegen das spanische Volk, sondern nur gegen die spanischen Invasionsbestrebungen habe. Die Voraussetzung für den Abschluß eines Friedensvertrages sei die Anerkennung der Unabhängigkeit des Rifs. Nur wenn Spanien Rifkämpfer freilasse und vier Millionen Peseten zahle, würden die spanischen Gefangenen ihre Freiheit wiedererlangen. Verhandlungen würden ausschließlich mit Zivilisten, nicht aber mit Militärs geführt ${ }^{120}$.

Luis de Oteyza war der erste Spanier, der die Sichtweise der Khattabis objektiv wiedergab. In der spanischen Presse erfuhr er nach seiner Rückkehr wenig Zustimmung. Insbesondere von den Zeitungen »Acción« und »A.B.C." wurde er als Verräter verunglimpft, der einen Kriegsgegner glorifiziere ${ }^{121}$. Er blieb auch der einzige spanische Journalist, der sich im Rif selbst ein Bild machte.

Am 7. Dezember 1922 wechselte in Spanien die Regierung. Santiago Alba y Bonifaz wurde neuer Ministerpräsident. Die Frage der Freilassung der im Rif festgehaltenen spanischen Kriegsgefangenen wurde Ende 1922 insbesondere durch Aktionen der Comisión pro-rescate stärker diskutiert. Alba war zu einer schnellen Lösung bereit ${ }^{122}$. Im Juli 1922 schon hatte Abdelkrim der spanischen Seite zuspielen lassen, daß er lediglich Horacio Echevarrieta als Ver-

\footnotetext{
118 Juan M. SÁNCHEZ ViGiL, Alfonso, fotografo de un siglo, Madrid 1990, S. 42.

${ }^{119}$ OTEYZA, Abd-el-Krim, S. 77-81, S. 89-116.

${ }^{120}$ Ibid. S. 119-132.

${ }^{121}$ MADARIAGA, Estudio, S. 25, S. 48; GÓMEZ APARICIO, Historia, Bd. 3, S. 658f.; HERNÁNDEZ MIR, Del desastre a la victoria, Bd. 2, S. $89 f$.

${ }^{122}$ SeCo SerRANo, El plano, S. 65-69; MARín ARCE, El gobierno, S. 169.
} 
mittler akzeptiere ${ }^{123}$. Der Baske hatte sein Interesse an der Rifregion nie verloren und war über Dris ben Saïd ständig auf dem Laufenden gehalten worden, auch wenn er von Juli 1921 an - also nach dem Beginn der Kampfhandlungen zwischen Spanien und den Rifkabylen - keinen direkten Kontakt mehr zu Abdelkrim aufrechterhalten hatte ${ }^{124}$. In Melilla etablierte er 1922 unter der Leitung von Luis Aranguren ein Büro, das rein für Marokkogeschäfte zuständig war. Dort sollten Bergbaufelder angezeigt, Bergbau-Konzessionen aufgekauft, Studien über Verkehrswege angefertigt sowie Waren erworben und verkauft werden. Dris ben Saïd fungierte als Chefunterhändler für die Gespräche mit Einheimischen. Im Herbst 1922 wandelte Echevarrieta seine bisherige Teilhaberschaft an den Jebel-Hamam-Rechten Henri Letelliers in einen Alleinbesitz $u^{125}$.

Echevarrietas Partner war ein Brite namens James Campbell aus Middlesborough. Neben seiner Beteiligung an der ägyptischen Sinai Mining Company betrieb Campbell seit 1910 zusammen mit Echevarrieta im spanischen Baskenland Bergbaugeschäfte ${ }^{126}$. Am 16. März 1914 hatte er die algerische Eisenmine von Lalla Marnia aufgekauft. Er mischte so erfolgreich im algerischen Bergbau mit, daß seine Firma als eine von zwei Bergbaugesellschaften die Weltwirtschaftskrise überlebte ${ }^{127}$.

Im Sommer 1922 unterbreitete Echevarrieta Campbell ein Angebot über Anteile an Eisenerzvorkommen in der Bucht von Alhucemas. Er bot eine fünfzigprozentige Beteiligung an den von der Schiedskommission bewilligten Rechten sowie an zusätzlichen von Abdelkrim zugesagten Konzessionen an ${ }^{128}$. Campbell wandte sich mit der Bitte um Unterstützung an das britische Außenministerium, doch sein Anliegen wurde als gewagte Spekulation, für die er selbst und allein das Risiko trage, abgetan ${ }^{129}$. Die britische Regierung verhielt sich während des Rifkrieges prinzipiell neutral. Dies erfuhr auch eine Rifdele-

${ }^{123}$ DIAZ MORLÁN, Horacio Echevarrieta, S. 132.

${ }^{124}$ MAdariaga, España y el Rif, S. 514f.; GómeZ APARICIO, Historia, Bd. 3, S. 666.

${ }^{125}$ DíAZ MORLÁN, Horacio Echevarrieta, S. 129-131; DERS., Un ejemplo, S. $106 f$.

${ }^{126}$ PRO-FO 371, 8355, 6082, 108: James Campbell an FO, 20.7.1922; SHAT 3H102: EMA, $2^{e}$ bureau, Bericht »Contrebande d'armes« o.D. [Juni 1925]; DíAZ MORLÁN, Horacio Echevarrieta, S. 86, S. 103, S. 118-125; DeRS., Capital minero, S. 160.

${ }^{127}$ Joëlle REDOUANE, La présence anglaise en Algérie de 1830 à 1930, in: Revue de l'occident musulman et de la méditerrannée 38 (1984) S. 15-36, S. 29; ADMAE Maroc 220, 145: MG, EMA an MAE, 2.7.1925; CADN Madrid C263: RG Rabat an MAE, 6.12.1924.

${ }^{128}$ PRO-FO 371, 8355, 6082, 108: James Campbell an FO, 20.7.1922; PRO-FO 371, 8355, 6082, 119: James Campbell an FO, 25.8.1922.

${ }^{129}$ PRO-FO 371, 8355, 6082, 107: Minute, 24.7.1922; PRO-FO 371, 8355, 6082, 111 : FO an James Campbell, 27.7.1922; PRO-FO 371, 8355, 6082, 116: FO an James Campbell, 23.8.1922; PRO-FO 371, 8355, 6082, 123: FO an James Campbell, 13.12.1922. 
gation, die sich zeitgleich - aber völlig unabhängig von James Campbells Interessen - in London aufhielt, um britischen Geschäftsleuten Bergbau-Konzessionen zu verkaufen ${ }^{130}$.

Der Bitte von Santiago Alba, sich als Unterhändler für die Freilassung der spanischen Gefangenen zur Verfügung zu stellen, entsprach Echevarrieta im Dezember 1922 gerne. Für ihn bedeutete dies eine Chance, seine Geschäfte mit Abdelkrim offiziell sanktionieren zu lassen. Über Dris ben Saïd verlief ein einmonatiger Briefwechsel, ehe die Bedingungen für eine Übergabe der spanischen Gefangenen feststanden. Spanien sollte 4270000 Peseten auszahlen und 93 gefangene Rifkämpfer freilassen. Am 23. Januar 1923 warf der Dampfer "Antonio Lopez« in der Bucht von Alhucemas seinen Anker. Echevarrieta und Dris ben Saïd gingen an Land und handelten mit Si Mohammed Azerkane die Modalitäten der Auslieferung aus. Ein großer Teil des Lösegeldes wurde in Münzen, die insgesamt 20 Tonnen wogen, übergeben. Am 27. Januar 1923 ließ Abdelkrim die spanischen Soldaten und Zivilisten frei, die mit Ruderbooten zur "Antonio Lopez« befördert wurden. Die meisten von ihnen befanden sich in einem sehr schlechten körperlichen Zustand ${ }^{131}$.

Neben dem Jubel über die Befreiung der Gefangenen gab es in der spanischen Presse auch kritische Stimmen, die Echevarrieta vorwarfen, sein humanitäres Engagement mit seinen wirtschaftlichen Plänen im Rif verbunden zu haben ${ }^{132}$. Der baskische Millionär hoffte nach wie vor, Abdelkrim dazu bewegen zu können, einer kampflosen Besetzung der strategisch wichtigen Bucht von Alhucemas durch Spanien zuzustimmen, um so eine privilegierte Position im Hinblick auf den Erwerb dortiger Bergbau-Konzessionen zu erhalten. Echevarrieta schwebte hierbei eine wirtschaftliche Durchdringung Nordmarokkos im Gegensatz zu den militärischen Aktivitäten, die seiner Ansicht nach in der indigenen Bevölkerung nur $\mathrm{HaB}$ hervorrufen würden, vor. Um diese

${ }^{130}$ Siehe hierzu S. 281-285.

${ }^{131}$ MARÍN ARCE, El gobierno, S. 169-177; DiAZ MORLÁN, Horacio Echevarrieta, S. 131136. Sowohl über die anfängliche Zahl der spanischen Kriegsgefangenen im Rif als auch über die Zahl der Überlebenden gibt es in der Literatur unterschiedliche Angaben: 300 Überlebende [DAOUD, Abdelkrim, S. 167]; 326 Überlebende [BOYD, Praetorian Politics, S. 241]; 326 Überlebende von ursprünglich 534 Gefangenen [BALFOUR, Deadly Embrace, S. 91]; 326 Überlebende von ursprünglich 570 Gefangenen [WOOLMAN, Rebels in the Rif, S. 111]; 330 Überlebende von ursprünglich 570 Gefangenen [ÁLVAREZ, The Betrothed of Death 2001, S. 85]; 330 Überlebende [MADARIAGA, España y el Rif, S. 547, Anm. 16; FLEMING, Primo de Rivera and Abd-el-Krim, S. 82]; 336 Überlebende [DíAZ MORLÁN, Horacio Echevarrieta, S. 134]; 357 Überlebende [SECO SERRANO, El plano, S. 69]; 396 Überlebende [KGERER, La Guerre du Rif espagnole, S. 149].

${ }^{132}$ La libération des prisonniers, in: BCAF 33 (1923) S. 59-64, S. 61f.; CrUZ SEOANE, SAIZ, Historia, Bd. 3, S. 234. 
Frage war es auch während der Gespräche mit Azerkane gegangen. Echevarrieta hielt zwar die Vorgehensweise der spanischen Militärs für falsch, nicht jedoch die spanische Oberhoheit in Nordmarokko an sich $^{133}$.

Abdelkrim verfolgte allerdings eigene Ziele. Die Höhe des Lösegeldes war ein Triumph für ihn und erhöhte sein Ansehen im Rif noch weiter ${ }^{134}$. Es bildete die finanzielle Basis für die Modernisierung der Rifarmee und die Ausgestaltung der »Rif-Republik«, deren Proklamation am 1. Februar 1923 - unmittelbar nach der Freilassung der spanischen Gefangenen - erfolgte ${ }^{135}$.

In seiner nunmehrigen Position als Oberhaupt des neuen Rifstaates glaubte sich Abdelkrim in einer gefestigteren Position für Verhandlungen mit offiziellen spanischen Vertretern - ein Irrglaube, wie sich zeigte. Am 16. April 1923 empfing der spanische General Alberto Castro Girona auf dem in der Bucht von Alhucemas liegenden Kriegsschiff "Regente« eine Rifdelegation, der unter anderem auch Ahmed Boudra und Si Mohammed Boujibar angehörten. Boudra bot Spanien gegen die Anerkennung des Rifstaates ein Wirtschaftsmonopol an. Mit Hilfe von spanischen Ingenieuren, Industriellen, Händlern und Wissenschaftlern sollte der Fortschritt im Rif angekurbelt werden. Wie stark der Wille innerhalb der Rifregierung verankert war, die Oberhoheit über die Bodenschätze, die man im Rif vorzufinden glaubte, zu erhalten, zeigte sich in seinen Zusatzerklärungen. Darin hob er hervor, daß dies ausdrücklich zur Verfügungsgewalt unabhängiger und freier Nationen gehöre. Bergbau und die Anerkennung der »Rif-Republik« waren untrennbar miteinander verknüpft ${ }^{136}$.

Castro Girona, der wie die meisten Offiziere eine militärische Unterwerfung der Rifkabylen befürwortete, entgegnete jedoch, daß Spanien die territoriale Integrität des dem marokkanischen Sultan unterstehenden Staatsgebiets nicht in Frage stellen könne, woraufhin die Verhandlungen abgebrochen wurden. Abdelkrim weigerte sich in der Folgezeit, weiter mit Castro Girona zu verhandeln ${ }^{137}$.

Die Vorschläge der Rifdelegierten ähnelten einem Plan zur wirtschaftlichen Erschließung des Rifs mit friedlichen Mitteln, den Dris ben Saïd für Echevarrieta entwickelt hatte. Seine Ideen umfaßten die Entsendung von Technikern,

${ }^{133}$ DIAZ MORLÁN, Horacio Echevarrieta, S. 131 f.

${ }^{134}$ PRO-FO 371, 9469, 44, 72: Consul of Tetuan an CG Tangier, 14.12.1922; PRO-FO 371, 9473, 898, 51: Minute, 6.2.1923.

${ }^{135}$ DIAZ MORLAN, Horacio Echevarrieta, S. 136; PENNELL, A Country, S. 123; KeERNER, La Guerre du Rif espagnole, S. 149.

${ }^{136}$ HERNÁNDEZ MIR, Del desastre a la victoria, Bd. 2, S. 116; MADARIAGA, España y el Rif, S. 517f.; BALfoUR, Deadly Embrace, S. 91; FlemING, Primo de Rivera and Abd-el-Krim, S. 83; CHANDLER, Spain, S. 316; GodED LlOPIS, Marruecos, S. 128; Les negotiations avec Abdel Krim, in: BCAF 33 (1923) S. 233f.; PRO-FO 371, 9469, 44, 174: Vice-Consulate of Tetuan an CG Tangier, 3.5.1923; PA-AA R72041, L057478: Konsulat Tetuan an Botschaft Madrid, 19.5.1923.

${ }^{137}$ HeRNÁNDEZ MIR, Del desastre a la victoria, Bd. 2, S. 118, S. 120. 
Spezialisten und Ingenieuren, die Ausbeutung der Bergbaufelder, den Bau eines Hafens in der Bucht von Alhucemas oder die Errichtung eines Straßenund Eisenbahnnetzes durch eine von Echevarrieta geleitete Chartergesellschaft. Im Gegenzug sollte Abdelkrim den marokkanischen Sultan und die spanische Autorität im Norden Marokkos anerkennen - ein Punkt, der nach der Proklamation der »Rif-Republik» nicht sehr realistisch war. Der Plan unterstellte, daß Abdelkrim nur an der Modernisierung und wirtschaftlichen Erschließung der Rifregion interessiert war, nicht aber an der Unabhängigkeit eines eigenen Staates ${ }^{138}$. Er glich in seinen Grundzügen sehr stark dem Mannesmann-Projekt von 1913. Er hatte auch große Ähnlichkeit mit einem Vertrag, den Abdelkrims Bruder Si M'hammed am 30. April 1923 mit dem Briten Charles Gardiner abgeschlossen hatte. Gardiner wurden hierin weitgehende wirtschaftliche Monopolrechte zugesichert ${ }^{139}$. Die Chancen für eines der beiden Monopole wären also schlecht gewesen. Dies unterstreicht Abdelkrims Grundprinzip, in seinen Verhandlungen in der Regel mehrgleisig zu verfahren.

Im Mai 1923 suchte der Chefingenieur der Gesellschaft Echevarrieta y Larrínaga, Primitivo Hernández Sampelayo, das Rif auf, um das Projekt vorzustellen und die dortigen wirtschaftlichen Möglichkeiten und Erfordernisse zu begutachten ${ }^{140}$. Direkt im Anschluß erneuerte Abdelkrim in einer Botschaft vom 21. Juni 1923 sein Angebot an die spanische Regierung, gegen die Anerkennung der Unabhängigkeit der Rifregion Privilegien im Bergbau, im Handel und in der Landwirtschaft zu gewähren ${ }^{141}$.

Das Vorhaben platzte noch am gleichen Tag mit dem Tode Dris ben Saïds, der während einer Inspektionstour mit spanischen Offizieren bei Tizi Azza von einem Einheimischen ermordet wurde ${ }^{142}$. Die Tat geschah kurz nach der Übernahme des Militärkommandos von Melilla durch General Martinez Añido, einem der aggressivsten Befürworter einer militärischen Lösung des Rifkonfliktes. Daher wurden schnell Gerüchte laut, Dris ben Saïd habe auf Betreiben des spanischen Militärs, das die Handelspläne unterwandern wollte, sterben müssen ${ }^{143}$.

${ }^{138}$ Madariaga, España y el Rif, S. 519-521, S. 548, Anm. 32; DIES., Mohammed ben Abdelkrim, S. 32; ADMAE Maroc 113, 224: Bericht „Projets d'utilité générale étudiés par la Société Etchevarrieta et le Fqih Abd el Krimu o.D.; Le programme Echevarrieta, in: BCAF 33 (1923) S. 175.

${ }^{139}$ Siehe S. 216-218 und S. 287-291.

${ }^{140}$ DIAZ MORLÁN, Horacio Echevarrieta, S. 137.

${ }^{141}$ HERNÁNDEZ MR, Del desastre a la victoria, Bd. 2, S. 144.

142 ADMAE Maroc 196, 96: Ambassade de Madrid an MAE, 22.6.1923; La démission de Dris Er-Riffi et la mort de Dris Ben Saïd, in: BCAF 33 (1923) S. 366f., S. 367; The Spanish Zone, in: Al-Moghreb al Aksa \& Tangier Gazette, 30.6.1923.

${ }^{143}$ Madariaga, España y el Rif, S. 522f.; Woolman, Rebels in the Rif, S. 113; Brown, Résistance, S. 473f.; CADN Madrid C274: MAE an Ambassade de Madrid, 4.9.1923. 
Abdelkrim verhandelte im Sommer dennoch weiter mit Spanien. Er bestand auf der Anerkennung eines souveränen Rifstaates. Aber der spanische Verhandlungsführer Diego Saavedra, der sich zweimal (am 2. und 13. Juli 1923) auf einem Schiff in der Bucht von Alhucemas mit einer Rifdelegation traf, war nicht bereit, darüber zu diskutieren ${ }^{144}$. Er verdeutlichte in einem Brief an $\mathrm{Si}$ Mohammed Azerkane vom 14. Juli 1923, daß keine Verhandlungen über eine Unabhängigkeit des Rifs jenseits des Protektoratsvertrages von 1912 möglich seien und allenfalls eine administrative und wirtschaftliche Autonomie in Aussicht gestellt werden könne ${ }^{145}$.

Damit ging die spanische Seite so weit wie noch nie. Für Abdelkrim waren die Souveränität der »Rif-Republik» und die Kontrolle über die Bodenschätze im Rif jedoch zu eng miteinander verknüpft. Er ließ die Gelegenheit für eine friedliche Einigung verstreichen. Azerkane sandte Saavedra am 24. Juli 1923 eine Erklärung der Rifregierung zu, in der er unterstrich, daß es in Spaniens eigenem - auch wirtschaftlichen - Interesse liege, mit der Rifbevölkerung in Frieden zu leben. Er schloß seinen Brief mit der Ankündigung, daß die Grundlage für weitere Verhandlungen die Anerkennung der Unabhängigkeit der »Rif-Republik« sei ${ }^{146}$. Diesen Schritt konnte sich keine spanische Regierung leisten. Die Friedensverhandlungen wurden daher abgebrochen ${ }^{147}$. Der erstmalige Einsatz von Senfgasgranaten beim Gefecht von Tizi Azza im Juli 1923 dokumentierte die harte Haltung der spanischen Militärs. Horacio Echevarrieta mußte seine marokkanischen Ziele ein Jahr zurückstellen ${ }^{148}$.

Der stetige Vormarsch der Riftruppen im Sommer 1924 brachte die spanische Westarmee in eine ernste Lage. General Primo de Rivera, der sich im September 1923 an die Macht geputscht hatte, mußte sein Konzept der »Halbabtretung " gegen starken Widerstand der Protektoratsarmee durchsetzen. Es verfolgte die Doppelstrategie, zum einen mit Abdelkrim zu verhandeln und zum anderen die spanischen Truppen bis zu einer Sicherheitslinie an der Küste mit den Zentren Ceuta und Melilla zurückzuziehen ${ }^{149}$.

Die Verhandlungen mit Abdelkrim sollte Horacio Echevarrieta führen. Der Baske befand sich mit seinen vielfaltigen Aktivitäten auf dem Höhepunkt seiner wirtschaftlichen Macht, war aber deswegen auch auf politische Unter-

144 Fleming, Primo de Rivera and Abd-el-Krim, S. 84; PaYNe, Politics, S. 186; WoOlman, Rebels in the Rif, S. 115.

${ }^{145}$ MADARIAGA, España y el Rif, S. 527; EsPaÑA, La actuación, S. 301f.; TNLA, Harris, BNS, 2: Don Diego Saavedra an Abdelkrim, 14.7.1923.

${ }^{146} \mathrm{Si}$ Mohammed Azerkane an Don Diego Saavedra, 24.7.1923, in: TAHTAH, Pragmatisme 1995, Dok. 19, S. 158-160; HERNÁNDEZ MiR, Del desastre a la victoria, Bd. 2, S. 153-159; WOOLMAN, Rebels in the Rif, S. 116-118.

${ }^{147}$ BaLfOUR, Deadly Embrace, S. 91f.; SALAS LARRAZÁBaL, Protectorado, S. 149.

${ }^{148}$ MADARIAGA, España y el Rif, S. 524.

${ }^{149}$ Sueiro SEOANE, España, S. 144; SAZ, Foreign Policy, S. 56; TUSELl, La dictadura, S. 283-292. 
stützung angewiesen. Marokko bot eine Gelegenheit, einem politischen Gegner wie Primo de Rivera einen Dienst zu erweisen. Der Auftrag sah vor, daß Echevarrieta bei einem Scheitern der Friedensgespräche zumindest versuchen sollte, ein weiteres Mal die spanischen Kriegsgefangenen freizubekommen ${ }^{150}$.

Im August 1924 wandte sich Echevarrieta an den britischen Direktor des Eisenbergwerks im algerischen Sebabna, das seinem britischen Partner James Campbell gehörte. Der Mann namens Kitchin hatte bereits die Freilassung der spanischen Gefangenen im Januar 1923 mit vorbereitet ${ }^{151}$. Er sollte sich mit der Rifregierung in Verbindung setzen, um ein Treffen zu arrangieren ${ }^{152}$. Auch diese Mission hatte wirtschaftliche Hintergründe. Echevarrieta hatte seinen Plan einer Chartergesellschaft nicht aufgegeben. Er wollte ihn in ein französisch-spanisches Gemeinschaftsprojekt, das mit Hilfe finanzieller Garantien der spanischen Regierung Eisenbahnen und Häfen errichten sollte, umwandeln, um mit wirtschaftlicher Betätigung und Ausbeutung der natürlichen Reichtümer des Rifs dessen spanische Übernahme herbeizuführen ${ }^{153}$.

Am 10. November 1924 legte Echevarrietas Jacht "Cosme Jacinta in der Bucht von Alhucemas an. Nur Echevarrieta und José María González Bellote, ein ehemaliger Beamter des spanischen Hochkommissariats, durften während der bis zum 12. November 1924 andauernden Gespräche an Land gehen ${ }^{154}$. Die Verhandlungen auf der Seite der Rifkabylen führten Si M'hammed, Si Abdeslam ben Mohammed el Khattabi und Si Mohammed Boujibar. Abdelkrims Forderungen lauteten: Völliger Rückzug der spanischen Truppen mit Ausnahme von Melilla und Ceuta, Zahlung von 20 Millionen Peseten sowie die Lieferung von 10000 Mausergewehren mit Munition, zwölf Flugzeugen und 25 Kanonen, wobei der Freikauf der 1146 spanischen Gefangenen nicht inbegriffen war. Echevarrieta entgegnete, daß er gekommen sei, um über Frieden zu verhandeln, nicht über Krieg. Daraufhin antwortete Si M'hammed, die Waffen könnten an der Südfront vor Französisch-Marokko gut gebraucht werden. Er wartete für Echevarrieta mit der Überraschung auf, daß diese Konditionen bereits im Vormonat Francisco Sostoa mitgeteilt worden seien, der von

${ }^{150}$ DíaZ MORLÁN, Un ejemplo, S. 106f., S. 115f.; DERs., Horacio Echevarrieta, S. 137.

151 ADMAE Maroc 219, 183: Sous-Préfet de Tlemcen an Préfet d'Oran, 26.12.1924; AN 313 AP 244: RG Rabat an MG, 18.5.1925; SHAT 3H102: EMA, $2^{\mathrm{e}}$ bureau, Bericht ॠContrebande d'armes« o.D. (Juni 1925); ADMAE Maroc 220, 145: MG, EMA an MAE, 2.7.1925.

${ }_{152}$ ADMAE Maroc 219, 140: Caïd Haddou an Si Mohammed Azerkane, 17.8.1924.

${ }^{153}$ CADN Madrid C263: Ambassade de Madrid an MAE, 25.12.1924; SHAT 3H134: Bericht "Espagne, Mines du Riff«, 27.12.1924; SHAT 3H134: MAE an MG, EMA, Section d'Afrique, 8.1.1925; AN 475 AP 86: Bericht "Au sujet des projets de Etchevarrieta«, 23.1.1925; CADN Madrid C263: RG Rabat an MAE, 23.1.1925; CADN Madrid C312: Ambassade de Madrid an MAE, 29.10.1925 mit dem Bericht „Note remise par Léon Rollin«, 24.8.1925.

${ }^{154}$ CADN Madrid C263: RG Rabat an MAE, 6.12.1924; SHAT 3H135: EMA, $2^{e}$ bureau, Renseignements, 7.9.1925; PRO-FO 371, 11077, 39, 163: Vice-Consulate of Tetuan an FO, 3.4.1925; SUEIRo SEOANE, España, S. 145. 
Primo de Rivera ebenfalls die Vollmacht erhalten hatte, mit der Rifregierung zu verhandeln. Der bloßgestellte Echevarrieta lieferte sich daraufhin in Tetuan eine lebhafte Auseinandersetzung mit dem spanischen Diktator, der den Wirtschaftsplänen des Basken skeptisch gegenüberstand ${ }^{155}$. Sostoas Vorschlag eines einmonatigen Waffenstillstandes war von Abdelkrim ebenfalls abgewiesen worden ${ }^{156}$.

Spanien befand sich in einer schlechten Verhandlungslage. Denn fünf Tage nach dem letzten Gespräch mit Echevarrieta zog Si M'hammed am 17. November 1924 an der Spitze der Riftruppen in Chichaouen ein. Der verlustreiche spanische Rückzug bis zur Primo-de-Rivera-Linie bedeutete für Abdelkrim einen Triumph und eine weitere Stärkung seiner Position ${ }^{157}$. Anfang 1925 war er dennoch zu weiteren Verhandlungen mit Spanien bereit. Im Grenzgebiet zur französischen Zone Marokkos mußte jederzeit mit militārischen Auseinandersetzungen gerechnet werden. Nachdem französische Truppen 1924 das fruchtbare Ouerghatal, das für das Rif ein äußerst wichtiges Reservoir an Nahrungsmitteln darstellte, besetzt hatten, ordnete Abdelkrim die Befestigung seiner südlichen Grenzen an. Nach dem Sieg von Chichaouen verschob er seine Truppen in Richtung Süden. Sein Interesse war, einen etwaigen Zweifrontenkrieg zu vermeiden ${ }^{158}$.

Daher zeigte Abdelkrim gegenüber Spanien Entgegenkommen. Zum einen entsandte er den amerikanischen Journalisten Vincent Sheean, der sich im Januar 1925 im Rif aufgehalten hatte, zu General Primo de Rivera ${ }^{159}$. Gleichzeitig schickte Außenminister Si Mohammed Azerkane am 10. Februar 1925 einen Brief an Horacio Echevarrieta, in dem er ihn darum bat, noch einmal seine Dienste als Vermittler zur Verfügung zu stellen. Abdelkrims Bedingungen für ein Friedensabkommen hatten sich seit dem November 1924 nicht wesentlich verändert. Er forderte weiterhin den vollständigen Rückzug Spaniens mit Ausnahme der Städte Ceuta und Melilla und die Auszahlung von 20 Millionen Peseten, nur reduzierte er das Militärmaterial, das ihm ausgehän-

15s ADMAE Maroc 133, 117: Bericht »Notes et remarques sur la question riffaine« o.D. von Daniel Bourmancé-Say; SHAT 3H134: Ambassade de Madrid, Attaché militaire an MG, EMA, $2^{e}$ bureau, 27.11.1924; CADN Tanger B31: MAE an CG Tanger, 28.11.1924; PA-AA R72043, L057718: Botschaft Madrid an AA, 26.11.1924; CADN Madrid C263: RG Rabat an MAE, 6.12.1924; CADN Madrid C263: Ambassade de Madrid an MAE, 25.12.1924; LEGEY, Ce que j'ai vu, S. 98f. Pablo Díaz Morlán und Susana Sueiro Scoane datieren die Verhandlungen Echevarrietas fälschlicherweise auf den August 1924 [DIAZ MORLAN, Horacio Echevarrieta, S. 137; SUEIRO SEOANE, España, S. 144].

${ }^{156}$ SHAT 3H1557: Contrôle civil de Taourirt, Bulletin de renseignements, 22.10.1924 und 20.11.1924.

${ }^{157}$ FLEMING, Primo de Rivera and Abd-el-Krim, S. 202f.

${ }^{158}$ GABRIELLI, Abd-el-Krim, S. 60.

${ }^{159}$ Siehe S. 307-309. 
digt werden sollte, auf zehn großkalibrige Kanonen ${ }^{160}$. Doch in seiner Antwort vom 5. März 1925 konnte Echevarrieta nur die Ansicht Primo de Riveras vermelden, daß die Rifkabylen entwaffnet werden sollten und der Sultan von Marokko anerkannt werden müsse ${ }^{161}$.

Abdelkrim kam nun ein überraschender Besuch gelegen, als Anfang April 1925 der Rechtsrat der italienischen Gesandtschaft von Tanger, Naldo Malmusi, im Rif erschien. Er war der Sohn eines früheren italienischen Konsuls von Tanger, der 1906 wegen seiner Gegnerschaft zu Frankreich abberufen worden war. Er hatte seine ganze Jugend in Tanger verbracht und sprach fließend Arabisch $^{162}$. Der Italiener erkundigte sich nach dem Schicksal der Besatzung des italienischen Segelschiffes $» 4$ novembre«, das an der Rifküste gekentert war ${ }^{163}$. Etwa zwei Wochen reiste Malmusi durch das Rif und fotografierte mit der Kamera des amerikanischen Konsuls von Tanger J. Lee Murphy ${ }^{164}$.

Abdelkrim zeigte sich während eines Gespräches über Italiens Ärger, am Tangerstatut nicht beteiligt worden zu sein, gut informiert. Er war der Meinung, daß Italien als Vermittler zwischen den Kriegsparteien diplomatische Vorteile erringen könnte, und bot als Gegenleistung U-Boot-Stützpunkte, Bergbau-Konzessionen sowie Arbeit für italienische Techniker, Ingenieure, Architekten und Ärzte an, die die Entwicklung des Rifs nun anstelle seiner spanischen, britischen oder französischen Geschäftspartner vorantreiben sollten. In seinen Friedensbedingungen forderte Abdelkrim nach wie vor den Rückzug Spaniens, die Anerkennung des Rifstaates, Entschädigungszahlungen, einen Gefangenenaustausch, freien Handelsverkehr sowie - dies war neu - die Annullierung der Marokko-Verträge von 1904 zwischen Spanien, Frankreich und Großbritannien. Der utopische Plan war, dem französisch-spanischen Protektorat die völkerrechtliche Grundlage zu entziehen ${ }^{165}$.

${ }^{160}$ Rifi Ouvertures to the Spaniards, in: Times, 11.3.1925; JACQUES, L'aventure riffaine, S. 85; GABRIELl, Abd-el-Krim, S. 56f.; PA-AA Paris 454a: Botschaft Madrid an AA, 3.4.1925.

${ }^{161}$ MadARIaGA, Mohammed ben Abdelkrim, S. 32.

162 PA-AA R15518, A21358: Botschaft Rom an AA, 19.12.1906; SHAT 3H102: EMA, $2^{e}$ bureau, Bericht »Renseignement au sujet de Monsieur Malmussi«, 1.7.1925; CADN Tanger C37: Tabor de police $\mathrm{N}^{\circ} 1$, Note, 31.7.1925; PRO-FO 371, 11920, 2328, 20 : CG Tangier an FO, 15.3.1926; GUILLEN, L'Allemagne, S. 301, S. 329; OVED, La gauche française, Bd. 1, S. 459, Anm. 59, S. 575; SUEIRO SEOANE, España, S. 343.

${ }^{163}$ ADMAE Maroc 111, 1: Bericht »Renseignements donnés par El Hadj Hitmi«, 22.6.1926; Benito Mussolini an Ambasciatori a Londra, a Madrid e a Parigi, 31.7.1925, in: Documenti diplomatici italiani, Ser. 7, Bd. 4, Dok. 77, S. 59f. Die Quellen sagen nichts darüber aus, was mit der Besatzung des Schiffes geschehen ist.

${ }^{164}$ Die Fotos sind aufbewahrt in: NARA 881.00, 1057: American Agency and Consulate General of Tangier an Secretary of State, 20.5.1925.

${ }^{165}$ Agente diplomatico a Tangeri an Benito Mussolini, 18.4.1925, in: Documenti diplomatici italiani, Ser. 7, Bd. 3, Dok. 803, S. 522f.; Javier TUSELL, Ismael SAZ, Mussolini y Primo de Rivera. Las relaciones políticas y diplomaticas de dos dictaduras mediterráneas, in: Boletín de la real academia de la historia 169 (1982) S. 413-483, S. 438. 
Nachdem er Malmusis Bericht erhalten hatte, erkannte Benito Mussolini die Gelegenheit, an zukünftigen Marokko-Verhandlungen wieder beteiligt zu werden. In der Tangerer Gesandtschaft ließ er anfragen, ob Abdelkrim einen persönlichen Brief von ihm erwarte, und die Botschaft in Madrid wies er an herauszufinden, ob Spanien Italiens Vermittlerrolle akzeptiere ${ }^{166}$. Doch Marqués de Magaz, der Präsident des Miliärdirektoriums, lehnte mit der Begründung $a b$, daß die Bedingungen Abdelkrims nicht akzeptabel seien ${ }^{167}$.

Just nach Malmusis Aufenthalt im Rif begann Abdelkrim noch im April 1925 mit dem Vormarsch gegen Französisch-Marokko. Ein brieflicher Kontakt mit dem Italiener blieb bestehen, wobei Malmusi die Hilfe Italiens in Aussicht stellte ${ }^{168}$. Die beschränkte sich zunächst Anfang Juni 1925 auf die Entsendung des Journalisten Mirko Ardemagni von der Zeitung »Popolo d'Italia«. Abdelkrim erhielt die Gelegenheit, seinen Angriff gegen Französisch-Marokko propagandistisch zu begründen. Er führte aus, er habe nur einem Angriff Frankreichs zuvorkommen wollen, sandte aber auch Signale der Verständigung, indem er hoffte, dies würde eine Anerkennung der »Rif-Republik« mit sich bringen ${ }^{169}$.

Ab September 1925 hielten sich der Journalist Alfredo Morea von der Zeitung "Vocce repubblicana« und der Pilot Mario Magri als Militärberater im Rif auf ${ }^{170}$. Wie der neue Generalkonsul von Tanger, Conte de Vannutelli, dem "Times «-Korrespondenten Walter Harris vertraulich mitteilte, spekulierte Benito Mussolini weiter darauf, daß letztendlich eine internationale Konferenz die Riffrage, die seiner Ansicht nach nicht von der Tangerfrage getrennt werden konnte, zu lösen habe. Daran, so hoffte er, mußte auch Italien beteiligt werden $^{171}$. Vannutelli schickte Abdelkrim mehrere Briefe, in denen er ihn ermutigte, den Kampf gegen Spanien und Frankreich fortzusetzen ${ }^{172}$.

${ }^{166}$ Benito Mussolini an Ambasciatore a Madrid, 24.4.1925, in: Documenti diplomatici italiani, Ser. 7, Bd. 3, Dok. 819, S. 534.

${ }^{167}$ Ambasciatore a Madrid an Benito Mussolini, 17.5.1925, in: Ibid. Dok. 839, S. 551f;; SUEIRO SEOANE, España, S. 343; Ruggero MOSCATI, La politica estera fascista nel '24-25, in: Rivista storica italiana 71 (1959) S. 313-320, S. 316f.; TUSELL, SAZ, Mussolini, S. $438 f$.

${ }^{168}$ ADMAE Maroc 111, 1: Bericht »Renseignements donnes par El Hadj Hitmi«, 22.6.1926; CADN Maroc DAI 189: Bericht " $2^{\circ}$ entrevue de Monsieur Sagnes avec Abdelkrim «, 3.6.1926; CADN Tanger C37: Région de Fès, SR, Note, 24.9.1925; ROGER-MATHIEU, Mémoires, S. 155.

${ }^{169}$ ARDEMAGNI, Abd el Krim, 16.6.1925; L'agression des Rifains contre le Maroc français, in: BCAF 35 (1925) S. 363; Audienz bei Abd el Krim, in: Vossische Zeitung, 18.6.1925; Die Fremdenlegionäre laufen über, in: Deutsche Allgemeine Zeitung, 17.6.1925; PA-AA Paris 454: Botschaft Rom an AA, 17.6.1925; LADREIT DE LACHARRIERE, Le rêve, S. 244; JACQUES, L'aventure riffaine, S. 232, Anm. 1.

${ }^{170}$ Siehe hierzu Kapitel 5, S. 202f;; MOREA, La guerra marochina, 4.11.1925.

${ }^{171}$ TNLA, BNS, 1, Williams: Walter Harris an Harold Williams, 30.9.1925; PRO-FO 371, 11076, 18, 108: CG Tangier an FO, 19.9.1925.

${ }^{172}$ ADMAE Maroc 133, 277: Tabor de police $\mathrm{N}^{\circ}$ 1, Information, 15.3.1926. 
Die italienische Botschaft in Berlin versuchte im Sommer 1925 sogar - wenngleich vergebens -, durch den Kauf des Mannesmann-Besitzes in Spanisch-Marokko »bei den kommenden internationalen Auseinandersetzungen über das Rif durch italienischen wirtschaftlichen Besitz eine wichtige Stimme zu haben ${ }^{173}$. Weder Mussolinis noch Abdelkrims Erwartungen wurden erfüllt. Im nachhinein machte sich Abdelkrim über den italienischen Diktator lustig, indem er ihn als einen »Komödianten « bezeichnete ${ }^{174}$.

Abdelkrim und Horacio Echevarrieta hatten den Kontakt über dessen Gefolgsmann José María González Bellote, der sich bei Kitchin im algerischen Sebabna aufhielt, auch nach dem Angriff auf Französisch-Marokko nicht abbrechen lassen. Als Vermittler fungierte Kitchins Freund Daniel BourmancéSay im Hafenort Port-Say, der Boten aus dem Rif empfing und mit neuen Schreiben wieder fortschickte ${ }^{175}$. Echevarrieta bemühte sich in Madrid um eine Einigung mit der Familie Salama, die mit ihren Teilhabern ebenfalls Bergbaurechte am Djebel Hamam im Rif besaß. Sein Vorschlag einer Fusion zu einer Sociedad minera mauritana, die die Erzfelder bearbeiten sollte, wurde wegen unüberbrückbarer Differenzen niemals Realität ${ }^{176}$.

Angesichts seiner anfänglichen militärischen Erfolge an der Südfront zu Französisch-Marokko zögerte Abdelkrim die Verhandlungen mit Echevarrieta hinaus ${ }^{177}$. Der nächste Anstoß zu Gesprächen ging von Spanien aus - unabgesprochen zu einer zeitgleichen französischen Friedensinitiative ${ }^{178}$ und parallel zu französisch-spanischen Verhandlungen über ein gemeinsames militärisches Vorgehen. González Bellote überbrachte Abdelkrim am 4. Juni 1925 einen Brief von Primo de Rivera, in dem dieser Spaniens Wunsch eines Modus vivendi übermittelte, und einen Brief von Echevarrieta, der ein Treffen mit Abdelkrim in Ajdir vorschlug ${ }^{179}$.

Am 20. Juni 1925 ging die Jacht »Cosme Jacinta《 erneut in der Bucht von Alhucemas vor Anker. Echevarrieta, sein Begleiter Marqués de Palomares und der Übersetzer Francesco Marín gingen an Land und überbrachten Abdelkrim, den der Baske nun erstmals persönlich antraf, ein weitreichendes Angebot Pri-

\footnotetext{
${ }^{173}$ PA-AA R118401, L525922: E. Niemann, „Brüder Mannesmann Konsortial-Büro Berlin» an AA, 29.11.1927.

${ }^{174}$ CADN Maroc DAI 189: Bericht $122^{e}$ entrevue de Monsieur Sagnes avec Abdelkrim«, 3.6.1926.

${ }^{175}$ SHAT 3H1 103: Contrôle civil de Taourirt, Bulletin de renseignements, 21.4.1925; ADMAE Maroc 220, 145: MG, EMA an MAE, 2.7.1925; PRO-FO 371, 11077, 39, 163: Vice-Consulate of Tetuan an CG Tangier, 3.4.1925; ADMAE Maroc 219, 192: Arrondissement de Tlemcen an Sous-Préfet de Tlemcen, 12.1.1925.

${ }^{176}$ DÍAZ MORLÁN, Horacio Echevarrieta, S. 137; CADN Madrid C312: Ambassade Madrid an MAE, 29.10.1925.

${ }^{17}$ PRO-FO 371, 11077, 39, 34: Embassy of Madrid an FO, 19.5.1925.

${ }^{178}$ SUEIRO SEOANE, España, S. 225. Siehe zur französischen Initiative S. $349 f$.

${ }^{179}$ FLEMING, Primo de Rivera and Abd-el-Krim, S. 257.
} 
mo de Riveras, das in ähnlicher Form bereits 1923 unterbreitet worden war. Hiernach wollte Spanien die Autonomie des Rifgebietes anerkennen, wobei dieses Mal sogar die Beibehaltung einer Rifarmee von 3000 bis 4000 Mann gestattet werden sollte. Drei Millionen Peseten sollten als Entschädigung an die Rifkabylen gezahlt werden. Abdelkrim sollte monatlich 250000 Peseten für die Verwaltung des Rifs erhalten. Primo de Rivera verlangte hierfür die Besetzung der Bucht von Alhucemas. Palomares, der Si M'hammed seit dessen Bergbaustudium in Madrid kannte, schlug zudem die Beteiligung der Khattabis an einer Gesellschaft zur Ausbeutung der Bodenschätze im Rif $\operatorname{vor}^{180}$. Es handelte sich um das am weitesten reichende Angebot, das Abdelkrim jemals erhalten sollte. Doch angesichts der noch günstigen militärischen Lage war er nicht bereit, über die Besetzung der Bucht von Alhucemas zu verhandeln. Er wollte weiterhin einen Frieden nur dann akzeptieren, wenn die Unabhängigkeit des Rifstaates anerkannt würde. Am 1. Juli 1925 lehnte er die spanische Offerte $a b^{181}$.

Mit dieser Mission endeten Echevarrietas von wirtschaftlichen Interessen geprägte Vermittlerdienste zwischen Spanien und dem Rif. Sein Plan einer Chartergesellschaft, den er in seinen Friedensverhandlungen immer wieder anklingen ließ, hatte keine echte Realisierungschance, da ihm die staatliche Unterstützung versagt blieb. Abdelkrim seinerseits war zwar am Verkauf von Bergbau-Konzessionen und an Wirtschaftsverträgen interessiert, aber nur gegen die Anerkennung der Unabhängigkeit des Rifstaates. Echevarrietas Interesse an Bergbaugeschäften machte ihn als Vermittler attraktiv. Abdelkrim hoffte, daß der Baske Einfluß auf die spanische Regierung nehmen konnte. Aber deren Ziele und Echevarrietas Pläne für Spanisch-Marokko unterschieden sich nur in den Methoden, nicht in der Grundhaltung, die spanische Herrschaft auf das Rif auszudehnen. Zum Schluß hatte Abdelkrim das Vertrauen in die Dienste Echevarrietas verloren ${ }^{182}$. Er hatte bereits andere Partner. Noch im Juli 1925 ließ Abdelkrim über seinen britischen Berater Robert GordonCanning eigene Friedensbedingungen veröffentlichen ${ }^{183}$.

${ }^{180}$ DfAZ MORLÁN, Horacio Echevarrieta, S. 138; SUERO SEOANE, España, S. 222-225; MARín ARCE, Primo de Rivera, S. 283f.; PENNEL, A Country, S. 196 (mit der falschen Zeitangabe 21. Juli 1925; auch in DERS., La guerra del Rif, S. 258); LEGEY, Ce que j'ai vu, S. 100; SHAT 3H1 103: Contrôle civil de Taourirt, Bulletin de renseignements, 4.7.1925; PRO-FO 371, 11080, 186, 124: CG Tangier an FO, 22.6.1925; PRO-FO 371, 11078, 39, 129: Embassy of Madrid an FO, 26.6.1925; PRO-FO 371, 11078, 39, 123: Embassy of Madrid an FO, 2.7.1925.

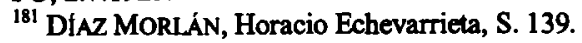

${ }_{18}$ PRO-FO 371, 11079, 39, 184: Bericht »Report on a Visit of a Messenger from Abdel Krim to W.B. Harris«, 24.7.1925; Vincent SHEEAN, Im Lager Abd-el-Krims, in: Neue Zürcher Zeitung, 21.10.1925.

${ }^{183}$ Siehe S. 334. 


\subsection{Abdelkrim und Daniel Bourmancé-Says Marokko-Visionen}

Im Vorfeld des Rifkrieges hatte sich 1921 nicht nur Horacio Echevarrieta als Vermittler zur Klärung der Riffrage zu etablieren bemüht. Der 37jährige Algerienfranzose Daniel Bourmancé-Say sollte für die Anfangsphase des Rifkrieges eine hervorstechende Rolle als politischer Berater Abdelkrims einnehmen ${ }^{184}$. Der Mann mit dem Beinamen $» H e r r$ Spitzbart ${ }^{185}$ galt als selbstsicherer Abenteurer, der seine Ziele zäh verfolgte ${ }^{186}$.

Bourmancé-Say hatte sich vorgenommen, eine Vision seines Adoptivvaters Louis-Jean Baptiste Say (30. Januar 1852-3. Oktober 1915) zu verwirklichen. Dieser war mehrere Jahre als Marineoffizier zur See gefahren, bis er sich nach mehreren Expeditionen in die libysche Sahara (1875-1879) als Mitglied der Commission supérieure du transsaharien mit kolonialen Themen beschäftigte und 1881 sogar zum stellvertretenden Kabinettschef des Ministeriums für kolonialen Handel aufstieg. 1886 hielt sich Louis Say zusammen mit Pierre-Juste Bourmancé, dem Vater Daniels, erstmalig in Marokko auf. Beide entwickelten die Idee, einen Hafenort im Westen Algeriens zu gründen. Bourmancé starb jedoch 1893. Sein Sohn Daniel wurde 1906 von Louis Say adoptiert. Say, der durch die Fabrikation von Zucker reich geworden war, gründete im Juli 1900 an der Westküste Algeriens den Ort Port-Say. 1906 legten dort 146 Schiffe an. Bis 1910 stieg die Einwohnerzahl auf 300. Durch die Ansiedlung von Beqqioua verfügten Say und Bourmancé-Say über gute Kontakte ins Rif. Zusammen mit Gabriel Delbrel unterstützten sie den Widersacher des marokkanischen Sultans Bou Hmara mit Waffenlieferungen. Die in Port-Say lebende Lehrerin Jeanne Esther Ondet - ihr Spitzname war »die Pantherin« - gewann mehr und mehr Einfluß auf Louis Say und erreichte, daß er Daniel Bourmancé-Say in seinem Testament vom 1. Juni 1914 enterbte und alle Güter auf sie übertrug. Als Louis Say 1915 starb, wurde Ondet verdächtigt, ihn vergiftet zu haben. Das Testament wurde annuliert, Bourmancé-Say übernahm den Besitz. Der Erste Weltkrieg und der Konkurrenzhafen Nemours führten jedoch zum Niedergang Port-Says. Die Hoffnung, daß sich der Ort zu einem Haupthafen für Westalgerien und Ostmarokko entwickeln würde, war zerstoben. Von hier aus hatte Frankreich nach Says Planungen mit der wirtschaftlichen Durchdringung Marokkos - inklusive des Rifgebirges - beginnen sollen. Über die Mündung

${ }^{184}$ Vgl. TAHTAH, Pragmatisme 1995, S. 88; RIVET, Lyautey, Bd. 3, S. 272; AYACHE, La Guerre du Rif, S. 173, S. 179; CADN Madrid C261: MAE an Ambassade de Madrid, 23.4.1926.

${ }^{185}$ LE GUILLERME, CH. $» 402 \ll$, S. 61.

${ }^{186}$ CADN Madrid C271: MAE an Ambassade de Madrid, 26.9.1921 mit Bezug auf einen Bericht von Capitaine Gaquière, 18.9.1921; ADMAE Maroc 133, 77: Commissaire chef de la brigade mobile de Tlemcen an Sûreté générale de l'Algérie o.D. [Ende 1925]; DAOUD, Abdelkrim, S. 17; GABRIELLL, Abd-el-Krim, S. 7, S. 9. 
des Moulouya-Flusses konnte Fes direkter erreicht werden als über den bisherigen Umweg Casablanca. Die Flotte und der Handel waren für Say der Schlüssel für eine erfolgreiche Expansion, nicht die militärische Eroberung. Mit der Errichtung der spanischen Einflußzone in Marokko (1912) hatten diese Pläne bereits einen Dämpfer erhalten ${ }^{187}$.

Dennoch gab Daniel Bourmancé-Say nicht auf. Er ging sogar noch weiter als sein Adoptivvater. Er plante eine heimliche französische Unterstützung Abdelkrims für seinen Kampf gegen Spanien ${ }^{188}$. Das Meer betrachtete er als Schlüssel für Eroberungen sowie als Grundlage für Reichtum und Macht ${ }^{189}$, und das Rifgebirge sah er als "Schiebefenster Frankreichs« zur Mittelmeerküste $a{ }^{190}$. Ein siegreiches Rif mit seinem Naturhafen in der Bucht von Alhucemas sollte über kurz oder lang in eine Art Unterprotektorat Frankreichs verwandelt werden, das dann in den Besitz der Bodenschätze und sonstigen Reichtümer gelangen und mit dem Zugang zum Mittelmeer dem zu starken Einfluß Großbritanniens begegnen sollte ${ }^{191}$. Der anglophobe Bourmancé-Say wollte eine große Rolle für sein Land spielen. Frankreichs politische und wirtschaftliche Expansion nach Nordmarokko stand daher im Mittelpunkt seines Tuns, weniger Abdelkrim und die Rifkabylen, die von ihm für seine Visionen funktionalisiert werden sollten.

Im April 1921, als Echevarrietas Gesandter Antonio Got mit den Khattabis wirtschaftliche und politische Gespräche führte, erschien Bourmancé-Say im französischen Außenministerium, um einen Termin mit Staatssekretär de Beaumarchais von der Afrika-Abteilung wahrzunehmen. Abdelkrim hatte weder Kenntnis von den wahren Absichten des Franzosen noch von dessen Pariser Aufenthalt. Als aber Bourmancé-Say seine Pläne sowohl dem Außenministerium als auch Jacques Bainville, einem führenden Mitglied der Action

${ }^{187}$ VALYNSEELE, Les Say, S. 365, S. 366-368, Anm. 2, S. 369, Anm. 5; Jean HeSS, Une Algérie nouvelle. Quelques principes de colonisation pratique sur le propos du Maroc oriental et de Port-Say, Paris 1909, "Vorwort«; LlaBADOR, Port-Say, S. 39-77, S. 87, S. 239f., S. 243-245; Luc TrICOU, La création de Port-Say, in: L'Afrique du Nord illustré, 20.3.1909; Gabrielli, Abd-el-Krim, S. 7f.; HALlGaRTEN, Imperialismus, Bd. 2, S. 665f.; MOWRER, The House of Europe, S. 448; AYACHE, La Guerre du Rif, S. 171-173; DERS., Les origines, S. 132 u. S. 132, Anm. 35 u. Anm 38; DAOUd, Abdelkrim, S. 97f., S. 129; LE GUILLERE, CH. »402«, S. 49; CAOM 10 APOM 295: Bericht von Robert Montagne »L'affaire riffaine - Abd el Krim«, 28.5.1937.

${ }^{188}$ ADMAE Maroc 133, 100: Bericht von Daniel Bourmancé-Say »La question riffaine vue de la méditerranéeর, 28.5.1925.

${ }^{189}$ Daniel BOURMANCE-SAY, Une heure avec Allouche le Corsaire, le vainqueur du général Navarro, in: Intransigeant, 10.9.1921.

${ }^{190}$ GABRIELl, Abd-el-Krim, S. 8.

${ }^{191}$ RIVET, Lyautey, Bd. 3, S. 272, Anm. 554; CADN Maroc DAI 189: RG Rabat an DAI Rabat, 17.8.1925; ADMAE Maroc 133, 77: Commissaire chef de la brigade mobile de Tlemcen an Sûreté générale de l'Algérie o.D. 8Ende 1925]; AN F7, 13413: Gouverneur général de l'Algérie an MI, DAI, 24.7.1925. 
française, vorbrachte und wegen des bevorstehenden Ausbruchs der Feindseligkeiten zwischen Spaniern und Rifkabylen auf eine schnelle Entscheidung drängte, wurde ihm so wenig Interesse entgegengebracht, daß er erbost wieder nach Algerien zurückkehrte ${ }^{192}$. In einem Brief an Colonel Huot von der Direction des affaires indigènes in Rabat beschwerte er sich später über die "Kretins in Paris, deren politische Weitsicht nicht weiter als bis zum nächsten Seine-Ufer reichen würde ${ }^{193}$.

Durch einige der in Port-Say lebenden Beqqioui verfügte Bourmancé-Say über gute Beziehungen ins Rif $^{194}$. Er kannte Allouche ben Haddou ben Ali, der auch »Allouche der Korsar» genannt wurde ${ }^{195}$, seit dessen Kindheit. Im Laufe des Jahres 1921 kehrte Allouche ins Rif zurück, um sich dem Widerstand gegen Spanien anzuschließen. Schnell avancierte er zu einem der Anführer. Er gehörte zur Delegation der Beqqioua, die Abdelkrim im April 1921 zu ihrem Befehlshaber ernannten. Allouche war der Onkel von Haddou ben Hammou - genannt »der Schwarze« -, der mit Bourmancé-Say in seiner Eigenschaft als Hilfskoch und als Pächter des Café au rendez-vous des pirates in Port-Say Freundschaft geschlossen hatte ${ }^{196}$.

Der junge Haddou hatte 1889 das Rif mit seiner Familie in Richtung Algerien verlassen, wo er eine Schulausbildung genoß, die ihm später während des Rifkrieges Vorteile erbrachte. Über Allouche und Haddou war es für Bourmancé-Say ein Leichtes, mit Abdelkrim in Verbindung zu treten und ihm seine Unterstützung anzubieten, ohne selbst ins Rif reisen zu müssen. Insbesondere Haddou, der fließend Spanisch und Französisch sprach, avancierte zum lange Zeit wichtigsten Vermittler zwischen Abdelkrim und Frankreich ${ }^{197}$. Bis 1925 fungierte Haddou allerdings auch als französischer Informant ${ }^{198}$. Er gehörte dem Kriegsrat Abdelkrims an, und er organisierte den Nachschub aus Alge-

${ }^{192}$ FonTAINE, L'étrange aventure, S. 126f.; AYACHE, La Guerre du Rif, S. 174, S. 175, Anm. 31; DAOUD, Abdelkrim, S. 97; ADMAE Maroc 133, 117: Bericht von Daniel Bourmance-Say »Notes et remarques sur la question riffaine« $0 . D$.

${ }^{193}$ CADN Maroc DAI 189: Daniel Bourmance-Say an Colonel Huot, 6.4.1925.

${ }^{194}$ GABRIELLI, Abd-el-Krim, S. 7; ADMAE Maroc 133, 77: Commissaire chef de la brigade mobile de Tlemcen an Sûreté générale de l'Algérie o.D. [Ende 1925].

${ }^{195}$ Daniel BOURMANCE-SAY, Allouche le Corsaire, âme de la révolte des Maures. Une autre puissance viendra-t-elle au secours des conquistadors du Riff, in: Intransigeant, 18.8.1921.

${ }^{196}$ DAOUD, Abdelkrim, S. 97f., S. 131; JACQUES, L'aventure riffaine, S. 82; SANCHEZ PEREZ, Abdelkrim, S. 153f.; GODED LLOPIS, Marruecos, S. 86; MOWRER, The House of Europe, S. 448; WARD PRICE, Extra-Special Correspondent, S. 162; CAOM 10 APOM 295: Bericht von Robert Montagne »L'affaire riffaine - Abd el Krim«, 28.5.1937.

${ }^{197}$ FONTAINE, L'étrange aventure, S. 72-75; PENNELL, A Country, S. 100; RIVET, Lyautey, Bd. 3, S. 259, Anm. 480; GABRIELl, Abd-el-Krim, S. 5-7; KHARCHICH, La France, S. 146, Anm. 3.

${ }^{198}$ AYACHE, La Guerre du Rif, S. 176 u. S. 176, Anm. 34 mit Bezug auf den Brief Haddou ben Hammou an Secrétaire de la préfecture d'Oran, 11.4.1924; CAOM Algérie 30H87: Chef d'annexe de Marnia an Général commandant de la division d'Oran, 24.4.1922. 
rien. Er war Oberbeauftragter für das Gesundheitswesen, Referent und Delegierter des Außenministeriums der "Rif-Republik» sowie ab 1924 Luftfahrtminister ${ }^{199}$. Haddou war zudem die Kontaktperson für all diejenigen, die Abdelkrim von Algerien aus einen Besuch abstatten wollten ${ }^{200}$.

Nach dem Sieg der Rifkabylen bei Annual im Juli 1921 setzte sich Bourmancé-Say mit dem Generalresidenten Französisch-Marokkos, Lyautey, in Verbindung. Sie kannten sich aus der Zeit, als der Marschall der Kommandant der Division von Oran in Algerien gewesen war und Port-Say gelegentlich einen Besuch abgestattet hatte. Louis Says Vision einer wirtschaftlichen Durchdringung und Lyauteys Ziel der militärischen Eroberung Marokkos waren unvereinbar gewesen ${ }^{201}$. Bourmancé-Say bewunderte Lyautey dennoch, der wie er ein Anhänger von Charles Maurras, dem Mitbegründer der nationalistischen Action française, war. Das Ziel seines Briefes vom 30. Juli 1921 war, Lyautey in die Geschehnisse im Rif einzubinden. Bourmancé-Say bot sich als Vermittlungsinstanz zwischen Frankreich und den Rifkabylen an ${ }^{202}$.

Lyautey verhielt sich vorsichtig. Alle Schritte Bourmance-Says wurden geheimdienstlich überwacht ${ }^{203}$. Seit während des Ersten Weltkrieges die deutsche »Marokko-Aktion« unter der Führung von Abdelmalek von SpanischMarokko aus gegen die französische Zone gelenkt worden war, hegte Lyautey großes Mißtrauen gegenüber Spanien. Abdelmalek konnte sich zu seinem groBen Ärger frei in Spanisch-Marokko bewegen ${ }^{204}$. Lyautey erkannte den rein antispanischen Charakter des Aufstandes im Rif. Sein Ziel war jedoch, jegliche militärische Involvierung im Norden der französischen Zone zu vermeiden, bevor nicht die >Pazifizierungı des Mittleren Atlas abgeschlossen war $^{205}$. Lyautey verfolgte eine ambivalente Strategie. Nach außen hin verhielt

${ }^{199}$ RUE, News, S. 273; FONTAINE, L'étrange aventure, S. 72; CADN Madrid C273: MAE an Ambassade de Madrid, 2.6.1922 mit Bezug auf den Bericht von A. Bourges 》Un voyage dans le Riff, Rapport d'un informateur«, 12.5.1922; ADMAE Maroc 199, 122: Caïd Haddou ben Hammou an MAE, 29.9.1924 (Briefkopf); CADN Maroc DAI 190: Haddous Visitenkarte im "Dossier personnel Caïd Haddou火.

${ }^{200}$ GABRIELLI, Abd-el-Krim, S. 15; CADN Maroc DAI 187: RG Rabat an MAE, 22.12.1923.

${ }^{201}$ AYACHE, Les origines, S. 59, S. 172; DAOUD, Abdelkrim, S. 129f.; Jean BRUNON, Lyautey aux confins algéro-marocains, in: Cahiers Charles de Foucauld 42 (1954) S. 105-119.

${ }^{202}$ AYACHE, La Guerre du Rif, S. 175. Es ist keine Antwort auf diesen Brief bekannt. Vgl. ADMAE Maroc 112, 124: Daniel Bourmance-Say an Haddou ben Hammou, 6.12.1921.

${ }^{203}$ ADMAE Maroc 133, 77: Commissaire chef de la brigade mobile de Tlemcen an Sureté générale de l'Algérie o.D. [Ende 1925].

${ }^{204}$ RIVET, Lyautey, Bd. 3, S. 266f.; LA PORTE, La atracción del imán, S. 138f.; PENNELL, A Country, S. 108f.

${ }^{205}$ HOISINGTON, Lyautey, S. 185-187; SHAT 3H1560: Général Aubert an Daniel Bourmancé-Say, 30.1.1922. 
sich die Generalresidenz in Rabat in dem Konflikt strikt neutral, aber die Möglichkeiten für einen Dialog mit Abdelkrim wurden offengehalten. Dies geschah über Allouche, Haddou und Bourmancé-Say ${ }^{206}$.

Besatzungen französischer Militärposten, die sich in direkter Nachbarschaft zum Rif befanden, zeigten Sympathie für die Rifkabylen, die bis zur Duldung von Nachschub- und Waffenlieferungen von Französisch-Marokko bzw. Algerien aus reichte. Abdelkrim hatte großes Interesse an Gesprächen mit offiziellen französischen Vertretern. Ein autonomes Rif unter einem französischen Protektorat war für ihn zu dieser Zeit noch vorstellbar. Zudem bestand zwischen dem Rif und der französischen Zone bzw. Algerien ein lebhafter Handelsverkehr, der nicht versiegen durfte. Noch am 21. Juli 1921, als die Schlacht von Annual begann, appellierte Abdelkrim an Sultan Moulay Youssef, die Rifkabylen unter seinen Schutz zu stellen - eine Initiative, die Lyautey schnell abblockte ${ }^{207}$.

Am 18. August 1921 schlug Abdelkrim in einem Schreiben an Haddou ben Hammou vor, sich persönlich mit einem französischen Vertreter am Moulouya-Fluß oder in Französisch-Marokko zu treffen. Direkte Kontakte Abdelkrims zum marokkanischen Sultan oder zur Generalresidenz kamen für die Franzosen aber nicht in Frage. Sie baten um eine Emennung ihres Informanten Haddou zum Sprecher Abdelkrims, um informell über ihn verhandeln zu können $^{208}$. „Der Schwarze« mußte sich allerdings zunächst als Organisator für die Überführung erbeuteten Kriegsmaterials ins Rif bewähren ${ }^{209}$. Erst im November 1921 wurde er von Abdelkrim zum Caïd und zum Delegierten für auswärtige Beziehungen ernannt ${ }^{210}$.

Abdelkrim entschied sich dafür, zunächst über Allouche mit Frankreich in Verbindung zu treten. Anfang September 1921 traf sich »der Korsar« mit Daniel Bourmancé-Say. Dieser diktierte ihm ein Telegramm, das Allouche am 7. September 1921 an Marschall Lyautey versandte. Der Generalresident wurde darin um seine Vermittlung für Verhandlungen mit Spanien gebeten. Gemeint war mehr oder weniger eine Parteinahme für die Rifkabylen und damit die Aufnahme freundschaftlicher Beziehungen, für die er Belohnungen erhalten sollte - die französische Übernahme vom Cap de l'eau und die Auslieferung Abdelmaleks ${ }^{211}$.

${ }^{206}$ HUETZ DE LEMPS, La collaboration, S. 86f; LA PORTE, La atracción del imán, S. 140; AYACHE, Les relations, S. 288; KHARCHICH, La France, S. 150.

${ }^{207}$ RIVET, Lyautey, Bd. 3, S. 266, S. 268, S. 271.

${ }^{208}$ AYACHE, La Guerre du Rif, S. 176f. u. S. 176, Anm. 33, S. 177, Anm. 35.

${ }^{209}$ PENNELL, A Country, S. $100 \mathrm{f}$.

${ }^{210} \mathrm{KHARCH}$ ICH, La France, S. 146, Anm. 4; RIVET, Lyautey, Bd. 3, S. 271, Anm. 548.

${ }^{211}$ AYACHE, La Guerre du Rif, S. $177 f$. 
In einem Brief vom 10. September 1921 beschwor Bourmancé-Say Abdelkrim förmlich, sich Abdelmaleks zu entledigen: "Dies wird Lyautey auf thre Seite bringen ${ }^{212}$. Abdelkrim ließ daraufhin auf den Märkten des Rifs die Order verkünden, Abdelmalek gefangenzunehmen ${ }^{213}$. Bourmancé-Say wandte sich in dieser Angelegenheit am 16. Januar 1922 auch direkt an den Generalresidenten. In dem Brief pries er die Vorteile einer Regelungan an, die Abdelkrim »eine führende Rolle« im Rif zusprechen sollte ${ }^{214}$. Eine Reaktion Lyauteys auf Bourmancé-Says Angebot ist allerdings nicht bekannt. Diese Initiative verpuffte ohne Erfolg.

Abdelkrims Streit mit Abdelmalek brachte das spanische Militär auf den Gedanken, ihn gegen die Rifkabylen einzusetzen. Es gab sogar Versuche, den Deutschen Albert Bartels, der während der »Marokko-Aktion« des Ersten Weltkrieges der deutsche Repräsentant an der Seite Abdelmaleks gewesen war, zu rekrutieren. Die beiden sollten gemeinsam Abdelkrims Verbindungen nach Französisch-Marokko unterbrechen. Bartels lehnte das Angebot jedoch $a b^{215}$. Er berichtete später, er habe die spanische Offerte ausgeschlagen, weil die »Unversehrtheit Abdelkrims « nicht garantiert worden $\operatorname{sei}^{216}$. Die Spanier setzten Abdelmalek an die Spitze einer nach ihm benannten Einheit von Regulares. 1924 starb er während eines Gefechts ${ }^{217}$.

Bourmancé-Say machte sich Gedanken, womit Abdelkrim internationale Aufmerksamkeit gewinnen konnte. Sein bereits erwähntes Schreiben vom 10. September 1921 war an den »Herrn Präsidenten der Rif-Republik« gerichtet. Nach Bourmancé-Says Aussagen war er selbst derjenige, der diese Bezeichnung erfunden und Abdelkrim davon überzeugt hatte. Der Sinn bestand darin, Sympathien in Europa - vor allem in Frankreich - zu erwerben und sie gegen Spanien auszunutzen ${ }^{218}$. Der Name »Rif-Republik« für das neue Staats-

${ }^{212}$ ADMAE Maroc 112, 143: Daniel Bourmancé-Say an Abdelkrim, 10.9.1921. Vgl. DAOUD, Abdelkrim, S. 128; KHARCHICH, La France, S. 145.

${ }^{213}$ CAOM Algérie 9H93: Chef d'annexe de Marnia an Général commandant de la division d'Oran, 5.4.1922.

${ }^{214}$ Zit. aus DAOUD, Abdelkrim, S. $130 \mathrm{f}$.

${ }^{215}$ CADN Maroc DAI 188: Renseignements, 2.1.1923; SHAT 3H1560: Région de Taza, SR, Bulletin de renseignements, 9.2.1923 und 31.3.1923; SHAT 3H1560: RG Rabat an Colonel commandant de la région de Taza, 18.4.1923; SHAT 3H1559: Commissariat de la sûreté régionale Oujda, Renseignements, 21.6.1923.

${ }^{216}$ PA-AA R71118: Albert Bartels an Preußisches Staatsministerium, 15.3.1934; PA-AA R70181: Albert Bartels an AA, 8.1.1933.

${ }^{217}$ PenNell, A Country, S. 160; CAMPos MARTínez, Abd-el-Krim, S. 87-97; Abdel Malek, in: BCAF 33 (1923) S. 175f., S. 370; Abdel Malek à Melilla, in: BCAF 33 (1923) S. 236.

${ }^{218}$ AYACHE, La Guerre du Rif, S. 179f.; DAOUD, Abdelkrim, S. 127f.; TAHTAH, Pragmatisme 1995, S. 104; ADMAE Maroc 112, 143: Daniel Bourmancé-Say an Abdelkrim, 10.9.1921; ADMAE Maroc 133, 117: Bericht von Daniel Bourmancé-Say »Notes et remarques sur la question riffaine» o.D.; CAOM 10 APOM 295: Bericht von Robert Montagne "L'affaire riffaine - Abd el Krim«, 28.5.1937. 
gebilde im Rif stand somit schon 1921 - zwei Jahre vor der endgültigen Proklamation - fest. Mit allen Mitteln wollte Bourmancé-Say Abdelkrims Herrschaft im Rif gegen die spanische Einflußnahme festigen, um so das französische Gewicht mit seiner Nachhilfe auszuweiten. Dies schloß auch die Organisation von Waffen- und Nachschublieferungen mit ein ${ }^{219}$.

Bourmancé-Say organisierte Papiervorlagen und Stempel, die den Briefkopf der $»$ Rif-Republik $\ll$ trugen $^{220}$. Das vom Herausgeber der algerischen Zeitung "Tablettes marocaines«, Eugène Allard, einem Freund Bourmancé-Says, angekündigte gedruckte offizielle Bulletin der Rifregierung wurde allerdings niemals Realität ${ }^{22 !}$. Bourmancé-Say war auch publizistisch für seine Ziele tätig. Ende 1921 gründete er eine eigene Zeitschrift, die den programmatischen Titel "La Moulouya française - Bulletin des intérêts nationaux au Maroc oriental « trug $^{222}$. Léon Gabrielli, der Kontrollbeamte von Taourirt, witzelte, daß Bourmancé-Say gleichzeitig Herausgeber, Redakteur und einer der wenigen Leser gewesen $\operatorname{sei}^{223}$.

Für die rechts ausgerichteten Pariser Zeitungen »Écho de Paris« und »Intransigeant« fungierte Bourmancé-Say als Korrespondent, der offen für die Sache Abdelkrims agitierte. In seinen Artikeln unterstrich er den Unabhängigkeitskampf der Rifkabylen sowie dessen »nationalistische« Komponente, und er war der erste, der Abdelkrim in der Presse als "Präsidenten der Rif-Republik« bezeichnete ${ }^{224}$. Damit dessen Herrschaft mit dem Protektoratsvertrag in Einklang zu bringen war, wechselte Bourmancé-Say später zu den Bezeichnungen "Chef der in einer Republik vereinten Rifbevölkerung, die unter der Autorität ihres Sultan steht und gegen die Invasion ihres Gebietes kämpft« bzw. »die provisorische Regierung der Rifnationalisten ${ }^{225}$.

Hinsichtlich des Gegensatzes zwischen Spaniern und den Rifkabylen entwarf Bourmancé-Say ein Schwarz-Weiß-Bild. Der Bevölkerung von Melilla warf er die angebliche Tötung unschuldiger Moslems vor, oder er berichtete wahrheitswidrig, die spanische Gegenoffensive ab September 1921 sei blutig

${ }^{219}$ Siehe Kapitel 5, S. 160-162, S. 166, S. 193.

${ }^{220}$ ADMAE Maroc 112, 124: Daniel Bourmance-Say an Caïd Haddou, 6.12.1921.

${ }^{221}$ SHAT 3H135: EMA, Section d'Afrique, Renseignement, 1.2.1924.

${ }^{222}$ CADN Maroc DAI 198: Daniel Bourmancé-Say an Abdelkrim, 5.12.1921; BouTBOUQALT, La Guerre du Rif, S. 74; DAOUD, Abdelkrim, S. 169. Es war nicht möglich, Exemplare dieser Zeitschrift zu finden.

${ }^{223}$ GABRIELLI, Abd-el-Krim, S. 8.

${ }^{224}$ Daniel BOURMANCÉ-SAY, Une véritable guerre d'indépendance, in: Intransigeant, 28.7.1921; DERS., Les représailles espagnoles ne font que redoubler le fanatisme des insurgés, in: Écho de Paris, 3.8.1921; DERS., Quelques épisodes de la lutte des Espagnols contre les Riffains, in: Écho de Paris, 25.8.1921; DERS., Le secret de l'échec espagnol. Union sacrée des tribus, commandement unique, armement sérieux, in: Intransigeant, 4.10.1921.

${ }^{225}$ DERS., Une lettre autographe de Si-Mohamed ben Abd-El-Krim, in: Intransigeant, 13.12.1921; DeRs., Une ruse riffaine, in: Intransigeant, 25.1.1922. 
zurückgeschlagen worden ${ }^{226}$. Hingegen stellte er die Rifkabylen, die katholische Kirchen verschonen, Massaker an spanischen Soldaten vermeiden und die Gefangenen nach internationalen Gesetzen behandeln würden, durchweg positiv dar, um Sympathien für sie zu erwecken ${ }^{227}$.

In einem fiktiven Interview ließ Bourmance-Say seinen Freund Allouche hervorheben, daß Marschall Lyautey ein möglicher Vermittler zwischen den Rifkabylen und Spanien sein könnte, denn dies sei der einzige Ausweg aus einer verfahrenen Situation ${ }^{228}$. Am 13. Dezember 1921 veröffentlichte Bourmancé-Say im "Intransigeant« die erste politische Verlautbarung Abdelkrims in der französischen Presse. Darin beschwerte sich dieser über die vermeintlichen Zivilisationsmaßnahmen Spaniens, die in Wahrheit auf eine militärische Unterdrückung hinausliefen. An die Franzosen appellierte Abdelkrim, nicht zu vergessen, daß viele Marokkaner während des Ersten Weltkrieges für sie gekämpft hätten. Auch vom marokkanischen Sultan erbat er Unterstützung für den Widerstandskampf in einem Teil seines Reiches, der grausam unterdrückt werde. Daniel Bourmancé-Say machte am Ende dieses Artikels keinen Hehl mehr aus seiner Haltung: „Was mich anbetrifft, muß ich meine Sympathie für die Rifkabylen nicht verbergen ${ }^{229}$.

Der Ausbruch des Rifkrieges hatte Mitte 1921 die Bergbauverhandlungen zwischen Abdelkrim und Horacio Echevarrieta zunächst zum Scheitern gebracht $^{230}$. Es war kein Zufall, daß sich Abdelkrim im Zuge seiner Annäherungsversuche an Frankreich an Henri Letellier wandte, an dessen Bergbaurechten im Rif Echevarrieta seit 1917 beteiligt war. Letellier war der Besitzer der Pariser Tageszeitung $»$ Le Journal ${ }^{231}$.

Seine Rechte gingen auf Landkäufe des französischen Abenteurers Comte de Chavagnac zurück, die dieser 1882 bis 1883 in der Nähe des Jebel Hamam im Bereich der Beni Ouriaghel getätigt hatte. Dort hatte Chavagnac Gold erhofft. Selbst war er nie vor Ort gewesen, da ihn die einheimische Bevölkerung nicht ins Land gelassen hatte. Nachdem Chavagnac 1886 von seinem Wohnort Tanger nach Frankreich zurückgekehrt war, übertrug er die Rechte am

${ }^{226}$ DERS., La population, 30.7.1921; DERS., L'offensive espagnole aurait Gchoué, in: Intransigeant, 25.9.1921; DERS., Dans le Riff marocain. Un récit émouvant du revers local que viennent de subir les Espagnols, in: Intransigeant, 18.1.1922.

${ }^{227}$ DERS., Les représailles, 3.8.1921; DERS., Les Espagnols temporisent, in: Écho de Paris, 10.8.1921.

${ }^{228}$ DERS., Une heure, 10.9.1921.

${ }_{229}$ DERS., Une lettre autographe, 13.12.1921.

${ }^{230}$ Siehe S. 224-226.

${ }^{231}$ Veronique DIGNAC, Bertrand JOLY, Historique du Journal 1892-1944, in: Archives nationales, Fonds du Journal (Sous-série 8AR), Répertoire numérique (1997). URL: http://www.archivesnationales.culture.gouv.fr/chan/chan/fonds/EGF/AP/noticesap/AR/8\%20 AR.html [11.4.2003]; Pierre ALBERT, La presse française de 1871 à 1940, in: Claude BELLANGER, Jacques GODECHOT, Pierre GuIRAL (Hg.), Histoire générale de la presse française, Bd. 3: De 1871 à 1940, Paris 1972, S. 135-622, S. 315, S. 521. 
26. Januar 1888 an Mlle Brazier. Kurz vor ihrer Heirat mit Comte Méry de la Canorgue am 5. Oktober 1903 vereinbarte sie mit diesem eine Rechteteilung. 1910 bis 1912 führte der französische Bergbauingenieur Duburguet auf ihren Auftrag hin mehrere Expeditionen zum Jebel Hamam durch, wo er reichhaltige und leicht abbaubare Kupfervorkommen gefunden haben wollte. Doch dann verlor Comte Méry de la Canorgue wegen der ungewissen bergrechtlichen Situation das Interesse. Er verkaufte am 11. Dezember 1913 über 10000 ha Land an Henri Letellier. Nachdem er 1914 eine Bergbaupetition an die Pariser Schiedskommission verschickt hatte, vereinbarte Letellier 1917 eine Beteiligung von Horacio Echevarrieta an seinen Rechten ${ }^{232}$.

Ein weiterer Teilhaber Letelliers war Jean du Taillis. Der freie Journalist und Hobby-Rennfahrer arbeitete nicht nur für das »Journal«, sondern auch für das »Petit Journal« und die Zeitschrift »L'Illustration«. Er verfaßte einige Bücher über Marokko ("Le Maroc pittoresque«, 1905; "Le nouveau Maroc«, 1923) sowie einen Touristenführer für Algerien und Tunesien ("Guide Dunlop, Le tourisme automobile en Algérie - Tunisie«, 1923) ${ }^{233}$.

Du Taillis kannte Daniel Bourmancé-Say seit 1904, als er im Zuge einer Nordafrikareise erstmals Port-Say aufgesucht hatte ${ }^{234}$. Nun erschien er Anfang Dezember 1921 ein weiteres Mal. Über Bourmancé-Says Vermittlung wollte er eine Reportage über das Rif schreiben und mit Abdelkrim über Bergbaugeschäfte sprechen ${ }^{235}$. Sein Versuch, am 24. Dezember 1921 über Taourirt, Camp Berteaux und Hassi Ouenzga das Rif zu erreichen, scheiterte. Der telegrafisch informierte Marschall Lyautey untersagte dem Journalisten, die französischen Linien zu passieren. Eine offizielle Erlaubnis hätte seiner Ansicht nach als Einmischung Frankreichs ausgelegt werden können ${ }^{236}$.

Eine Woche später trafen Bourmancé-Say und du Taillis in Guerruau auf eine aus Außenminister Si Mohammed Azerkane und Abdelkrims Cousin Si Abdelkrim ben Ziane bestehende Rifdelegation, die von 500 Rifkämpfern bis zur Grenze von Französisch-Marokko eskortiert worden war. Ihr Ziel war, mit einem Repräsentanten des marokkanischen Sultans oder der Generalresidenz

${ }^{232}$ Miege, Le Maroc, Bd. 4, S. 48 u. S. 48, Anm. 7; PARSONS, The Origins, S. 114, S. 135, S. 622; AYACHE, La Guerre du Rif, S. 186f., S. 221f.; HART, The Aith Waryaghar, S. 360f.; WoOlman, Rebels in the Rif, S. 38f.; AZZA, Le Rif, S. 136; MADARIAGA, L'Espagne et le Rif, Bd. 1, S. 210, S. 212f.; DIAZ MORLAN, Horacio Echevarrieta, S. 127, S. 341, Anm. 283; MOULIERAS, Le Maroc, Bd. 1, S. 96-99; ADMAE Maroc 133, 100: Bericht von Daniel Bourmancé-Say "La question riffaine vue de la méditerranée«, 28.5.1925; ADMAE Maroc 220, 145: MG, EMA an MAE, 2.7.1925.

${ }^{233}$ RIVET, Lyautey, Bd. 3, S. 259, Anm. 479; GABRIELLl, Abd-el-Krim, S. 15.

${ }^{234}$ CADN Maroc DAI 195: Daniel Bourmance-Say an RG Rabat, 31.12.1921; DU TAILLIS, Le nouveau Maroc, S. 325.

${ }^{235}$ ADMAE Maroc 112, 124: Daniel Bourmancé-Say an Caïd Haddou, 6.12.1921.

${ }^{236}$ ADMAE Maroc 193, 65: Bericht NNote pour la sous-direction d'Afrique au ministère des Affaires étrangères«, 17.1.1922; CADN Madrid C263: MAE an Ambassade de Madrid, 4.2.1922. 
von Rabat Gespräche zu führen ${ }^{237}$. Am 2. und am 7. Januar 1922 bat Bourmancé-Say Marschall Lyautey telegrafisch, entweder den Leiter der Direction des affaires indigènes, Colonel Huot, oder den Kontrollbeamten von Beni Snassen, Rousseau, für ein Treffen mit der Rifdelegation nach Berkane in Algerien zu schicken. Lyautey erteilte jedoch die Anweisung, Rousseau allenfalls zur Identifizierung der Rifdelegierten zu entsenden, nicht jedoch für Verhandlungen. Er traute Bourmancé-Say nicht über den $\mathrm{Weg}^{238}$. Dieser setzte indes in Lyautey alle Hoffnungen, die seiner Ansicht nach günstige Gelegenheit einer französischen Präsenz im Rif nicht verstreichen zu lassen. Vergebens, denn Lyautey brach in Begleitung von Colonel Huot nach Frankreich auf, um sich von einer Krankheit zu erholen ${ }^{239}$.

Am 19. Januar 1922 trafen Azerkane und ben Ziane nach einer Autofahrt über Oujda und Camp Berteaux in Taza ein, wo sie der genau von Lyautey instruierte Militärkommandant General Aubert empfing. Er ermutigte sie zwar, nur Franzosen zu erlauben, Bergbauforschung im Rif zu betreiben, aber er machte ihnen auch klar, daß eine Weiterreise zum marokkanischen Sultan nach Fes ausgeschlossen sei. Die Rifdelegierten waren über den Empfang, den man ihnen in der französischen Zone Marokkos bereitete, überrascht und kehrten ins Rif zurück, um neue Instruktionen zu erhalten ${ }^{240}$. In einem Brief an General Aubert vom 23. Januar 1922 brachte Bourmancé-Say seine Verwunderung über das französische Verhalten zum Ausdruck, denn die gleichen Vertreter der Generalresidenz, die seit Wochen Gesprächsbereitschaft mit den Rifdelegierten signalisiert hätten, würden ihnen nun den Rücken zukehren ${ }^{241}$.

Von der Wahl Raymond Poincarés zum neuen französischen Ministerpräsidenten erhofften sich Bourmancé-Say und Caïd Haddou im Januar 1922 eine diplomatische Wiederbelebung ${ }^{242}$. Da sich Lyautey und Huot in Paris aufhielten, trafen Abdelkrim und Bourmancé-Say die Entscheidung, Si Mohammed Azerkane, Si Abdelkrim ben Ziane und Caïd Haddou in die französische Hauptstadt zu entsenden. Thre Mission verfolgte mehrere Ziele: Die Herstellung eines direkten Kontaktes zur französischen Regierung, wirtschaftliche Gespräche mit Henri Letellier in Bezug auf die Ausbeutung von Bodenschätzen im Rif und den Ankauf von Waffen bis hin zu Flugzeugen ${ }^{243}$. Daniel

${ }^{237}$ ADMAE Maroc 193, 87: Gouverneur général de l'Algérie an MAE, 21.1.1922 mit einem Bericht des Chef d'annexe de Marnia, 11.1.1922.

${ }^{238}$ ADMAE Maroc 193, 40: RG Rabat an MAE, 12.1.1922.

${ }^{239}$ AYACHE, La Guerre du Rif, S. 186; RIVET, Lyautey, Bd. 3, S. 272.

${ }^{240}$ CAOM Algérie 9H93: Chef d'annexe de Marnia an Général commandant de la division d'Oran, 6.2.1922.

${ }^{241}$ SHAT 3H1560: Daniel Bourmancé-Say an Général Aubert, 23.1.1922.

${ }^{242}$ RIVET, Lyautey, Bd. 3, S. 272; KHARCHICH, La France, S. 148; AYACHE, La Guerre du Rif, S. 186, Anm. 54.

${ }^{243}$ Siehe Kapitel 5, S. 193. 
Bourmancé-Say begleitete die Delegierten und streckte die Mittel für die Reise - rund 10000 Francs - vor. Über Oran und Marseille erreichten sie Ende Januar 1922 Paris $^{244}$.

Ihr erstes Treffen führte sie mit Camille Crespin alias Camille du Gast (1868-1942) zusammen. Sie war eine der ersten Französinnen, die sich im Bereich des Sports einen Namen machten. 1895 stellte sie mit dem berühmten Louis Capazza einen neuen Höhenrekord für Ballonfahrten (3 000 Meter) auf. Sie fuhr Motorboot- und Skirennen. 1901 bis 1903 nahm sie mit ihrem Panhard-Rennwagen »Valkure«, der es auf $60 \mathrm{~km} / \mathrm{h}$ brachte, an mehreren Langstreckenrennen zwischen Paris, Berlin, Wien und Madrid teil. Sie war auch Vizepräsidentin der französischen Liga für Frauenrechte ${ }^{245} .1912$ hatte die Abenteurerin eine Expedition nach Marokko unternommen, um im Auftrag des Pariser Museums für Naturkunde Menschenschädel zu sammeln. Mit 23 Exponaten - darunter einigen aus dem Rif - war sie nach Frankreich zurückgekehrt ${ }^{246}$. In ihrem riesigen Atelier voller exotischer Reichtümer und marokkanischer Parfums empfing sie die Rifdelegation am 1. Februar 1922. Caïd Haddou bat sie, als Vermittlerin für Abdelkrim zu fungieren und sie ins Rif zu begleiten. Aber Camille du Gast erregte sich über die schlechte Behandlung der spanischen Kriegsgefangenen und lehnte $a b^{247}$.

Während ihrer Bergbaugespräche einigten sich Letellier und die Rifdelegierten darauf, daß Jean du Taillis eine Expedition von Fachleuten ins Rif begleiten sollte ${ }^{248}$. Zwischen den Rifkabylen und der französischen Regierung kam kein Kontakt zustande. Ministerpräsident Poincaré verfolgte andere Interessen. Er versuchte zu dieser Zeit, Spaniens geschwächte Lage in seiner Einflußzone auszunutzen und die Stellung Frankreichs in Tanger gegen den Widerstand Großbritanniens zu verbessern ${ }^{249}$.

244 ADMAE Maroc 193, 101: Gouverneur général de l'Algérie an MAE, 25.1.1922; CADN Madrid C263: MAE an Ambassade de Madrid, 30.1.1922; ADMAE Maroc 112, 119: Si Mohammed Azerkane an Abdelkrim, 26.1.1922; CAOM Algérie 9H93: Chef d'annexe de Marnia an Général commandant de la division d'Oran, 20.2.1922; Trois chefs riffains à Paris, in: Journal, 30.1.1922; DAOUD, Abdelkrim, S. 134; AYACHE, La Guerre du Rif, S. 186; KHARCHICH, La France, S. 149.

${ }^{245}$ Alexandre BUISSERET, Les femmes et l'automobile à la Belle Époque, in: Le mouvement social 192 (2000) S. 41-64, S. 47f.; Cyril Posthumus, First Lady of Racing. The Remarkable Camille du Gast, in: Automobile Quarterly 14 (1976) S. 351-361, S. 353, S. 359f; Monique de SAINT MARTIN, L'espace de la noblesse, Paris 1993, S. 149, Anm. 42; The AlgiersToulon Motor Boat Race, in: Scientific American, 3.6.1905.

${ }^{246} \mathrm{R}$. VERNEAU, Les crânes marocains de la mission de Madame Camille du Gast, Angers 1913, S. 4; Mme du Gast l'exploratrice parle du Maroc, in: Petit Journal, 29.7.1921.

${ }^{247}$ Mme Camille du Gast parlementaire au Riff, in: Petit Journal, 2.2.1922; Le Riff à Paris. Une négotiation difficile, in: CEuvre, 3.2.1922; Les chefs riffains à Paris, in: Temps, 5.2.1922 und 6.2.1922. Trois caïds du Riff à Paris, in: Éclair, 5.2.1922;

${ }^{248}$ TAHTAH, Pragmatisme 1995, S. 103; KHARCHICH, La France, S. 150; DAOUD, Abdelkrim, S. 135.

${ }^{249}$ BENNETT, British Foreign Policy, S. 139. 
Nur Bourmancé-Say gelang es, mit Generalresident Lyautey eine Zusammenkunft in Paris zu vereinbaren. Später erzählte er davon, daß der Marschall ihm angesichts seiner Aktivitäten für die Rifkabylen damit gedroht habe, zukünftig die Einreise nach Französisch-Marokko zu untersagen. Bei einem Treffen in Letelliers Haus trafen Azerkane und ben Ziane allerdings zu ihrer Überraschung auf Colonel Huot. Es kam zu einer informellen Vereinbarung. Im Gegenzug für einen freien Handelsgrenzverkehr zwischen dem Rif sowie Französisch-Marokko und Algerien sicherten die Rifkabylen zu, Letelliers Mission von Bergbauexperten freundlich zu empfangen. Huot versprach, das Nötige dafür zu tun, um das Verhältnis zwischen Frankreich und dem Rif zu verbessern. Weitere Zugeständnisse konnte oder wollte er nicht geben. Huots Einsatz für Letellier und du Taillis hing möglicherweise damit zusammen, daß der Chef des "Journal L Lyautey gut kannte. Am 12. Februar 1922 kehrten Haddou, Azerkane und ben Ziane nach Port-Say zurück. Zwei Tage später folgte ihnen Bourmancé-Say, der wütend war, in Paris nicht mehr erreicht zu haben ${ }^{2 s 0}$.

Auch Abdelkrim war enttäuscht. Da Frankreich nicht auf die Verhandlungsangebote reagiert hatte und er sich auch vom marokkanischen Sultan im Stich gelassen fühlte, war er bereit, die Hilfe jeden Landes gegen Spanien anzunehmen. Von nun an kam die bisher im Bereich des Möglichen liegende Anerkennung des Sultans nicht mehr in Frage ${ }^{251}$. Die Verunsicherung gegenüber Frankreich war so groß, daß Abdelkrim bei Bourmancé-Say nachfragte, ob die Rif-Wanderarbeiter auch in diesem Jahr nach Algerien kommen dürtten ${ }^{252}$.

In einem Brief an Abdelkrim vom 16. März 1922 bereitete Bourmancé-Say die Bergbau-Mission von Jean du Taillis vor. Er stellte in Aussicht, daß die Ausbeutung von Bodenschätzen dazu führen werde, die nötigen Mittel für eine völlige Unabhängigkeit des Rifs zu erhalten ${ }^{253}$. Während Letellier in Paris auf eine Entscheidung der Pariser Schiedskommission bezüglich seiner Bergbaurechte im Rif wartete, entsandte er du Taillis nach Port-Say. Ihn begleiteten die Bergbauingenieure P. Robert und Duburguet. Letzterer kannte das Rif von

${ }^{250}$ AYACHE, La Guerre du Rif, S. 187; TAHTAH, Pragmatisme 1995, S. 103; KHARCHICH, La France, S. 149-151; DAOUD, Abdelloim, S. 134; DUNET, La sanglante aventure, S. 50; CAOM Algérie 9H93: Chef d'annexe de Marnia an Génćral commandant de la division d'Oran, 20.2.1922; ADMAEE Maroc 193, 266: Chef du contrôle civil des Beni Snassen an Chef du contrôle de la région d'Oujda, 22.2.1922; ADMAE Maroc 196, 202: Daniel Bourmancé-Say an Camille du Gast, 28.8.1923.

${ }^{251}$ CADN Madrid C263: CG Tanger an MAE, 2.4.1922.

252 CAOM Algérie 9H93: Chef d'annexe de Marnia an Général commandant de la division d'Oran, 11.4.1922.

${ }^{253}$ ADMAE Maroc 112, 133: Daniel Bourmancé-Say an Abdelkrim, 16.3.1922. 
seinen die Letellier-Rechte betreffenden Erkundungen von 1910 bis 1912 her. Der frühere Pilot P. Robert betrieb in Oujda eine Firma für Bergbauuntersuchungen und Forstwirtschaft ${ }^{254}$.

In zwei Artikeln für die Zeitschrift „L'Illustration« beschrieb du Taillis später seine - diesmal von französischer Seite unbehinderte - Reise ins Rif vom 28. März bis zum 18. April $1922^{255}$. Er erhielt für die Berichte von Abdelkrim 40000 Peseten $^{256}$. Er war der erste einer Reihe von Reportern, die das Rif besuchten und der einzige, der selbst wirtschaftliche Interessen verfolgte. Mit keinem Wort ging du Taillis in seinen Artikeln darauf ein. Am 7. April 1922 führte er eine mehrstündige Unterhaltung mit Abdelkrim, der sich als Reformer, der die Zeichen der sich wandelnden Zeit erkannt habe, ausgab: "Dieser Wandel darf allerdings nicht unsere Institutionen, die freie Verfügung über unser Land und unsere vollständige Unabhängigkeit beeinflussen « $^{257}$. In diesem ersten Interview, das Abdelkrim einem Journalisten gab, betonte er also seine Einsicht in notwendige Veränderungen. Dazu war er aber nur unter der Beibehaltung der untrennbaren wirtschaftichen und politischen Entscheidungsfreiheit der Rifkabylen bereit.

In der Nähe von Ouberrane traf du Taillis am 9. April 1922 Abdelkrims Bruder Si M'hammed, der als studierter Bergbauingenieur der Verhandlungspartner für das Geschäft mit Letellier war. Si M'hammed zeigte auf die Bergspitze des Jebel Hamam im Westen und wies auf die Wasserkraft seiner Flüsse und Wasserfalle hin. Die bergbaulichen Möglichkeiten des Rifs pries er in den höchsten Tönen. Er war sich aber auch der damit verbundenenen Gefahren im Hinblick auf ausländische Begehrlichkeiten bewußt. Das Rifvolk habe das Recht, seine Bodenschätze selbst auszubeuten, ohne daß Armeen den Weg für Ingenieure bereiten müssten, betonte $\mathrm{er}^{258}$.

Caïd Haddou und zwei weitere einheimische Führer zeigten du Taillis und seinen Begleitern die Punkte, wo sich Bodenschätze befinden sollten ${ }^{259}$. Nicht erlaubt wurden den Franzosen die Anfertigung von Plänen vor Ort und die Mitnahme von Proben. Dies war kein Einzelfall. Auch in der Folgezeit sollte Rifbesuchern verwehrt bleiben, Beweise für das Vorhandensein von Bodenschätzen zu sammeln. Fast scheint es, als ob Si M'hammed und Abdelkrim das Risiko negativer Ergebnisse nicht eingehen wollten. Robert, der von Letellier

\footnotetext{
${ }^{254}$ SHAT 3H1 102: P. Robert an Lt.-Col. Delpy, 25.3.1924; SHAT 3H1 102: SR Rabat, Bericht "Liste des personnes à surveiller《 o.D. (1924); CADN Madrid C273: MAE an Ambassade de Madrid, 26.6.1922; ADMAE Maroc 194, 185: RG Rabat an MAE, 12.6.1922.

${ }^{255}$ Jean DU TAllLIS, Au coeur du Rif inconnu, in: L'lllustration 80 (1922) S. 195-199, S. 226-229.

${ }^{256}$ FONTANE, L'étrange aventure, S. 86f.

${ }^{257}$ Du TAll LIS, Behind the Moorish Lines, S. 168.

${ }^{258}$ Ibid. S. 169.

${ }^{259}$ CAOM Algérie 30H87: Chef d'annexe de Marnia an Général commandant de la division d'Oran, 24.4.1922.
} 
beauftragt worden war, ein Dossier mit Karten und Profilen für die interessantesten Bergbauregionen des Rifs anzufertigen, mußte sich auf seine Erinnerung und auf die Angaben Si M'hammeds verlassen. In seinem Abschlußbericht zählte er neben Eisenerzvorkommen auch Fundstätten für Bergteer, Mangan, Gips, Kupfer, Blei, Zink, Kobalt und Silber auf. Sein Fazit gerade für den Jebel Hamam und für Beni Saïd lautete: »Diese Zone Marokkos wird sicher ein sehr interessantes Feld für Bergbauaktivitäten werden ${ }^{260}$.

So schloß die von Si M'hammed und Si Mohammed Azerkane vertretene Rifregierung mit dem Letellier-Beauftragten Jean du Taillis am 14. April 1922 einen Exklusivvertrag über Bergbaufelder im Einflußbereich Abdelkrims. Der Kontrakt beinhaltete eine Konzession zur bergbaulichen Erkundung und Ausbeutung auch im Falle von Neuentdeckungen mit dem Monopol des auswärtigen Handels über das Meer. Er sah vor, daß Rechte an andere Bergbaugesellschaften übertragen werden konnten - mit der Auflage, daß ein Sitz in deren Verwaltung einem Rifkabylen vorbehalten sein müsse. Die Kosten für die Rifsoldaten, die die Bergbaufelder bewachen sollten, hatten Letellier und du Taillis zu übernehmen. Gegen ein Monatsgehalt von 1000 Duros wurde Si M'hammed zum Leiter einer Erforschungsmission für Erzfundstätten bestimmt. In einer dreimonatigen Frist sollte ein Vorschuß von einer Million Francs an die Rifregierung gezahlt werden. Abdelkrims Hoffnungen auf direkte Wirtschaftsbeziehungen mit dem Ausland wurden geweck ${ }^{261}$. Gleichzeitig vereinbarte du Taillis in einem Zusatzvertrag die Abholzung des Waldes von Tizrat - der zum Teil einem anderen Geschäftspartner Abdelkrims, dem Briten John Arnall, gehörte - und die Lieferung militärischen Schmuggelguts ${ }^{262}$. Diese Verbindung zwischen Bergbauverträgen und Bestellungen für Militärgerät sollte sich noch einige Male wiederholen.

Am 4. Mai 1922 sprach die Pariser Schiedskommission Henri Letellier statt der erhofften 10000 ha lediglich 1600 ha für bergbauliche Forschungen im Jebel-Hamam-Gebiet zu. Letellier war damit der einzige Vertragspartner Abdelkrims, der über Rechte verfügte, die dem marokkanischen Bergbaugesetz entsprachen ${ }^{263}$. Während Letellier in Paris versuchte, das Geld für den vertraglich vereinbarten Vorschuß zusammenzubekommen, schlug Daniel Bourmancé-Say Abdelkrim vor, bis dahin selbst eine Kupfer- oder Bleimine bearbeiten zu lassen und die Erze im Schutz der Dunkelheit auszuschiffen.

${ }^{260}$ ADMAE Maroc 112, 239: Bericht „Rapport minier présenté par M.P. Robert«, 29.4.1922.

${ }^{261}$ KHARCHICH, La France, S. 151 u. S. 151, Anm. 2; AYACHE, La Guerre du Rif, S. 222 u. S. 222, Anm. 29; DAOUD, Abdelkrim, S. 159; DUNET, La sanglante aventure, S. 51-58.

${ }^{262}$ ADMAE Maroc 112, 250: Jean du Taillis an Si M'hammed o.D. [1922]; PRO-FO 371, 8354, 4882, 91: John Arnall an FO, 16.7.1922.

${ }^{263}$ MADARIAGA, L'Espagne et le Rif, Bd. 1, S. 197, S. 215f.; DIAZ MORLÁN, Horacio Echevarrieta, S. 129; GODCHOT, Le mystère, S. 249. 
Gleichzeitig deutete er an, daß ein international anerkannter Rifstaat für die Akzeptanz der abgeschlossenen Verträge mit Letellier und du Taillis von Vorteil sein würde ${ }^{264}$.

Im Mai 1922 schickte Abdelkrim Si el Haj Mohammed ben el Haj Mekki el Ouezzani und Si Braham ben Abdallah el Ouezzani nach Fes, um mit dem dortigen Militärkommandanten General Maurial über die Anerkennung der Rifregierung und über Erleichterungen für die Grenzüberquerung von Nachschubkarawanen zu verhandeln. Als Gegenleistung bot Abdelkrim den Abschluß eines allgemeinen Wirtschaftsvertrages an. Maurial weigerte sich, die Gesandten persönlich zu empfangen und schickte zwei höhere Funktionäre vor. Lyautey lobte ihn nachher dafür, dem Besuch der Gesandten keinen offiziellen Charakter gegeben zu haben. Die französische Zone sei offen für jeden, der sich an die Gesetze halte und den marokkanischen Sultan anerkenne, räumte er ein. Frankreich müsse sich jedoch an internationale Verträge halten, daher gelte, daß weder etwas gesagt noch getan werden dürfe, das als Anerkennung der »Pseudo-Regierung « im Rif hätte interpretiert werden können ${ }^{265}$.

Etwas moderater klang Colonel Huot, der etwa zur gleichen Zeit Caïd Haddou in Rabat empfing. Huot sicherte den Rifkabylen freien Zugang nach Frankreich und Französisch-Marokko sowie freien Handelsverkehr $\mathrm{zu}^{266}$. In den französischen Militärkreisen Marokkos gab es Differenzen wegen der Politik Lyauteys. Regelrechte Anhänger Abdelkrims befürworteten eine Niederlage Spaniens. Der tolerierte Waffenschmuggel ins Rif nahm 1922 deutlich zu. Auf regionaler Ebene beglückwünschte ein Mann wie Capitaine France, der Chef des Nachrichtenbüros in Taourirt, Abdelkrim zu seinen Erfolgen über die Spanier. Ein Mitarbeiter der Generalresidenz, der Caild Haddou heimlich in Taourirt aufsuchte, schlug vor, daß Abdelkrim Vertreter der Rifregierung zum Genfer Völkerbund entsenden solle ${ }^{267}$. Im September 1922 schickten die in London weilenden Rifdelegierten Si Mohammed Boujibar und Si Abdelkrim ben el Haj Ali Luh tatsächlich eine Demarche an den Völkerbund. Das französische Außenministerium nahm dies so ernst, daß es die französischen Delegierten in Genf anwies, das Ansinnen der »Rif-Republik« zu ignorieren ${ }^{268}$.

Letellier und du Taillis kämpften unterdessen mit Finanzierungsproblemen. Die Frist für die Zahlung des Vorschusses war mittlerweile abgelaufen. Anfang August 1922 benachrichtigte Jean du Taillis Si M'hammed, daß er weiter ohne Unterlaß für die Verwirklichung des abgeschlossenen Vertrages arbei-

${ }^{264}$ CADN Maroc DAI 198: Daniel Bourmancé-Say an Abdelkrim, 22.5.1922.

${ }^{265}$ JACQUES, L'aventure riffaine, S. 15-18. Vgl. AGERON, Les socialistes français, S. 276; RIVET, Lyautey, Bd. 3, S. 271; HUETZ DE LEMPS, La collaboration, S. 87.

${ }^{266}$ AYACHE, La Guerre du Rif, S. 245f. u. S. 245, Anm. 36.

${ }^{267}$ CADN Maroc DAI 198: Caïd Haddou an Abdelkrim, 24.6.1922.

${ }^{268}$ CADN Madrid C273: MAE an Ambassade de Madrid, 15.9.1922. 
$\mathrm{te}^{269}$. So kam es am 20. August 1922 zu einer Erneuerung des Kontraktes zwischen der Rifregierung und du Taillis ${ }^{270}$. Dieses Mal sollte der Vorschuß von einer Million Francs bis zum 15. Oktober 1922 ausgezahlt werden. Als du Taillis am 8. Oktober 1922 um einen weiteren Aufschub bat, war klar, daß das Geschäft auch dieses Mal nicht zustande kommen würde. Über die Gründe Letelliers und du Taillis' kann man nur spekulieren. War es die mangelnde juristische Basis der international wertlosen Abmachung, oder war es der Letellier zu weitgehende Wunsch Abdelkrims nach wirtschaftlicher Unabhängigkeit? Jedenfalls veräußerte Letellier seinen Rifbesitz im Herbst 1922 an seinen bisherigen Teilhaber Horacio Echevarrieta ${ }^{271}$.

Abdelkrims Verträge mit Letellier und du Taillis waren der Auftakt für eine ganze Reihe von fehlgeschlagenen Bergbaugeschäften. Seine weiteren Bemühungen, mit Franzosen Wirtschaftsverträge abzuschließen, liefen ebenso ins Leere. Auf die im Februar 1923 erfolgte Ankündigung der Gruppe Menard, Fribourg und Chenay, Kapital für den Erwerb von Bergbau-Konzessionen auftreiben zu wollen, folgten keine Taten ${ }^{272}$. Es gab sporadische Verhandlungen mit der algerischen Société anonyme marocaine ${ }^{273}$. Der Franzose Levasseur bemühte sich im August 1923 vergeblich um einen Bergbau- und Wollevertrag $^{274}$. Ein Angebot des französischen Handelsvertreters Alfred Garnier aus dem algerischen Oran vom 4. Oktober 1923, eine Gesellschaft zur Ausbeutung von Bergbaufeldern zu organisieren, fand mehr Aufmerksamkeit. Als Caïd Haddou das Geschäft von der Lieferung eines Jagdflugzeugs abhängig machte, brach der Kontakt $\mathbf{a b}^{275}$.

Ende 1923 konnte Abdelkrim seinen Machtbereich in Richtung französische Einflußzone ausdehnen. Diesen Teil nördlich des Ouergha-Flusses, der für die Lebensmittelversorgung des Rifs unverzichtbar war, planten die französischen Truppen seit längerem zu besetzen, da er vertraglich noch zum französischen

\footnotetext{
${ }^{269}$ CADN Maroc DAI 197: Jean du Taillis an Si M'hammed, 8.8.1922.

${ }^{270}$ CADN Maroc DAI 198: Vertragstext "Traité commerciale et minier conclu entre le gouvernement riffain et $M$. Jean du Taillis«, 20.8.1922. Maria Rosa de Madariaga nennt das falsche Datum 13.8.1922 [MADARIAGA, España y el Rif, S. 532].

${ }^{271}$ CADN Maroc DAI 198: Jean du Taillis an Si Mohammed Mohammedine Hitmi, 8.10.1922; AYACHE, La Guerre du Rif, S. 222f. u. S. 222, Anm. 29; KHARCHICH, La France, S. 151f.; DAOUD, Abdelkrim, S. 159; DLAZ MORLAN, Horacio Echevarrieta, S. 137; RIVET, Le commandement français, S. 107, Anm. 27; DUNET, La sanglante aventure, S. 58.

${ }^{27}$ CADN Madrid C274: MAE an Ambassade de Madrid, 28.2.1923.

${ }^{273}$ ADMAE Maroc 196, 132: RG Rabat an MAE, 20.7.1923 mit Bezug auf einen Bericht des Commissaire divisionnaire de Casablanca, 18.7.1923.

${ }^{274}$ SHAT 3H1102: Bericht »Liste de personnes à surveiller« o.D. (1924); SHAT 3H1559: Région de Taza, Cercle de Guercif, SR, Feuille de renseignements, 10.9.1923; SHAT 3H1559: Bureau de renseignements de Taourirt an Commandant le cercle de Guercif, 1.12.1923; ROGER-MATHIEU, Mémoires, S. 225.

275 CAOM Algérie 30H86: Préfet du département d'Oran an Gouverneur général de l'Algérie, 22.10.1923.
} 
Protektorat gehörte ${ }^{276}$. In einem Schreiben an das Kriegsministerium vom 22. März 1924 bat Lyautey um die Erlaubnis, den Fluß zu überschreiten. Er begründete diesen Schritt mit der notwendigen Sicherung der Verbindung von Fes über Taza nach Algerien, da »)der zunehmende Einfluß Abd el Krims in unserer Zone und seine Haltung uns gegenüber eine Gefahr bedeutet « ${ }^{277}$. Er warnte vor einem autonomen moslemischen Gemeinwesen an der Mittelmeerküste, das schnell zu einem Sammelbecken für Dissidenten und Unzufriedene aus ganz Marokko werden könnte ${ }^{278}$.

Aufgrund der Spannungen mit der Generalresidenz in Rabat bat Abdelkrim Vertraute aus Algerien um Vermittlerdienste. Ende 1923 und Anfang 1924 erklärte er dem ihm vom geplatzten Letelliergeschäft bekannten Bergbauingenieur P. Robert bei einigen Treffen, er wolle den Franzosen die Ausbeutung der Rifreichtümer gegen die Zusicherung von Nachschublieferungen offenhalten. Robert selbst plante den Bau einer Eisenbahnstrecke zwischen Ajdir und Guercif. Er präsentierte sich den französischen Stellen als »Bürger des Rifs«, der aber auch den Wirtschaftsinteressen Frankreichs dienen wolle. Gegenüber dem Militärkommandanten von Guercif, Capitaine Vincent, betonte Robert am 21. Januar 1924, daß Abdelkrim Frankreich sehr ergeben sei und nichts anderes sein wolle als »Oberhaupt der föderalen Rif-Republik unter der Oberhoheit des Sultans und des französischen Protektorats ${ }^{279}$.

Der Wahrheitsgehalt dieser angeblichen Aussage Abdelkrims muß stark angezweifelt werden, insbesondere was die Anerkennung der Hoheit des Sultans anbetrifft. Dies kann höchstens in religiöser Hinsicht gemeint gewesen sein. Allerdings war Abdelkrim sehr an einer Verbesserung des Verhältmisses zu Frankreich interessiert. Hierfür benötigte er Vermittler wie die Algerienfranzosen P. Robert oder Dr. Yves Marion-Gallois, der im Winter zuvor die Schwester Abdelkrims verarztet hatte ${ }^{280}$. Im April 1924 schickte Abdelkrim einen Brief an Marion-Gallois, in dem er versicherte, den Tag herbeizusehnen, an dem Frankreich ihm die Hände reichen werde. Er bat ihn, dem französischen Konsul von Oujda einen Brief vom 14. April 1924 zu übergeben, in dem er den Wunsch der Rifregierung zu guten Beziehungen mit Frankreich bekräftigte $^{281}$.

${ }^{276}$ KHARCHICH, Les négotiations, S. 295; RIVET, Le commandement français, S. 104; DERS., Lyautey, Bd. 3, S. 275.

${ }^{27}$ Zit. aus ABDELKRIM, Memoiren, S. 164.

${ }^{278}$ HOISINGTON, Lyautey, S. 189f.; USBORNE, The Conquest, S. 262; Marechal Lyautey an MAE, 27.2.1924, in: JACQUES, L'aventure riffaine, S. 55f.

${ }^{279}$ SHAT 3H1102: Territoire de Taza, Cercle de Guercif, SR, Feuille de renseignements, 10.12.1923, 20.1.1924, 22.1.1924 und 26.2.1924; SHAT 3H1 102: P. Robert an Lt.-Col. Delpy, 25.3.1924.

${ }^{280}$ Siehe Kapitel 3, S. $68 f$.

${ }^{281}$ ABDELKRIM, Memoiren, S. 172f.; FONTAINE, L'étrange aventure, S. 59, S. 128, S. 134. 
Zudem entsandte er mehrere Delegierte nach Fes, die den Vorschlag unterbreiteten, die Grenze zwischen dem Rif und Französisch-Marokko genauer zu definieren ${ }^{282}$. Gleichzeitig aber griffen Riftruppen Kabylen und Teilfraktionen in der Ouergha-Region, die sich Abdelkrims Herrschaft nicht unterordnen wollten, an, wurden aber Ende Mai 1924 zurückgeschlagen. Lyautey nutzte die Gelegenheit. Am 27. Mai 1924 überquerten 12000 Mann die Ouergha. Abdelkrim ließ keinen Widerstand leisten, da seine Truppen im Nordwesten benötigt wurden, um die Spanier aus dem Jebala-Gebiet zu vertreiben. Die Ereignisse im Frühjahr 1924 waren die "Wasserscheide« in den Beziehungen zwischen Französisch-Marokko und dem Rif $^{283}$.

Die Nachschubkarawanen aus dem französischen Protektorat in Richtung Rif wurden von nun an strenger kontrolliert ${ }^{284}$. Lyautey erntete für sein Vorgehen nicht nur Zustimmung. Franzosen in Marokko und Algerien warfen der französischen Generalresidenz in Rabat vor, ihnen den Weg zu den Riferzen zu versperren ${ }^{285}$. Um weiterhin sein Wohlwollen zu demonstrieren, schloß Abdelkrim am 21. Juni 1924 mit den Algerienfranzosen Joseph Abad und Henri Guigal einen Monopolvertrag für alle Rifexporte ab. Im Gegenzug verpflichteten sich die beiden Franzosen zur Lieferung von Versorgungsgütern. Der Vertrag wurde jedoch nie erfüllt ${ }^{286}$.

Gegenüber dem französischen Journalisten Jacques de Marsillac von der Zeitung »Journal«, den Daniel Bourmancé-Say ins Rif vermittelt hatte, versicherte Abdelkrim im Dezember 1924, daß er alles tun werde, um mit Frankreich zu einer Verständigung zu kommen ${ }^{287}$. Dieser Besuch eines Reporters erhöhte seine Reputation in der westlichen Welt nicht. Marsillac kam schwer krank zurück und schimpfte über den Schmutz im Lande sowie über die mangelnde Organisation, die zur Folge habe, daß nichts funktioniere und sogar Abdelkrims Autos defekt seien ${ }^{288}$.

${ }^{282}$ USBORNE, The Conquest, S. 268; JACQUES, L'aventure riffaine, S. 32, S. 36-39, S. 4346; RIVET, Lyautey, Bd. 3, S. 276; Caïd Haddou an Général de Chambrun o.D. [April 1924], in: ABDELKRIM, Memoiren, S. 122-124, S. 123f.

${ }^{283}$ GERSHOVICH, French Military Rule, S. 128; HoISINGTON, Lyautey, S. $190 \mathrm{f}$.

${ }^{284}$ SHAT 3H1 102: RG Rabat an Consul de France Oujda, 29.7.1924; CADN Maroc DAl 195: RG Rabat an Chef de la région d'Oujda, 28.7.1924.

${ }^{285}$ CADN Londres C519: MAE an Ambassade de Londres, 26.5.1924 mit dem beigefügten Brief RG Rabat an MAE, 16.5.1924.

${ }^{286}$ ADMAE Maroc 220, 153: Vertrag zwischen der Rifregierung und Joseph Abad sowie Henri Guigal, 21.6.1924.

${ }^{287}$ Jacques de MARSILLAC, "Je désire vivement m'entendre avec la France et je ferai tout ce qui est possible pour y réussir«, in: Journal, 20.1.1925. Vgl. zur Reise Marsillacs auch DERS., Un voyage au cœur du Riff sur le chemin qui mène vers Abd el Krim, in: Journal, 18.1.1925; GABRIELLI, Abd-el-Krim, S. 15.

${ }^{288}$ CADN Maroc DAI 197: Région d'Oujda, Renseignements, 20.12.1924. 
Daniel Bourmancé-Says Beratertätigkeit für Abdelkrim war bereits nach dem mißglückten Letellier-Bergbauvertrag beendet worden, wobei nicht klar ist, wer von beiden den Schlußstrich zog. Der Franzose war weiter an Nachschub- und Schmuggellieferungen aus Algerien beteiligt, aber angesichts der winkohärenten Rifpolitik der französischen Regierung ${ }^{289}$ sah er wenig Chancen, seinem Ziel einer Ausweitung des französischen Einflusses näher zu kommen. Als ihn im Herbst 1924 sein Freund Kitchin vom algerischen Bergwerk in Sebabna fragte, ob er in Horacio Echevarrietas Projekt einer französisch-spanischen Chartergesellschaft einsteigen wolle, schöpfte er kurzfristig neue Hoffnung. Bourmancé-Say malte sich aus, daß eine dominante französische Position innerhalb dieser Chartergesellschaft Frankreich den Küstenstreifen des Rifs einbringen könne. Doch als er seinen Gedanken in der Generalresidenz von Rabat vorbrachte, wurde ihm keinerlei Interesse entgegengebracht ${ }^{290}$.

Nach dem Beginn der Feindseligkeiten zwischen den Truppen des Rifs und Frankreichs im April 1925 bot sich Bourmancé-Say als Vermittler an, indem er gleichzeitig seine Loyalität zu Frankreich und seine guten Kontakte zu Abdelkrim, der noch immer ein Freund der Franzosen sei, betonte ${ }^{291}$. Die algerischen Behörden waren jedoch mißtrauisch und ließen ihn überwachen ${ }^{292}$.

Im September 1925 empfing Bourmancé-Say, der Kolonialist und Monarchist aus dem äußerst rechten politischen Spektrum, einen für ihn ungewöhnlichen Gast. Es handelte sich um den französischen Kommunisten Jacques Doriot, der seit 1922 auch Mitglied des Exekutivkomitees der Kommunistischen Internationale (Komintern) war. 1923 hatte er den Widerstand innerhalb der französischen Armee gegen die Ruhrbesetzung organisiert, und er leitete die Jugendorganisation Jeunes communistes ${ }^{293}$. Die erste Fühlungnahme der Kommunistischen Partei Frankreichs (Parti communiste français, PCF) zu den Rifkabylen war 1923 entstanden, als sich André Berthon und Si M'hammed während dessen Pariser Aufenthaltes zu einem Gespräch in einem

${ }^{289}$ ADMAE Maroc 196, 202: Daniel Bourmancé-Say an Camille du Gast, 28.9.1923.

${ }^{290}$ ADMAE Maroc 133, 117: Bericht von Daniel Bourmancé-Say »Notes et remarques sur la question riffaine« o.D.; ADMAE Maroc 219, 183: Sous-Prefet de Tlemcen an Préfet d'Oran, 26.12.1924; CADN Madrid C263: RG Rabat an MAE, 6.12.1924; CADN Madrid C263: Ambassade de Madrid an MAE, 25.12.1924; SHAT 3H134: RG Rabat an MAE, 23.1.1925; SHAT 3H134: MAE an MG, EMA, Section d'Afrique, 8.1.1925; AYACHE, La Guerre du Rif, S. 173, S. 174, Anm. 28, S. 178, Anm. 38.

${ }^{291}$ CADN Maroc DAI 189: Ministère de la Marine an RG Rabat, 17.8.1925 mit dem Bericht „Conversation avec Monsieur Bourmancé-Say«, 26.7.1925; CADN Maroc DAI 189: RG Rabat an DAI Rabat, 17.8.1925.

${ }^{292}$ ADMAE Maroc 99, 161: EMA, $2^{\mathrm{e}}$ bureau, Bericht "Achats de M. Bourmancé-Say à Oran«, 10.8.1925.

${ }^{293}$ Pierre BROUE, Histoire de l'Internationale communiste 1919-1943, Paris 1997, S. 990; Jakob MONETA, Die Kolonialpolitik der französischen KP, Hannover 1968, S. 287f. 
Café getroffen hatten ${ }^{294}$. Doriot plante die »Fraternisierung« mit Abdelkrim. Im Jahr zuvor hatte die Komintern auf ihrem vom 17. Juni bis zum 8. Juli 1924 andauernden V. Kongreß ein neues Programm beschlossen, das die Selbstbestimmung der Nationen, die Befreiung der Kolonien und die Hilfe für alle kolonialen Bewegungen gegen den Imperialismus in den Vordergrund der Aktivitäten stellte ${ }^{295}$.

Die erst 1921 gegründete Kommunistische Partei Spaniens (Partido comunista español) befand sich noch in der Aufbauphase, weswegen sich ihre politischen Aktionen in Bezug auf Marokko auf ein Minimum beschränkten ${ }^{296}$. Die Kommunistische Partei Deutschlands profilierte sich lediglich als Fürsprecher von Deutschen in der spanischen Fremdenlegion und schloß sich weitestgehend der PCF-Kampagne $a^{297}$. Zwischen moslemischen Studenten-

${ }^{294}$ André BERTHON, Abd el Krim et Poincaré, in: Humanité, 12.5.1925; SLAVIN, Anticolonialism, S. 92; ADMAE Maroc 111, 1: Bericht »Renseignements donnés par El Hadj Hitmi«, 22.6.1926.

${ }^{295}$ Mohieddine HADHRI, L'URSS et le Maghreb. De la révolution d'octobre à l'indépendance de l'Algérie 1917-1962, Paris 1985, S. 36; DERS., Nationalisme et anti-impérialisme. La place du Maghreb dans la stratégie soviétique au cours des années vingts, in: Cahiers de Tunisie 29 (1981) S. 307-334, S. 313; David H. SLAVIN, The French Left and the Rif War 1924-1925. Racism and the Limits of Internationalism, in: Journal of Contemporary History 26 (1991) S. 5-32, S. 9; Robert WOHL, French Communism in the Making 1914-1924, Stanford 1966, S. 408f.; CREMAdEILlS, Le Parti communiste français, Bd. 1, S. 75; GiorGIMignot, Les milieux, S. 255; Demetrio BOERSNER, The Bolsheviks and the National and Colonial Question 1917-1928, Genf 1957 (Etudes d'histoire économique, politique et sociale, 20), S. 150, S. 179f.; Jean-Pierre BIONDL, Les anti-colonialistes 1881-1962, Paris 1992, S. 121; La discussion sur la tactique des partis communistes dans la question nationale et coloniale, in: Humanité, 6.7.1924. Ein direkter Kontakt der Komintern zu Abdelkrim ist unwahrscheinlich [CREMAdeILLS, Le Parti communiste français, Bd. 1, S. 102; FremEAUX, La France, S. 165; SLAvIN, Anticolonialism, S. 137]. Dies im russischen Archiv fur sozialpolitische Geschichte in Moskau, wo die Akten der Kommunistischen Internationale gelagert sind, eingehender zu erforschen, hätte den Rahmen dieser Arbeit gesprengt.

${ }^{296}$ MADARIAGA, Le Parti socialiste espagnol, S. 343, Anm. 78, S. 344f;; Gerald H. MEAKER, The Revolutionary Left in Spain 1914-1923, Stanford 1974, S. 437f.; Yveline RIOTTOT, Joaquín Maurin. De l'anarcho-syndicalisme au communisme 1919-1936, Paris u.a. 1997, S. 84; Antonio ELORZA, Marta BIZCARRONDO, Queridos camaradas. La Internacional comunista y España 1919-1939, Barcelona 1999, S. 27f., S. 33f.; Die Spanische KP gegen den marokkanischen Krieg, in: Rote Fahne, 15.8.1921; Les communistes espagnols contre la guerre, in: Humanité, 8.8.1921; Le prolétariat révolutionnaire espagnol et le soulèvement au Maroc, in: Humanité, 16.9.1924; Les Communistes espagnols et la guerre marocaine, in: Humanité, 15.7.1925; Die KP Spaniens schlägt die Einheitsfront gegen den Krieg in Marokko vor, in: INPREKORR 5 (1925) S. 1310.

${ }^{297}$ AN F7, 13413: MI, Sûreté géntrale, Bericht »Extraits des comptes rendus journaliers de l'armŁe du Rhin«, 18.7.1925; Gruß der pommerschen Jungkommunisten an die französischen Kammerdelegierten, in: INPREKORR 5 (1925) S. 1246; Die Konferenz der Kommunistischen Jugendverbände Europas an die kommunistische Jugend Frankreichs, in: INPREKORR 5 (1925) S. 1598; Die kommunistischen Jugendverbände Europas und das EKKJ an die arbeitende Jugend, in: INPREKORR 5 (1925) S. 1704f.; Imperialistenkrieg gegen das freie Rifvolk, in: Rote Fahne, 17.5.1925; Heldenhafter Freiheitskampf der Rifkabylen, 
bzw. Exilorganisationen und Kommunisten bestand aufgrund des gemeinsamen Kampfes gegen die koloniale Unterdrückung vor allem in Berlin ein enger Kontakt ${ }^{298}$.

Auf der ersten Sitzung des in Paris errichteten Internationalen Kolonialbüros und des Kolonialausschusses der Kommunistischen Partei Frankreichs wurde am 10. September 1924 beschlossen, in Bezug auf den Marokkokrieg tätig zu werden ${ }^{299}$. Schon einen Tag später gab es in Paris einen bewußt provozierten Skandal, als die kommunistische Zeitung "Humanité ein Telegramm von Parteiführer Pierre Sémard und von Jacques Doriot im Namen der Jeunes communistes abdruckte, in dem sie Abdelkrim zu seinem Erfolg gegen Spanien (Sieg im Westen der spanischen Einflußzone) beglückwünschten ${ }^{300}$. Zwei Gesandte namens Lacoste und Couture wurden im Herbst 1924 nach Ajdir geschickt $^{301}$. Der deutsche Militärberater Abdelkrims Josef Klems, der sie beherbergte, war sich sicher, daß sie Geld übergaben. Doch Abdelkrims Verhältnis zu ihnen und zum Kommunismus allgemein blieb distanziert, da er eine Vereinbarkeit mit dem Islam ausschlo $B^{302}$.

in: Rote Fahne, 21.5.1925; Nieder mit dem räuberischen Marokkofeldzug, in: Rote Fahne, 29.5.1925; Genosse Doriot gegen den Marokkofeldzug, in: Rote Fahne, 30.5.1925; Marokkokrieg und revolutionäre Bewegung, in: Rote Fahne, 14.6.1925; Heldenkampf der Rifkabylen, in: Rote Fahne, 27.9.1925.

${ }^{298}$ Mustafa HAIKAL, Für eine Internationale der Völker. Zur Tätigkeit arabischer Antikolonialisten in der "Liga gegen Imperialismus und für nationale Unabhängigkeit», in: Asien, Afrika, Lateinamerika 18 (1990) S. 846-856, S. 846f.; Juliette BESSIS, Chekib Arslan et les mouvements nationalistes au Maghreb, in: Revue historique 259 (1978) S. 467-489, S. 471.

${ }^{299}$ John CallaghaN, Rajani Palme Dutt. A Study in British Stalinism, London 1993, S. 59f.; Mustafa HAIKAL, Das Internationale Kolonialbüro der Komintern in Paris, in: Jahrbuch für historische Kommunismusforschung 1 (1993) S. 126-130, S. 126-128.

${ }^{300}$ Roland GAUCHER, Histoire secrete du Parti communiste français 1920-1974, Paris 1974, S. 123f.; Jean-Paul BRUNeT, Jacques Doriot. Du communisme au fascisme, Paris 1986 , S. 54; Nicole LE GUENNEC, Le Parti communiste français et la Guerre du Rif, in: Le mouvement social 78-81 (1972) S. 39-64, S. 41; JEDERMANN, La sbolchévisation " du Parti communiste français, Paris 1971, S. 89; SLAVIN, Anticolonialism, S. 78; Dieter WoLF, Die Doriot-Bewegung. Ein Beitrag zur Geschichte des französischen Faschismus, Stuttgart 1967 (Quellen und Darstellungen zur Zeitgeschichte, 15), S. 33f., BIONDI, Les anti-colonialistes, S. 119; Edward MorTIMER, The Rise of the French Communist Party 1920-1947, London, Boston 1984, S. 154; FremeauX, La France, S. 165; Jacques FaUVET, Histoire du Parti communiste français de 1920 à 1976, Paris 1977, S. 61; Le Parti communiste français unanime félicite Abd-el-Krim pour ses succès, in: Humanité, 11.9.1924; Communists in France, in: Times, 10.12.1924.

${ }^{301}$ OVED, La gauche française, Bd. 1, S. 294; SHEEAN, My Meeting, S. 848.

${ }^{302}$ PRO-FO 371, 11077, 39, 103: Robert Gordon-Canning an FO, 9.2.1925 mit einer beiliegenden Erklärung Si M'hammeds, 28.1.1925; RUE, Riff Warriors, 25.6.1925; CADN Maroc DAI 199: EMA, $2^{e}$ bureau, 6.7.1926 mit dem beiliegenden Bericht "Note sur les renseignements foumis par le légionnaire Klems« 0.D.; SHAT 12J3797, 28: Vernehmung von Josef Klems vor dem 2. Kriegsgericht Meknes, 19.6.1926. 
Nach dem Angriff der Rifkabylen auf Französisch-Marokko wurde das Comité central d'action contre la guerre au Maroc unter der Leitung von Maurice Thorez gegründet ${ }^{303}$, dessen Propaganda gegen den Rifkrieg unter den Schlagworten "Sofortiger Frieden mit dem Rif - Sofortige Evakuierung Marokkos - Verbrüderung der französischen Soldaten mit den Rifkabylen« geführt wur$\mathrm{de}^{304}$. Zu einer kommunistischen Versammlung gegen den Rifkrieg im Pariser Luna-Park kamen am 16. Mai 1925 rund 15000 PCF-Anhänger ${ }^{305}$. In Artikeln der Parteizeitung »Humanité« herrschte ein regelrechter "Abdelkrimismus« vor. Sie hoben die wnationale« Befreiungsbewegung der Rifkabylen, die Modernität der »Rif-Republik« und den revolutionären Kampf gegen den Imperialismus hervor ${ }^{306}$. Auch die Pariser Surrealisten um André Breton und Louis Aragon stimmten mit einer in der »Humanité« veröffentlichten Erklärung in die Kampagne mit ein ${ }^{307}$. Im Gegensatz dazu erklärte die sonstige französische Presse den Rifkrieg zumeist zu einer Prestigefrage für Frankreich ${ }^{308}$, oder sie unterlag in Französisch-Marokko einer rigiden Zensur durch Marschall Lyautey ${ }^{309}$.

${ }^{303}$ BIONDI, Les anti-colonialistes, S. 136; LE GUENNEC, Le Parti communiste, S. 42; SLAVIN, The French Left, S. 17f.; FAUVET, Histoire, S. 61f.; CremadeILIS, Le Parti communiste français, Bd. 1, S. 115-127; Philippe ROBRIEUX, Maurice Thorez. Vie secrète et vie publique, Paris 1975, S. 90-92; Stéphane COURTOIS, Marc LAZAR, Histoire du Parti communiste français, Paris 1995, S. 93.

${ }^{304}$ MONETA, Die Kolonialpolitik, Text 7, S. 42f.; Hoover Institution Archives, Stanford: Henri BARBE, Souvenirs, Ms. o.O., ca. 1950, S. 81; Gegen den Krieg in Marokko. Aufruf des ZK der KP Frankreichs an die Arbeiter und Bauern Frankreichs und der Kolonien, in: INPREKORR 5 (1925) S. 1146f.; Gegen den Krieg in Marokko. Nieder mit dem imperialistischen Krieg in Marokko, in: INPREKORR 5 (1925) S. 1264f.; Gegen den Krieg in Marokko. Erzwingen wir den Frieden! Verbrüdern wir uns, in: INPREKORR 5 (1925) S. 1357; Gegen den Krieg in Marokko. Manifest des Pariser Arbeiterkongresses, in: INPREKORR 5 (1925) S. 1516f.; Aux ouvriers et aux paysans de France et des colonies, in: Humanité, 14.5.1925; À bas la guerre du Maroc! Faites la paix immédiate avec le Riff, in: Humanité, 23.5.1925; À bas la guerre du Maroc! Un appel du comité exécutif de l'Internationale communiste, in: Humanité, 19.6.1925.

${ }^{305}$ Plus de quinze mille travailleurs condamnent la Guerre du Rif, in: Humanité, 17.5.1925; SLAVIN, The French Left, S. 13, BoutbouQALT, La Guerre du Rif, S. 76-80.

${ }^{306}$ René GALLISSOT, Le parti communiste et la Guerre du Rif, in: Abd el-Krim et la Republique du Rif, S. 237-261, S. 251; SLAVIN, The French Left, S. 16; OVED, La gauche française, Bd. 1, S. 208.

${ }^{307}$ Les travailleurs intellectuels aux côtés du prolétariat contre la guerre du Maroc, in: Humanité, 2.7.1925; Mark PolizzotT, Revolution des Geistes. Das Leben André Bretons, München, Wien 1996, S. 343-349; Jack J. SPECTOR, Surrealist Art and Writing 1919-1939. The Gold of Time, Cambridge u.a. 1997, S. 74f.; Maurice NADEAU, Geschichte des Surrealismus, Reinbek 1997, S. 95-105; Pierre DAIX, Aragon. Une vie à changer, Paris 1975, S. 171175 .

${ }^{308}$ AGERON, La presse parisienne, S. 7-16.

${ }^{309}$ Jamaâ BAÏDA, La presse marocaine d'expression française. Des origines à 1956, Rabat 1996, S. 121-123. 
Auf dem Pariser Kongreß des Comité central d'action contre la guerre au Maroc vom 4. bis zum 5. Juli 1925, an dem 2500 Delegierte teilnahmen, wurde beschlossen, eine Delegation nach Marokko zu entsenden: Jacques Doriot, Henri Barbé, Lucienne Maranne, François Joseph Albert und Paul Landrue. Ihr Ziel war, Propaganda für einen sofortigen Friedensschluß zu betreiben, mit lokalen Nationalbewegungen in Algerien Verbindung aufzunehmen und Abdelkrim die Solidarität der französischen Arbeiterklasse zu bekunden. Obwohl sie, als sie Ende August 1925 im algerischen Oran an Land gingen, sofort von den dortigen Sicherheitskräften erkannt und observiert wurden, gelang es Doriot, heimlich nach Port-Say zu Daniel Bourmancé-Say zu gelangen ${ }^{310}$.

Doriot sah in Bourmancé-Say einen Mittelsmann, um ins Rif zu gelangen, aber warum half dieser einem Kommunisten? Da die französische Regierung und die Generalresidenz in Rabat nicht auf seiner Seite waren, suchte Bourmancé-Say neue Verbündete. Doriot forderte, was auch er gerne im Sinne seiner erhofften Allianz zwischen Franzosen und Rifkabylen gesehen hätte, nämlich Friedensverhandlungen. Bourmancé-Say ärgerte sich zudem über englische 'Machenschaften (zwischen Tanger und dem Rif. Er meinte damit insbesondere den Tangerer "Times«-Korrespondenten Walter Harris, der über sehr gute Kontakte zu Abdelkrim verfügte. Insofern ist anzunehmen, daß mit Britenhaß vermengte Rachsucht ihren Teil dazu beigetragen hat, daß es zu Bourmancé-Says Liaison mit den französischen Kommunisten kam.

Sie währte kurz. Bourmancé-Say bat den Kontrollbeamten von Taourirt Léon Gabrielli, in der Generalresidenz von Rabat einen Passierschein für seinen Gast zu erwirken. Gabrielli freute sich schon darauf, daß ein Besuch im Rif Doriot desillusionieren würde, aber Lyautey erteilte keine Erlaubnis. Daher telegrafierte Gabrielli das vereinbarte Losungswort nach Port-Say, daß „das Päckchen wieder zurückgeschickt« werden müsse ${ }^{311}$. Doriot kehrte nach Frankreich zurück, ohne einen Fuß ins Rif gesetzt zu haben. Nach seiner mißglückten Rolle als Vermittler zwischen Abdelkrim und Jacques Doriot wurde es still um Daniel Bourmancé-Say.

Ein für den 12. Oktober 1925 von den französischen Kommunisten angesetzter Generalstreik mobilisierte landesweit nur rund 400000 Menschen, die gegen den Rifkrieg protestieren wollten. Nach diesem Mißerfolg kam die

${ }^{310}$ BARBÉ, Souvenirs, S. 82f., S. 87f,; BIONDI, Les anti-colonialistes, S. 119; WOHL, French Communism, S. 409; Sean MCMEEkn, From Moscow to Vichy. Three Working-Class Militants and the French Communist Party 1920-1940, in: Contemporary European History 9 (2000) S. 1-38, S. 16, Anm. 48; BRUNET, Jacques Doriot, S. 9; OVED, La gauche française, Bd. 1, S. 290, S. 456, Anm. 30; Wolf, Die Doriot-Bewegung, S. 40; GAUCHER, Histoire, S. 126f.; SLAVIN, Anticolonialism, S. 272-275.

${ }^{311}$ GaBRIELLI, Abd-el-Krim, S. 10-12; DAOUD, Abdelkrim, S. 277; ADMAE Maroc 133, 6: Gouverneur général de l'Algérie an MAE, 19.9.1925; AN 313 AP 245: Gouverneur général de l'Algérie an EMA, 2.11.1925 
PCF-Kampagne bis auf wenige Ausnahmen praktisch zum Erliegen ${ }^{312}$. Sie war ein völliger Fehlschlag. Es kam nur zu vereinzelten >Verbrüderungsaktionen<, und selbst die Grundidee einer Zusammenarbeit mit den moslemischen Rifkabylen hatte nie die Chance einer Verwirklichung. Letztendlich diente die Kampagne gegen den Rifkrieg mehr dem Selbstzweck, in Frankreich mehr Anhänger zu gewinnen ${ }^{313}$.

Nach seinem Ausschluß aus der kommunistischen Partei im Jahre 1934 gründete Doriot eine faschistische Gruppierung (Parti populaire français). Mit der Légion tricolore kämpfte er während des Zweiten Weltkrieges auf der Seite der Wehrmacht gegen die Sowjetunion. Am 22. Februar 1945 kam er bei einem Luftangriff in Sigmaringen ums Leben ${ }^{314}$.

\subsection{Abdelkrim und John Arnalls Bergbaupläne}

Was Daniel Bourmancé-Say und Horacio Echevarrieta anfangs nicht ahnten, war, daß Abdelkrim 1921 bis 1922 gleichzeitig zu seinen Avancen in Richtung Frankreich und Spanien versuchte, politische und wirtschaftliche Kontakte nach Großbritannien herzustellen.

Den ersten Versuch einer diplomatischen Kontaktaufnahme zwischen dem Rif und Großbritannien hatte es bereits im 19. Jahrhundert gegeben. Nachdem Rifpiraten mehrmals britische Schiffe an der Küste geentert hatten, begab sich im Jahre 1856 der perfekt Arabisch sprechende Generalkonsul von Tanger,

${ }^{312}$ BIONDI, Les anti-colonialistes, S. 120, S. 139; GALLISSOT, Le parti communiste, S. 246; Ronald TIERSKY, French Communism 1920-1972, New York, London 1974, S. 43, JEDERMANN, La »bolchévisation«, S. 91; LE GUENNEC, Le parti communiste, S. 53; Mohammed KHARCHICH, Left Wing Politics in Lyon and the Rif War, in: Joumal of North African Studies 2 (1997) S. 34-45, S. 44; MORTMER, The Rise, S. 156; Jacques DucLOS, Mémoires 1896-1934. Le chemin que j'ai choisi. De Verdun au parti communiste, Paris 1968, S. 241; Robert CHARVIN, Le parti communiste français face à la Guerre du Rif, in: Abd el-Krim et la République du Rif, S. 218-236, S. 227; SLAVIN, The French Lef, S. 25; CoURTOIS, LAZAR, Histoire, S. 93; Scott NEARING, Stopping a War. The Fight of French Workers Against the Moroccan Campaign of 1925, New York 1926; Gegen den Krieg in Marokko. Vorbereitung eines 24stündigen allgemeinen Demonstrationsstreiks in Frankreich, in: INPREKORR 5 (1925) S. 2013f.; Generalstreik gegen den Marokkokrieg, in: Rote Fahne, 11.10.1925; Der Einspruchsaufstand der Kommunisten, in: Kölnische Zeitung, 13.10.1925; PA-AA R70934: Botschaft Paris an AA, 14.10.1925.

${ }^{313}$ SLAVIN, The French Left, S. 15, S. 27; OVED, La gauche française, Bd. 1, S. 288, S. 295.

${ }^{314}$ BROUE, Histoire, S. 990; MONETA, Die Kolonialpolitik, S. $287 \mathrm{f}$. 
John Drummond Hay, zu Verhandlungen ins Rif. Er erreichte, daß die Angriffe aufhörten. Er hatte derartigen Eindruck gemacht, daß einige Rifkabylen während der 1860er Jahre - wenngleich vergeblich - darauf hofften, unter britischen Schutz gestellt zu werden ${ }^{315}$.

Ihr nächster politischer Vermittler nach Großbritannien wurde John Arnall $^{316}$. Seine sozialistische Ideale vertretende politische Karriere begann 1891 während des Streiks der Zimmermänner. Er war ein Schüler und Anhänger von John Elliott Burns, einem der führenden Köpfe in der Anfangszeit der Independent Labour Party (ILP) zwischen 1892 und 1895, bevor dieser der Liberal Party beitrat ${ }^{317}$. Die ILP galt als wichtigster Ideenpool für die größere Labour Party, entfernte sich jedoch während des Ersten Weltkrieges und nach dessen Ende durch ihre pazifistischen und anti-imperialistischen Ideale mehr und mehr von der Mutterpartei ${ }^{318}$.

1918 übernahm Arnall die Geschäftsführung des ILP-Distrikts Nord-London. Er wurde der Nachfolger von Herbert Bryan - einem späteren Mitglied des von Robert Gordon-Canning ins Leben gerufenen Londoner Riff-Committees $^{319}$. Arnall gehörte als Geschäftsführer der englischen Sektion der Workers Welfare League of India (WWLI) an, die seine Freunde Arthur Field von der ILP und Charles Foster Ryder 1917 mit dem Ziel gegründet hatten, die Gewerkschaftsbewegung in Indien zu unterstützen. Der spätere kommunistische Parlamentsabgeordnete Shapurji Saklatvala, ein enger Vertrauter Arnalls und

${ }^{315}$ Francis R. FLoURNOY, British Policy towards Morocco in the Age of Palmerston 18301865, Westport 1970 (Nachdr. d. Ausg. London 1935), S. 40, S. 45, S. 122-124, S. 153-165; VAIDON, Tangier, S. 67; Ronald BAILEY, Anglo-Moroccan Relations to 1900. A Short History, in: Maghreb Review 16 (1991) S. 200-239, S. 217 f.

${ }^{316}$ Maria-Rosa de Madariaga setzt den Beginn der Aktivitäten John Arnalls zu spät an - nämlich erst 1921 [MADARIAGA, España y el Rif, S. 529; vgl. DAOUD, Abdelkrim, S. 160162 (sie tauft Amall in »Aznell« um)]. Germain Ayache geht nicht auf die Bergbauinteressen Arnalls ein und beginnt mit der Beschreibung seiner Aktivitäten erst ab dem Jahr 1922 [AYACHE, La Guerre du Rif, S. 244-247].

${ }_{317}$ TNLA, RD, 1, Deakin: Walter Harris an Ralph Deakin, 7.6.1922; Chris CoOK, Sources in British Political History 1900-1951, Bd. 3, London 1977, S. 70; AYACHE, La Guerre du Rif, S. 246; DAOUD, Abdelkrim, S. 13.

${ }^{318}$ Henry R. WNKKLER, The Emergence of a Labor Foreign Policy in Great Britain 19181929, in: Journal of Modern History 28 (1956) S. 247-258, S. 251f.; Gerhard A. RITTER, Friedensbewegung in Großbritannien 1914-1918/19. Die Union of Democratic Control und ihr Kampf um eine gerechte Friedensordnung, in: Archiv für Sozialgeschichte 22 (1982) S. 403-471, S. 418; Keith LAYBOURN, Recent Writing on the History of the ILP 1893-1932, in: DerS., David James, Tony JowITT $(\mathrm{Hg}$.), The Centennial History of the Independent Labour Party. A Collection of Essays, Halifax 1992, S. 317-336, S. 317.

${ }^{319}$ PRO-FO 371, 3253, 125283: DOT an FO, 18.7.1918 mit dem beigefügten Brief John Arnall an DOT, 12.6.1918 (Briefkopf); Marvin SWARTZ, The Union of Democratic Control in British Politics during the First World War, Oxford 1971, S. 89-91. 
Fields, war Geschäftsfiuhrer der indischen Sektion der WWLI ${ }^{320}$. Auch Field und Ryder arbeiteten ab 1925 im Riff-Committee mit. Saklatvala leitete den mit Abdelkrim sympathisierenden East-West Circle $^{321}$.

1918 erhielt Arnall »aufgrund von Äußerungen, die die Beziehungen zwischen Großbritannien und seinen Alliierten gefährden könnten«, eine dreimonatige Gefängnisstrafe ${ }^{322}$. Trotzdem kandidierte er im Dezember 1918 als Labour-Kandidat für den Londoner Bezirk Islington North, aber er verlor klar gegen seinen konservativen Kontrahenten Sir Newton Moore ${ }^{323}$.

Das wirtschaftliche Interesse des Briten am Rifgebiet reichte zurück bis in das Jahr 1913. Arnall, der zu dieser Zeit ein Fotostudio in Marseille führte, hatte zuvor als Geschäftspartner des Iren James Conolly Nordafrika bereist und auch in der Türkei Bergbauerkundungen durchgeführt. Nun kam er mit Si Abdelkrim ben el Haj Ali Luh (Kurzform: Ali Luh) in Kontakt. Anfang des 20. Jahrhunderts war Ali Luh mit seiner Familie aus dem Beqqioua-Gebiet im Rif nach Algerien ausgewandert, wo er sich auch in Port-Say aufgehalten hatte $^{324}$. Er war der Schwager von Raïs Messaoud Amar alias Sibbera, dem späteren Marineminister der »Rif-Republik«. Während des Rifkrieges spielte er als Kontaktmann Abdelkrims in Tanger eine wichtige Rolle ${ }^{325}$.

1913 machte sich Ali Luh auf den Weg nach Paris, um dort Eisenerzproben aus dem Rif analysieren zu lassen. John Arnall witterte ein Geschäft und schickte ihn zurück nach Marokko, um die Besitztitel zu beschaffen ${ }^{326}$. Er selbst fuhr Anfang 1914 nach London und versuchte vergebens, das britische Außenministerium für die Bergbaufelder Nordmarokkos zu begeistern ${ }^{327}$. Daraufhin bat er den liberalen Parlamentsabgeordneten John Ward, den er aus Kindheitstagen kannte ${ }^{328}$, um Hilfe. Ward hatte zunächst als Land-, Kanalund Bauarbeiter gewirkt und nach einem abenteuerlichen Intermezzo im Sudan (1885) und nach dem Beitritt zur Social Democratic Federation - dem Vorgänger der Labour Party - im Jahre 1889 die Gewerkschaft für Erdarbeiter

${ }^{320}$ Sehri SaKLatvala, The Fifth Commandment. A Biography of Shapurji Saklatvala, Kalkutta 1996, S. 77, S. 79f.

${ }^{321}$ Siehe zum East-West Circle und zum Riff-Committee S. 325-333.

${ }^{322}$ PRO-FO 372, 1407, 7277, 104: WO an FO, 24.6.1920; A Park Speaker's Offence. Unsuccessful Appeal, in: Times, 16.7.1918; PENNELL, A Country, S. 51, S. 55.

${ }^{323}$ General Election, 1918. The Candidates, in: Times, 9.12.1918; General Election, 1918. The Polls, in: Times, 30.12.1918; Local Notes, in: Al-Moghreb al Aksa \& Tangier Gazette, 10.5.1919; MADARIAGA, L'Espagne et le Rif, Bd. 2, S. 201.

${ }^{324}$ CAOM Algérie 9H93: Chef d'annexe de Marnia an Général commandant de la division d'Oran, 16.2.1922.

${ }^{325}$ PENNELL, A Country, S. 55; GHIRELLI, Monografia, S. 81f.; SHAT 3H1557: Territoire de Taza, SR, Bericht »Renseignements de Tanger«, 10.9.1924.

${ }^{326}$ PRO-FO 371, 2713, 79156, 92736: John Arnall an FO, 16.5.1916.

${ }^{327}$ PRO-FO 371, 2044, 2134 und 6114: John Arnall an FO, 9.1.1914 und FO an John Arnall, 16.2.1914.

${ }^{328}$ PRO-FO 371, 4533, 6333, 83: CG Tangier an FO, 20.8.1920. 
gegründet. Seit 1906 saß er für Stole-on-Trent im britischen Parlament ${ }^{329}$. Doch auch Wards Interventionsversuche änderten die neutrale Grundhaitung des britischen Außenministeriums bei marokkanischen Angelegenheiten nicht, zumal 1912 das französische Protektorat und die spanische Einflußzone Marokkos - mit britischer Absegnung - gebildet worden waren ${ }^{330}$.

John Arnall und Ali Luh, der mittlerweile in Großbritannien eingetroffen war, trafen sich am 8. März 1914 mit John Dixon Kendall, einem Bergbauingenieur der Olga Iron Ore Company aus Glasgow. Sie vereinbarten die Inspektion von Gebieten der Temsamane, Beni Oulichek und Beqqioua, wo größtenteils Eisenerz vermutet wurde. Das britische Außenministerium warnte die Olga Iron Ore Company davor, daß es für das Rif eine ganze Reihe konkurrierender Ansprüche gebe ${ }^{331}$.

Anfang Mai 1914 erreichte Kendall Tanger und suchte die dortige britische Vertretung auf. Generalkonsul Sir Herbert E. White zweifelte die Vertrauenswürdigkeit von Ali Luh an und riet davon ab, Landstriche zu erwerben, bevor ein genaues Bild erstellt worden sei. Whites Informant war der Tangerer »Times «-Korrespondent Walter B. Harris. Er war der Repräsentant der neunprozentigen englischen Aktionärsgruppe innerhalb der Union des mines marocaines, die ebenfalls an Landerwerb in Nordmarokko interessiert war und offensichtlich die schottische Konkurrenz ausbooten wollte. Als Harris in der "Times« über angebliche bürgerkriegsähnliche Zustände im Rif berichtete, rief die Olga Iron Ore Company John Kendall am 20. Mai 1914 zurück $^{332}$.

Ihr Repräsentant für Marokko blieb John Arnall. Ende Juni 1914 schaffte er es, in der Bucht von Alhucemas Verhandlungen mit den umliegenden Kabylen-Anführern einzuleiten. Ob Abdelkrims Vater daran teilnahm, ist nicht überliefert, aber anzunehmen. Die Versammlung - so berichtete John Arnall später - habe beschlossen, angesichts der Unfähigkeit Spaniens, dem Rif Fortschritt zu bringen, lieber mit Großbritannien zu paktieren. Als Pfand für die Zusage friedlicher wirtschaftlicher Beziehungen sollten die Söhne des Landes nach England geschickt werden. Nachdem er Anfang Juli 1914 wieder mit Ali

${ }^{329}$ COOK, Sources, Bd. 4, S. 223; STENTON, LEES, Who's Who, Bd. 3, S. 366; Richard M. CONNAughton, The Republic of the Ushakovka. Admiral Kolchak and the Allied Intervention in Siberia 1918-1920, London, New York 1990, S. 59; David HowELL, British Workers and the Independent Labour Party 1888-1906, Manchester 1983, S. 122; Obituary, Lieut.-Colonel John Ward. A Leader in Peace and War, in: Times, 20.12.1934.

${ }^{330}$ PRO-FO 371, 2044, 2134, 12435: John Ward an FO, 20.3.1914; PRO-FO 371, 2044, 2134, 14483: John Ward an FO, 30.3.1914; PRO-FO 371, 2044, 2134, 9305: Bericht »Parliamentary Question«, 26.2.1914; PRO-FO 371, 2049, 32634, 183: Bericht »Parliamentary Question«, 15.7.1914.

${ }^{331}$ PRO-FO 371, 2044, 2134, 10674: FO an Olga Iron Ore Company, 16.3.1914.

332 PRO-FO 371, 2713, 79156, 92736: John Arnall an FO, 16.5.1916; PRO-FO 371, 2044, 2134, 22814: CG Tangier an FO, 13.5.1914. 
Luh in London eingetroffen war, wollte sich John Arnall im Außenministerium nach geeigneten Erziehungsanstalten erkundigen, doch die britischen Diplomaten blockten diese Initiative sogleich $\mathrm{ab}^{333}$.

Nach dem Ausbruch des Ersten Weltkrieges kehrte Ali Luh nach Marokko zurück, um die erworbenen Ländereien zu beaufsichtigen. Als er im Mai 1915 im algerischen Oran wegen fehlender Papiere verhaftet wurde, hielt die Olga Iron Ore Company an ihm fest. Die Glasgower baten das britische Außenministerium, bei Ali Luhs Freilassung mitzuwirken, indem sie auf seine Bedeutung für die britische Stahlindustrie, die er als einer der wenigen Kenner der Eisenerzvorkommen besitze, hinwiesen. Die britische Regierung blieb jedoch weiter untätig ${ }^{334}$. Dies sollte daher das letzte Engagement der schottischen Bergbaugesellschaft für Marokko bleiben. Erst im Januar 1916 kam Ali Luh wieder frei ${ }^{335}$.

John Arnall gab wenig später sein Fotostudio in Marseille auf und kehrte am 9. März 1916 nach London zurück ${ }^{336}$. Schon bald startete er neue Initiativen bei der englischen Regierung. Diesmal hob er die kriegswirtschaftliche Notwendigkeit der Riferze für Großbritannien hervor. Ende April 1916 schlug Amall vor, eine Expedition ins Rif zu leiten, um französischen Interessen zuvorzukommen. Dies sollte die Hauptantriebsfeder in Arnalls Tun überhaupt werden. Er meinte, Großbritannien müsse sich die Bergbaurechte in Nordmarokko sichern, um dem sich ausbreitenden Einfluß Frankreichs zu begegnen ${ }^{337}$. Kriegsminister David Lloyd George bewertete die Vorschläge als unwichtig. Genauso im Sande verliefen Arnalls Vorstöße im Handels- und im Außenministerium. Großbritanniens Gegner im Ersten Weltkrieg waren die Mittelmächte, nicht Frankreich ${ }^{338}$.

Ein Jahr lang lagen Arnalls Bergbaupläne auf Eis. Dann, am 8. Juni 1917, erhielt das britische Handelsministerium einen Brief vom Bergbaufachmann Arnold Lupton. Er kannte Arnall über seinen liberalen Parteigenossen John Burns und über W.M. Crook von der Home Counties Liberal Federation ${ }^{339}$. Lupton und Arnall engagierten sich zudem beide in der Society for Studying

${ }^{333}$ PRO-FO 371, 2049, 32211, 173: John Arnall an FO, 15.7.1914; PRO-FO 371, 2049, 32211, 176: FO an John Arnall, 18.7.1914; PRO-FO 371, 2049, 34872, 350: CG Tangier an FO, 31.7.1914.

${ }^{334}$ PRO-FO 371, 2415, 156537: Olga Iron Ore Company an FO, 22.10.1915.

${ }^{335}$ PRO-FO 371, 2713, 79156, 92736: John Arnall an FO, 16.5.1916.

${ }^{336}$ PRO-FO 372, 1407, 7277, 104: WO an FO, 24.6.1920.

${ }^{337}$ PRO-FO 371, 2713, 79156: Ministry of Munitions of War an FO, 26.4.1916.

${ }^{338}$ PRO-FO 371, 2713, 79156, 83594: John Arnall an FO, 2.5.1916; PRO-FO 371, 2713, 79156, 87748: John Arnall an FO, 9.5.1916; PRO-FO 371, 2713, 79156, 92736: John Arnall an FO, 16.5.1916.

${ }_{339}^{33}$ PRO-FO 371, 2415, 114826: John Arnall an FO, 9.7.1915; PRO-FO 371, 7082, 8256, 159: W.M. Crook an FO, 28.7.1921; General Election, 1918. The Candidates, in: Times, 9.12.1918; COOK, Sources, Bd. 3, S. 70. 
Oriental Races ${ }^{340}$. Lupton bat für eine selbstfinanzierte Bergbauexpedition ins Rif um Unterstützung. Er verdeutlichte, daß ihn hauptsächlich geschäftliche Interessen antreiben würden, aber er mahnte auch, daß sich Großbritannien die Eisenerzvorkommen in Nordmarokko rechtzeitig sichern müsse ${ }^{341}$. Wie Lupton in einem weiteren Brief mitteilte, sollten der Expedition der Bergbauingenieur Major W. Waterhouse, der Erzexperte von der Royal School of Mines, Herbert Gladstone Smith ${ }^{342}$, und John Arnall angehören. Arnalls Mitwirkung hatte man im Außenministerium bereits befürchtet. Eine Zusammenarbeit war ausgeschlossen $^{343}$. Luptons Drängen auf eine schnelle Entscheidung wurde daher mit der - vorgeschobenen - Begründung abgewiesen, daß die spanischen Behörden eine Expedition ins Rif unter keinen Umständen erlauben würden ${ }^{344}$. Lupton gab zunächst auf.

Nach dem Ende des Ersten Weltkrieges beschloß John Arnall, daß er für seine Geschäfte den Standort wechseln mußte. Am 28. August 1919 erreichte er Tanger, um sich dort als Fotograf niederzulassen ${ }^{345}$. Unmittelbar nach seiner Ankunft gründete er zusätzlich die Firma The British Riff Company ${ }^{346}$. Als frischgebackenes Mitglied der britischen Handelskammer für Marokko handelte er mit Nutzholz aus dem Rif. In der Bucht von Alhucemas gehörten ihm Teile eines Zedernwaldes ${ }^{347}$. Als weitere Produkte vertrieb er Holzkohle und Naturerzeugnisse wie Eier, Bienenwachs, Leder, Mandeln, Honig und Tabak $^{348}$. Ferner war er an vermeintlichen Erdölvorkommen in der Tangerregion bei Charf el Akab und im Rif interessiert ${ }^{349}$.

${ }^{340}$ The Riff Committee, in: The Patriot 10 (1926) S. 120f., S. 121.

341 PRO-FO 368, 1766, 120316: Arnold Lupton an BT, 8.6.1917.

342 Der Verfasser des Standardwerks $\gg$ Minerals and the Microscope. An Introduction to the Study of Petrology, London 1914 «.

${ }^{343}$ PRO-FO 368, 1766, 120316, 129490: Arnold Lupton an FO, 29.6.1917; PRO-FO 368, 1766, 120316, 129490: Minute, 7.7.1917.

${ }^{344}$ PRO-FO 368, 1766, 120316, 132284: Annold Lupton an FO, 3.7.1917; PRO-FO 368, 1766, 120316, 129490: FO an Arnold Lupton, 11.7.1917.

${ }^{345}$ PRO-FO 371, 3844, 93449: CO an FO, 2.9 .1919 mit dem beigefügten Brief Governor of Gibraltar an CO, 20.8.1919; PRO-FO 371, 3844, 93449: John Arnall an Passport Office, 16.6.1919; PRO-FO 371, 3844, 93449: CG Tangier an FO, 22.9.1919; PRO-FO 372, 1407, 7277, 104: WO an FO, 24.6.1920 mit dem Bericht "Secret: John Arnall«, 18.6.1920; Local Notes, in: Al-Moghreb al Aksa, 10.5.1919, 30.8.1919 und 22.11.1919.

346 John ARNALL, Correspondence, in: Al-Moghreb al Aksa, 25.10.1919.

${ }^{347}$ British Chamber of Commerce for Morocco, in: Al-Moghreb al Aksa, 10.4.1920; PROFO 371, 4531, 4281, 182: CG Tangier an FO, 16.6.1920.

${ }^{348}$ PRO-FO 371, 4533, 6333, 83: CG Tangier an FO, 20.8.1920; PRO-FO 371, 4531, 4281, 193: John Arnall an FO, 20.7.1920; PRO-FO 371, 7082, 8256, 170: John Arnall an FO, 13.8.1921.

${ }^{349}$ IORL, P\&J, 12, 230, 1671, 1924: A. Merry del Val an Lord Birkenhead, Secretary of State for India, 18.3.1925; CADN Tanger A427: Renseignements, 23.3.1922. 
Arnall betätigte sich weiter in der Politik und engagierte sich für die in Tanger und in Gibraltar beschäftigten Hafenarbeiter ${ }^{350}$. In kürzester Zeit machte er sich durch seine gewerkschaftlichen Aktivitäten und seine antifranzösischen Äußerungen einen Namen und viele Feinde. Er war in zahlreiche Fettnäpfchen getreten und galt vielen als unerwünschte Person ${ }^{351}$. Es gab jedoch auch Stimmen, die Arnall als geachtetes Mitglied der britischen Gemeinschaft bezeichneten, und Ansichten, daß Arnall lediglich das ausgedrückt habe, was viele in Tanger insgeheim über Frankreich dachten ${ }^{352}$. Von daher war er keineswegs isoliert. Viele dort lebende Engländer waren antifranzösisch eingestellt ${ }^{353}$.

Mancher mit Arnall befreundete Brite teilte dessen Interesse an Bergbaugeschäften in Marokko. P.J. Sterwin, ein früherer Angestellter der britischen Post Tangers, importierte nicht nur Holloway's Dry London Gin $^{354}$, sondern war auch an Arnalls Erdölaktivitäten bei Charf el Akab in der Tangerzone beteiligt $^{355}$. Arthur Gassett interessierte sich ebenfalls für Bergbaufragen und sollte später in einem Leserbrief an die Zeitung "Al-Moghreb al Aksa \& Tangier Gazette« vorschlagen, die Riffrage durch die Beschäftigung der Rifbevölkerung in Bergwerken zu lösen ${ }^{356}$.

Der schottische Geschäftsmann Ernest Waller und seine Ehefrau Ruth waren 1894 nach Tanger gekommen, um dort die Firma Waller \& Co., Nurserymen \& Seedsmen zu gründen. Ab 1921 beteiligte sich der schottische Marquess of Bute alias John Crichton-Stuart daran ${ }^{357}$. Waller gehörte der britischen Handelskammer in Tanger und der British Merchant's Morocco Association an ${ }^{358}$. Er war seit 1910 einer der Direktoren des Anglo-Moroccan Mining Syndicate, dem andere in Tanger lebende Briten wie John Arthur Kirby Green, Finlay

${ }^{350}$ Correspondence, Matt Giles an Editor of Al-Moghreb al Aksa, in: Al-Moghreb al Aksa, 1.11.1919; Local Notes, in: Al-Moghreb al Aksa, 1.11.1919; PRO-FO 372, 1407, 7277, 104: WO an FO, 24.6.1920; PRO-FO 371, 4524, 1727, 171: CG Tangier an DOT, 26.7.1920; PRO-FO 371, 4531, 4281, 193: John Arnall an FO, 20.7.1920; PRO-FO 371, 4533, 6333, 83: CG Tangier an FO, 20.8.1920.

${ }^{351}$ PRO-FO 372, 1407, 7277, 104: WO an FO, 24.6.1920; PRO-FO 371, 4533, 6333, 83: CG Tangier an FO, 20.8.1920.

${ }_{352}$ PRO-FO 371, 4533, 6333, 83: CG Tangier an FO, 20.8.1920; TNLA, RD, 1, Deakin: Walter Harris an Ralph Deakin, 7.6.1922.

${ }^{353}$ CADN Londres C523: MAE an Ambassade de Londres, 15.5.1922.

${ }^{354}$ Local Notes, in: Al-Moghreb al Aksa \& Tangier Gazette, 23.7.1921.

${ }^{355}$ CADN Tanger A427: Renseignements, 23.3.1922; CADN Maroc DAI 193: Moises Azancot - M. Commandant Ract-Brancaz, Rabat, 27.2.1924.

${ }^{356}$ Arthur GASSETT, Correspondence, in: Al-Moghreb al Aksa \& Tangier Gazette, 31.10.1925.

${ }^{357}$ VAIDON, Tangier, S. 149, S. 213; Local Notes, in: Al-Moghreb al Aksa \& Tangier Gazette, 29.11.1919; Anzeige der Waller \& Co., in: Al-Moghreb al Aksa \& Tangier Gazette, 2.6.1923; WoOlmaN, Stars in the Firmament, S. 99f.

${ }^{358}$ PRO-FO 368, 1332, 152703: Bericht "British Chamber of Commerce, Tangier, 1915«; Sixth Annual Report 1923, hg. von der British Merchant's Morocco Association, London 1923, S. 24. 
D. Stewart, W. Reginald Stewart, John M. Berntich oder David Wallace MacLeod angehörten. Der bekannte Tangerer Bankier Isaac Abensur, der sich mit der Salama-Gruppe im Besitz von Rechten am Jebel Hamam wähnte, der ehemalige Leiter der britischen Post von Tanger und nunmehrige Grundstïcksmakler Roque de Sots Lyons, welcher später mit Arnall Schmuggelgeschäfte mit dem Rif betrieb, oder der berühmte finnische Ethnologe Edward Westermarck hatten Anteile ${ }^{359}$.

Die Gesellschaft hatte unter anderem im Sommer 1910 Erzproben aus mehreren Teilen des Gebietes der Beni Ouriaghel - Aït Kamara (dort lebte Abdelkrim), Ain Deddar, El Bibane Kaf el Abad - und Geznaya (Jebel Tazroutine, Akhbar el Kadi) sammeln lassen ${ }^{360}$. Die Anträge des Anglo-Moroccan Mining Syndicate bei der Pariser Schiedskommission wurden allerdings abgewie$\operatorname{sen}^{361}$. Am 22. Juni 1928, bezeichnenderweise erst nach dem Ende des Rifkrieges, löste sich die Gesellschaft auf ${ }^{362}$. John Arnall bewegte sich in Tanger also in einem Milieu, das sehr stark am Bergbau im Rif interessiert war.

Ende Mai 1920 kamen Arnalls Kindheitsfreund John Ward und dessen Partner James Fordham in Tanger an. Ward hatte während des Ersten Weltkrieges das 25. Bataillon des Middlesex Regiments in Hongkong kommandiert, das von Juli 1918 bis November 1919 nach Sibirien entsandt worden war, um dort Admiral Koltschak in seinem Kampf gegen die Rote Armee zu unterstützen. Seinen 1920 neu errichteten Familiensitz in Appleshaw, Hampshire, taufte Ward zur Erinnerung »Omsk ${ }^{363}$. Von seinen sibirischen Erlebnissen handelte

${ }^{359}$ PRO-BT 31, 19288, 108057: Bericht »Return of Allotments Made the 6th of June 1910«, 23.6.1910; PRO-BT 31, 19288, 108057: Berichte «Copy of Register of Directors or Managers of the Anglo-Moroccan Mining Syndicate«, 18.3.1910 und 12.8.1910; PRO-FO 371, 935, 24513, 367: CG Tangier an FO, 23.7.1910; PRO-BT 31, 19288, 108057: Bericht »Return of Allotments Made the 22th of Octobre 1910«, 10.11.1910; PRO-BT 31, 19288, 108057: Bericht »Summary of Share Capital and Shares of Anglo-Moroccan Mining Syndicate Limited«, 31.12.1921; SHAT 3H102: Ambassade de Madrid an MG, EMA, $2{ }^{\mathrm{e}}$ bureau, 27.3.1924; CADN Madrid C312: Ambassade de Madrid an MAE, 29.10.1925; LAREDO, Les noms, S. 1030f.; VAIDON, Tangier, S. 148. Vgl. zu Westermarck Kirsti SUOLINNA, The Relationship between Edward Westermarck and Abdessalam El-Baqqali, in: Suomen antropologi 19 (1994), H. 4, S. 51-55; DIES., Abdessalam El-Baqqali, informateur et ami d'Edward Westermarck, in: Temenos 31 (1995) S. 1-12; DIES., Edward Westermarck's Fieldwork and Field Expeditions in Morocco, in: DiES., Catherine af HĀLLSTRŌM, Tommy LAHTINEN (Hg.), Portraying Morocco. Edward Westermarck's Fieldwork and Photographs 1898-1913, Ábo 2000, S. 7-26.

${ }^{360}$ PRO-FO 368, 433, 55, 27928 und 36911: Consulate of Fez an FO, 19.6.1910 und 3.9.1910.

${ }^{361}$ PRO-BT 31, 19288, 108057: G.H.E. Goodman an The Registrar 14.2.1927.

${ }^{362}$ PRO-BT 31, 19288, 108057: Note, 22.6.1928.

${ }^{363}$ Connaughton, The Republic, S. 59f., S. 83-88, S. 94-97, S. 175; Peter Fleming, The Fate of Admiral Kolchak, London 1963, S. 92, S. 104f., S. 108, S. 113, S. 117, S. 123; Jonathan D. SMELE, Civil War in Siberia. The Anti-Bolshevik Government of Admiral Kolchak 1918-1920, Cambridge u.a. 1996, S. 98f., S. 119, S. 174, S. 340; STENTON, LEES, Who's Who, Bd. 3, S. 366. 
sein Buch "With the `Die-Hards in Siberia« (1920). James Fordham gehörte die Firma J.J. Fordham \& Co., Ltd., General Merchants in der Londoner Cannon Street ${ }^{364}$. Er galt als skrupelloser Geschäftsmann ${ }^{365}$.

In der britischen Gesandtschaft Tangers gab der mit einem Einführungsschreiben von Außenminister Lord George Curzon ausgestattete Ward bekannt, daß er die wirtschaftlichen Möglichkeiten Marokkos ausloten wolle. Schnell wurde klar, daß die von Arnalls Holzgeschäften inspirierten Ward und Fordham Ländereien an der Westküste der Alhucemas-Bucht erwerben wollten. Die Rede war sogar vom Bau einer Schmalspurbahn und eines kleinen Hafens innerhalb der Bucht. Der neue britische Generalkonsul von Tanger, Clark Kerr, konnte sie nur warnen, daß die spanischen Behörden ihnen Steine in den Weg legen würden ${ }^{366}$. Nach seiner Ankunft in Tetuan sagte Ward dem britischen Konsul C.R.B. Atkinson, daß seine zutiefst antifranzösische Haltung ihn dazu treibe, alles in seiner Macht stehende zu tun, um Frankreich davon abzuhalten, weitere Teile der Mittelmeerküste an sich zu bringen. Darin waren er und Arnall einer Meinung ${ }^{367}$.

Die Wirtschaftsgespräche von Ward und Fordham in Tetuan liefen schlecht. John Arnalls Kompagnon Ali Luh berichtete von einem Anthrazitfund bei Taghessa in Ghomara, doch die Briten sahen keine Gelegenheit, vor Ort Untersuchungen durchzuführen. Hochkommissar Dámaso Berenguer y Fusté hatte ihre Bitte abgelehnt, das wöchentliche Wassertaxi zwischen Tetuan und Melilla in der Bucht von Alhucemas - also mitten im sunbefriedeten، Gebiet - landen zu lassen. Deshalb wurde beschlossen, daß Ali Luhs Bruder mit Anthrazitproben nach Gibraltar kommen sollte, wo Ward und Fordham sie untersuchen wollten. Konsul Atkinson arrangierte auch ein Treffen mit Abraham Pinto und Duque de Tovar, die in Beni Saïd und Ghomara Land erworben hatten. Für ihre Petitionen an die Pariser Schiedskommission suchten sie britische Partner. Eine fünzigprozentige Beteiligung an einer zu gründenden Gesellschaft und an den Kosten des Landerwerbs überstieg die finanziellen Mittel der Briten. Im Juni 1920 kauften Ward und Fordham über John Arnall als Vermittler ein Stück Land in der Bucht von Alhucemas, das an der Westküste an ein bereits von Duque de Tovar erworbenes Gebiet grenzte. Thre erhoffte Kooperation mit ihm kam genauso wenig zustande wie John Wards Pläne, für die Reise nach Alhucemas ein Segelboot zu chartern oder einen britischen

${ }^{364}$ PRO-FO 371, 4534, 9051, 124: James Fordham an FO, 24.9.1920.

${ }^{365}$ PRO-FO 371, 4531, 4281, 188: Clark Kert an Sperling, 18.6.1920.

${ }^{366}$ PRO-FO 371, 4531, 4281, 182: CG Tangier an FO, 16.6.1920.

${ }^{367}$ PRO-FO 371, 4531, 4281, 188: Clark Kerr an Sperling, 18.6.1920; Empire Day, in: AlMoghreb al Aksa, 29.5.1920. 
Admiral dazu zu bewegen, ihm dafür einen Zerstörer zur Verfügung zu stellen. Ward ärgerte sich maßlos, und als er auch noch an Ruhr erkrankte, trat er am 15. Juni 1920 zusammen mit Fordham die Heimreise nach London $a^{368}$.

Ein halbes Jahr später erschien am 6. Februar 1921 der britische Bergbauingenieur John Bevan in Gibraltar. Fordham hatte ihn beauftragt, im Rif Untersuchungen vorzunehmen. Bevan überredete den britischen Geschäftsmann William Moxon aus Tanger, ihn ins Rif zu begleiten. Moxon hatte Tanger während des Ersten Weltkrieges als Kommandant eines im Hafen liegenden Kriegsschiffes kennen- und schätzen gelernt. 1919 hatte er sich dort als Vertreter von Messrs. Branton's Factory of Wire and Wire Rope aus Musselburgh niedergelassen ${ }^{369}$.

Am 1. April 1921 quartierten sich Bevan und Moxon im Bristol-Hotel in Gibraltar ein und stellten in der Folgezeit Nachforschungen an, wie man ins Rif gelangen könnte, wo Ali Luh auf sie wartete. Dies geschah zu einem Zeitpunkt, als der von General Silvestre angeführte spanische Vormarsch in Richtung Rif in vollem Gange war, Abdelkrim über den Echevarrieta-Agenten Antonio Got auch anderweitige Pläne im Visier hatte und Daniel Bourmancé-Say das Pariser Außenministerium von seinen Marokko-Visionen überzeugen wollte. Kurz darauf erlitten Bevan und Moxon mit einem kleinen Boot an der afrikanischen Küste Schiffbruch. Ein spanisches Schiff las die havarierten Briten auf und brachte sie nach Malaga. Nach ihrer Rückkehr nach Gibraltar am 10. Mai 1921 mußten sie zur Genesung eine Woche im Colonial Hospital verbringen $^{370}$.

John Arnall blieb nicht untätig. Trotz der feindseligen Haltung der spanischen Behörden und trotz der Kämpfe zwischen Rifkabylen und spanischen Truppen schickte er am 7. Juli 1921 drei Forschungsgesuche für Bergbaugelände in der Nähe der Bucht von Alhucemas an den Servicio de minas del protectorado ${ }^{371}$. Arnall befand sich zu dieser Zeit über Ali Luh in direktem Kontakt zu Abdelkrim. Als er am 18. Juli 1921 Tanger verließ, um sich nach Großbritannien einzuschiffen, hatte er Angebote des Anführers der Rifkabylen an britische Wirtschaftsleute im Gepäck ${ }^{372}$.

${ }^{368}$ PRO FO 371, 4531, 4281, 185: Bericht "Memorandum by Mr C.R.B. Atkinson on the Visit of Colonel John Ward M.P. and Mr. J.J. Fordham to Tetuan, 16.6.1920; PRO-FO 371, 4531, 4281, 182: CG Tangier an FO, 16.6.1920; PRO-FO 371, 4531, 4281, 181: Note, 29.6.1920; PRO-FO 371, 4531, 4281, 182: CG Tangier an FO, 16.6.1920. Vgl. zur PintoFamilie Joseph TOLEDANO, La saga des familles. Les juifs du Maroc et leurs noms, Tel-Aviv 1983, S. 290f.; SERELS, A History, S. 286f. Siehe zu Duque de Tovar auch S. 214-216.

${ }^{369}$ Local Notes, in: Al-Moghreb al Aksa, 29.11.1919 und 29.1.1921; VAIDON, Tangier, S. 208.

${ }^{370}$ PRO-FO 371, 9470, 44, 200: Governor of Gibraltar an FO, 24.11.1923; PRO-FO 371, 9470, 44, 173: New Scotland Yard an FO, 21.11.1923.

${ }^{371}$ MADARIAGA, España y el Rif, S. 530.

${ }^{372}$ PRO-FO 371, 7082, 8256, 170: John Arnall an FO, 13.8.1921. 
Dies geschah noch vor dem Sieg der Rifkabylen bei Annual. Abdelkrim muß sich daher seiner Sache in militärischer Hinsicht recht sicher gewesen sein. Politisch betrachtet, nahm er vielleicht an, daß Amall aufgrund seiner Parteikarriere in der Independent Labour Party ein diplomatischer Fachmann war. Abdelkrim erhoffte sich durch den Abschluß von Bergbauverträgen finanzielle Zuschüsse für den Widerstandskampf und die von ihm geplanten Reformen im $\mathrm{Rif}^{373}$. Durch die Unterstützung der britischen Regierung sollte den Bergbaurechten, die Abdelkrim vergeben wollte, eine höhere Wertigkeit zukommen ${ }^{374}$.

Nach Arnalls Ankunft in London vermittelte ihn sein Freund W.M. Crook über den stellvertretenden Staatssekretär Cecil Harmsworth an das britische Außenministerium weiter ${ }^{375}$. John Arnalls Auftritt am 3. August 1921 hinterließ keinen guten Eindruck. Die Diplomaten ärgerten sich über seine "Schwatzhaftigkeit« und maßen seinen Worten keine Bedeutung bei ${ }^{376}$. Harmsworth schrieb an Crook, daß es nicht nötig sei, Arnall zu einem weiteren Besuch zu drängen ${ }^{377}$.

Damit war dessen London-Aufenthalt eigentlich schon gescheitert, bevor er richtig begonnen hatte. Fast täglich traktierte Amall das Außenministerium mit Briefen ${ }^{378}$. Am 13. August 1921 versandte er ein 18 Seiten langes Manuskript über Abdelkrims politische Angebote sowie über die Bedeutung des Rifs für die britische Mittelmeerpolitik und für die britische Wirtschaft. Darin hieß es, daß Abdelkrim gegen die Anerkennung der Unabhängigkeit monopolartige Bergbaurechte offeriere. Arnall erinnerte an die guten Beziehungen zwischen Gibraltar und der Rifbevölkerung, die einen regen Handelsverkehr ermöglicht hätten. Neben der kuriosen Offerte, daß das Rif gut ein Viertel des britischen Bedarfs an Seife sicherstellen könne, präsentierte sich der Brite als Rif-Bevollmächtigter für Landverkäufe im Gebiet der Beni Touzine und Beni Ouriaghel. Er brüstete sich ebenso als militärischer Stratege und betonte die Bedeutung der marokkanischen Mittelmeerküste für Großbritannien angesichts der Nähe von Gibraltar: „Wenn wir den Südeingang des Mittelmeeres preisgeben, werden wir auch Gibraltar aufgeben müssen ${ }^{379}$. Das Eingehen auf Amalls Angebote hätte für die britische Regierung einen gravierenden Ver-

${ }^{373}$ KHARCHICH, La France, S. 145.

${ }^{374}$ MadariagA, L'Espagne et le Rif, Bd. 2, S. 200.

${ }^{375}$ PRO-FO 371, 7082, 8256, 159: W.M. Crook an Cecil Harmsworth, 28.7.1921; STENTON, LEES, Who's Who, Bd. 3, S. 151.

${ }^{376}$ PRO-FO 371, 7082, 8256, 155: Minute, 3.8.1921.

${ }^{377}$ PRO-FO 371, 7082, 8256, 165: Cecil Harmsworth an W.M. Crook, 6.8.1921.

${ }^{378}$ PRO-FO 371, 7068, 184, 194, 201, 208, 212, 214: John Amall an FO, 19.8.1921, 20.8.1921, 21.8.1921, 30.8.1921 und 31.8.1921.

${ }^{379}$ PRO-FO 371, 7082, 8256, 170: John Amall an FO, 13.8.1921. 
stoß gegen internationale Verträge bedeutet. Seine Initiative war daher illusorisch $^{380}$. Intern mokierte sich Gerald Villiers, Unterstaatssekretär im Außenministerium, darüber, daß Arnall lediglich seine wirtschaftlichen Ziele im Sinn habe $^{381}$.

Die britische Industrie hatte in der Regel kein Interesse daran, sich in Spanisch-Marokko zu engagieren. Dies mußten im Sommer 1921 auch Abraham Pinto und sein Partner Duque de Tovar erfahren, die die Gründung einer spanisch-englischen Bergbaugesellschaft zu gleichen Anteilen planten. Das Angebot wurde sieben britischen Firmen unterbreitet ${ }^{382}$. Die einzige Rückmeldung kam von H.J. Palmar vom Central European Trust. Er glaubte an einen Beitrag einer derartigen Gesellschaft zur >Befriedung, Spanisch-Marokkos und war fest überzeugt davon, daß die spanische Regierung sich dieser Lösung nicht verschließen könne ${ }^{383}$. Die Initiative ereilte das gleiche Schicksal wie der durchaus ähnliche Mannesmann-Plan von 1913 - sie verlief im Sande.

Investoren aus Großbritannien wurden vor allem dadurch abgeschreckt, daß das britische Morocco Minerals Syndicate bei den Entscheidungen der Pariser Schiedskommission im Jahre 1921 der große Verlierer war. Im Dezember 1912 hatte Rafael Cecil Leack für 300000 Pfund umfangreiche Besitzungen von Francisco Ruíz Pastor, dem Partner Horacio Echevarrietas, gekauft ${ }^{384}$. David Alfred Thomas alias Lord Rhondda, der im walisischen Rhondda-Tal Kohlengruben besa ${ }^{385}$, war der Meinung, daß sich Großbritannien die seiner Ansicht nach wertvollen Eisenerzvorkommen in Spanisch-Marokko sichern müsse. Mit einer kleinen Gruppe Gleichgesinnter gründete er noch im gleichen Monat das Morocco Minerals Syndicate ${ }^{386}$.

Da die bis 1914 in ganz Spanisch-Marokko erworbenen 68 Bergbaugebiete eine Fläche von sagenhaften 873050 ha ausmachten, avancierte die Gesellschaft zum bis dato bedeutsamsten Antragsteller bei der Pariser Schiedskommission. Ihre Ansprüche umfaßten fast das gesamte spanische Einflußgebiet.

${ }^{380}$ PRO-FO, 371, 7082, 8256, 169: Note, 20.8.1921; PRO-FO 371, 7082, 8256, 195: G. Villiers an John Arnall, 24.8.1921; PRO-FO, 371, 7082, 8256, 200: Note, 25.8.1921; PRO-FO 371, 7082, 8256, 207: Note, 2.9.1921.

${ }^{381}$ PRO-FO 371, 7082, 8256, 169: Note, 20.8.1921.

${ }^{382}$ PRO-FO 371, 7082, 8233, 151: DOT an FO, 13.8.1921.

${ }^{383}$ PRO-FO 371, 7082, 8329, 3: Scottish Office an FO, 3.8.1921 mit dem beigefügten Brief H.J. Palmar an Robert Munro, House of Commons, 2.8.1921.

${ }^{384}$ DIAZ MORLÁN, Horacio Echevarrieta, S. 101-103, S. 338, Anm. 212; DERS., Capital mineto, S. 164f:; MADARIAGA, España y el Rif, S. 513.

${ }^{385}$ Margaret HAIG ThOMAS (The Viscountess RhONDDA), This Was My World, London 1933, S. 191-198.

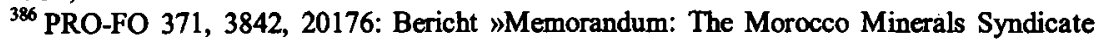
Limited", 14.11.1918; PRO-FO 371, 2047, 7710: Morocco Minerals Syndicate an FO, 19.2.1914; PRO-FO 371, 3842, 20176: Lord Wolmer an FO, 4.2.1919. 
Allein der erste Antrag für die Konzession »Triunfo« - im Kerngebiet des Rifs und damit im Einflußbereich der Khattabis - bezog sich auf ein Gebiet von $250000 \mathrm{ha}^{387}$.

Weitere britische Firmen und Wirtschaftsleute hatten sich um Konzessionen in Nordmarokko bemüht. Genannt seien etwa: Anglo-African Petroleum Syndicate (die spätere BP), das Anglo-Moroccan Mining Syndicate ${ }^{388}$, British Morocco Company ${ }^{389}$, Compagnie anglo-française marocaine (Gesellschaft nach britischem Recht) ${ }^{390}$, European and North African Mines, Ltd. ${ }^{391}$, French Iron Ore Company ${ }^{392}$, Commander Livingston Learmouth ${ }^{393}$, Arnold Lupton ${ }^{394}$, H. Maconochie ${ }^{395}$, Morocco Riff Mining Syndicate ${ }^{396}$, Riff Mining Compa$\mathrm{ny}^{397}$, Tangier and Riff Trading and Mining Syndicate ${ }^{398}$.

Doch nur das Morocco Minerals Syndicate hatte es geschaff, erfolgversprechende Landkäufe zu tätigen. 1917 bearbeitete Abdelkrim die Petitionen in Melilla. Zwischen den Briten, deren Ansprüche im Rif zu denen der Mannesmanns in direkter Konkurrenz standen, und den Khattabis hatte es allerdings nie direkte Verhandlungen gegeben ${ }^{399}$. Viele Rechtstitel wurden von der Oficina central de tropas y asuntos indígenas in Frage gestelit, weil angeblich Dokumente oder spezifische Daten fehlten. Die Spanier standen den Interessen der britischen Gesellschaft geradezu feindlich gegenüber ${ }^{400}$.

Vor der entscheidenden Verhandlung der Pariser Schiedskommission reichte das Morocco Minerals Syndicate daher nur noch fünf (»Triunfo«, »Teresa«, "Piedad«, »Luisa«, »Esperanza«) von ursprünglich 68 Petitionen ein. Sie machten lediglich 83500 ha, also etwa ein Zehntel des anfänglich geplanten

${ }^{387}$ MADARIAGA, España y el Rif, S. 186.

${ }^{388}$ PRO-FO 371, 930, 727, 94: CG Tangier an FO, 30.1.1910; PRO-BT 31, 19288, 108057: Mappe "Anglo-Moroccan Mining Syndicate, Ltd. 1910«.

${ }_{389}$ PRO-BT 31, 20673, 122048: Mappe »British Morocco Co., Ltd. 1912«.

${ }^{390}$ PRO-FO 371, 930, 727, 94: CG Tangier an FO, 30.1.1910; PRO-FO 371, 4520, 1106 , 332: Compagnie anglo-française marocaine an FO, 17.11.1920.

391 AZIZA, Le Rif, S. 143.

${ }^{392}$ PRO-FO 371, 3842, 20176: Embassy of Madrid an FO, 30.12.1919; PRO-BT 31, 24047, 150343: Mappe »French Iron Ore Company 1918«.

${ }^{393}$ PRO-FO 371, 4524, 1371, 131: Commander Livingston Learmouth an FO, 9.4.1920.

394 PRO-FO 368, 1766, 120316: Arnold Lupton an BT, 8.6.1917; PRO-FO 368, 1766, 120316, 129490: Arnold Lupton an FO, 29.6.1917.

${ }^{395}$ PRO-FO 368, 1766, 5772: H. Maconochie an FO, 10.1.1917.

${ }^{396}$ PRO-BT 31, 20509, 120595: Mappe »Morocco Riff Mining Syndicate, Ltd. 1912«; PROFO 371, 1691, 28217: Morocco Riff Mining Syndicate an FO, 19.6.1913; Mining Titles in Morocco, in: Morocco, 21.4.1923.

${ }^{397}$ PRO-FO 371, 2044, 2134, 2283: Embassy of Madrid an FO, 13.1.1914.

${ }^{398}$ Local Notes, in: Al-Moghreb al Aksa, 24.1.1920.

${ }^{399}$ PRO-FO 371, 3253, 130013: Morocco Minerals Syndicate an FO, 10.12.1918; SHEEAN, My Meeting, S. 848f.

${ }^{400}$ PRO-FO 371, 4518, 921, 88: Vice-Consulate of Tetuan an CG Tangier, 20.3.1920; PROFO 371, 4527, 2495, 2: Embassy of Madrid an FO, 17.4.1920. 
Landerwerbs, aus. Zur Sicherheit wurden 1125 Kilogramm Papier an den Servicio de minas del protectorado eingereicht. Doch die Mühe war vergebens. Am 24. Mai 1921 wurde von der Schiedskommission lediglich die RechtmäBigkeit der Petition 173E "Esperanza《 in Beni Touzine in einer deutlich reduzierten Version anerkannt. 2615 ha von ursprünglich über 800000 ha waren übriggeblieben. Alle Petitionen für den Kernbereich des Rifs wurden abgelehnt $^{401}$.

Da die britische Diplomatie auf ihn nicht reagierte, wandte sich John Arnall am 5. September 1921 an den Genfer Völkerbund. Er wies darauf hin, daß die Bevölkerung des Rifs trotz der religiösen Hoheit des marokkanischen Sultans immer seine Unabhängigkeit bewahrt habe. Die Rifkabylen bäten darum, als Volk anerkannt zu werden. Dafür versprächen sie im Gegenzug, ihr Land der Wirtschaft zu öffnen und friedliche Beziehungen zu allen Ländern einzugehen. Amall appellierte an den Völkerbund, den Kämpfern den Status von Kriegführenden zuzuerkennen ${ }^{402}$. Der Franzose Paul Mantoux, der Leiter der politischen Sektion des Völkerbundes, legte jedoch - wohl auf Betreiben des französischen Außenministeriums - sowohl diesen als auch Arnalls zweiten Brief vom 6. September $1921 \mathrm{zu}$ den Akten, ohne eine Aktion einzuleiten ${ }^{403}$.

Der Versuch, die Rifsoldaten als Kriegsteilnehmer anerkennen zu lassen, wurde in der Folgezeit über Jahre weiterverfolgt. Vergeblich, denn Völkerrechtler erwiderten als Gegenargument, daß die Rifkabylen innerhalb des von Spanien und Frankreich geführten Protektorats Marokko als Rebellen, die nicht einmal Anspruch auf humanitäre Hilfe hätten, angesehen werden müßten. Der Rifkrieg war nach dieser Sichtweise eine innerstaatliche Angelegenheit Spaniens und später Frankreichs ${ }^{404}$. Arnall und andere Berater Abdelkrims wie Charles Gardiner oder Robert Gordon-Canning zielten nicht nur auf den humanitären Aspekt ab. Sie meinten, eine Anerkennung der Kriegführung Abdelkrims wäre mit dem Zugeständnis der unrechtmäßigen Anwesenheit Spaniens in Marokko gleichbedeutend gewesen ${ }^{405}$.

Am 2. Oktober 1921 kehrte John Arnall nach Tanger zurück. Er war bisher nicht in der Lage gewesen, genügend bergbauinteressierte Finanziers zu finden. Sein einziger Kandidat war Major F.E.V. Taylor von der Gesellschaft The Officers' Partnership Guardian. Der leichtgläubige Offizier erkundigte sich am 10. November 1921 bei seiner Regierung, ob es sinnvoll sei, in den

${ }^{401}$ PRO-FO 371, 8350, 555, 10: Observations, 7.2.1922; GODCHOT, Le mystère, S. 249; MADARIAGA, España y el Rif, S. 186, S. 190.

${ }^{402}$ John Arnall an League of Nations, 5.9.1921, in: MADARIAGA, L'Espagne et le Rif, Bd. 2, Dok. 5, S. 2666 .

${ }^{403}$ TAHT AH, Pragmatisme 1995, S. 103.

${ }^{404}$ Nathaniel BERMAN, wThe Appeals of the Orient $\lll$. Colonized Desire and the War of the Riff, in: Karen KNOP (Hg.), Gender and Human Rights, Oxford 2004 (The Collected Courses of the Academy of European Law, 12, 2), S. 195-230, S. 202-204.

${ }^{405}$ BoYD, Praetorian Politics, S. 200. 
Rifbergbau zu investieren. Aber von dort erhielt er nur die Antwort, daß Arnall von ihr keine Unterstützung zu erwarten habe ${ }^{406}$. Staatssekretär Kirkpatrick stöhnte über Taylor, der am Telefon so gewirkt hätte, als halte er das Rif für einen unabhängigen Staat im Inneren von Marokko, der sich unter der Herrschaft von Arnall befinde ${ }^{407}$.

Anfang November 1921 ließ Abdelkrim durch John Arnall einen Brief an die Gesandtschaften Tangers weiterleiten. Im Namen der Humanität appellierte er an die zivilisierte Welt zu helfen. Falls die Rifkabylen scheitern würden, läge die Schuld bei Europa, das diplomatisch nicht eingegriffen habe. Er betonte auch hier, daß der Handel seines Landes für jede Nation offen sei ${ }^{408}$. Zur Bekräftigung ließ Abdelkrim im November 1921 auf den Märkten des Rifs verkünden, daß jeder Europäer in seiner Einflußzone Gastrecht genieße $\mathrm{e}^{409}$.

In sein Firmenkennzeichen der British Riff Company hatte Arnall mittlerweile den Schriftzug $» J o h n$ Arnall/Mines \& Minerals/(Owner, Merchant \& Agent)« aufgenommen. Sein nimmermüder Appell an das britische Außenministerium, daß nur durch seine Mithilfe Großbritanniens Nachschub an Bodenschätzen gesichert und Frankreich von der Kontrolle des westlichen Mittelmeeres abgehalten werden könne, fruchtete nichts ${ }^{410}$. Arnalls Reputation war so schlecht, daß Gerald Villiers die Anweisung gab, in Zukunft jeglichen Kontakt zu meiden ${ }^{411}$.

Ende 1921 hatte Arnall nicht viel erreicht. Seit 1914 war für ihn die wirtschaftliche Komponente - der Erwerb von Bergbau-Konzessionen - die Hauptantriebsfeder. Verbunden war dies mit der Hoffnung einer generellen gegen Frankreich gerichteten Ausweitung des britischen Einflusses in Nordmarokko. Hingegen sah Abdelkrims Plan vor, daß Briten im Rif Bergbaugelände erwerben sollten, um ihre Regierung dazu zu veranlassen, diese Interessen zu schützen. Da Abdelkrim gemäß dem marokkanischen Bergbaugesetz kein Recht hatte, Bergbau-Konzessionen zu vergeben, wäre die Wahrung der britischen Interessen nur über die Anerkennung von Abdelkrims Herrschaft möglich gewesen. Dies stand für die britische Regierung aber nie zur Debatte, auch wenn die Situation in Spanisch-Marokko mehr als kritisch betrachtet wurde.

${ }^{406}$ MADARIAGA, España y el Rif, S. 530f.; PRO-FO 371, 7085, 11829, 72: John Arnall an FO, 2.11.1921; PRO-FO 371, 7085, 11829, 79 und 80: Major F.E.V. Taylor an FO, 10.11.1921, FO an Major F.E.V. Taylor, 18.11.1921.

${ }^{407}$ PRO-FO 371, 7085, 11829, 77: Note, 11.11.1921.

${ }^{408}$ PRO-FO 371, 7086, 12931, 228: Abdelkrim an CG Tangier o.D. [Anfang November 1921]; ADMAE Maroc 192, 128: Abdelkrim an CG Tanger, 5.11.1921.

${ }^{409}$ CAOM Algérie 9H93: Chef d'annexe de Marnia an Général commandant de la division d'Oran, 26.11.1921.

${ }^{410}$ PRO-FO 371, 7086, 12777, 210: John Arnall an FO, 13.12.1921.

411 PRO-FO 371, 8341, 171, 97: Note, 13.1.1922. 
Es gab im Außenministerium Gedankenspiele, daß Frankreich von der prekären Situation Spaniens profitieren und die nordafrikanische Küste von Casablanca bis Tunis kontrollieren könnte. Esme Howard, der britische Botschafter in Madrid, propagierte eine "Realpolitik«, die im Rahmen einer generell neutralen Haltung vorsah, die Aufrechterhaltung des spanischen Einflusses in Nordmarokko zu favorisieren, um so Großbritanniens strategische Mittelmeerposition, Gibraltar und den Seeweg nach Indien zu sichern. Dies schloß die militärische Neutralität und die Internationalisierung der Tangerzone mit ein. Der Status quo sollte aufrechterhalten werden. Eine Unterstützung Abdelkrims war von Anfang an ausgeschlossen ${ }^{412}$.

Ende Januar 1922 mußte John Amall in Tanger erfahren, daß die Rifkabylen angesichts der mäßigen Resonanz vorerst aufgegeben hatten, britisches Kapital für ihre Bodenschätze zu interessieren ${ }^{413}$. Der Umstand, daß Abdelkrim im Februar 1922 eine vom Algerienfranzosen Daniel Bourmancé-Say begleitete Rifdelegation nach Paris entsandte ${ }^{414}$, alarmierte den Briten zusätzlich. Er sah seine Felle davonschwimmen. Daher beschloß er, ein weiteres Mal ins Rif aufzubrechen. Über Si Abdelkrim ben el Haj Ali Luh holte er Abdelkrims Zustimmung ein. Sein Ziel war zum einen, den durch den Rifkrieg zusammengebrochenen Handel seiner British Riff Company wieder anzukurbeln, und zum anderen, mit Abdelkrim über zukünftige Bergbaurechte zu sprechen ${ }^{415}$.

Am 19. März 1922 machte sich Arnall auf den Weg und durchquerte über Casablanca, Rabat, Fes, Taza und Taourirt die französische Zone Marokkos. Um nicht als Europäer erkannt zu werden, hatte er sich einen Bart wachsen lassen, und er trug einheimische Kleidung ${ }^{416}$. Als er mit seinen Begleitern gerade die französischen Linien passiert hatte und bei Sidi Ali Bou Roqba das Gebiet der Geznaya erreicht hatte, wurde er am 16. April 1922 festgehalten und aufgefordert, ein Lösegeld von 20000 Francs zu entrichten ${ }^{417}$. Um ihre Forderungen zu untermauern, beraubten die Geznaya John Arnall seiner Gold-

${ }^{412}$ Memorandum on the Foreign Policy of His Majesty's Government o.D. [April 1926], in: MEDLICOTT u.a. (Hg.), Documents, Bd. 1, S. 846-881, S. 851; PRO-FO 371, 8354, 4882, 53: Note, 19.6.1922; PRO-FO 371, 8342, 171, 43: Note, 28.6.1922. Vgl. MIEGE, L'arrièreplan diplomatique, S. 223; Brian J. MCKERCHER, $\gg$ A Dose of Fascismor. Esme Howard in Spain 1919-1924, in: International History Review 9 (1987) S. 555-585, S. 573, S. 579; DERS., Esme Howard, S. 249; BENNETT, Britain's Relations, S. 58f., S. 66; DERS., British Foreign Policy, S. 138; LA PORTE, La atracción del imán, S. 182, S. 193.

${ }^{413}$ PRO-FO 371, 8352, 1824, 277: Memorandum, 9.2.1922.

${ }^{414}$ Siehe S. 250-252.

415 TNLA, RD, 1, Deakin: Walter B. Harris an Ralph Deakin, 7.6.1922; PRO-FO 371, 8354, 4882, 54: Bericht »Memorandum of Statement Made by Mr. John Arnall«, 28.5.1922.

${ }^{416}$ CADN Madrid C263: RG Rabat an MAE, 8.5.1922; CADN Madrid C263: RG Rabat an MAE, 18.6.1922; CADN Tanger A427: Renseignements, 28.3.1922; CADN Tanger A427: Centre de renseignements extérieurs du Maroc, Tanger an CG Tanger, 12.6.1922; TNLA, RD, 1, Deakin: Walter B. Harris an Ralph Deakin, 7.6.1922.

${ }^{417}$ PRO-FO 371, 8354, 4882, 42: John Arnall an Arthur Field, 29.5.1922. 
zähne. Der Tangerer "Times«-Korrespondent Walter Harris witzelte boshaft, dies wäre »ein klarer Beweis für die Fähigkeit der Rifkabylen, seltene Metalle aufzuspüren $\kappa^{418}$.

Arnall schickte zwei Briefe nach Ajdir, um Hilfe zu erbitten. Abdelkrim machte in einer entschiedenen Botschaft an die Geznaya deutlich, daß sein Land für jeden Europäer, der Handel betreiben wolle, offenstehe. Zur Bekräftigung entsandte er eine Streitmacht von 2000 Mann. Dies bewirkte, daß Arnall am 5. Mai 1922 wieder freigelassen wurde ${ }^{419}$. Der Brite, der hinter seiner Geiselnahme französische Machenschaften vermutete, ließ sich nicht beirren. Am 8. Mai 1922 erreichte er Ajdir. Knapp drei Wochen hielt sich Arnall im Rif auf. Thm wurden das Schlachtfeld von Annual, die Schützengräben der Rifkämpfer und die Leistungen der Rif-Artillerie vorgeführt ${ }^{420}$.

Obwohl Abdelkrim wegen der abweisenden Haltung der britischen Regierung in der Vergangenheit sehr verärgert war, wollte er weiterverhandeln. Er erklärte, er habe Konzessionen für zwölf Bergbaufelder, ein Waldgebiet sowie Bergbau- und Handelsrechte in Ghomara anzubieten. Während den Franzosen der Hafen von Sidi Driss vorbehalten sein sollte, wollte Abdelkrim britischen Interessenten den besten Naturhafen der Rifküste in der Nähe von Morro Nuevo übergeben. Als Gegenleistung verlangte er die Anerkennung der Unabhängigkeit des Staatsgebildes im Rif. Versehen mit diesen Vorschlägen, sollte Amall mit einer Rifdelegation nach London aufbrechen ${ }^{421}$.

Der Umstand, daß kurz zuvor noch Jean du Taillis einen Bergbauvertrag abgeschlossen hatte und sich zeitgleich mit ihm die Franzosen Carlo de Carli, Berthelier und A. Bourges - ein Agent der Direction des affaires indigènes der Generalresidenz in Rabat - in Ajdir aufhielten, verstärkte Arnalls Ansicht, daß dem französischen Einfluß im Rif Einhalt geboten werden müsse. In Wahrheit hatte es sich um ein für Abdelkrim eher unerfreuliches Geschäftsgespräch gehandelt. Am 27. Mai 1922 kehrte Arnall nach Tanger zurück ${ }^{422}$. Caïd Haddou teilte Abdelkrim mit, daß die französischen Geschäftspartner über den

\footnotetext{
${ }^{418}$ HARRIS, The Moroccan Campaign, 11.9.1924.

${ }^{419}$ CADN Madrid C273: MAE an Ambassade de Madrid, 2.6.1922 mit dem beiliegenden Bericht von A. Bourges „Un voyage dans le Riff, Rapport d'un informateur», 12.5.1922; CADN Madrid C263: RG Rabat an MAE, 18.6.1922; PENNELL, A Country, S. 235.

${ }^{420}$ PRO-FO 371, 8354, 4882, 42: John Arnall an Arthur Field, 29.5.1922.

${ }^{421}$ PRO-FO 371, 8354, 4882, 54: Bericht »Memorandum of Statement Made by Mr. John Arnall ${ }^{2}$, 28.5.1922.

${ }^{422}$ CAOM Algérie 9H93: Général commandant de la division d'Oran an Gouverneur général de l'Algérie, 30.5.1922; CADN Madrid C263: RG Rabat an MAE, 18.6.1922; TNLA, RD, 1, Deakin: Walter B. Harris an Ralph Deakin, 7.6.1922; CADN Tanger A427: Centre de renseignements extérieurs du Maroc, Tanger an CG Tanger, 12.6.1922.
} 
Aufenthalt des Engländers im Rif ungehalten waren. Daher habe er in Bourmancé-Says Zeitung "La Moulouya française« verlauten lassen, daß Europäer das Rif nur noch mit seiner ausdrücklichen Genehmigung betreten dürften ${ }^{423}$.

Dieses - einmalige - Zusammentreffen von potentiellen wirtschaftichen Konkurrenten im Rif zeigt auf, daß Abdelkrim beabsichtigte, die Rivalen gegeneinander auszuspielen, um weder den britischen noch den französischen Einfluß im Rif zu groß werden zu lassen. Die Ziele seiner europäischen Berater interessierten ihn nur insoweit, als sie mit seinen eigenen Plänen - Unabhängigkeit in politischen wie wirtschaftlichen Angelegenheiten - in Einklang zu bringen waren.

Am 28. Mai 1922 erstattete John Arnall dem britischen Generalkonsulat in Tanger einen Bericht über seine Reise. Er drückte seine Befürchtung aus, daß französische Missionen nicht nur einen Beitrag bei der Errichtung einer Republik geleistet hätten, sondern bereits ein geheimes Bündnis zwischen Frankreich und dem Rif entstanden sei, dem Großbritannien seinerseits durch einen Pakt mit Abdelkrim begegnen müsse ${ }^{424}$. Arnall übergab »Times«-Korrespondent Walter Harris eine Erklärung Abdelkrims, die am 30. Mai 1922 veröffentlicht wurde. Mit ihr erfuhr die britische Öffentlichkeit erstmalig aus erster Hand von den Zielen der Rifkabylen. Abdelkrim verdeutlichte, daß er »Frieden, Ordnung und Handel« sowie die "Freundschaft mit der ganzen Welt« anstrebe. Er hob hervor, daß die Fähigkeit der Rifkabylen, sich selbst zu regieren, nicht geringer sei als die der Europäer: "Wir fordern, wie es so viele christliche oder islamische kleine Nationen getan haben, unsere Rechte und unsere Unabhängigkeit ein.« Zum Abschluß verband Abdelkrim die Forderung nach Anerkennung der Souveränität mit der in Aussicht gestellten Öffnung des Rifs für Europäer und für europäischen Handel ${ }^{425}$.

In zwei Briefen vom 29. und 30. Mai 1922 bat John Arnall seinen Londoner Freund Arthur Field, der über gute Kontakte zur moslemischen Gemeinschaft Londons verfuigte, die Ankunft der Rifdelegation vorzubereiten. Sie kannten sich von der Workers Welfare League for India und der Independent Labour Party (ILP) her ${ }^{426}$. Anfang Juli 1922 traf sich Arnall mit den Rifemissären Si Mohammed Boujibar und Si Abdelkrim ben el Haj Ali Luh in Gibraltar, von wo sie auf der »R.M.S. Orsovak der Orient Line of Royal Mail Steamers in

\footnotetext{
${ }^{423}$ ADMAE Maroc 111, 142: Caïd Haddou an Abdelkrim, 16.5.1922; TAHTAH, Pragmatisme 1995, Dok. 14, S. 144-146, S. 145f.

${ }^{424}$ PRO-FO 371, 8354, 4882, 54: Bericht »Memorandum of a Statement Made by Mr. John Arnallk, 28.5.1922.

${ }^{425}$ HARRIS, Spain's Moroccan War, 30.5.1922. Vgl. Une déclaration d'Abd el Krim, in: BCAF 32 (1922) S. $301 \mathrm{f}$.

${ }^{426}$ PRO-FO 371, 8354, 4882, 40 und 42: John Amall an Arthur Field, 29.5.1922 und 30.5.1922; PRO-FO 371, 8354, 4882, 39: New Scotland Yard an FO, 10.6.1922; PRO-FO 371, 8342, 171, 53: Bericht "Memorandum by Mr Wingfield on the Moroccan Situation«, 5.7.1922.
} 
Richtung Großbritannien aufbrachen. Am 10. Juli 1922 erreichten sie London $^{427}$. Ali Luh trug einen Brief Abdelkrims bei sich, der ihn dazu berechtigte, als Repräsentant des Rifs politische und wirtschaftliche Verhandlungen mit jedem europäischen Land zu führen ${ }^{428}$.

Das vom spanischen Botschafter vorgewarnte britische Außenministerium veranlaßte bei der Ankunft eine gründliche Durchsuchung des Gepäcks. Zivilbeamte von Scotland Yard überwachten die weiteren Bewegungen der Delegation $^{429}$. Auch die spanische Botschaft Londons ließ Amall und die Rifkabylen von nun an beschatten. Botschafter Merry del Val befürchtete, daß die Rifabgesandten in Großbritannien Waffen kaufen wollten. Ein Detektiv namens Stockley verfolgte sie auf Schritt und Tritt. Spanien hatte auch in anderen Hauptstädten Europas Detekteien beauftragt, das Rif beliefernde Waffenschmuggler aufzuspüren. In Paris arbeitete die Agentur Jourdain für die dortige spanische Botschaft ${ }^{430}$.

Die »Times« vom 12. Juli 1922 veröffentlichte eine weitere Erklärung Abdelkrims. Zusätzlich zu seiner Forderung nach Anerkennung der Unabhängigkeit und seiner Garantie der wirtschaftlichen Gleichbehandlung für alle Nationen und Religionen nannte er auch Friedensbedingungen. Er verlangte von Spanien die Räumung des Rifs mit Ausnahme von Melilla sowie der Festungen in der Bucht von Alhucemas und von Peñon de Vélez de la Gomera. Das Zeichen war deutlich. Damit hätte Tetuan, der Sitz des spanischen Hochkommissariats, geräumt werden müssen ${ }^{431}$.

Am gleichen Tag bat John Arnall das Außenminsiterium brieflich darum, die Rifdelegation zu empfangen, was kategorisch abgelehnt wurde ${ }^{432}$. Für Unter-Staatssekretär Gerald Villiers war längst klar: »Was sie wollen - und was besonders Mr. John Arnall will - ist Geld. Ihr Ziel ist, diese Bergbau-Konzessionen zu verkaufen ${ }^{433}$. Neben der Haltung der britischen Regierung, den Status quo in Marokko beibehalten zu wollen, kam just zu dieser Zeit die noch ungeklärte Tangerfrage hinzu. Hier gab es erhebliche Meinungsverschieden-

${ }^{127}$ CADN Londres C524: MAE an Ambassade de Londres, 22.7.1922; CADN Tanger A427: Centre de renseignements extérieurs du Maroc, Renseignements, 8.7.1922; TNLA, GGD, 1: Walter Harris an Geoffrey Dawson, 9.7.1922; Riff Mission to England, in: Daily Telegraph, 10.7.1922; Riff Arabs Delegation, in: Daily Telegraph, 11.7.1922; MADARIAGA, L'Espagne et le Rif, Bd. 2, S. 203; TAHTAH, Pragmatisme 1995, S. 105.

${ }_{428}$ SHAT 3H1559: Région de Fè, SR, Bulletin de renseignements, 26.4.1923.

${ }^{429}$ PRO-FO 371, 8354, 4882, 87: Scotland House an FO, 12.7.1922.

${ }^{430}$ PRO-FO 371, 8354, 4882, 101: Note, 5.8.1922; PRO-FO 371, 8354, 4882, 102: John Arnall an FO, 31.7.1922; APP BA 1678: Bericht "A.S. de la contrebande d'armes à destination du Riff«, 24.2.1925; SUEIRO SEOANE, Contrabando, S. 263f.

${ }^{431}$ Rifis' Demand for Independence. Delegates Reach England, in: Times, 12.7.1922; Les aspirations d'Abd el Krim, in: BCAF 32 (1922) S. 350.

432 PRO-FO 371, 8354, 4882, 83: John Arnall an FO, 12.7.1922; PRO-FO 371, 8354, 4882, 85: FO an John Arnall, 19.7.1922.

${ }^{433}$ PRO-FO 371, 8354, 4882, 66: Note, 7.7.1922. 
heiten speziell zwischen Großbritannien und Frankreich. Die französische Regierung unter Raymond Poincaré wollte die durch den Rifkrieg geschwächte Position Spaniens dahingehend ausnutzen, ihren Einfluß in Tanger zu erhöhen. Großbritannien indes beharte auf der Neutralität Tangers. Eine Einmischung in den Rifkrieg jedweder Art hätte die britische Verhandlungsposition nur erschwert ${ }^{434}$.

Arnalls Suche nach Wirtschaftskontakten hatte wenig Erfolg. Britische Finanziers waren nur bei einer politischen Absicherung bereit, große Summen Geld für das Rif auszugeben. Ende Juli 1922 sprach Arnalls Vertrauter Colonel John Ward in Begleitung seines Geschäftspartners Joseph Nolan im AuBenministerium vor und regte ein Treffen mit der Rifdelegation an. Arnall bat ebenfalls dringend um einen Termin mit britischen Regierungsvertretern, um - wie er schrieb - zu verhindern, daß die Rifdelegierten Spekulanten in die Falle gingen. Er bekräftigte erneut, daß es für Großbritannien um die Sicherung des Wasserweges nach Gibraltar gehe, denn nach einer Niederlage Spaniens werde Frankreich den Rifdistrikt übernehmen, um dort Ordnung zu schaffen ${ }^{435}$. Auch im August 1922 traktierte Arnall das Außenministerium mit Briefen. Einmal bat er um die Weitervermittlung der Delegierten an die British Trade Corporation ${ }^{436}$, ein anderes Mal drängte er auf ein zumindest inoffizielles Treffen, um die Delegierten nicht mit der Meinung, Großbritannien sei der Feind des Islam, ins Rif zurückkehren zu lassen ${ }^{437}$. Schließlich platzte Gerald Villiers der Kragen. Er untersagte jegliche weitere Korrespondenz mit Arnall und der Rifgesandtschaft ${ }^{438}$.

Mittlerweile hatte Arnall einen Appell Abdelkrims »an die zivilisierten Nationen« erhalten, den er dem Außenministerium am 2. September 1922 zukommen ließ. Abdelkrim rief dazu auf, den Rifkabylen gegen Spanien beizustehen und eine Konferenz zur Klärung der Riffrage einzuberufen. Und weiter hieß es, daß die Rifbevölkerung weder der »modernen Zivilisation« noch "Projekten der Reformierung" oder »wirtschaftlichen Beziehungen mit Europa» abgeneigt sei. Sie wolle eine Regierung bilden, die nach eigenem Willen Gesetze erlasse und wirtschaftliche Verträge abschließe ${ }^{439}$. Hier zeigte sich der Zusammenhang zwischen Abdelkrims Wunsch nach Unabhängigkeit und seinem Willen $\mathrm{zu}$ eigenständigen wirtschaftlichen Entscheidungen besonders deutlich.

\footnotetext{
${ }^{434} \mathrm{Zu}$ den Tanger-Verhandlungen zu dieser Zeit: BENNETT, Britain's Relations, S. 69-73; DERS., British Foreign Policy, S. 139f.

${ }^{435}$ PRO-FO 371, 8354, 4882, 102: John Arnall an FO, 31.7.1922; PRO-FO 371, 8354, 4882, 97 und 148: Minute, 21.7.1922 und 28.7.1922.

${ }_{436}$ PRO-FO 371, 8354, 4882, 114: John Arnall an FO, 7.8.1922.

${ }^{437}$ PRO-FO 371, 8354, 4882, 123: John Arnall an FO, 11.8.1922; ähnlich PRO-FO 371, 8354, 4882, 133: John Armall an FO, 29.8.1922.

${ }^{438}$ PRO-FO 371, 8354, 4882, 132: Note, 31.8.1922.

${ }^{439}$ PRO-FO 371, 8354, 4882, 153: John Arnall an FO, 2.9.1922.
} 
Drei Tage später legten Si Mohammed Boujibar und Si Abdelkrim ben el Haj Ali Luh dieses Manifest ihrem einzigen selbst verfaßten Brief an das Außenministerium nochmals bei. Sie wiesen darauf hin, daß sie nun seit zwei Monaten darauf warteten, vorgelassen zu werden, und verdeutlichten, daß Großbritannien nur um Hilfe gebeten werden solle, um einen Frieden mit Spanien zu schließen. Dies käme auch dem internationalen Handel zugute ${ }^{400}$.

Die Verbindung zwischen politischen Ansprüchen und wirtschaftlichen Angeboten stach auch in ihrem zur gleichen Zeit an die Vollversammlung des Genfer Völkerbundes gerichteten Zwölf-Punkte-Appell hervor. In ihm drückten sie unter anderem den Willen der Rifregierung zu einem Friedensabkommen mit Spanien sowie die Bereitschaft zu einer Festlegung der Grenzen und zur garantierten Öffnung des Handels mit allen Nationen aus. Auf ihre Bitte, als Repräsentanten des Rifs Gehör zu finden, wurde jedoch nicht eingegangen $^{44 !}$.

Mehr Resonanz erhielten Boujibar und Ali Luh in moslemischen Kreisen Londons $^{442}$. Sie trafen Syed Ameer Ali von der British Red Crescent Society, der vergeblich eine Zusammenkunft mit dem spanischen Botschafter zu vermitteln versuchte, und den indischen Journalisten Abdelkroum Malek ${ }^{443}$. Von der pan-islamistischen Gruppierung El Khalifa el Islamia erhielten sie Hilfsgüter und etwas Geld ${ }^{444}$. Über ihre Londoner Kontakte - darunter die von Indern geführte Zeitung »Muslim Outlook« - ließen sie einen Appell Abdelkrims an die moslemische Welt um Unterstützung in Zeitungen und Zeitschriften Nordafrikas und des Nahen Ostens veröffentlichen ${ }^{445}$.

Anfang Dezember 1922 arrangierte John Arnall ein Treffen der Rifdelegierten mit seinem Parteigenossen von der Independent Labour Party Edmund Dene Morel. Morel hatte sich als Begründer und Geschäftsführer (1904-1912) der gegen Menschenrechtsverletzungen protestierenden Congo Reform Association einen Namen gemacht. Ihr gehörte auch Ernest N. Bennett, der spätere Präsident des Londoner Riff-Committees, an. Morel hatte ebenso als VizePräsident der Anti-Slavery Society fungiert. Er war Autor des Buches »Mo-

${ }^{440}$ PRO-FO 371, 8354, 4882, 160: Si Mohammed Boujibar, Si Abdelkrim ben el Haj Ali Luh an FO, 5.9.1922.

${ }^{41}$ PRO-FO 371, 8354, 4882, 166: John Arnall an FO, 5.9.1922 mit einer Kopie des Appells; CADN Madrid C273: MAE an Ambassade de Madrid, 15.9.1922.

${ }^{442}$ MadariagA, L'Espagne et le Rif, Bd. 2, S. 205; AYACHE, La Guerre du Rif, S. 248; DERS., Les implications internationales, S. 197.

${ }^{443}$ IORL, P\&J, 12, 230, 1671, 1924: A Merry del Val an Lord Birkenhead, Secretary of State for India, 18.3.1925; CADN Maroc DAI 189: Bericht »Renseignements donnés par Boujibari beau-frère d'Abdelkrim« o.D. [1926]. Siehe zu Syed Ameer Ali Kapitel 3, S. 65, S. 67, S. 70-73, S. 80-84.

44 CADN Londres C518: MAE an Ambassade de Londres, 30.12.1922, Ambassade de Londres an MAE, 17.1.1923.

${ }^{445}$ IORL, P\&J, 12, 230, 1671, 1924: A. Merry del Val an Lord Birkenhead, Secretary of State for India, 18.3.1925. 
rocco in Diplomacy « (1912), Mitglied der Liberal Party bzw. nach dem Ersten Weltkrieg der Independent Labour Party (ILP), Herausgeber der Zeitung "West African Mail» (1903-1925) und der Zeitschrift »Foreign Affairs« sowie Mitbegrïnder und Aktivist der pazifistischen Union of Democratic Control (UDC). Die Zeitschrift »Foreign Affairs« wurde in der Folgezeit ab 1924 zu einem Podium der Rif-Sympathisanten in London ${ }^{446}$. Morel war aber auch der Autor des rassistischen Werkes "The Horror on the Rhine« (1920), das die Besetzung des Rheinlandes durch farbige Soldaten Frankreichs anprangerte ${ }^{447}$.

Morels Vermittlungsversuch scheiterte kläglich. Eine Antwort auf sein Schreiben an das Außenministerium vom 4. Dezember 1922 blieb aus ${ }^{448}$. Die enttäuschten Ali Luh und Boujibar gaben ihre Bemühungen auf und verließen London $^{49}$. Durch Morels Einsatz waren allerdings erste Kontakte zu Sympathisanten in London geknüpft worden. Arnalls Mission war in diplomatischer wie wirtschaftlicher Hinsicht ein völliger Fehlschlag. Nach der gescheiterten Rifmission in Frankreich im selben Jahr handelte es sich um einen weiteren politischen Rückschlag für Abdelkrim. Später erzählte er dem amerikanischen Journalisten Paul Scott Mowrer, daß ihn der Mißerfolg sehr gekränkt habe ${ }^{450}$. Ende 1922 war damit John Arnalls Zeit als Kontaktmann Abdelkrims nach Großbritannien abgelaufen.

Nichts deutet darauf hin, daß Daniel Bourmancé-Say oder John Arnall 1921 davon gewußt hatten, daß es jeweils einen anderen politischen Vermittler der Rifkabylen gab. Es war kurios: Abdelkrim wurde 1921 bis 1922 von einem anglophobischen Franzosen und von einem gallophobischen Briten vertreten, deren Interessen diametral entgegengesetzt waren. Beide vereinte nur ihr Grundgedanke, daß sie wesentlich mehr von der Riffrage zu verstehen glaubten als die Diplomaten in den Heimatländern. Vermutlich wollte Abdelkrim sie entweder gegeneinander ausspielen, oder er hoffte, daß eine der beiden oder gar beide Initiativen Früchte tragen würden.

${ }^{446}$ STENTON, LEES, Who's Who, Bd. 3, S. 249f.; Adam HoCHSCHILD, Schatten über dem Kongo. Die Geschichte eines fast vergessenen Menschheitsverbrechens, Reinbek 2002, S. 319 und passim.

${ }^{447}$ Robert REINDERS, Racialism on the Left. E.D. Morel and the "Black Horror on the Rhine火, in: International Review of Social History 13 (1968) S. 1-28; Keith L. NELSON, The "Black Horror on the Rhine«. Race as a Factor in Post-World War I Diplomacy, in: Journal of Modern History 42 (1970) S. 606-627; LEBZELTER, "Schwarze Schmach«, S. 37-58; LüSEBRINK, Kolonialsoldaten, S. 53-64.

${ }_{448}^{48}$ PRO-FO 371, 8354, 4882, 184: Edmund D. Morel an FO, 4.12.1922.

499 PRO-FO 371, 8354, 4882, 191: John Arnall an FO, 11.12.1922.

${ }^{450}$ CADN Londres C519: MAE an Ambassade de Londres, 10.11.1924 mit einem Bericht Mowrers über seinen Rifaufenthalt. 


\subsection{Abdelkrim und der Monopolvertrag mit Charles Gardiner}

Im Dezember 1922 schickte Abdelkrim seinen Bruder Si M'hammed und Si Mohammed Mohammedine Hitmi mit politischen, militärischen und wirtschaftlichen Aufträgen nach Paris. Über Tlemcen und Algier gelangten sie in europäischer Kleidung und unter falschem Namen nach Frankreich ${ }^{451}$.

In Paris empfing sie der örtliche Rifrepräsentant Ahmed Balloul. Der Algerier lehrte seit 1918 am Pariser Collège Sainte-Barbe Mathematik. Er gehörte dem Comité de souscription en faveur des miséraux en Algérie an und war Chefredakteur der 1922 von Jean-Marie Bouteloup gegründeten Zeitschrift "Le Courrier de France et Afrique«. Als Generalsekretär der Ligue pour la représentation des indigènes algériens kämpfte er dafür, daß Algerier Mitglied des französischen Parlaments werden konnten. Er war ein Anhänger des algerischen Nationalisten Emir Khaled el Hachemi, der im ägyptischen Exil lebte $^{452}$.

Am 20. Dezember 1922 traf sich Balloul mit dem stellvertretenden Direktor der Afrikaabteilung des französischen Außenministeriums Peretti della Rocca und übermittelte ihm den Dank Abdelkrims für die bisherige Duldung der Nachschublieferungen von Französisch-Marokko ins Rif. Dafür sollten Frankreich ein Handelsmonopol und wichtige Bergbau-Konzessionen gewährt werden. Balloul erkundigte sich nach der Möglichkeit des Erwerbs von Waffen, was Peretti della Rocca strikt ablehnte. Er ließ Abdelkrims Bruder ausrichten, daß momentan lediglich »die Augen verschlossen werden könnten«, wenn der Aufenthalt der Delegierten streng geheim bleibe und sich auf eine sehr kurze Dauer beschränke ${ }^{453}$. Am gleichen Tag verkaufte Si M'hammed an Henri François Moulis, Marcel Collin, Henri Bousquié und Mohammed Damardji Bergbaurechte für den Jebel Hamam im Wert von 13 Millionen Francs. Zur Moulis-Gruppe zählte ebenso der Belgier Jean-Baptiste Garcin. Der Vertrag war an ein Waffengeschäft gekoppelt ${ }^{45}$ und in den Redaktionsräumen der Zeitschrift "Le courrier de France et Afrique« über deren Besitzer Jean-Marie Bouteloup und über Ahmed Balloul ausgehandelt worden ${ }^{455}$.

\footnotetext{
${ }^{451}$ ABDELKRIM, Memoiren, S. 78.

452 APP BA 1678: Bericht "A.S. de la contrebande d'armes à destination du Riff «, 24.2.1925; AN F7, 13413: MI, Direction générale, Cabinet de direction, Note, 22.7.1925; SueIRo SEOANE, España, S. 25; Ahmed KoulaKSSIS, Gilbert MEYNIER, L'émir Khaled, premier za'im? Identité algérienne et colonialisme français, Paris 1987, S. 119, S. 187, S. 206; Une lettre de l'émir Khaled, banni, à M. Herriot, in: Humanité, 3.7.1924.

${ }^{453}$ ADMAE Maroc 195, 234: Bericht »Note au sujet d'Abd el Krim«, 20.12.1922.

${ }^{454}$ ADMAE Maroc 111, 92: Vertrag zwischen Si M'hammed und Marcel Collin, Henri Moulis, Henri Bousquié sowie Mohammed Damardji, 20.12.1922; KHARCHKH, La France, S. 152, Anm. 1. Siehe zum Waffengeschäft Kapitel 5, S. 179.

${ }^{455}$ AN F7, 13413: MI, Direction générale, Cabinet de direction, Note, 22.7.1925.
} 
Moulis suchte Finanziers und wandte sich über den Wermelskirchener Geschäftsmann Karl Hackländer an den Engländer Captain Charles Alfred Percy Gardiner. Im Januar 1923 kam es zur ersten Zusammenkunft zwischen dem Briten und Si M'hammed. Die Unterredung fand in der Pariser rue des Pyramides in den Büroräumen des in Frankreich geborenen Norwegers Christian Deboe statt. Deboe, der Gardiner seit 1919 kannte, fungierte als Übersetzer, da der Brite nur Englisch sprach. An den Gesprächen nahm Hackländer teil ${ }^{456}$. Auf der Seite der Rifkabylen saß neben Si M'hammed und Si Mohammed Mohammedine Hitmi nun auch Si Mohammed Boujibar, der von der erfolglosen Arnall-Mission im Jahr zuvor aus London nach Paris gekommen war ${ }^{457}$. $\mathrm{Da}$ Moulis und seine Partner nicht in der Lage waren, fristgerecht ihre Zahlungen zu leisten, übernahm Gardiner das Geschäft und weitete es aus. Am 30. April 1923 schloß er mit der Rifregierung einen umfassenden wirtschaftlichen Monopolvertrag $\mathrm{ab}^{458}$.

Der Zeitpunkt der kurz zuvor erfolgten Proklamation der "Rif-Republik» - der 1. Februar 1923 - war daher kein Zufall, sondern von Abdelkrim mit Bedacht gewählt worden, um Verhandlungen mit ausländischen Kapitalgebern zu erleichtern. Ein Rifstaat sollte für Investoren interessanter wirken ${ }^{459}$. Damit setzte Abdelkrim eine Idee von Daniel Bourmance-Say aus dem Vorjahr in die Tat um - allerdings hauptsächlich zugunsten von dessen Hauptfeinden, den Briten ${ }^{460}$. Nichts deutet darauf hin, daß Gardiner von zeitgleichen Verhandlungen Abdelkrims mit Horacio Echevarrieta über ein Projekt einer Chartergesellschaft wußte. Hier zeigt sich also erneut, daß Abdelkrim gerne parallel in mehrere Richtungen verhandelte.

Gardiner protzte in Paris mit seinen internationalen Kontakten. In einem Schreiben an Si M'hammed vom 30. April 1923, also dem Tag des Vertragsabschlusses, führte er aus, ein Arrangement mit einer aus Briten, Franzosen, Belgiern und Amerikanern bestehenden Finanzierungsgruppe eingegangen zu

${ }^{456}$ ADMAE Maroc 133, 15: Notice o.D. (August 1925); CADN Londres C519: MAE an Ambassade de Londres, 26.5.1924; ADMAE Maroc 133, 136: Embajada de Paris an MAE, 30.12.1924; PRO-FO 371, 9474, 2275, 121: Embajada de Londres an FO, 18.6.1923; AN F7, 13413: Bericht »Déclaration de M. Deboe«, 30.7.1925. Siehe zu Hackländer auch Kapitel 5, S. 179f., S. 184, S. 201 f.

${ }^{457}$ GARDINER, Ambassador, 26.7.1925; GABRIELl, Abd-el-Krim, S. 44; FURNEAUX, Abdel Krim, S. 156. In den Quellen deutet nichts auf eine Verbindung zwischen John Arnall und Charles Gardiner hin.

${ }^{458}$ Charles Gardiner an Moulis \& Cie., 21.4.1923, in: DUNET, La sanglante aventure, S. 93-96, S. 93f.; ADMAE Maroc 111, 25: Vertrag zwischen der Rifregierung und Charles Gardiner, 30.4.1923.

${ }^{459}$ TahtAH, Pragmatisme 1995, S. 89; Spain's Problem in Morocco. The Riff Rebellion (Abdruck eines Artikels aus dem »Daily Telegraph«), in: Al-Moghreb al Aksa \& Tangier Gazette, 15.9.1923; SHEEAN, War in Africa, S. 259.

${ }^{460}$ CADN Maroc DAI 198: Daniel Bourmancé-Say an Abdelkrim, 22.5.1922; DAOUD, Abdelkrim, S. 159. 
sein. Dies behauptete Gardiner einen Monat später auch in der britischen Botschaft von Paris ${ }^{461}$. Sein Partner Christian Deboe bestätigte finanzielle Verbindungen Gardiners nach Großbritannien und in die USA ${ }^{462}$. Um wen genau es sich handelte, blieb offen. Doch es war alles. andere als ein angesehenes internationales >Syndikat<, das mit Gardiner zusammenarbeitete.

Die Franzosen und der Belgier. Die einzigen Franzosen, mit denen Gardiner zu tun hatte, waren Henri François Moulis, Marcel Collin, Henri Florent Bousquié, Jean-Marie Bouteloup, Mohammed Damardji (seine Nationalität ist unklar) sowie der Belgier Jean-Baptiste Garcin, die ihn mit den Rifkabylen zusammengebracht hatten. Während Gardiner ihnen eher skeptisch gegenüberstand, erkannte Si M'hammed Collin, Damardji und Bouteloup am 21. Juni 1923 eine einprozentige Gewinnbeteiligung an den Geschäften des Briten $\mathrm{zu}^{463}$.

Die Skandinavier. Der Norweger Christian Deboe versuchte 1923, zusammen mit seinem Landsmann Gotfred Hofseth und dem Dänen Jonas Lind die im Gardiner-Vertrag vereinbarten Schiffsverfrachtungen von und nach Marokko zu organisieren. Vermutlich mit wenig Erfolg, denn schon Anfang 1924 löste sich diese Gruppe wieder auf ${ }^{164}$.

Die Amerikanerin. Christian Deboe zufolge war eine mit Gardiner befreundete Amerikanerin namens »Mlle Tinker«, die im Pariser Hôtel de Castille residierte, am Vertrag mit der Rifregierung beteiligt. Sie starb Ende 1923 oder Anfang 1924 an den Folgen einer in London durchgeführten Operation ${ }^{465}$.

Der Deutsche. Karl Hermann Hackländer galt als engster Geschäftspartner Gardiners $^{466}$. Er sollte mit potentiellen deutschen und holländischen Interessenten in Verbindung treten ${ }^{467}$. Darunter befand sich die Gesellschaft Wm. H. Müller \& Co., die 1923 mit der Oberhausener Gutehoffnungshütte (GHH) die Sociedad minera marroquí mit Sitz in Santander gründete, um die marok-

461 ADMAE Maroc 111, 46: Charles Gardiner an Si M'hammed, 30.4.1923; PRO-FO 371, 9474, 2275, 208: Embassy of Paris an FO, 29.5.1923; Charles A.P. GARDINER, A Correction (Leserbrief), in: Al-Moghreb al Aksa \& Tangier Gazette, 28.11.1925.

${ }^{462}$ AN F7, 13413: Bericht »Déclaration de M. Deboek, 30.7.1925.

${ }^{463}$ Charles Gardiner an Moulis \& Cie., 21.4.1923, in: DUNET, La sanglante aventure, S. 93-96, S. 93f.; ADMAE Maroc 111, 96-98: Erklärungen von Si M'hammed, 23.6.1923.

${ }^{464}$ APP BA 1678: Bericht "A.S. de la contrebande d'armes à destination du Riff", 24.2.1925.

${ }^{465}$ AN F7, 13413: Bericht "Déclaration de M. Deboe«, 30.7.1925; ADMAE Maroc 133, 136: Embajada de Paris an MAE, 30.12.1925.

${ }^{466}$ APP BA 1678: Bericht "A.S. de la contrebande d'armes à destination du Riff", 24.2.1925; ADMAE Maroc 133, 15: Notice o.D. [August 1925].

${ }^{467}$ AN F7, 13413: Bericht "Déclaration de M. Deboe«, 30.7.1925; PRO-FO 371, 9474, 2275, 121: Embajada de Londres an FO, 18.6.1923. 
kanischen Erzvorräte zu erschließen. Dies sollte der deutsch-holländischen Gesellschaft aber versagt bleiben, auch wenn ihr am 1. August 1926 eine Konzession über 774 ha in Beni Sicar erteilt wurde ${ }^{468}$.

Die Briten. Der damals fast 59jährige 18. Baron von Teynham alias Henry John Philip Sidney Roper-Curzon kannte Gardiner bereits von dessen in Konkurs gegangener Firma Gardiner Shipbuilding \& Enginnering Company her ${ }^{469}$. Er hatte ebenso wie Hackländer an den Verhandlungen mit der Rifdelegation teilgenommen ${ }^{470}$.

Auch die Gesellschaft International Oil Suppliers zählte zu Gardiners Partnern. Die am 19. Mai 1922 gegründete Firma verfolgte als Ziel, weltweit Handel mit Bergbau-Konzessionen aller Art zu betreiben, Bergbaubetriebe aufzukaufen sowie die Infrastruktur für den Betrieb von Bergbauanlagen - Eisenbahnstrecken, Straßen, Telegrafenleitungen, Häfen u.ä. - zu errich$\operatorname{ten}^{471}$. Diese Zielsetzung paßte sehr gut zum Gardiner-Vertrag. Als sich der spanische Botschafter von London darüber beschwerte, daß die Gesellschaft mit Waffenschmuggel zu tun habe ${ }^{472}$, gab ein Captain Miller von New Scotland Yard Entwarnung: "Diese Leute verfügen über keinen Schilling und haben nicht das Kaliber von Waffenhändlern. Sie wollen einen Dummkopf dazu bringen, ihnen in der Hoffnung, Konzessionen im Rif zu erwerben, Geld vorzuschießen. Wenn sie dies schaffen können, werden sie wahrscheinlich untertauchen ${ }^{473}$. Der Geschäftsführer der International Oil Suppliers, Thomas Israel Perrott, war allerdings tatsächlich in Waffengeschäfte mit dem Rif verwickelt $^{474}$.

Nicht minder dubios war Gardiners Partner Bernard Maimon, ein Bekannter Karl Hackländers ${ }^{475}$. Der gebürtige Malteser hatte sich Ende des 19. Jahrhunderts als Spion des türkischen Sultans verdingt und 1911 einen Riesenskandal in Frankreich verursacht, als er aus dem französischen Außenministerium Geheimunterlagen über den Bau der Bagdadbahn gestohlen und zur Veröffentli-

\footnotetext{
${ }^{468}$ MASCHKE, Es entsteht ein Konzern, S. 81; LEONIDOFF, Der Kampf, S. 1971; MoRALES LEZCANO, Las minas, S. 79.

${ }^{469}$ PRO-FO 371, 9474, 2275, 208: Embassy of Paris an FO, 29.5.1923; PRO-BT 31, 25262, 160911: Bericht »Register of Directors or Managers of the Gardiner Shipbuilding \& Engineering Company«, 20.11.1920. Zu Teynham: Who's Who 78 (1926) S. 2862; Who Was Who 3 (1947) S. 1335.

${ }^{470}$ PRO-FO 371, 9474, 2275, 200: Lord Teynham an FO, 29.5.1923; GARDINER, Ambassador, 26.7.1925.

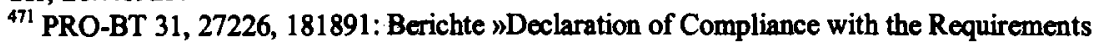
of the Companies (Consolidation) Act, 1908«, 19.5.1922, "Memorandum of Association of the International Oil Suppliers«, 19.5.1922.

${ }^{47}$ PRO-FO 371, 9470, 44, 91 und 94: Embajada de Londres an FO, 17.10.1923 und 18.10 .1923 .

${ }^{473}$ PRO-FO 371, 9470, 44, 125: Note, 23.10.1923.

${ }^{474}$ Siehe Kapitel 5, S. 200.

${ }^{475}$ PRO-FO 174, 305, 88: Karl Hackländer an Arthur J. Barry, 2.11.1925.
} 
chung freigegeben hatte. Nun, 1923, suchte er Finanzierungsmöglichkeiten für Gardiners Syndikat zur Entwicklung des Rifs ${ }^{476}$. Mehr hatte Gardiner nicht aufzubieten. Er konnte weder zum Zeitpunkt des Vertragsabschlusses noch später eine Gruppe mit einem nennenswerten finanziellen Hintergrund vorweisen. Es handelte sich um einen Bluff.

Der für 99 Jahre gültige Vertrag mit der Rifregienung sah vor, daß Gardiner ein Exklusivrecht für alle wirtschaftlichen Angelegenheiten der »Rif-Republik« erhielt. Dies beinhaltete das alleinige Recht zum Bau von Gebäuden (auch Theater oder Kinos), Eisenbahnstrecken, Telegrafen- und Telefonleitungen, Hafenanlagen, Raffinerien oder Straßen sowie zur Ausbeutung aller Bodenschätze und land- bzw. forstwirtschaftlichen Ertragsgüter. Gardiner erhielt das Monopol zum Betreiben von Kasinos. Das Postwesen, die Luft- und Schiffahrt, die Fischerei, das Schul- und Universitätswesen, der 〉öffentliche Nahverkebr`, das Elektrizitätswesen oder das Gesundheitssystem sollten von Gardiner entwickelt werden. Der Brite vereinbarte als Gesamtpreis für alle Konzessionen die Summe von einer Million Pfund. Bis zum 30. Oktober 1923 hatte er Schmuggelgut im Wert von 300000 Pfund auszuliefern und bis zum 30. August 1923500000 Pfund als Hypothek auf eine Pariser Bank zu überweisen. Der Vertrag galt nicht für militärische Gebiete und religiöse Stätten. Punkt 16 bestimmte, daß im Falle der Gründung einer internationalen Gesellschaft zur wirtschaftlichen Erschließung des Rifs entweder Si M'hammed oder ein anderer Rifkabyle deren Präsident werden müsse ${ }^{477}$.

Im neunten Nachtrag des Vertrages und in einer Zusatzerklärung vom 30. April 1923 wurde festgelegt, daß von Abdelkrim bereits verkaufte Gebiete nicht Bestandteil der Vereinbarung waren ${ }^{478}$. Es handelte sich um Rechte, die Abdelkrim an die Sociedad anónima minera Setolazar ${ }^{479}$ und an die Compañía española de Minas del Rif ${ }^{480}$ vergeben hatte. Er brauchte diesen Trumpf für

${ }^{476}$ PRO-FO 371, 9470, 44, 169: New Scotland Yard an FO, 21.11.1923; PRO-FO 174, 305, 88: Karl H. Hackländer an A.J. Barry, 2.11.1925. Vgl. zu Maimon auch HALLGARTEN, Imperialismus, Bd. 2, S. 163, Anm. 2, S. 220 u. S. 220, Anm. 2, S. 655.

${ }^{477}$ ADMAE Maroc 111, 25: Vertrag zwischen der Rifregierung und Charles Gardiner, 30.4.1923; ADMAE Maroc 111, 49: Charles Gardiner an Si M'hammed, 30.4.1923; DUNET, La sanglante aventure, S. 85-91; WOOLMAN, Rebels in the Rif, S. 127; MADARIAGA, España y el Rif, S. 535; ESPAÑa, La actuación, S. 294; TAHTAH, Pragmatisme 1995, S. 104; Kharchich, La France, S. 158; ShIN, La Guerte du Rif, S. 119f.; Pennell, A Country, S. 210f.; FONTAINE, L'étrange aventure, S. 93.

${ }^{478}$ ADMAE Maroc 111, 40, 42 und 46: Si M'hammed an Charles Gardiner, 30.4.1923, Vertragszusatz »Addendum 9 conçernant les clauses du contrat passé le 30 avril 1923«, Charles Gardiner an Si M'hammed, 30.4.1923.

${ }^{479} 1907$ und 1920 hatte Abdelkrim Bergbaugebiete in Beni Ouriaghel und Beni Touzine veräußert [TAHTAH, Pragmatisme 1995, S. 82; MADARIAGA, Mohammed ben Abdelkrim, S. 28f.; DIES., España y el Rif, S. 493-495, S. 503].

${ }^{480}$ ADMAE Maroc 111, 15: RG Rabat an MAE, 6.7.1926; CADN Madrid C274: MAE an Ambassade de Madrid, 10.3.1923; ADMAE Maroc 195, 321: CG Tanger an MAE, 9.3.1923. 
seine parallelen Gespräche mit spanischen Unterhändlern. In seinen späteren Friedensbedingungen vom September 1923 machte Abdelkrim klar, daß Bergbau-Konzessionen, die ohne seine Zustimmung erlangt worden waren, ungültig seien - mit Ausnahme der von den beiden spanischen Gesellschaften erworbenen Gebiete im Bereich der Guelia, Beni Touzine, Beni Selimane und Anjera $^{481}$.

Die restlichen Bergbaugebiete des Rifs wurden an Gardiner übertragen. Si M'hammed und Si Mohammed Mohammedine Hitmi brachten Henri Letellier dazu, das von P. Robert verfaßte Bergbaugutachten von 1922 an Gardiner und seine Gruppe zu veräußern. Der Bericht von Robert erfuhr keinerlei Veränderungen oder Aktualisierungen, sondern wurde lediglich übersetzt und umdatiert $^{482}$. Dies war die einzige Grundlage, auf der Gardiners wirtschaftliche Hoffnungen beruhten.

Eine Besonderheit des Vertrags war der Auftrag an Gardiner, eine Staatsbank des Rifs mit einer eigenen Währung zu gründen - eine Idee, die Abdelkrims ausgemusterter Berater Daniel Bourmancé-Say ebenfalls im Jahr zuvor angeregt hatte ${ }^{483}$. Artikel 3 ließ Gardiner freie Hand. Er war berechtigt, neben Ajdir und London an allen Orten der Welt Filialen zu eröffnen. Er allein durfte Banknoten in von ihm zu bestimmenden Werten ausliefern, und nur er durfte Kredite vergeben ${ }^{484}$. Schon kurz nach der Unabhängigkeitserklärung der $»$ RifRepubliku hatte Abdelkrim im Februar 1923 verlautbaren lassen, daß innerhalb des Rifs nur noch die französische Währung benutzt werden sollte ${ }^{485}$. Die in der Regel verwendeten spanischen Peseten sollten aus dem Leben der Rifbewohner verschwinden und, wie es in einem souveränen Staat üblich war, durch eine eigene Währung ersetzt werden. Über die geplante Nationalbank des Rifs sollten die von Gardiner getätigten Geschäfte ablaufen ${ }^{486}$. "Kurz gesagt, Abdelkrim hat das Rif verkauft«, resümierte die französische Zeitung "Paris-Midi«, als der Vertrag später bekannt wurde ${ }^{487}$.

${ }^{481}$ PRO-FO 371, 9474, 2275, 230: Minute, 20.9.1923.

${ }^{482}$ ADMAE Maroc 195, 234: Bericht "Note au sujet d'Abd el Krim«, 20.12.1922; ADMAE Maroc 111, 59: Bericht »Mining Report from the Riff«, 29.4.1923; FONTANE, L'étrange aventure, S. 87.

${ }^{483}$ ADMAE Maroc 112, 133: Daniel Bourmancé-Say an Abdelkrim, 16.3.1922.

${ }^{484}$ ADMAE Maroc 111, 25: Vertrag zwischen der Rifregierung und Charles Gardiner, 30.4.1923; GODED LLOPIS, Marruecos, S. 93; KGRNER, La Guerte du Rif espagnole, S. 151; SHIN, La Guerre du Rif, S. 120; WoOLMAN, Rebels in the Rif, S. 127.

${ }^{485}$ PENNELL, A Country, S. 133.

${ }^{486}$ ADMAE Maroc 111, 42: Vertragszusatz "Addendum 9 conçernant les clauses du contrat passé le 30 avril $1923 \ll$.

${ }^{487}$ Abd el Krim a vendu le Rif, in: Paris-Midi, 13.12.1925. Vgl. Un document curieux. Le contrat d'Abdelkrim avec un anglais, in: Les annales tangéroises, 21.11.1925. 
Viele Fragen bezüglich der Intentionen Abdelkrims und Gardiners bleiben offen. Gingen die Khattabis Gardiner auf den Leim, war der Vertrag von seiner Seite aus reiner Betrug ${ }^{488}$ ? Und was trieb den offenbar vom Reichtum des Rifs überzeugten Briten dazu, ohne echte Beweise einen derartigen Vertrag abzuschließen? Was wollten die Khattabis mit dem Vertrag erreichen? Wollten sie sich angesichts einer vereinbarten Gewinnbeteiligung von $30 \%$ selbst bereichern ${ }^{489}$ ? Gerüchte über wirtschaftliche Eigeninteressen Abdelkrims gab es immer wieder. Daniel Bourmancé-Say, sein französischer Berater, behauptete dies mehrfach ${ }^{490}$. Auch der britische Konsul von Tetuan, C.A.W. Were, vermutete Ende 1922, daß Abdelkrim seine Position ausnutzte, um sich finanzielle Vorteile zu verschaffen ${ }^{491}$. Der schwedische Rifbesucher Hans Langlet, der alles andere als ein Gegner Abdelkrims war, sah ebenfalls "private ökonomische Interessen hinter den vermeintlichen patriotischen Forderungen $\kappa^{492}$.

Oder planten die Khattabis eine Art »Hongkong Nordafrikas ${ }^{493}$ ? Zweifelsfrei sahen sie eine umfassende Modernisierung des Rifs vor. Gardiners Monopolvertrag hatte Ähnlichkeit mit dem Mannesmann-Projekt von 1913, das allem Anschein nach als Grundlage für die Wirtschaftsverhandlungen von 1923 diente. Nahmen die Delegierten Gardiners Erzählungen von einer internationalen Finanzienungsgruppe, die nur dazu dienten, sie von der bevorstehenden Realisierung des Projektes zu überzeugen, wirklich ernst ${ }^{494}$ ? Wollte Abdelkrim nach fast zwei Jahren erfolgloser Verhandlungen endlich einen Vertrag mit einem Briten vorweisen können? Wollte er Gardiner funktionalisieren? Die vorhandenen Quellen sagen nichts darüber aus. Vermutlich hofften Abdelkrim und sein Bruder Si M'hammed, daß ein derartiger Vertrag nicht nur das Investitionsinteresse in Großbritannien erhöhen, sondern auch den Regierungen Europas die Ernsthaftigkeit ihrer Absichten im Hinblick auf eine eigenverantwortliche Umgestaltung des Rifs verdeutlichen würde.

Derweil versuchte Abdelkrim, die Bevölkerung auf die Veränderungen vorzubereiten. Es gab unter den Rifkabylen Befürchtungen, daß sich Europäer in der gesamten Region verbreiten würden, und Gegner Abdelkrims warnten davor, daß er das Rif verraten habe. Er betrieb daher regelrechte Propaganda

\footnotetext{
${ }^{488}$ Madariaga, España y el Rif, S. 535.

${ }^{489}$ KHARCHICH, La France, S. 163; DUNET, La sanglante aventure, S. 60; ADMAE Maroc 112, 292: Bericht »Reconnaissance Ahmed Balloul«, 21.6.1923; PRO-FO 371, 9470, 44, 98 : WO an FO, 17.10.1923.

${ }^{490}$ CADN Maroc DAI 189: Ministère de la Marine an RG Rabat, 17.8.1925 mit dem Bericht »Conversation avec Monsieur Bourmancé-Say«, 26.7.1925; SHAT 3H134: RG Rabat an MAE, 23.1.1924.

${ }^{491}$ PRO-FO 371, 9469, 44, 72: Consulate of Tetuan an CG Tangier, 14.12.1922.

492 LANGLET, Life, 1.5.1926.

${ }^{493}$ BoutBouQALT, La Guerte du Rif, S. 34.

494 AN F7, 13413: Bericht »Déclaration de M. Deboek, 30.7.1925.
} 
für seine Straßen- und Bergbauprojekte, und er begann mit dem Bau eines Verkehrsweges zwischen der Bucht von Alhucemas und dem Jebel Hamam. Diese Straße hatte rein wirtschaftliche Zwecke ${ }^{495}$.

Ebenfalls am 30. April 1923 wurde Gardiner zum »bevollmächtigten Minister und Berater der Regierung der Rif-Republik« ernannt. Seine Aufgabe bestand darin, wirtschaftliche und politische Verhandlungen mit dem Ausland zu führen ${ }^{496}$. Abdelkrim gab demnach seine Hoffnung nicht auf, durch Verbindung von Wirtschaft (Lockmittel Bergbau) und Politik (Hoffnung auf Anerkennung der »Rif-Republik«) diplomatische Fortschritte zu erreichen. Wie schon zuvor John Arnall versuchte auch Charles Gardiner, die britische Diplomatie für seine Suche nach Investoren einzuspannen. Er stellte sich am 28. Mai 1923 der britischen Botschaft in Paris als Repräsentant der Rif-Regierung vor und berichtete von seinem Wirtschaftsvertrag. Dort wurde ihm lediglich entgegnet, daß seine Sicherheiten recht dürftig seien, woraufhin Gardiner betonte, diesbezüglich keine Befürchtungen zu haben ${ }^{497}$. Lord Teynham stand ihm zur Seite und schrieb an sein Außenministerium, daß der per Kopie beigefügte Vertrag mit der Rifregierung von hoher Bedeutung für den britischen Handel sei, da er das gesamte Rifgebiet umfasse. Gleichzeitig bat er die britische Regierung um die offizielle Bestätigung der Konzessionen, denn trotz der Existenz eines »spanischen Protektorats« werde Abdelkrims Herrschaft vor Ort fast überall anerkannt ${ }^{498}$. Teynham und Gardiner versuchten, ihre Regierung von den vermeintlich großartigen wirtschaftlichen Aussichten im Rifgebiet zu überzeugen.

Hätte das britische Außenministerium ihren Vertrag als gültig bestätigt, wäre dies einer Anerkennung des Rifstaates gleichgekommen. Doch dort reagierte man mit äußerstem Erstaunen. Staatssekretär Kirkpatrick wunderte sich über den »albernen Plan«, und er fragte sich, wo Teynham das Geld auftreiben wolle. Er schlug vor, den Lord mit dem Hinweis »abzuschütteln«, daß er selbst für seine Aktivitäten das Risiko trage ${ }^{499}$. Am 5. Juni 1923 erhielt Teynham eine deutliche Absage ${ }^{500}$. Nicht mehr Erfolg hatte Gardiner bei seinem persönlichen Besuch am 30. Juni 1923. Er betonte, daß die Rifkabylen angesichts der Unfähigkeit Spaniens ein Recht auf eine eigene Verwaltung besäßen. Derzeit erarbeite er mit Abdelkrim den Entwurf für ein Abkommen. Es besage, daß Spanien der wRif-Republik« die gesamte Einflußzone mit Ausnahme von Ceuta und Melilla überlassen solle. Auf Gardiners Frage, ob die

${ }^{495}$ PRO-FO 371, 9469, 44, 115: Vice-Consulate of Tetuan an CG Tangier, 8.2.1923; SHAT 3H1559: Territoire d'Ouezzane, SR, Bulletin de renseignements, 31.7.1923.

${ }^{496}$ ADMAE Maroc 111, 45: Emennungsurkunde für Charles Gardiner, 30.4.1923; GARDINER, Ambassador, 26.7.1925.

${ }_{497}$ PRO-FO 371, 9474, 2275, 208: Embassy of Paris an FO, 29.5.1923.

498 PRO-FO 371, 9474, 2275, 200: Lord Teynham an FO, 29.5.1923.

499 PRO-FO 371, 9474, 2275, 198: Minute, 1.6.1923.

${ }^{500}$ PRO-FO 371, 9474, 2275, 203: FO an Lord Teynham, 5.6.1923. 
britische Regierung Einwände gegen den Erwerb von Rifkonzessionen durch eine britische Firma habe, betonte Kirkpatrick erneut, daß niemand davon abgehalten werden könne, dies auf eigene Verantwortung zu tun ${ }^{501}$.

Diese Haltung entsprach Großbritanniens prinzipieller Politik der Nichteinmischung. Gardiner hätte sich zudem keinen schlechteren Zeitpunkt für seine Initiative aussuchen können. Denn am 29. Juni 1923 wurde eine Konferenz zur Erarbeitung eines Tanger-Statuts in London eröffnet. Die weiteren Verhandlungen dauerten bis zum 18. Dezember 1923, ehe sich Spanien, Frankreich und Großbritannien einigen konnten ${ }^{502}$. Hierbei handelte es sich für die britische Regierung angesichts der strategischen Bedeutung Tangers um eine essentielle Frage. Jegliche Kontaktaufnahme auch zu einer frisch proklamierten »Rif-Republik« war damit ausgeschlossen.

Ebenso wenig Wirkung zeigte eine Erklärung der Rifregierung an die Nationen der Welt, die Gardiner dem Außenministerium am 31. August 1923 zukommen ließ. Abdelkrim propagierte zum wiederholten Male unter der Voraussetzung der »absoluten politischen Unabhängigkeit« eine Wirtschaftspolitik der offenen Tür. Er lud Staatsregierungen ein, Konsulate und diplomatische Einrichtungen in Ajdir einzurichten. Gardiner versuchte dies seinem Land damit schmackhaft zu machen, daß er betonte, im Namen der Rifregierung das alleinige Recht zu besitzen, Bergbau-Konzessionen an Briten zu erteilen $^{503}$.

Der gleiche Brief ging an die Londoner Botschaften Frankreichs ${ }^{504}$, der USA $^{505}$, der Türkei ${ }^{506}$, Persiens ${ }^{507}$, Perus ${ }^{508}$ und Österreichs ${ }^{509}$ sowie an die Regierungen Lettlands ${ }^{510}$, Kolumbiens ${ }^{511}$, Mexikos und Rumäniens ${ }^{512}$. Der deutschen Regierung schickte Gardiner die Unabhängigkeitserklärung der "Rif-Republik« ebenfalls direkt ${ }^{513}$. Am 28 . August 1923 stattete er der deut-

${ }^{501}$ PRO-FO 371, 9474, 2275, 214: Minute, 30.6.1923.

${ }^{502}$ BENNETT, Britain's Relations, S. 73-77.

${ }^{503}$ PRO-FO 371, 9474, 2275, 223: Charles Gardiner an FO, 31.8.1923; PRO-FO 371, 9474, 2275, 221: Charles Gardiner an FO, 3.8.1923.

${ }^{504}$ CADN Londres C519: "The Agent-General for the Government of the Riff (Morocco)《 an Ambassade de Londres, 21.8.1923; ADMAE Maroc 196, 189: Ambassade de Londres an MAE, 23.8.1923; CADN Madrid C274: MAE an Ambassade de Madrid, 30.8.1923.

${ }^{505}$ HALL, The United States, S. 755.

${ }^{506}$ SHAT 3H102: EMA, $2^{e}$ bureau, Note, 11.1.1926.

${ }^{507}$ CADN Londres C519: Gohlam Ali Khan Ardalani an Ambassade de Londres, 2.1.1924.

${ }^{508}$ PRO-FO 371, 9474, 2275, 233: Peruvian Legation an FO, 14.12.1923.

${ }^{509}$ PRO-FO 371, 9474, 2275, 226: Österreichische Gesandtschaft an FO, 18.9.1923.

${ }^{510}$ CADN Madrid C274: MAE an Ambassade de Madrid, 24.9.1923 mit einem Bericht des französischen Botschafters de Vienne, der süffisant bemerkte, daß die lettische Regierung wahrscheinlich nicht auf Gardiners Angebot eingehen werde, da sich ihre aus drei Schiffen bestehende Flotte sonst mit der spanischen Armada messen müsse.

${ }^{511}$ ADMAE Maroc 198, 6: Ambassade de Bogota an MAE, 25.4.1924.

512 PENNELL, A Country, S. 211.

${ }^{513}$ PA-AA R72063: Charles Gardiner an AA, 27.8.1923. 
schen Botschaft in London einen Besuch ab. Er wies auf die freundschaftliche Haltung der Rifkabylen während des Ersten Weltkrieges hin und lud deutsche Unternehmer ins Rif ein, um die dortige Verkehrsentwicklung, insbesondere die des Eisenbahnwesens, voranzutreiben. Botschaftsrat Dufour-Feronce hatte keine gute Meinung von Gardiner: »Persönlich gefällt er mir nicht $~^{514}$. Dieser Eindruck verstärkte sich im Berliner Auswärtigen Amt noch, als der Brite dort am 8. September 1923 vorsprach, um deutsche U-Boote für die »Rif-Republik« aufzukaufen ${ }^{515}$. Derartige Initiativen Gardiners riefen allenfalls Irritationen bei den Adressaten hervor.

Zwei Briten hatten sich Monate zuvor für Bergbauverhandlungen ins Rif aufgemacht - John A. Bevan und Louis de La Garde. Ihre Anwesenheit zeigte erneut, daß es Abdelkrim mit >Monopolen` nicht so genau nahm, denn sie waren sowohl Konkurrenten von Charles Gardiner als auch von Horacio Echevarrieta. Bevan, Bergbauingenieur in Diensten von J.J. Fordham \& Co., startete nach seinem Mißgeschick von $1921^{516}$ einen neuen Versuch, ins Rif zu gelangen. Sein Ziel war es, die Mine von Iger Aïch in Beqqioua sowie Felder im Gebiet der Temsamane zu inspizieren ${ }^{517}$. Am 17. April 1923 tauchte Bevan in Gibraltar auf und bereitete seine Reise vor. Als er versuchte, in einheimischer Kleidung von der französischen Zone aus über Taza das Rif zu erreichen, stoppten ihn französische Soldaten und schickten ihn zurück. Nach seiner Rückkehr nach Gibraltar beschwerte sich Bevan, daß John Arnall - der ausgemusterte Tanger-Vertreter Fordhams ${ }^{518}$ - ihn aus Rachsucht bei den französischen Behörden von Tanger verraten hätte ${ }^{519}$.

Mitte Mai 1923 brach John Bevan auf einem Schmuggelschiff von Gibraltar aus erneut in Richtung Rif auf. An der Beqqiouaküste wurde er von Caïd Haddou ben Hammou in Empfang genommen und am 19. Mai 1923 in dessen Auto nach Ajdir gebracht, wo er von Abdelkrim begrüßt wurde ${ }^{520}$. Fast zeitgleich hielt sich der Echevarrieta-Mitarbeiter Primitivo Hernández Sampelayo im Rif auf. Bevan war der erste Europäer, der das Innenleben des neu proklamierten Rifstaates für längere Zeit beobachtete und darüber Artikel in der britischen Presse veröffentlichte. Er beschrieb Abdelkrim als "großen Reformer«, der dem Land durch die Abschaffung der Blutfehden und die Etablierung von

\footnotetext{
${ }^{514}$ PA-AA R72063: Botschaft London an AA, 28.8.1923.

515 PA-AA R72063: Geheimvermerk, 8.9.1923.

${ }^{516}$ Siehe S. 273.

${ }^{517}$ CADN Londres C519: MAE an Ambassade de Londres, 26.5.1924; SHAT 3H1559: Région de Taza, Annexe de Bab Mouroudj, SR, Bulletin de renseignements, 28.5.1923.

518 PRO-FO 371, 9470, 44, 173: New Scotland Yard an FO, 21.11.1923.

519 PRO-FO 371, 9470, 44, 200: Governor of Gibraltar an FO, 24.11.1923; PRO-FO 371, 9470, 44, 29: CG Tangier an FO, 2.9.1923; CADN Londres C519: MAE an Ambassade de Londres, 26.5.1924.

${ }^{220}$ WARD PRICE, Extra-Special Correspondent, S. 172; HARRIS, The Moroccan Campaign, 11.9.1924; PRO-FO 371, 9470, 44, 29: CG Tangier an FO, 2.9.1923.
} 
»Recht und Ordnung« inneren Frieden gebracht hätte. Bevan beschrieb die gute Organisation innerhalb des Rifs, aber er beobachtete auch, daß die Minister der Regierung wenig Verantwortung trugen und selbst geringfügige Entscheidungen von Abdelkrim bestätigen lassen mußten ${ }^{521}$.

Ein Passierschein Abdelkrims erlaubte Bevan das ungehinderte Bereisen des Rifs $^{522}$. Sein Weg führte ihn unter anderem nach Aït Abdallah und zum Jebel Hamam $^{523}$. Als er von Algerien aus am 30. August 1923 nach Tanger zurückkehrte, fiel sein Fazit nüchtern aus ${ }^{524}$. Genauere Bergbauuntersuchungen waren ihm - wie im Jahr zuvor der Mission von Jean du Taillis - verwehrt worden. Bevans sporadische Analysen ergaben keinerlei Kohle- oder Ölvorkommen. Eisenerzfunde auf dem Gebiet der Beni Touzine bewertete er im Zusammenhang mit dem Bau von Eisenbahnstrecken als am ehesten interessant. Aber er hatte bemerkt, daß das Interesse europäischer Spekulanten an den Riferzen bei Abdelkrim eine übertriebene Vorstellung von deren Wertigkeit bewirkt hatte. Deswegen kam Bevan zu dem Schluß, daß die vorhandenen Vorkommen an Eisenerz, Zink, Blei, Kupfer und Antimon nicht rentabel abzubauen waren ${ }^{525}$.

Bevans und Fordhams Interesse war damit erloschen. Nach seiner Rückkehr nach London publizierte Bevan in der "Morning Post« (22. bis 24. Oktober 1923) drei analyseartige Artikel über das Rif, doch dort kam das Thema Bergbau nicht vor. In den Quellen deutet nichts darauf hin, daß zwischen Gardiner und John Bevan bzw. James Fordham eine Verbindung bestanden hat. In seinem Bericht für das britische Generalkonsulat Tanger erwähnte Bevan zwar den Letellier-Vertrag, nicht aber das Gardiner-Monopol. Angesichts der Tatsache, daß Gardiner seinen Geschäften trotz der eher mageren Forschungsergebnisse Bevans weiter nachging, ist davon auszugehen, daß sie nichts miteinander zu tun hatten.

Für kurze Zeit reiste John Bevan mit einem Landsmann durch das Rif ${ }^{526}$. Es handelte sich um Louis de La Garde, dessen Name von seinem französischen Vater herrührte. Das Mitglied des Londoner Royal Aero Club gelangte im Juli

S21 BEVAN, Spain and Morocco II, 23.10.1923.

${ }^{522}$ PRO-FO 371, 9470, 44, 29: CG Tangier an FO, 2.9.1923 mit Bezug auf Aussagen von John Bevan.

${ }^{523}$ SHAT 3H1559: Région de Taza, Annexe de Bab Mouroudj, SR, Bulletin de renseignements, 28.5.1923; SHAT 3H1559: Annexe de contrôle civil d'El Aĩoun, Bulletin de renseignements, 28.6.1923.

324 CADN Londres C525: MAE an Ambassade de Londres, 24.9.1923.

${ }_{225}$ PRO-FO 371, 9470, 44, 29: CG Tangier an FO, 2.9.1923.

${ }^{526}$ PRO-FO 371, 9470, 44, 82: FO an Embajada de Londres, 17.10.1923. 
1923 ebenfalls von Gibraltar aus mit einem Schmuggelschiff ins Rif ${ }^{527}$. La Garde wollte Abdelkrim gegen ein Monopol für Naturprodukte und gegen Bergbau-Konzessionen vier Flugzeuge, vier Mörser, Ausrüstung für Telegrafenstationen und Feldtelefone verkaufen. Da er keine Liefergarantien vorweisen konnte, brach Abdelkrim die Verhandlungen $\mathrm{ab}^{528}$.

In einigen Zeitungsartikeln rächte sich der Brite, indem er sich über die innere Organisation im Rif lustig machte ${ }^{529}$. La Garde betrachtete Abdelkrim als "absoluten und despotischen Herrscher " und bilanzierte: "Weder hat jemals eine Rif-Republik existiert, noch gibt es Versuche, selbst die einfachste

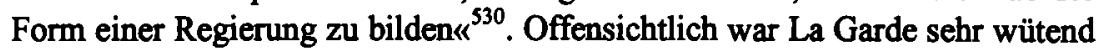
auf Abdelkrim, denn in einem Memorandum übermittelte er seine im Rif gewonnenen Erkenntnisse sowohl der französischen als auch der spanischen Botschaft in London ${ }^{531}$. Der stellvertretende Militärattaché der britischen Botschaft von Madrid, Major N.E. Weatherhall, vermittelte La Garde an den spanischen Generalstab weiter. Dort händigte der Brite von ihm angefertigte Zeichnungen, Karten, Pläne und Fotografien aus, und er erteilte Ratschläge für eine eventuelle Landung spanischer Truppen in der Bucht von Alhucemas ${ }^{532}$. Die Informationen waren so wertvoll, daß ihm der Orden »cruz del merito militar con distintivo blanco« verliehen wurde ${ }^{533}$.

Nach der Proklamation der »Rif-Republik« startete Abdelkrim neue Avancen in Richtung Frankreich. Am 4. April 1923 sandte Außenminister Azerkane im Namen des »Präsidenten der Rif-Republik» einen Brief an den Generalresidenten des französischen Protektorats Lyautey. Hierin hob er einmal mehr die enge Freundschaft zwischen dem Rif und Frankreich hervor, mit dessen Hilfe die Rifnation Einzug in die internationale Staatenwelt halten wolle. Azerkane betonte ausdrücklich - wenn auch wahrheitswidrig -, daß die Rifregierung nur mit Frankreich politische und wirtschaftiche Beziehungen eingehen wolle. Lyautey weigerte sich, den Brief schriftlich zu beantworten. Dem

${ }^{527}$ CADN Madrid C274: MAE an Ambassade de Madrid, 23.8.1923; ADMAE Maroc 196, 182: Ambassade de Londres an MAE, 18.8.1923; LA GARDE, The Rif Rising, 25.8.1923; DERS., The Moroccan War, 15.9.1923; Chez Abd el Krim, in: BCAF 33 (1923) S. 563f.; A Visit to Abdul Krim, in: Morocco, 22.9.1923.

${ }^{528}$ CADN Madrid C274: MAE an Ambassade de Madrid, 27.8.1923 mit Bezug auf Aussagen des La Garde begleitenden Übersetzers.

${ }^{529}$ LA GARDE, The Rif Rising, 25.8.1923.

${ }^{530}$ DERS., The Moroccan War, 15.9.1923.

${ }^{531}$ CADN Londres C519: Louis de La Garde an Ambassade de Londres, 15.8.1923; CADN Madrid C274: MAE an Ambassade de Madrid mit dem beiliegenden Bericht »Memorandum from Louis de La Garde to First Secretary of the French Ambassy« o.D.

${ }_{532}$ PRO-FO 371, 12692, 236, 30: Major E.N. Weatherhall an FO, 13.5.1927; PRO-FO 372, 2068, 12430, 345: Louis de La Garde an FO, 5.12.1923; PRO-FO 372, 2068, 12430, 349: Embajada de Londres an FO, 6.12.1923.

${ }^{533}$ PRO-FO 372, 2068, 12430, 340: WO an FO, 29.11.1923. 
Rifboten ließ er mitteilen, daß Frankreich seine strikte Haltung der Neutralität nicht aufgeben werde. Gleichzeitig wurde ein von Abdelkrim zum marokkanischen Sultan entsandter Emissär namens Dadi ben Messaoud abgewiesen ${ }^{534}$.

Abdelkrim glaubte indes, durch Kontakte seiner Delegierten Si M'hammed, Si Mohammed Mohammedine Hitmi und Si Mohammed Boujibar, die sich 1923 mehrere Monate in Paris aufhielten, Fortschritte im politischen Milieu Frankreichs erreicht zu haben. Hitmi und Si M'hammed trafen sich mit dem kommunistischen Parlamentsabgeordneten André Berthon ${ }^{535}$. Gardiners Partner Christian Deboe organisierte ein Gespräch mit dem Abgeordneten und Journalisten der Zeitung »Homme libre« Eugène Lautier, der versprach, sich für die Rifkabylen einzusetzen ${ }^{536}$. Si M'hammed hatte eine Unterredung mit dem Politiker Paul Painlevé (Parti radical), ") und er sagte mir damals, daß er bereit sei, alles, was in seiner Macht stände, zu tun, um uns zu helfen, den Frieden und die Unabhängigkeit zu erringen « $^{537}$.

Dem Bruder Abdelkrims gelang auch ein kurzer Besuch beim französischen Ministerpräsidenten Raymond Poincaré ${ }^{538}$. Dieser bestätigte das Treffen am 19. Juli 1923 in einem Schreiben an die französische Botschaft Madrid ${ }^{539}$. Später erinnerte er sich nicht mehr gern daran: »)Mein Gedächtnis erlaubt es mir [...] nicht, den Besuch eines Rifabgesandten förmlich zu dementieren. [...] Der Außenminister Abd el Krims (gemeint ist Si M'hammed, DS) behauptete, daß der Riffuihrer sogar bereit war, Frankreich die Gruben des Rifgebietes abzutreten. Ich finde, daß er zu großzügig über den Besitz verfügte, der der spanischen Verwaltung unterstellt war « ${ }^{540}$. Poincaré und Painlevé waren Ehrenpräsidenten des Comité de souscription en faveur des miseraux d'Algerie,

534 JACQUES, L'aventure riffaine, S. 22-26; RIVET, Lyautey, Bd. 3, S. 272f.; Jacques BENOIST-MECHN, Lyautey l'Africain ou le rêve immolé 1854-1934, Paris 1978 (Le rêve le plus long de l'histoire, 6), S. 327.

${ }_{535}$ ADMAE Maroc 111, 1: Bericht »Renseignements donnés par El Hadj Hitmi«, 22.6.1926; BERTHON, Abd el Krim, 12.5.1925; SLAVIN, Anticolonialism, S. 92. Abdelkrims Militärberater Josef Klems sagte später aus, er habe einen Brief Berthons gesehen, in dem dieser 1925 seinen Glückwunsch für die Siege über die französischen Truppen ausgesprochen habe [SHAT 12J3797, 28: Vernehmung von Josef Klems vor dem 2. Kriegsgericht Meknes, 19.6.1926].

${ }^{536}$ AN F7, 13413: Bericht »Déclaration de M. Deboe«, 30.7.1925.

${ }^{537} \mathrm{Zit}$. aus SHEEAN, Im Hauptquartier, 2.10.1925.

${ }^{538}$ RIVET, Lyautey, Bd. 3, S. 273.

${ }^{539}$ CADN Madrid C274: Raymond Poincaré an Ambassade de Madrid, 19.7.1923. In Biographien über Poincaré findet sich hierüber nichts [z.B. Daniel AMSON, Poincaré. L'acharné de la politique, Paris 1997; John F.V. KEIGER, Raymond Poincaré. Cambridge u.a. 1997; Pierre MIQUEL, Poincaré, Paris 1984].

${ }^{540}$ Aus der Vorgeschichte des Marokkoaufstandes, in: Deutsche Allgemeine Zeitung, 4.9.1925 mit Bezug auf einen Artikel des »Matin«. 
dessen Geschäftsführer Ahmed Balloul - Abdelkrims Pariser Repräsentant - war $^{541}$. Über Balloul waren höchstwahrscheinlich die Verbindungen zustande gekommen.

Auch über den tunesischen Scherif Moulay Mohammed ben Moulay Mohammed Salah el Tidjani bemühte sich Abdelkrim um Kontakte zu französischen Stellen. Schon im Dezember 1922 hatte sich Tidjani zur Unterstützung der Rifdelegierten Si Abdelkrim ben el Haj Ali Luh und Si Mohammed Boujibar nach London aufgemacht, war dort aber auf einen Trickbetrüger hereingefallen, der ihm sein ganzes Geld abnahm. Colonel Clifford Boardham Winter, der sich nach einer politischen Karriere im britischen Außenministerium (1895-1906) und als Konsul im persischen Turbat-i-Haidari (1906) sowie nach einer militärischen Laufbahn in Indien und Mesopotamien nun für Bergbaugeschäfte im Rif interessierte, hielt Tidjani finanziell über Wasser und wollte ihn nach Marokko begleiten ${ }^{542}$. Doch aus seinen Plänen wurde nichts, zumal ihm die britische Regierung jegliche Unterstützung versagte ${ }^{543}$.

Als Tidjani daraufhin im Frühjahr 1923 nach Marokko zurückkehrte, verstand er es, die in Casablanca ansässigen Geschäftsleute Epinat und Cané dazu $\mathrm{zu}$ bringen, ihm für seine Reise ins Rif 2000 Francs auszuhändigen. Dort überzeugte er Abdelkrim, ihn weiter als Gesandten für politische und wirtschaftliche Belange zu beschäftigen ${ }^{544}$. Neben einer reichhaltigen finanziellen Ausstattung gab Abdelkrim dem Tunesier und dem heimgekehrten Si Mohammed Boujibar zahlreiche gleichdatierte (18. Juni 1923) Briefe mit auf den Weg, die diese den französischen Militärs in Fes aushändigten. Sie waren an den Generalresidenten Lyautey, an den Delegierten der französischen Regierung in Rabat, Urbain Blanc, an den französischen Generalkonsul von Tanger, an den französischen Präsidenten Alexandre Millerand, an Raymond Poincaré, an den Politiker Franklin-Bouillon, an den ehemaligen Außenminister Gabriel Hanotaux und an den marokkanischen Sultan gerichtet. An Hanotaux richtete Abdelkrim den Appell, daß Frankreich dem Rif wegen der guten Nachbarschaft und wegen seiner politisch-ökonomischen Interessen Unterstützung gewähren müsse $\mathrm{s}^{545}$. Und Poincaré wurde von Abdelkrim umschmeichelt,

541 AN F7, 13413: MI, Direction générale, Cabinet du direction, Note, 22.7.1925.

${ }^{542}$ PRO-FO 371, 8356, 10130, 367 und 371: Minute, 14.12.1922 und 19.12.1922; PRO-FO 371, 8356, 10130, 362: FO an Embajada de Londres, 18.12.1922; Who Was Who 3 (1947) S. 1476.

${ }_{543}$ PRO-FO 371, 8356, 10130, 373: FO an Colonel Clifford Winter, 22.12.1922; PRO-FO 371, 8356, 10130, 375: Colonel Clifford Winter an FO, 22.12.1922. Weiter taucht Winter in den Akten nicht auf, daher nahm er wohl von seinen Plänen Abstand. Die Quellen sagen nichts über eine etwaige Beziehung zwischen Winter und John Arnall aus.

544 ADMAE Maroc 196, 132: RG Rabat an MAE, 20.7.1923.

${ }^{545}$ ADMAE Maroc 196, 162: Abdelkrim an Gabriel Hanotaux, 18.6.1923. 
daß die Rifkabylen an der Größe Frankreichs, das stets für die Freiheit kleiner Völker und für die Einhaltung der Menschenrechte eingetreten sei, teilhaben wollten ${ }^{546}$.

Es war eine diplomatische Offensive, in der Abdelkrim seinen Charme spielen ließ. Doch auf unterer Ebene wurde den Rifdelegierten in Rabat mitgeteilt, daß aufgrund der Verträge mit dem Sultan kein Abkommen mit ihnen abgeschlossen werden könne. Auf dem Weg nach Frankreich stürzte sich Tidjani zunächst ins Nachtleben von Casablanca, wo er sich in die Prostituierte Mlle "Maude« Metivier verliebte. Sie hatte in Rabat zweifelhafte Berühmtheit erlangt, als der von ihr ruinierte Kaufmann Lallier sich vor ihren Augen das Leben nahm. Sie war gleichzeitig die Geliebte des spanischen Konsuls von $\mathrm{Ca}$ sablanca, den sie mit Informationen versorgte ${ }^{547}$.

In Paris konnten Tidjani und Boujibar ebenfalls diplomatisch nichts ausrichten. Weder für die französische Regierung noch für Lyautey kam eine Anerkennung der »Rif-Republik» in Frage. Lyautey betrachtete den Rifkrieg als Garantie für die Zurückhaltung der Rifkabylen gegenüber Frankreich und als Gelegenheit, zu weit gehende spanische Forderungen in der Tangerfrage zu vermeiden. Er versuchte, Abdelkrim in diesem Sinne zu instrumentalisieren. Dies konnte aber nur solange gelingen, wie dessen Erfolge nicht zu groß wur$\operatorname{den}^{548}$.

Tidjani betätigte sich auch als Vermittler zwischen Spanien und Abdelkrim. Charles Gardiner wußte davon nichts. Kaum hatte General Miguel Primo de Rivera y Orbaneja am 13. September 1923 durch einen Staatsstreich die Macht in Spanien übernommen, da erschien Gardiner im britischen Außenministerium. Er händigte Staatssekretär Kirkpatrick einen Umschlag mit Abdelkrims Friedensbedingungen an Spanien aus. Sie vereinigten in gewohnter Manier politische und wirtschaftliche Forderungen. Spanien wurde aufgefordert, die "vollständige Unabhängigkeit des Rifs« anzuerkennen und seine Truppen vom Rif-Territorium abzuziehen. In Punkt 4 betonte Abdelkrim, daß die Rifregierung keine von ihr nicht gebilligten Bergbau-Konzessionen akzeptiere. Spanien müsse an Parteien, die deswegen Benachteiligungen erleiden würden, Entschädigungen zahlen. Großbritannien sollte den Friedensvertrag vermitteln. Gardiners Anfrage, ob die britische Regierung Spanien inoffiziell zu einem Frieden mit Abdelkrim drängen könne, wurde abgewiesen ${ }^{549}$.

${ }^{546}$ CADN Maroc DAI 187: Abdelkrim an Raymond Poincare, 18.6.1923.

\$47 ADMAE Maroc 196, 132: RG Rabat an MAE, 20.7.1923; JACQUES, L'aventure riffaine, S. 27-29; HUETZ DE LEMPS, La collaboration, S. 87; FURNEAUX, Abdel Krim, S. 153; GABRIELl1, Abd-el-Krim, S. 44; FuRneauX, Abdel Krim, S. 156; КнARCHICH, La France, S. 156; RIVET, Lyautey, Bd. 3, S. $272 f$.

${ }^{348}$ GERSHOVICH, French Military Rule, S. 126f.; AYACHE, Les relations, S. 290.

549 PRO-FO 371, 9474, 2275, 230: Minute, 20.9.1923. 
Währenddessen fragte Tidjani völlig unabhängig von Gardiners Londoner Initiative den in Paris weilenden Ricardo Ruíz Orsati - einen engen Vertrauten Primo de Riveras - ob es von spanischer Seite aus neue Friedensvorschläge für Abdelkrim gebe. Aus Madrid kam in strengster Geheimhaltung das Angebot einer weitgehenden Autonomie für das Rif innerhalb der spanischen Einflußzone. Abdelkrim als Emir des Rifs sollte ein fünfköpfiger Rat zur Seite gestellt werden. Der spanische Vorschlag sah vor, daß die Rifkabylen bis auf eine Armee von 3000 Mann vollständig entwaffnet werden sollten ${ }^{550}$. Tidjani machte sich auf den Weg ins Rif, um Abdelkrim zu informieren. Eine erneute Frauenaffaire hielt ihn jedoch wochenlang in Malaga auf. Abdelkrim war so erbost, daß er den Tunesier nach seiner Ankunft einkerkern ließ $\beta^{551}$. Charles Gardiner übernahm im November 1923 zusammen mit Lord Teynham, Si Mohammed Boujibar und Si Mohammed Mohammedine Hitmi die Verhandlungen mit der spanischen Botschaft von Paris. Er führte die Gespräche, an denen auch Christian Deboe teilnahm, bis zum Februar 1924 weiter. Die Positionen gingen jedoch zu weit auseinander. Von daher lehnte Abdelkrim, der nur die Anerkennung der Unabhängigkeit akzeptieren wollte, das spanische Angebot ab. Hitmi und Boujibar kehrten im Januar 1924 ins Rif zurück ${ }^{552}$.

Gardiners diplomatische Initiativen hatten nichts bewirken können. Aber auch in wirtschaftlicher Hinsicht sah es schlecht aus. Vergeblich warb Gardiner in der Londoner Presse um Investitionen für die Entwicklung des Rifs. Das Fachblatt »Moroccou spottete angesichts der mäßigen Resonanz, daß nicht alle Interessenten zugleich vorsprechen sollten, und es warnte vor den Gefahren, im Rif Geld zu verlieren ${ }^{553}$. Si Mohammed Mohammedine Hitmi, der zu Gardiners Unterstützung nach London kam, mußte zu seiner Frustration erleben, $\mathrm{da} B$ niemand in ein Land investieren wollte, in dem eine Revolte stattfand ${ }^{554}$. Ende 1923 hatte Abdelkrims Vertrauen in Gardiners Bemühungen, Waffen zu liefern und Gelder für seinen Monopolvertrag aufzutreiben, stark abgenommen. In seiner Verzweiflung kehrte Si M'hammed am 21. Dezember 1923 zu seinem ursprünglichen Vertragspartner zurück. Er schloß mit Henri Moulis einen Vertrag über die Bildung einer Bewirtschaftungsgesellschaft für das Rif $a b$, die jedoch nie gegründet wurde ${ }^{555}$.

${ }^{550}$ HERNÁNDEZ MIR, Del desastre a la victoria, Bd. 2, S. 218-226; SUEIRO SEOANE, España, S. 142-144; PAYNe, Politics, S. 208; FlemING, Primo de Rivera and Abd-el-Krim, S. 117f.; DERS., Primo de Rivera and Spain's Moroccan Problem, S. 85-87.

${ }^{551}$ CADN Madrid C275: MAE an Ambassade de Madrid, 24.11.1924; SHAT 3H1557: Contrôle civil de Taourirt, Bulletin de renseignements, 22.10.1924.

552 AN F7, 13413: Bericht "Déclaration de M. Deboer, 30.7.1925; SHAT 3H1102: RG Rabat an Contróleur civil de Chaouia, 11.1.1924.

${ }^{553}$ Rif and Reality, in: Morocco, 1.9.1923; Rif-Raff Finance, in: Morocco, 25.8.1923.

5s4 SHEEAN, My Meeting, S. 845.

${ }^{555}$ KHARCHICH, La France, S. 152, Anm. 1; GODCHOT, Le mystère, S. 253; ADMAE Maroc 111, 99: Vertrag zwischen Si M'hammed und Moulis \& Cie., 21.12.1923. 
1924 begann Abdelkrim ernsthaft damit, die Presse als Propagandamittel zu nutzen, da er »begriff, welche ungeheuren Gefahren aus der Presse-Isolierung des Freiheitskampfes der Rifkabylen sich ergeben « konnten ${ }^{356}$. In der Folgezeit förderte er Besuche ausländischer Journalisten, um über sie seine Ziele einer weltweiten Öffentlichkeit zu vermitteln. Sein erster Besucher im Sinne dieser neuen Strategie war der Brite George Ward Price, der seit 1912 für die Londoner Zeitung »Daily Mail« arbeitete ${ }^{557}$.

Ende 1923 führte Ward Price ein Interview mit General Primo de Rivera. Er fragte ihn dabei, ob er Abdelkrim ebenfalls einen Besuch abstatten dürfe. Der spanische Diktator lehnte ein Überqueren der spanischen Linien strikt ab. Auch in der Generalresidenz in Rabat wurde Ward Prices Begehren einer Einreise ins Rif offiziell untersagt. Allerdings verwies man ihn an Colonel Huot von der Direction des affaires indigènes, der ihm den Rat gab, Caïd Haddou ben Hammou in Oujda aufzusuchen. Beide erwähnte Ward Price in seinen Artikeln von 1924 nicht, um sie verabredungsgemäß nicht zu diskreditieren. Mit Haddous Hilfe und in Begleitung von zwei Rifkabylen konnte Ward Price, der einheimische Kleidung trug und sich einen Bart hatte wachsen lassen, von Taourirt aus am 4. April 1923 ins Rif reiten. Seine schriftliche Erklärung, er wolle das englische Volk über die Ziele der Rifkabylen aufklären, kam Abdelkrim gelegen, da in Großbritannien ein Regierungswechsel stattgefunden hatte. James Ramsay MacDonald wurde der erste Labour-Premierminister. Von ihm erhoffte sich Abdelkrim nach dem Mißerfolg der London-Delegation von 1922 und den vergeblichen Bemühungen Gardiners eine Änderung der britischen Haltung. Am 6. April 1924 traf Ward Price mit Abdelkrim, der von einer 500 Mann starken Leibgarde bewacht wurde, in der Nähe von Ajdir zusammen. Si Mohammed Boujibar fungierte als Übersetzer. Von einer $»$ RifRepublik« war schon keine Rede mehr, als Ward Price nach der Regierungsform fragte. Abdelkrim führte aus, daß die islamische Religion nur die Herrschaft eines Emir vorsehe. Er betonte die internationale Dimension des Rifkonfliktes und wiederholte gegenüber dem Journalisten seine Botschaft vom Zusammenhang zwischen der Anerkennung der Unabhängigkeit und der wirtschaftlichen Öffnung des Landes. Abdelkrim äußerte seine Hoffnung, daß die von pazifistischen Idealen geleitete neue Regierung in Großbritannien ihn unterstützen werde, und er regte an, daß eine internationale Konferenz die Riffrage klären solle ${ }^{558}$.

${ }^{556}$ Ahmed H. MATTAR, Abd el Krim und Europa, in: Mitteilungen des Bundes der Asienkämpfer 8 (1925), S. 31.

${ }^{557}$ Robert W. DESMOND, Crisis and Conflict. World News Reporting between Two Wars 1920-1940, Iowa City 1980, S. 276; FURNEAUX, Abdel Krim, S. 97.

${ }_{558}$ WARD PRICE, First News, 24.4.1924; DERS., The Journey, 26.4.1924; DERS., Midnight in Morocco, in: Daily Mail, 28.4.1924; SHAT 3H1103: Contrôle civil de Taourirt, Bulletin de renseignements, 13.4.1923. 
Ward Price erhielt einen Brief ausgehändigt, den er seinem Premierminister MacDonald überreichen sollte. Der Umstand, daß just zu dieser Zeit Charles Gardiner im Rif erwartet wurde, den Abdelkrim ebenfalls mit dieser Aufgabe hätte betrauen können, zeigt, daß dessen Reputation im Rif angesichts seiner Mißerfolge stark abgenommen hatte. In dem Schreiben bat Abdelkrim wim Namen der Menschlichkeit« um britische Vermittlungsdienste, um den Krieg zu beenden ${ }^{559}$. Nach Jean du Taillis, Luis de Oteyza, John Bevan oder Louis de La Garde, die entweder wirtschaftliche Interessen verfolgt oder einer Kriegspartei angehört hatten, war Ward Price der erste neutrale Berichterstatter, der ein Interview mit Abdelkrim geführt hatte ${ }^{560}$.

Am 22. April 1924 - während einer Konferenz in Southport - übergab Ward Price das Schreiben dem irritierten MacDonald ${ }^{561}$. Die britische Regierung wollte jedoch mit den Problemen in Nordmarokko nicht konfrontiert werden und wandte sich zudem gegen parallele Initiativen Primo de Riveras, die eine Internationalisierung Spanisch-Marokkos oder einen Austausch zwischen Gibraltar und Ceuta vorsahen ${ }^{562}$. Viele Militärs befürworteten dies, weil Ceuta wegen des weiteren Hinterlandes eine strategisch günstigere Lage hatte. Doch in diesem Falle wäre Großbritannien direkt mit dem Problem Abdelkrim konfrontiert gewesen. So nahm die britische Regierung auch von derartigen Plänen Abstand ${ }^{563}$.

Ward Prices Artikel erregten Aufsehen in der britischen Presse. Da sie aber in Spanien nicht erscheinen durften, machte er sich mit dem Brief Abdelkrims zu einem Treffen mit Primo de Rivera und dessen Außenminister Don Fernando de Espinosa de los Monteros nach Madrid auf. Für Primo de Rivera kam »ein kleiner unabhängiger Staat von Wilden « in der Nähe Europas nicht in Frage. Er war aber weiterhin dazu bereit, den Rifkabylen eine sehr weitgehende Autonomie innerhalb der spanischen Einflußzone zu gewähren - ein Punkt, den Abdelkrim nicht akzeptieren wollte ${ }^{564}$. Damit endeten Ward Prices

s59 Ward PrICE, How Peace Might Come to Morocco, in: Daily Mail, 1.5.1924; FURNEAUX, Abdel Krim, S. 107f.; MARín ARCE, Primo de Rivera, S. 275; LADREIT DE LACHARRIÈRE, Le rêve, S. 152; FONTAINE, L'étrange aventure, S. 95; Le chef maure demande que l'Europe reconnaisse l'indépendance du Rif, in: Matin, 24.4.1924.

${ }^{560}$ FurNEaUX, Abdel Krim, S. 101.

${ }^{561}$ WARD PRICE, First News, 24.4.1924; DERS., Extra-Special Correspondent, S. 173.

${ }^{562}$ PRO-FO 371, 10583, 783, 2: Embassy of Madrid an FO, 8.5.1924; FLEMING, Primo de Rivera and Abd-el-Krim, S. 144-150; DERS., Primo de Rivera and Spain's Moroccan Problem, S. 88f.; SAZ, Foreign Policy, S. 56; SUEIRO SEOANE, España, S. 125-136.

${ }^{563}$ HILLS, Rock of Contention, S. 407-409.

${ }^{564}$ WARD PRICE, How Peace Might Come, 1.5.1924; DERS., Extra-Special Correspondent, S. 173; Spanish Dictator \& Mr. Ward Price, in: Daily Mail, 1.5.1924. 
Vermittlungsdienste. In den 1930er Jahren sollte er durch sein Faible für Hitler und für nationalsozialistisches Gedankengut auffallen ${ }^{565}$. 1954 besuchte er Abdelkrim während dessen Exil in Kairo ${ }^{566}$.

Charles Gardiner hatte sich mittlerweile um die Bildung einer Rifwährung gekümmert. Wo genau er die Geldscheine in Großbritannien herstellen ließ, ist unklar. Da alle aufgefundenen Banknoten das Datum »10.10.1923« trugen, läßt sich nur der Zeitpunkt der Herstellung festlegen. Das nach Art der englischen Pfundnoten durchnummerierte Rifgeld wurde »Riffan« getauft. Die Einer-Noten waren grün, die Fünfer-Noten fleischfarben. Ein »Riffan« sollte dem Wert einer spanischen Peseta entsprechen ${ }^{567}$. Am 10. April 1924 - vier Tage nach Ward Prices Interview mit Abdelkrim - landete Gardiner mit seinem Schiff "Sylvia« an der Rifküste und präsentierte die Geldscheine und eine Druckmaschine ${ }^{568}$. Als er fünf Millionen Duros für die Banknoten verlangte, befürchtete Abdelkrim, daß nicht alles mit rechten Dingen zuging. Der Verdacht lag nahe, daß es Gardiner um die Geldreserven des Rifs ging. Abdelkrim war nicht bereit, die wertlosen Papierbündel entgegenzunehmen und ließ sie ins Meer werfen ${ }^{569}$. Monate später wunderten sich die Küstenbewohner Andalusiens über die unbekannten Geldscheine, die vom Wasser angespült wur$\operatorname{den}^{570}$. Der »Riffan« kam nie in Umlauf, und die spanische Währung blieb daher das Zahlungsmittel im Rif ${ }^{571}$.

Gardiner hatte durch seine desaströse wirtschaftliche wie politische Arbeit sowie durch sein Unvermögen, die im Vertrag mit der Rifregierung angeforderten Waffen anzuliefern, stark an Kredit verloren. Sehr erbost war Abdelkrim, als der Kontrakt im Herbst 1924 in der europäischen Presse veröffent-

${ }^{565}$ GRIFFITHS, Patriotism, S. 67, S. 70.

${ }^{566}$ WARD PRICE, Extra-Special Correspondent, S. 173.

${ }^{567}$ GODED LLOPIS, Marruecos, S. 93; YOUSSOUFI, Les institutions, S. 95; Und doch Rifbanknoten, in: Das Notgeld 7 (1925) S. 165.

${ }^{368}$ FURNEAUX, Abdel Krim, S. 117; WOOLMAN, Rebels in the Rif, S. 127; Die Rifbanknoten, in: Das Notgeld 7 (1925) S. 205f., S. 205.

${ }^{369}$ CADN Maroc DAI 198: Bericht »Déclarations de Si el Hassan Kadiri«, 26.6.1926; CADN Maroc DAI 189: Bericht »Notes sur une conversation tenue avec Abdelkrim«, 31.5.1926; ADMAE Maroc 111, 1: Bericht »Renseignements donnts par El Hadj Hitmi«, 22.6.1926; Youssoufl, Les institutions, S. 95 u. S. 95, Anm. 22; KHARCHICH, La France, S. 118.

${ }^{370}$ ESPAÑA, La actuación, S. 298; SÁNCHEZ PÉREZ, Abdelkrim, S. 152f.; Spanish Dictator on the War in Morocco, in: Al-Moghreb al Aksa \& Tangier Gazette, 27.9.1924; TNLA, BNS, 1, Williams: Walter Harris an Harold Williams, 18.9.1924; PRO-FO 371, 10584, 783, 112 : CG Tangier an FO, 10.10.1924.

${ }^{571}$ PenNell, A Country, S. 133; SheEAN, War in Africa, S. 259; DeRS., An American, S. $303 f$. 
licht wurde. Der Vertrauensbruch hatte zur Folge, daß Gardiner das Rif nicht mehr betreten durfe ${ }^{572}$. Seine Zeit war vorbei. Sein deutscher Partner Karl Hackländer sagte sich von ihm $\operatorname{los}^{573}$.

\subsection{Abdelkrim und die Besuche amerikanischer Journalisten}

Einige Male hatte Abdelkrim versucht, mit amerikanischen Diplomaten in Kontakt zu treten. Im September 1921 hatte John Amall das Generalkonsulat der USA in Tanger angeschrieben und für die Anerkennung der Herrschaft Abdelkrims wirtschaftliche Vorteile versprochen ${ }^{574}$. Am 4. Januar 1922, im Juli und im September 1922 sowie im August 1923 waren von Arnall bzw. von Charles Gardiner Briefe an den amerikanischen Generalkonsul von Tanger sowie an die US-Botschaft in London weitergeleitet worden ${ }^{575}$. Aber nie erfolgte eine Reaktion. Abdelkrim war vom technischen Fortschritt der USA fasziniert - eines seiner drei Autos war ein Ford -, und er erhoffte Sympathien von einem Land, das selbst aus einem Unabhängigkeitskrieg hervorgegangen war. Der Kampf des David gegen Goliath lockte abenteuerlustige amerikanische Journalisten an, die eine gute Story und Ruhm erhofften. Mit ihrer Hilfe spekulierte Abdelkrim auf mehr Aufmerksamkeit in der amerikanischen Öffentlichkeit ${ }^{576}$. Als erster versuchte es 1922 der Reporter Leonidas Herbert Lee vergeblich, über die französische Zone Marokkos ins Rif zu gelangen. Am 25. Mai 1922 nahmen ihn Angehörige der Bou Hillil gefangen, weil sie ihn für einen Deserteur der französischen Fremdenlegion hielten und ihn in der Hoffnung auf eine Belohnung den Franzosen auslieferten. Ein weiterer Versuch endete zwei Tage später, als französische Truppen Lee bei Taourirt verhafteten und endgültig nach Rabat eskortierten ${ }^{577}$.

Der erste US-Amerikaner, der es schaffte, Abdelkrim zu interviewen, war der Journalist Paul Scott Mowrer. 1913 hatte er die Leitung des Pariser Büros der »Chicago Daily News« übernommen. Während des Ersten Weltkrieges

\footnotetext{
${ }^{572}$ WOLF, Les secrets, S. 123f;; If in the Rif, in: Al-Moghreb al Aksa \& Tangier Gazette, 29.11.1924; SHAT 3H1559: Tabor de police $N^{\circ} 1$, Note, 1.11.1924.

${ }^{573}$ HARRIS, Captain Canning and Abd-el-Krim, 30.1.1926.

${ }^{574}$ CADN Madrid C272: MAE an Ambassade de Madrid, 5.10.1921.

${ }^{575}$ Une déclaration d'Abd el Krim, in: BCAF 32 (1922) S. 302; Les aspirations d'Abd el Krim, in: BCAF 32 (1922) S. 350; HALI, The United States, S. 755; VAIDON, Tangier, S. $197 \mathrm{f}$.

${ }^{576}$ HAROUCHI, Les États-unis, S. 368f.; El-Mostafa AzzoU, Les relations franco-américaines en Maroc entre 1906 et 1956, Paris (Diss.) 1992, S. 163f.

${ }^{57}$ CADN Madrid C273: MAE an Ambassade de Madrid, 27.6.1922; CADN Maroc DAI 198: Caïd Haddou an Abdellorim, 24.6.1922; MoWrER, The House of Europe, S. 452.
} 
organisierte er ein Netzwerk von Reportern an allen Fronten. Nach dem Kriegseintritt der USA im Jahre 1917 akkreditierte er sich bei den französischen Truppen. Aufgrund seiner Berichte wurde er 1918 Mitglied und 1933 Offizier der französischen Ehrenlegion. Nach einer Reise auf den Balkan und durch Osteuropa im Jahre 1920 veröffentlichte Mowrer mehrere Bücher über außenpolitische Themen (»Balkanized Europe, A Study in Political Analysis and Reconstruction«, 1921; "Our Foreign Affairs«, 1924). 1923 übernahm er die Europa-Leitung der »Chicago Daily News«. 1924 sollte er Präsident der Pariser Anglo-American Press Association werden und 1928 den PulitzerPreis für Auslandsberichterstattung gewinnen. Als Pariser Korrespondent verfügte er über beste Beziehungen zu den politischen Kreisen Frankreichs. Auf seiner Suche nach neuen Herausforderungen $\mathrm{kam}$ ihm die Idee, ein Interview mit Abdelkrim zu führen, den er als Rebellen gegen den europäischen Imperialismus betrachtete $\mathrm{e}^{578}$.

Von Paris aus nahm Mowrer im Sommer 1924 Verbindung zu Abdelkrims Agenten in Algerien auf. Mit der französischen Generalresidenz von Marokko handelte er aus, daß sie ihn gegen einen ausführlichen Bericht von seinen Erlebnissen passieren lassen sollte. Die Franzosen benötigten Erkenntnisse aus dem Rif, da sich die Beziehungen zu Abdelkrim wegen des Konflikts um das Ouergha-Tal verschlechtert hatten. Mowrer war aufgrund seiner frankophilen Grundhaltung ein geeigneter Mann. Der Kontrollbeamte von Taourirt, Léon Gabrielli, gab dem einheimisch gekleideten Journalisten Anfang Oktober 1924 den Algerier Si Mohammed el Fassi als Führer mit auf die Reise ins Rif. Die Rifkabylen führten Mowrer an möglichst vielen Stellungen und Posten ihrer Armee vorbei, um ihm die gute Organisation und den technischen Fortschritt des Feldtelefonnetzes zu demonstrieren. In Ajdir wurde Mowrer am 7. Oktober 1924 von Abdelkrims Militärberater Josef Klems alias Caiid el Haj alemán empfangen. Er stellte ihm eine Schreibmaschine auf den Tisch und trug ihm auf, ein Einfuihrungsschreiben zu verfassen ${ }^{579}$.

Drei Tage nach seiner Ankunft wurde Mowrer bei Izemouren in ein Zelt geführt, vor dem Abdelkrim als deutliches Zeichen für seine >Progressivität< eines seiner Autos hatte parken lassen. Der Journalist war vom Wissen Abdelkrims hinsichtlich der weltpolitischen Lage beeindruckt. Der Rifchef wieder-

${ }^{578}$ Maurice R. Cullen, Paul Scott Mowrer, in: Perry J. ASHLey (Hg.), American Newspaper Journalists 1926-1950, Detroit 1984 (Dictionary of Literary Biography, 29), S. 256-261; Mitchel P. ROTH, Historical Dictionary of War Journalism, London 1997, 211f.; Catherine CASSARA, Edgar Ansel Mowrer and Paul Scott Mowrer, in: John A. GARRATY, Mark C. CARNES (Hg.), American National Biography, Bd. 16, New York 1999, S. 42-44, S. 42f.; Morrell HEALD, Transatlantic Vistas. American Journalists in Europe 1900-1940, Kent, London 1988, S. 8f., S. 14f., S. 26, S. 54f.; DESMOND, Crisis and Conflict, S. 317.

${ }^{579}$ MOWRER, The House of Europe, S. 447-455, S. 465, S. 468; GABRIELLI, Abd-elKrim, S. 15-18; SHAT 3H1557: Contrôle civil de Taourirt, Bulletin de renseignements, 17.10.1924. 
holte den bereits gegenüber John Arnall und George Ward Price geäußerten Gedanken, daß eine internationale Konferenz die Riffrage lösen könne. Er hoffte darauf, daß Großbritannien die Unabhängigkeit der »Rif-Republik« befürwortete, um Frankreich von der Straße von Gibraltar fernzuhalten. Einen Vertragsabschluß bei derartigen Verhandlungen setzte Abdelkrim mit der Anerkennung des Rifstaates gleich. Er berichtete von Planungen, die Geldmittel für einen Staatsaufbau nach europäischem Vorbild durch den Verkauf von Bergbau-Konzessionen einzunehmen. Es gebe viele Anfragen für Bergbaurechte, aber bisher habe das Rif noch keine Konzession vergeben, hieß es von ihm. Mit keiner Silbe ging Abdelkrim auf seine bisherigen Vertragsabschlüsse ein, wohl um potentielle amerikanische Investoren nicht abzuschrecken. Er prahlte, daß er die Umwandlung von Ajdir in eine Stadt wie London oder New York plane, wobei er hervorhob, daß es im Rif sicherer als in manchen europäischen Staaten zugehe ${ }^{580}$.

In seinen Artikeln stellte der faszinierte Mowrer den Macher und den legendenumwobenen Reformer Abdelkrim in den Vordergrund: "An der Spitze dieses Volkes steht ein Mann mit praktischer und klarer Intelligenz, ein Organisator und ein Führer mit absoluter Macht. Das immense Prestige, das er genießt, basiert zugleich auf seinen militärischen Erfolgen, seinen Fähigkeiten als Verwalter und Planer und seinen weitreichenden Modernisierungsvorhaben ${ }^{581}$. Abdelkrim übergab Mowrer einen Gruß an das amerikanische Volk. Hierin verglich er den Drang der Rifkabylen nach Freiheit und Unabhängigkeit mit den Anfängen der amerikanischen Staatsgeschichte. Zweifelsohne erhoffte er sich mit dieser Maßnahme Pluspunkte in der öffentlichen Meinung ${ }^{582}$.

Im Januar 1925 erschien der nächste amerikanische Journalist im Rif. Es handelte sich um (James) Vincent Sheean von der Zeitung "Chicago Tribune«. Zunächst hatte Sheean für die "New York Daily News« gearbeitet, bevor er auf eigene Kosten nach Europa gefahren und 1923 Assistent des Pariser Büros der »Chicago Tribune« geworden war. 1925 wechselte er zur North American Newspaper Alliance. Sheean sollte später über den spanischen Bürgerkrieg berichten und während des Zweiten Weltkrieges als Geheimagent in Nordafrika und Italien fungieren. Seine Autobiographie »Personal History« (1940) wurde ein Bestseller, der auch verfilmt wurde. 1948 wurde er Zeuge der Ermordung Gandhis. 1983 erhielt Sheean posthum den Leland Stowe Journalism

${ }^{580}$ MOWRER, The House of Europe, S. 477f. Vgl. auch Mowrers Berichte in: CADN Londres C519: MAE an Ambassade de Londres, 10.11.1924; SHAT 3H102: Bericht »Notes au sujet du voyage de M. Scott Mowrer dans le Rif \% o.D. [Oktober 1924]; CADN Maroc DAI 192: Bericht »Biographie d'Abdelkrim faite par M. Scott Mowrer, correspondant du Chicago Daily News《, 31.12.1924.

${ }_{581}$ MOWRER, Une visite, S. $1522 \mathrm{f}$.

${ }^{582}$ DERS., The House of Europe, S. 478. 
Award der University of Michigan. Er gab nie vor, ein unparteiischer Beobachter zu sein, und er war für seine leidenschaftliche Verachtung für soziale Ungerechtigkeiten bekannt ${ }^{583}$.

Mowrers Berichte in der lokalen Konkurrenzzeitung Chicagos hatten viel Aufsehen erregt. Im Zuge eines Interviews mit General Primo de Rivera, das er im Dezember 1924 in Tetuan führte, beschloß Sheean, es seinem Landsmann gleichzutun und Abdelkrim einen Besuch in Ajdir abzustatten. Da Rivera jegliche Unterstützung mit dem Argument, Spanien dürfe nicht den Bruch seiner eigenen Blockade dulden, ablehnte, machte sich Sheean über den Umweg Rabat, Fes und Taza nach Taourirt auf. Am 6. Januar 1925 erschien er - wie sein Vorgänger - bei Léon Gabrielli und bat um Unterstützung für sein Vorhaben, ins Rif aufzubrechen. Der französische Protektoratsbeamte hielt den 25jährigen Reporter mit dreijähriger Berufserfahrung zwar für unbedarft und forsch, aber er gab ihm unter der Bedingung, namentlich in Zeitungsberichten nicht erwähnt zu werden, einen Führer an die Seite. Zwei Tage nach seinem Aufbruch am 7. Januar 1925 wurde Sheean von den Metalsa, die ein Lösegeld einfordern wollten, festgehalten. Durch einen Befehl aus Ajdir kam der Amerikaner am 19. Januar 1925 wieder frei, und er erreichte einen Tag später Abdelkrims Wohnort Aït Kamara ${ }^{584}$.

Sheean schien es, daß Abdelkrim während des Gesprächs auf europäische Umgangsformen achtete, so als wolle er auf diese Weise smoderners erscheinen $^{585}$. Abdelkrim schwebte eine Art neue Algeciras-Konferenz vor. Deren Bedeutung sah er vor allem darin, Beschlüsse für klare Grenzlinien zu fassen, um Grenzstreitigkeiten mit dem französischen Protektorat Marokkos zu vermeiden. Er schloß die Anerkennung des marokkanischen Sultans Moulay Youssef weiterhin kategorisch aus. Erneut bekrättigte er seine Hoffnung auf englische und amerikanische Investitionen im Zusammenhang mit dem Selbstbestimmungsrecht der Rifkabylen in wirtschaftlichen und politischen Fragen $^{586}$. Ihm war bewußt, daß die Voraussetzung für derartige Investitionen ein Friedensvertrag war, denn »drei Jahre vergeblicher Verhandlungen hatten ihm gezeigt, daß die angelsächsischen Kapitalisten keinen Dollar für die Eisenfelder des Rifs riskieren würden, bevor nicht die gesamte Situation durch internationales Recht geregelt ist ${ }^{587}$.

${ }^{583}$ ROTH, Historical Dictionary, S. 281; HEALD, Transatlantic Vistas, S. 15f., S. 47, S. 190; Meyer L. STEIN, Under Fire. The Story of American War Correspondents, Parsippany 1968, S. 80; Raymond STOCK, The Works of Vincent Sheean. The Dust of an Honest Man, in: Journalism History 11 (1984) S. 46-50; DESMOND, Crisis and Conflict, S. 123f., S. 332f.

${ }^{584}$ SheEAN, An American, S. 15-19, S. 77-89; DeRS., Personal History, S. 92-99, S. 101112; DeRS., Arab Chieftain Puts sTribuner Man in Prison, in: Chicago Tribune, 11.2.1925.

${ }_{585}$ DERS., Abd-el-Krim's Terms, 7.2.1925.

${ }^{586}$ DERS., Riff Sultan, 8.2.1925; DERS., SHEEAN, My Meeting, S. 855 f.

${ }^{587}$ DERS., War in Africa, S. 259. 
Sheeans weitere Reise führte ihn vom Gebiet der Beni Bou Ifrah über das Mittelmeer nach Oued Lau und von dort über Amtar nach Taghzout ${ }^{58}$. Hier hatte Abdelkrims Bruder Si M'hammed sein militärisches Hauptquartier errichtet. Er empfing Sheean am 29. Januar 1925. Der Amerikaner war von Si M'hammed sehr beeindruckt und schaute fasziniert auf dessen sorgsam etikettierte Sammlung von Gesteinsproben aus dem gesamten Rif. Der zweite Mann der Rifregierung gab an, für das späte Frühjahr 1925 eine Reise nach Paris und London zu planen, um dort Wirtschaftsgespräche zu führen ${ }^{589}$. Er imponierte seinem Gast derartig, daß dieser sich bereitwillig funktionalisieren ließ und später über die angeblich »immensen« Erzfelder des Rifs schwelgte: "Möglicherweise wird dieser Reichtum das Rif zum wichtigsten Industrieland Nordafrikas machen ${ }^{590}$. Damit betrieb Sheean die bis dato beste Werbung für die vermeintlichen Bodenschätze des Rifs.

Es war auch weiterhin genau durchdacht, worüber der amerikanische Reporter berichten durfte. Während seines Rückweges nach Tanger erhielt Sheean die Gelegenheit, den gerade gefangengenommenen Ahmed el Risouni zu interviewen. Es handelte sich um eine Gefalligkeit Abdelkrims für die Amerikaner, hatte doch Risouni im Jahre 1904 durch seine Lösegelderpressung für den aus Tanger entführten Ion Perdicaris die Wut Amerikas und seines Präsidenten Theodore Roosevelt auf sich gezogen. Im "Tal des Todes« wurden Sheean auch die verblichenen Knochen der zahlreichen gefallenen spanischen Soldaten des Chichaouen-Rückzugs präsentiert ${ }^{591}$.

Der Londoner "Daily Telegraph « hatte gerade mit dem Hinweis, er sei als Spion erschossen worden, einen Nachruf auf ihn veröffentlicht, da tauchte Sheean am 5. Februar 1925 wieder in Tanger auf. Die Rifkabylen hatten ganze Überzeugungsarbeit geleistet. Wie Sheean seinem Helfer Léon Gabrielli am 11. März 1925 in einem Brief mitteilte, war er ganz begeistert vom "Charme« der Rifkabylen. Er habe das Land mit der Gewißheit verlassen, daß Abdelkrim in allen Punkten recht habe. Dies schlug sich in Sheeans tendenziöser Berichterstattung nieder, die Generalresident Lyautey veranlaßte, jedem Journalisten das Passieren der französischen Linien von nun an zu verbieten ${ }^{592}$.

Sheean ließ sich auf eine Vermittlertätigkeit ein und fuhr nach Madrid, um sich dort am 10. Februar 1925 mit General Primo de Rivera zu treffen und ihm - wie ein Jahr zuvor George Ward Price - Abdelkrims Friedensbedingungen

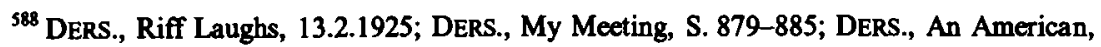
S. 216f., S. 222-230; DERS., Personal History, S. 117.

${ }_{589}$ DERS., Riff General, 14.2.1925; DERS., »Robin Hood《, S. 974.

${ }^{590}$ DERS., Riffis Fight, 12.2.1925.

${ }^{591}$ DerS., An American, S. 252f., S. 278, S. 293-298; DERS., Personal History, S. 119f.; DerS., Raisuli, Best Bad Man, Faces Treason Trial, in: Chicago Tribune, 9.2.1925; DeRS., Chief Raisuli, 10.2.1925.

${ }^{592}$ CADN Maroc DAI 194: Vincent Sheean an Leon Gabrielli, 11.3.1925; STOCK, The Works, S. 17; BoutbOUQALT, La Guetre du Rif, S. 127. 
mitzuteilen. Rivera hatte den Zusammenhang zwischen der "Ausbeutung der natürlichen Ressourcen« und Abdelkrims Streben nach Unabhängigkeit seines Staates erkannt. Er war bereit, ihm "freie Hand innerhalb seiner Grenzen« zu garantieren und "praktisch die Unabhängigkeit» im Zusammenhang mit spanischer Hilfe bei der Entwicklung des Landes anzubieten, bestand allerdings auf der Anerkennung der Hoheit des marokkanischen Sultans und auf der Entwaffnung der Rifarmee ${ }^{593}$. Abdelkrim befand sich zu dieser Zeit jedoch auf dem Höhepunkt seiner Macht und hatte es nicht nötig, ein derartiges Risiko einzugehen, zumal er den Spaniern tief mißtraute. Sheean kehrte daraufhin in die USA zurück, um in der Zeitschrift "Asia" der American Asiatic Association ausführlichere Reportagen über seine Erlebnisse im Rif zu veröffentlichen, die er dann in seinem Buch "An American among the Riffi« (1926) zusammenfaßte ${ }^{594}$.

Nach dem Angriff Abdelkrims auf das französische Protektorat entsandten nur wenige europäische oder amerikanische Zeitungen Korrespondenten ins Kriegsgebiet. Lediglich über wagemutige Reporter, die sich ins Rif aufmachten, sowie über politische Sympathisanten und Berater gelangte die Presse an Verlautbarungen oder Briefe Abdelkrims. Tanger wurde zur Basis für britische und amerikanische Reporter wie zum Beispiel Clarence Streit und Harold Norman Denny von der »New York Times«, Daniel Ashworth vom »Daily Express«, Floyd Gibbons von der »Chicago Tribune« oder Thomas J. Topping von "Associated Press«. Sie glaubten, dort am besten an Informationen zu gelangen. Tanger war eine neutrale Zone, in der alle Kriegsparteien Vertreter hatten, und über das Kabel der Eastern Telegraph Company gelangten Informationen schnell in die Redaktionen. Um Zensurmaßnahmen zu entgehen, wurde den Telegrammen die Anzahl der Wörter beigefügt. Viele Korrespondenten hofften auf einen Augenzeugenbericht von der Front oder auf ein Abenteuer im Rif ${ }^{595}$. Nach der Sperrung der französischen Grenzen war der gefährliche Weg von Tanger über Schmuggelpfade oder über das Meer ins Rif die einzige verbliebene Möglichkeit, vor Ort ein Interview mit Abdelkrim zu führen.

Der Amerikaner Larry Rue war einer der Europakorrespondenten der »Chicago Tribune«, für die er seit 1919 von allen Brandherden berichtete ${ }^{596}$. Er schaffte es im Juni 1925, mit einem Boot die Bucht von Alhucemas zu er-

${ }^{593}$ Vincent SHEEAN, Rivera Outlines Peace Terms, in: Chicago Tribune, 17.2.1925; SHAT 3H102: Vincent Sheean an Si M'hammed, 14.2.1925.

${ }^{594}$ DERS., Personal History, S. 128-130.

${ }^{995}$ STEIN, Under Fire, S. 81; VAIDON, Tangier, S. 204; MOWRER, The House of Europe, S. 520; DESMOND, Crisis and Conflict, S. 231, S. 302; BouTBOUQALT, La Guerre du Rif, S. 128f.; TERruER, Les »Frères de la côte« 1925, S. 549; Tangier News, in: Al-Moghreb al Aksa \& Tangier Gazette, 5.9.1925.

${ }^{596}$ Who Was Who in America 4 (1968) S. 817; DESMOND, Crisis and Conflict, S. 40, S. 329, S. 331; ROTH, Historical Dictionary, S. 263 f. 
reichen ${ }^{597}$. Abdelkrim nutzte nach seinen guten Erfahrungen die Gelegenheit, einem Amerikaner seine an Frankreich und Spanien gerichteten Friedensbedingungen mitzuteilen und damit einer breiteren Öffentlichkeit zugänglich zu machen. Gegen die Anerkennung der Unabhängigkeit bot er Frankreich den Friedensabschluß im Rahmen der im Vertrag von Algeciras festgelegten Grenzen an. An Spanien richtete er zusätzlich die Forderung einer wahlweisen Evakuierung von Tetuan bzw. von Melilla und Ceuta. Abdelkrim lud amerikanische Ärzte sowie Experten für die Errichtung eines Schulwesens und für die Organisation einer Industrie ins Rif ein und betonte noch einmal ausdrücklich, daß nur von ihm vergebene wirtschaftliche Konzessionen innerhalb der bestehenden Grenzen des Rifs Gültigkeit hätten ${ }^{598}$.

Zur gleichen Zeit stand der Emir des Rifs im Zuge seiner parallelen Kontakte $z u$ mehreren Beratern mit den Briten Walter Harris und Robert GordonCanning in Verbindung, und wenige Tage nach Rue traf der italienische Journalist Mirko Ardemagni ein. Das Interview mit Abdelkrim brachte Larry Rue eine Titelgeschichte und einen hohen Bekanntheitsgrad ein. Nach einem ähnlichen Abenteuer in Afghanistan wurde Rue ein eigenes Flugzeug zur Verfügung gestellt, mit dem er als sogenannter »fliegender Reporter« zu seinen Einsätzen gelangen konnte ${ }^{599}$.

Abdelkrim intensivierte seine überseeischen Pressekontakte bis hin nach Lateinamerika. Sein Mittelsmann war der Sudanese Ahmed Hassan Mattar. Er war Anfang 1924 nach Tanger gekommen, um für die Zeitung »Akhbar el Alam« zu arbeiten, die Captain S. Cyril Beresford Mundey - der örtliche Vertreter der British Red Crescent Society - gehörte ${ }^{600}$. Über dessen Vermittlung gelangte Mattar im Sommer 1924 ins Rif $^{601}$. Abdelkrim trug ihm auf, zukünftig »in Südamerika und Europa die Aufklärungsarbeit über die Ereignisse im Rif zu organisieren ${ }^{602}$.

${ }^{597}$ RUE, News, S. 257f., S. 264-269; SHAT 3H102: EMA, $2^{e}$ bureau, Bericht »La contrebande à Tanger «, 25.7.1925; PRO-FO 371, 12687, 11, 190: Ambassade de Londres an FO, 25.2.1927; CADN Maroc DAI 195: Tabor de police $\mathrm{N}^{\circ}$ 1, Note, 10.7.1925.

${ }_{598}$ RUE, News, S. 280.

${ }^{599}$ Ibid. S. 79, S. 84, S. 276.

${ }^{600}$ Ahmed H. MATTAR, Sindbad min as-Sudan, Khartum ${ }^{2} 1976$, S. 21 f., S. 37-40; ADMAE Maroc 133, 284: Tabor de police $N^{\circ}$ 1, Information, 21.3.1926; BOUTBOUQALT, La Guerre du Rif, S. 175, Anm. 135.

${ }^{601}$ ADMAE Maroc 133, 228: MI, Säreté générale an MAE, 23.2.1926; TERRIER, Les »Frères de la côte« 1926, S. 69; MATTAR, Abd el Krim und Europa, S. 31.

${ }^{602}$ Gerhard HŌPP, Die arabischen Nationalrevolutionäre in Berlin und die Liga, in: Hans PiAZZA (Red.), Die Liga gegen Imperialismus und für nationale Unabhängigkeit 1927-1937. Zur Geschichte und Aktualität einer wenig bekannten antikolonialen Weltorganisation. Protokoll einer wissenschaftlichen Konferenz am 9. und 10. Februar 1987 an der Karl-MarxUniversität Leipzig, Leipzig 1987, S. 105-112, S. 106. 
Im April 1925 machte sich Mattar nach Brasilien auf, wo er Herausgeber der Zeitung »Al Taçahol» und Chefredakteur des »O Jornal« wurde ${ }^{603}$. Er veröffentlichte einen Brief Abdelkrims, in dem dieser seinen festen Willen zum Frieden mit Frankreich erklärte ${ }^{604}$. Der französische Botschafter in Rio de Janeiro zeigte sich über Abdelkrims Schreibstil erstaunt: „Mann kann den Rifchef bekämpfen und brandmarken, aber als Joumalist für die südamerikanische Öffentlichkeit versteht er sein Handwerk ${ }^{605}$. Mattar leitete Abdelkrims Brief im Juli 1925 an die argentinische Studentengruppe Renovación weiter, die ihn wegen seiner ähnlichen Ideale zu Feierlichkeiten zur Unabhängigkeit Perus eingeladen hatte ${ }^{606}$. Der französische Botschafter in Lima spottete, daß die enthusiastischen Abdelkrim-Berichte der peruanischen Zeitung „El Tiempo« die Grenzen der Hysterie überschreiten würden ${ }^{607}$. Doch im Herbst 1925 kehrte Mattar nach Europa zurück, ohne Wesentliches erreicht zu haben ${ }^{608}$.

Ende 1925 tauchte er in Berlin auf. Er hielt in moslemischen Kreisen sowie auf Veranstaltungen der Internationalen Arbeiterhilfe (IA) und des Roten Frontkämpferbundes Vorträge ${ }^{609}$. Noch lange nach Abdelkrims Kapitulation trat Mattar im Februar 1927 während des Kongresses gegen koloniale Unterdrückung und gegen Imperialismus als »Vertreter der Verteidigungsgesellschaft des Rifs in Südamerika und in Europa auf ${ }^{10}$.

Neben Ahmed Hassan Mattar, Scherif Tidjani und Ahmed Balloul gibt es nur wenige Beispiele aus der moslemischen Welt, die Abdelkrim direkt in politischer Hinsicht unterstützten, obwohl er die Wünsche moslemischer Na-

${ }^{603}$ MATTAR, Sindbad, S. 23; ADMAE Maroc 133, 231 : Bericht »Note sur le sieur Mattar« o.D. [1926]; PRO-FO 371, 11083, 7118, 89: WO an FO, 23.7.1925 mit dem beiliegenden Brief Ahmed H. Mattar an Robert Gordon-Canning, 25.5.1925.

${ }^{604}$ Lutando pelo direto de existir soberanamente, in: O Jornal, 3.7.1925.

${ }^{605}$ ADMAE Maroc 129, 55: Ambassade de Rio de Janeiro an MAE, 3.7.1925.

${ }^{606}$ L'agression des Rifains contre le Maroc français, in: BCAF 35 (1925) S. 362f; Un message d'Abd el Krim aux peuples de l'Amérique latine, in: Humanité, 24.9.1925; Abd-elKrim: Unser Kampf um die Freiheit, in: Das Tagebuch 6 (1925) S. 1735-1737.

${ }^{607}$ ADMAE Maroc 129, 170: Ambassade de Lima an MAE, 29.7.1925.

${ }^{608}$ ADMAE Maroc 133, 33: Ambassade de Berne an MAE, 4.11.1925.

${ }^{609}$ MATTAR, Abd el Krim und Europa, S. 31; DeRS., Der Kampf ums Rif, in: Der Koloniale Freiheitskampf, 15.2.1926; DERS., Memorandum der Rifkabylen an den Völkerbund, in: Der Koloniale Freiheitskampf, 15.2.1926; DERS., Sindbad, S. 35-41, S. 57; Une proposition de paix d'Abd el Krim. Un messager riffain serait arrivé à Genève, in: Humanité, 3.11.1925; Gerhard HōPP, Zwischen Moschee und Demonstration. Muslime in Berlin 1922-1930, in: Moslemische Revue 10 (1990) S. 230-238, S. 233; DERS., Die arabischen Nationalrevolutionăre, S. 106-110; BROUÉ, Histoire, S. 390, S. 1047; BOUTBOUQALT, La Guerre du Rif, S. 175, Anm. 135.

${ }^{610}$ HAIKAL, Internationale, S. 848, S. 850; Das Flammenzeichen von Palais Egmont. Offizielles Protokoll des Kongresses gegen koloniale Unterdrückung und Imperialismus, Brüssel, 10.-15. Februar 1927, hg. von der Liga gegen Imperialismus und für nationale Unabhängigkeit, Berlin 1927, S. 104; BA R1507, 112, 3: Oberpräsident Provinz Westfalen an Preußischer Minister des Innern, 5.9.1927. 
tionen, sich von der europäischen Dominanz zu befreien, nahezu personifizierte $^{611}$. Abdelkrims Aufruf an die moslemische Welt von 1922 hatte nur die Auseinandersetzung hochpolitisierter Sympathisanten mit seinem Freiheitskampf bewirkt. Die türkische und nordafrikanische Presse berichtete ausgiebig vom >Heldentum ‘ der Rifkabylen in ihrem Kampf gegen den europäischen Imperialismus ${ }^{612}$. In Syrien gab es 1925 vor dem Ausbruch des Drusenaufstandes gegen die französische Mandatsmacht Solidaritätsbekundungen mit Abdelkrim $^{613}$.

Vereinzelte konkrete Hilfeleistungen beschränkten sich auf propagandistische Aktionen oder auf Versuche, humanitäre Unterstützung zu leisten. In Berlin, einem Zentrum arabischer Anti-Kolonialisten zu dieser Zeit, organisierte etwa der Ägypter Mansour Rifat von der Ägyptischen National-Radikalen Partei eine Kundgebung gegen den spanischen Giftgaseinsatz im Rif. In der Zeitung »Die Ägyptische Flagge« solidarisierte sich die ägyptische Gemeinschaft Berlins mit den gegen Frankreich kämpfenden Drusen und Rifkabylen $^{614}$. Das tunesische Comité central pour la libération de l'Afrique du Nord beschwor den einheitlichen Kampf gegen die seuropäischen Despoten $\kappa^{615}$. 10000 Moskauer Moslems unterschrieben eine Protestnote gegen Frankreichs Verwicklung in den Rifkrieg ${ }^{616}$. Abdelkrim rief zwar im August 1925 die Völker Nordafrikas erneut zur Unterstützung der Rifkabylen auf, betrachtete den Krieg aber abseits der pan-islamistischen Hoffnung einer Vereinigung islamischer Staaten als rein patriotischen Kampf ${ }^{617}$.

Im September 1925 - kurz vor der Landung der spanischen Truppen in der Bucht von Alhucemas, die den Wendepunkt des Rifkrieges einläutete - suchte Vincent Sheean, der nun unter Vertrag der North American Newspaper Alliance stand, das Rif ein zweites Mal auf. Rifagenten schmuggelten ihn durch die spanische Blockade der internationalen Zone Tangers und führten ihn zum

${ }^{611}$ HOISINGTON, Lyautey, S. $198 \mathrm{f}$.

${ }^{612}$ Bilge CRISS, Pinar BILGIN, Turkish Foreign Policy toward the Middle East, in: Middle East Review of International Affairs 1 (1997). URL = http://www.biu.ac.il/SOC/besa/meria/ journal/1997/issuel/jvlnla3.html [10.6.2001]; CADN Londres C536: Ministère des Colonies, Bericht »Revue de la presse et des questions musulmanes«, 15.7.1924, 15.9.1924 und 30.9.1924; Roger LABONNE, L'Islam et la révolte riffaine, in: Correspondant 300 (1925) S. 801-827, S. 801; BoutbouQALT, La Guerre du Rif, S. 133-137; Fleming, Primo de Rivera and Abd-el-Krim, S. 220.

${ }^{613}$ CADN Maroc DAI 195: Haut-Commissaire de Syrie an DAI Rabat, 24.4.1925.

${ }^{614}$ HÖPP, Die arabischen Nationalrevolutionäre, S. 87-89, S. 93, S. 107f.; HŌPP, Zwischen Moschee und Demonstration, S. 232-234; PA-AA R72044, L057920: Mansour Rifat an AA, 5.6.1925; BA R43I, 43, 27: AA an Reichskanzlei, 2.7.1925.

${ }^{615}$ La propagande d'Abd el Krim dans l'Afrique du Nord, in: BCAF 36 (1926) S. 15-17, S. 17.

${ }^{616}$ PA-AA Paris 454a: Botschaft Moskau an AA, 9.7.1925.

${ }^{617}$ AN F7, 14978: Note, 15.8.1925; L'agression des Rifains contre le Maroc français, in: BCAF 35 (1925) S. 262; RUE, Tribune, 23.6.1925. 
westlichen Hauptquartier der Rifarmee in Taghzout, wo Si M'hammed auf ihn wartete $^{618}$. Der Bruder Abdelkrims betonte während eines am 13. September 1925 geführten Interviews, daß wwir für unsere Existenz und für unser Recht, in Freiheit zu leben, kämpfen. [...] Alles, was wir wünschen, ist Unabhängigkeit für das Rifgebiet und für die damit zusammenhängenden Gebiete«. Er appellierte erneut an die Regierungen der USA, Großbritanniens und Italiens, eine internationale Friedenskonferenz einzuberufen ${ }^{619}$.

Als Sheean am 24. September 1925 in Ajdir eintraf, unterstrich Abdelkrim deutlich, daß die Anerkennung des Rifstaates die unabdingbare Voraussetzung für Verhandlungen sei ${ }^{620}$. Der Rifchef erwartete bei einer längeren Kriegsdauer einen Umschwung der öffentlichen Meinung in Frankreich und Spanien, der die Regierungen zwingen würde, Frieden zu schließen. Sheean war von Abdelkrims Selbstvertrauen angesichts der Gefahr durch die angreifenden Spanier tief beeindruckt und ließ jegliche journalistische Neutralität fallen: »Früher hatte ich geglaubt, Abd-el-Krim sei ein intelligenter kleiner Advokat, den der Zufall und das Glück in eine Stellung von weltgeschichtlicher Bedeutung erhoben haben. Als ich ihn aber gestern inmitten eines höllischen Kampflärms unter seinen Leuten sah, während feindliche Bomben und Granaten sein Leben jeden Augenblick bedrohten, erschien er mir in einem neuen Licht. Er schien wirklich das zu sein, wofür ihn das Volk hält, - ihr Mohammed und ihr Napoleon zugleich ${ }^{621}$.

Abdelkrim stattete Sheean, der Ende Oktober 1925 nach Tanger zurückkehrte, mit seinen Friedensvorschlägen für Frankreich und Spanien aus - unter der Bedingung, sie erst nach deren Übergabe zu veröffentlichen ${ }^{622}$. Erneut ging er dabei parallel mehrere Wege, denn zeitgleich bemühte sich Abdelkrims britischer Berater Robert Gordon-Canning um Kontakte zur französischen Regierung. Es war grotesk. Während Gordon-Canning nach einer Unterredung mit Ministerpräsident Painlevé von Paris aus zur Generalresidenz FranzösischMarokkos nach Rabat unterwegs war, startete Sheean von dort aus fast gleichzeitig mit einem Flugzeug nach Paris, um mit Painlevé zu sprechen ${ }^{623}$. Beide wußten nichts voneinander. Die geheime Friedensaktion Gordon-Cannings, die mit Billigung Painlevés vonstatten gehen sollte, wurde durch Sheean gefährdet. Der französische Regierungschef empfing den Reporter mit offenem Mißtrauen und ließ ihn während seines Aufenthaltes in der französischen Hauptstadt beschatten ${ }^{624}$.

${ }^{618}$ SHEEAN, Personal History, S. 130, S. 135-141; DERS., Im Rif, 29.9.1925.

${ }^{619}$ DERS., Im Hauptquartier, 2.10.1925. Vgl. DERS., Die Lage im Rif, in: Neue Zürcher Zeitung, 1.10.1925.

${ }^{620}$ DERS., Personal History, S. 149.

${ }^{621}$ DERS., Im Lager, 21.10.1925. Vgl. DERS., Vor dem Fall, 21.10.1925.

${ }^{622}$ DERS., Personal History, S. 163f.; DerS., Abd el Krims europäische Helfer, 10.11.1925.

${ }^{623}$ Tangier News, in: Al-Moghreb al Aksa \& Tangier Gazette, 7.11.1925 und 14.11.1925.

${ }^{624}$ SHEEAN, Personal History, S. 171-173. 
In seinen Friedensbedingungen beharrte Abdelkrim als Grundlage zukünftiger Gespräche auf der Anerkennung der Unabhängigkeit des Rifstaates und der Einschaltung des Völkerbundes. Eine Kommission sollte nun die Grenzen zwischen Französisch-Marokko und dem Rif festlegen. Abdelkrim erklärte sich zur Anerkennung der religiösen Hoheit des Sultans bereit ${ }^{625}$. Frankreich hingegen wollte lediglich eine Autonomie und Handelsfreiheit furr das Rif zubilligen, wobei die Handels- und Wirtschaftspolitik den Vertragsverpflichtungen der europäischen Staaten entsprechen mußten: "Mit anderen Worten, Abd-el-Krim könnte weder Konzessionen erteilen noch eine Kontrolle der Bergwerkbetriebe in seinem Gebiet ausüben. Dies ist bei weitem die unangenehmste Bedingung der Franzosen und Spanier ${ }^{626}$. Da die Entscheidungsfreiheit in wirtschaftlichen Fragen für Abdelkrim ein immens wichtiger Bestandteil der Selbstbestimmtheit in einem unabhängigen Rifstaat war, gingen die Ansichten sehr weit auseinander.

Paul Scott Mowrers, Larry Rues und Vincent Sheeans Reportagen über den Rifkrieg zielten in erster Linie auf die abenteuerlustige amerikanische Leserschaft ab und erregten große Aufmerksamkeit. Sie wurden ebenfalls in europäischen Zeitungen abgedruckt. Sie zeigten auf, daß die Rifkabylen in einem organisierten Staatswesen um ihre Unabhängigkeit fochten. Abseits der spanischen und französischen Kriegspropaganda wurde Abdelkrim in nie zuvor erreichter Weise weltweit bekannt. Einige amerikanische Politiker äußerten Bedenken, ob die bisherige Politik der strikten Neutralität der USA im Rifkonflikt der richtige Weg sei. Die einflußreichen Senatoren William Edgar Borah aus Idaho und A. Piat Andrew aus Massachusetts verhehlten ihre Sympathie für Abdelkrim nicht, erreichten aber kein Umdenken in der amerikanischen Regierung ${ }^{627}$. Diese definierte ihre Politik der Neutralität so weit, daß sie amerikanischen Piloten, die auf der Seite der Franzosen aufsehenerregende Lufteinsätze gegen die Rifkabylen flogen, den Verlust ihrer Staatsbürgerschaft androhte. Im November 1925 wurde die Staffel aufgelöst ${ }^{628}$.

${ }^{625}$ DERS., Condition for an Armistice, in: Al Moghreb al-Aksa \& Tangier Gazette, 5.12.1925.

${ }^{626}$ DERS., Frankreichs Friedensbedingungen für Abd-el-Krim, in: Neue Zürcher Zeitung, 26.11.1925. Vgl. DERS., Peace in Morocco, in: Asia 26 (1926) S. 259f.

${ }^{627}$ AzzoU, Les relations, S. 166; HALL, The United States, S. 757f.; BouTbOUQALT, La Guerre du Rif, S. 129f; AGERON, La presse parisienne, S. 8; CULLEN, Paul Scott Mowrer, S. 261; STOCK, The Works, S. 47; ROTH, Historical Dictionary, S. 281; SLAVIN, Anticolonialism, S. 294; HAROUCHI, Les États-Unis, S. 369f., S. 372.

${ }^{628}$ Amerikaner in Marokko, in: Kölnische Zeitung, 16.7.1925; Amerikanische Flieger an der Marokkofront, in: Kölnische Zeitung, 27.7.1925; Die amerikanischen Flieger, in: Kölnische Zeitung, 21.9.1925; Quinze officiers américains qui servirent sur le front français vont combattre dans l'aviation française au Maroc, in: Matin, 17.7.1925; M. Painlevé salue les neuf aviateurs américains qui vont partir pour le Maroc, in: Matin, 31.7.1925; American Fliers Ordered to Quit Riffian Campaign, in: New York Herald, 21.9.1925; Kellogg Draws Censure for Warning Riff Fliers, in: New York Herald, 22.9.1925; Our Fighting Flyers in Mo- 
Angeregt durch die Berichte Vincent Sheeans und durch die zeitgleichen Aktionen des Londoner Riff-Committees gründete der Verleger Herbert Myrick im Januar 1926 in Springfield, Massachusetts, eine Gruppierung namens American Friends of the Riff. Myrick war unter anderem der Gründer der Farmers' Political League und des Farm Bloc, der Präsident der American Education Press sowie der Herausgeber der Zeitschriften "Good Housekeeping Magazine«, "Southern Farming und »Farm and Home ${ }^{629}$. Er verfolgte das ambitionierte Ziel, mittels einer landesweiten Dachorganisation, der America's Commission for the Riff, Druck auf die öffentliche Meinung auszuüben, um einen Friedensschluß, die Anerkennung der Rifkabylen als Kriegführende und die internationale Bestätigung eines souveränen Staatsgebildes im Rif zu erreichen ${ }^{630}$. Die Gruppe erlangte aber allenfalls regionale Bedeutung. Somit blieben Abdelkrims Tuchfühlungen auf Nord- wie Südamerika auf propagandistische Auswirkungen beschränkt.

\subsection{Abdelkrim, Robert Gordon-Canning und das Riff-Committee}

Der einflußreichste Mann im britischen Pendant der Friends of the Riff - dem Riff-Committee - sollte Captain Robert Gordon-Canning werden. Der finanziell unabhängige Bewunderer des Islam hatte das Ehepaar John und Gertrude Arnall während eines langen Tangeraufenthaltes im Jahre 1923 kennengelernt und über sie Kontakt zu den Tangerer und Londoner Sympathisanten Abdel-

rocco, in: Literary Digest, 3.10.1925; American Bombers and Riff Babies, in: Literary Digest, 31.10.1925; Secretary of State an A. Piat Andrew, 21.10.1925, in: Papers Relating to the Foreign Relations of the United States 1925, Bd. 2, S. 607-609; Edward A. PowELL, In Barbary. Tunisia, Algeria, Morocco and the Sahara, New York, London 1926, S. 369; HALL, The United States, S. 759; VaIDON, Tangier, S. 198; Paul Ayers RockWELL, Dale L. WALKER, Moroccan Bomber. American Fighters in the Rif War 1925, in: Aviation Quarterly 5 (1979) S. 108-135; El-Mostafa AzzoU, L'escadrille Lafayette: Des aviateurs américains dans la Guerre du Rif 1921-1926, in: Guerres mondiales et conflits contemporains 53 (2003) S. 57-63.

629 Who Was Who in America 4 (1943) S. 866; Paul J. MIRANTl, Herbert Myrick, in: GARRATY, CARNES (Hg.), American National Biography, Bd. 16, S. 209f.; Alvin F. HaRLow, Herbert Myrick, in: Dumas MALONE (Hg.), Dictionary of American Biography, Bd. 13, London, New York 1934, S. 376f., S. 377.

${ }^{630}$ NARA 881.00, 1196: Herbert Myrick an Secretary of State, 6.2.1926; ADMAE Maroc 133, 184: Ambassade de Washington an MAE, 4.2.1926; ADMAE Maroc 133, 192: Note, 8.2.1926; Cause of the Riffs Arouses Sympathy, in: Springfield Republican, 17.1.1926; Plan Started on Riff League at Local Club, in: Springfield Republican, 12.1.1926; TERRIER, Les „Frères de la côte« 1926, S. 69; HALL, The United States, S. 758f; AZzOU, Les relations, S. 165. 
krims aufgenommen ${ }^{631}$. Doch zunächst überschattete ein Todesfall seine erste Fühlungnahme. Während der Besichtigung eines vermeintlichen Ölfeldes bei Charf el Akab erlitt John Arnall am 11. März 1924 eine tödliche Herzattacke $^{632}$. Gertrude Arnall übernahm die Rif-Aktivitäten ihres verstorbenen Ehemannes. Zusammen mit den Tangerer Rifagenten Si Larbi el Ouezzani, Si Abdelkrim ben el Haj Ali Luh und Moulay Ali el Khamlichi ${ }^{633}$ diente sie Abdelkrim in der Folgezeit als sogenannter "Briefkasten nach Europa«, indem sie dessen Schreiben nach Europa weiterleitete und die Korrespondenz von dort ins Rif schmuggeln lieB $B^{634}$.

Als Berater Abdelkrims sollte Gordon-Canning von nun an eine bedeutende Rolle spielen ${ }^{635}$. Nach seiner Rückkehr nach London im Frühjahr 1924 ergriff er in einem Artikel für die Zeitschrift »Contemporary Review« deutlich Partei für Abdelkrim, der als anerkanntes Oberhaupt die im Rif herrschenden Streitigkeiten zwischen unterschiedlichen Fraktionen beseitigt habe. Gordon-Canning hob hervor, daß die Anerkennung des Rifstaates die Voraussetzung für ausländische Bergbauaktivitäten sei. Abdelkrim habe präzise Ansichten hinsichtlich der Entwicklung seines Landes, wolle aber keine finanzielle Dominanz von Europäern zulassen, da dies häufig die militärische Besetzung nach sich ziehe. Gordon-Canning übernahm John Arnalls Argumente hinsichtlich der Gefährdung des britischen Seewegs nach Indien, die eine Ausweitung des französischen Einflusses auf ganz Marokko nach sich ziehen könnte, und er appellierte - wie ebenfalls schon John Arnall oder Charles Gardiner - an die

${ }^{631}$ CADN Tanger C37: Bericht Note au sujet du Capitaine anglais Gordon-Canning et sur la mission qui lui est confiée par Abdelkrimu, 19.12.1925; ADMAE Maroc 135, 190: CG Tanger an MAE, 2.2.1926; PRO-FO 371, 11920, 3636, 90: CG Tangier an FO, 22.4.1926; PA-AA R71126, K430427: Botschaft London an AA, 5.5.1924. Siehe Kapitel 3, S. 71-74.

${ }^{632}$ PRO-FO 174, 303, 76: G.C. Allchin an Lt.-Col. P.R. Cummings, Military Headquarters, Gibraltar, 18.3.1924; Local Notes, in: Al-Moghreb al Aksa \& Tangier Gazette, 15.3.1924.

${ }^{633}$ SHAT 3H442: Renseignements o.D. [Mitte 1926]; SHAT 3H1557: Territoire de Taza, SR, Bericht »Renseignements de Tanger «, 10.9.1924; CADN Maroc DAI 193: Tabor de police $\mathrm{N}^{\circ}$ 1, Note, 25.11.1924; PRO-FO 371, 10582, 101, 137 und 141: Embassy of Madrid an FO, 8.11.1924 und 12.11.1924; SPENCER PRYSE, Through the Lines, S. 437f;; SHEEAN, Eye to Eye, S. 1077f.; Ders., Personal History, S. 131; Goded LloPIS, Marruecos, S. 86; PENNel, A Country, S. 55; TAHTAH, Pragmatisme 1995, S. 187, Anm. 4; KHARCHICH, La France, S. 135.

${ }^{634}$ PRO-FO 371, 11076, 18, 196: Walter Harris an CG Tangier, 14.11.1925; CADN Tanger C39: Tabor de police $\mathrm{N}^{\circ}$ 1, Information, 17.7.1925; CADN Maroc DAI 199: EMA, $2^{\complement}$ bureau an RG Rabat, 6.7.1926 mit dem Bericht "Note sur les renseignements fournis par le légionnaire Klems«; CADN Tanger B30: RG Rabat an CG Tanger, 26.9.1924; PRO-FO 371, 11079, 39, 81: CG Tangier an Embassy of Madrid, 21.7.1925; ADMAE Maroc 133, 128: General Jordana an Embajada de Paris, 28.12.1925; PRO-FO 174, 305, 88: CG Tangier an FO, 8.1.1926; PRO-FO 174, 305, 88: CG Tangier an FO, 25.1.1926; PRO-FO 371, 12687, 11, 190: Ambassade de Londres an FO, 25.2.1927.

${ }^{635}$ TAHTAH, Pragmatisme 1995, S. 187, Anm. 2; FONTAINE, L'étrange aventure, S. 93; CADN Tanger C37: Bericht »Note au sujet du Capitaine anglais Gordon-Canning et sur la mission qui lui est confice par Abdelkrim«, 19.12.1925. 
britische Regierung, die Riffrage vom Völkerbund entscheiden zu lassen ${ }^{636}$. In einem Leserbrief an die "Times« unterstrich er dies noch einmal ausdrücklich: wIch bin sehr zuversichtlich [...], daß Abdelkrim und die spanische Regierung, wenn sie zusammen vor das unparteiische Tribunal des Völkerbundes gebracht werden könnten, in der Lage wären, zufriedenstellende Lösungen für beide Seiten zu finden ${ }^{637}$.

In seinem Vortrag "The Riffis - Their History and Cause«, den GordonCanning Anfang Oktober 1924 vor Mitgliedern der Near and Middle East Association hielt, wies er auf die enge Verflechtung zwischen der Unabhängigkeit des Rifs und europäischen Investitionen hin: "Was verlangt Abdelkrim? (1.) Die Unabhängigkeit seines Landes [...]. (2.) Die auf einer wirtschaftlichen Basis begründete Entwicklung der Reichtümer seines Landes in Verbindung mit europäischem Kapital und europäischer Wissenschaft, aber unter der Voraussetzung, daß sein Land einen fairen Anteil an seinen Reichtümern haben und nicht von Fremden ausgebeutet werden sollte«. Die Rifkabylen, so führte Gordon-Canning aus, würden um freundschaftliche Hilfe bitten, und er rief dazu auf, wirtschaftliche und strategische Betrachtungen zur Seite zu schieben, um den Völkerbund dazu zu bringen, ihren Staat anzuerkennen ${ }^{638}$.

Die Bemühungen von Gordon-Canning zielten also auf die Unabhängigkeit der »Rif-Republik« ab. Nur hatte er selbst längst nicht alle ökonomischen Interessen beiseite gelegt. Die Gerüchteküche brodelte, daß Abdelkrim mit einer Londoner Gruppe einen hochdotierten Bergbauvertrag abgeschlossen habe ${ }^{639}$. Die »Daily News« berichteten von einer in der Londoner Regent Street ansässigen Gesellschaft, die Abdelkrim 500000 Pfund für Bergbau-Konzessionen habe zahlen wollen ${ }^{640}$.

Diese Gruppe gab es tatsächlich. Dort, in der Regent Street No. 324 hatte Thomas Israel Perrott von der Gesellschaft International Oil Suppliers sein Büro. Von dort aus verhandelte er mit der Rifregierung über Bergbauverträ-

${ }^{636}$ Gordon-CANNING, Tangier, S. 179-181.

${ }^{637}$ DERS., Spain and Morocco (Leserbrief), in: Times, 12.9.1924.

${ }^{638}$ DERS., The Riffis - Their History and Their Cause. A Lecture Given before the Near and Middle East Association Last Month, in: African World, North African Monthly Supplement No. 1, 15.11.1924.

${ }^{639}$ CADN Tanger B30: RG Rabat an CG Tanger, 26.9.1924 mit dem Bericht »Politique britannique«, 10.9.1924; CADN Londres C519: MAE an Ambassade de Londres, 26.5.1924; PA-AA Madrid 135: Botschaft London an AA, 31.1.1925.

${ }_{640}$ To Buy Up the Riffs. London Offer for $£ 500,000$ (Abdruck aus den "Daily News $\lll$ ), in: Al-Moghreb al Aksa \& Tangier Gazette, 23.5.1925; Vote for War, in: Irish Independent, 12.5.1925; L'agression des Rifains contre le Maroc français, in: BCAF 35 (1925) S. 251262, S. 259. 
ge $^{641}$. Perrott war bereits am Gardiner-Vertrag von 1923 beteiligt gewesen, hatte sich aber mittlerweile von ihm losgesagt ${ }^{642}$. Mit seinen Hintermännern wartete er auf die Anerkennung der Unabhängigkeit des Rifstaates. Spaniens Botschafter Merry del Val hatte Erkundigungen eingezogen, daß einflußreiche Wirtschaftsleute hinter dem Briten standen, die bereit waren, viel Geld in den Bergbau zu investieren, sobald die Souveränität des Rifs erreicht sei. Perrott hoffte in diesem Fall auf eine hohe Provisionszahlung ${ }^{643}$. Merry del Val wies daher in der "Times« ausdrücklich darauf hin, daß Bergbau-Konzessionen in Marokko nur aufgrund des Bergbau-Gesetzes vom Januar 1914 vergeben werden könnten und alle von Abdelkrim erteilten Rechte ungültig seien ${ }^{644}$.

Anfang Oktober 1924 brachen Robert Gordon-Canning und sein Freund, der bekannte Maler Gerald Spencer Pryse, nach Tanger auf. Offiziell handelte es sich um eine Hilfsmission der British Red Crescent Society ${ }^{645}$. Ein großer Teil ihrer Reise wurde allerdings von Perrott bezahlt. Er war ihr Geschäftspartner ${ }^{646}$. Arthur Field, der Gordon-Canning durch seinen verstorbenen Freund John Amall kennengelernt und ein enges Vertrauensverhältnis zu ihm aufgebaut hatte, bezeichnete ihn als "Agenten einer britischen Finanzierungsgruppe, die bereit war, Abdelkrim eine halbe Million Pfund für Konzessionen zu zahlen ${ }^{647}$. Es ging auch um angeblich im Rif vorhandenes Erdöl. Ahmed Hassan Mattar, der sudanesische Sympathisant Abdelkrims, berichtete in seinen Memoiren, daß der Brite ihn beauftragt habe, für ihn ein im Kriegsgebiet befindliches Ölvorkommen in London zu verkaufen ${ }^{648}$. Ihm zufolge soll GordonCanning für die Shell Company gearbeitet haben ${ }^{649}$. Wahrscheinlicher ist jedoch, daß es sich um die International Oil Suppliers von Thomas Perrott gehandelt hat.

Das Thema Erdöl taucht im Vorfeld und während des Rifkrieges immer wieder auf, ohne daß sich anhand von Quellen oder in der Literatur etwas wirklich Handfestes ableiten läßt. Probebohrungen der Mannesmanns ließen nördlich

${ }^{641}$ PRO-FO 371, 11080, 94, 3: Embajada de Londres an FO, 31.12.1924; AN F7, 14980: Oficina mixta hispano-francesca, Section française, Note, 26.3.1927; PRO-FO 371, 10582, 101, 156: Memorandum o.D. [November 1924]. Siehe zur Gesellschaft International Oil Suppliers S. 289.

${ }_{642}$ PRO-FO 371, 11080, 94, 10: Embajada de Londres an FO, 31.1.1925.

${ }^{643}$ IORL, P\&J, 12, 230, 1671, 1924: A. Merry del Val an Lord Birkenhead, 18.3.1925.

${ }^{644}$ Mining Concessions in Morocco. Spanish Warning, in: Times, 21.10.1924.

${ }^{645}$ Siehe hierzu Kapitel 3, S. 74.

${ }^{646}$ PRO-FO 371, 11080, 94, 10: Embajada de Londres an FO, 31.1.1925.

${ }^{647}$ IORL, P\&J, 12, 230, 1671, 1924: Bericht »Indians, and Others, in England«, 13.3.1925. Vgl. CADN Madrid C263: RG Rabat an MAE, 8.11.1924.

${ }_{64 B}$ MATTAR, Sindbad, S. 39.

${ }^{649}$ DERS., Abd el Krim und Europa, S. 31. 
von Fes und im Inneren des Rifs Petroleum vermuten ${ }^{650} .1918$ hatte Abdelkrim mit Sadia Cohen Benaïm einen Erdölvertrag über Vorkommen auf dem Gebiet der Beni Touzine abgeschlossen ${ }^{651}$. Eine Petition (106E) des Anglo-African Petroleum Syndicate über angebliche Erdölareale am Monte Negro hatte die Schiedskommission am 5. Dezember 1919 abgewiesen ${ }^{652}$. Auch John Arnall hatte sich für Erdöl im Rif interessiert. Im September 1920 versuchte er vergebens, mit der amerikanischen Firma S. Pearson \& Sons in Kontakt zu treten $^{653}$. S. Pearson \& Sons konkurrierten mit Wm. H. Müller \& Co. um Gebiete am Jebel Tselfat im Norden Französisch-Marokkos. Letztere erhielten 1920 die Erlaubnis, Probebohrungen durchzuführen ${ }^{654}$.

Erdölkonzessionen für ganz Spanisch-Marokko wollte 1920 Commander Livingston Learmouth aufkaufen. Er gab vor, im Namen der Anglo-Persian Oil Company - der späteren British Petroleum Company (BP) - zu sprechen $^{655}$. Dort hatte man zwar von ihm noch nichts gehört, aber Direktor Sir Edmond Slade zeigte sich für den Fall, daß Learmouth die Konzessionen tatsächlich erhalten sollte, nicht uninteressiert ${ }^{656}$. Bergbauingenieur John Bevan stellte 1923 fest, daß es im Rif kein Erdöl gab ${ }^{657}$. Dort sind bis heute keine Ölvorkommen bekannt geworden. Im französischen Protektorat hingegen, am Jebel Tselfat bei Petitjean (heute Sidi Kacem), bei Boudra, Ain Hamra und im Rharb-Gebiet wurde tatsächlich Erdōl gefunden. Die Felder wurden von der Compagnie française des pétroles du Maroc und der Société de recherches et forages bewirtschaftet ${ }^{658}$.

Die humanitären Hilfslieferungen, die Gordon-Canning und Spencer Pryse im Herbst 1924 ins Rif überführten, dienten als Vorwand für politische und wirtschaftliche Gespräche mit Abdelkrim. Dies zeigt sich schon darin, daß Gerald Spencer Pryse dem »Manchester Guardian« nach seiner Rückkehr kei-

${ }^{650}$ BEN ASSAR, Kampf um das Schatzland, S. 44; Les richesses minières, in: BCAF 31 (1921) S. 66; Morocco Minerals Syndicate, Ltd., in: Morocco, 8.1.1921; PRO-FO 371, 3252, 17373: Bericht "Mineral Deposits in Morocco«, 1.1.1918; PRO-FO 368, 2150, 18170: Consulate of Tetuan an CG Tangier, 18.1.1919; MïGE, Le Maroc, Bd. 4, S. 49.

${ }^{651}$ ADMAE Maroc 112, 176: Vertrag zwischen Abdelkrim und Sadia Cohen Benaïm, 28.5.1918.

${ }^{652}$ Boletín oficial de la zona de protectorado español en Marruecos, Número 3, 10 de febrero de 1920 , Madrid 1920, S. $93 f$.

${ }^{653}$ IORL, P\&J, 12, 230, 1671, 1924: A. Merry del Val an Lord Birkenhead, 18.3.1925; CADN Londres C518: MAE an Ambassade de Londres, 22.9.1922.

${ }^{654}$ Les petroles au Maroc, in: BCAF 30 (1920) S. 284f.

${ }^{655}$ PRO-FO 371, 4524, 1371, 131: Commander Livingston Learmouth an FO, 9.4.1920; PRO-FO 371, 4524, 1371, 141: Note, 27.5.1920.

${ }^{656}$ PRO-FO 371, 4524, 1371, 151: Anglo-Persian Oil Company an FO, 3.6.1920.

${ }^{657}$ PRO-FO 371, 9470, 44, 29: CG Tangier an FO, 2.9.1923. Dies wurde bestätigt in: Mineral Wealth of the Rif, in: Al-Moghreb al Aksa \& Tangier Gazette, 3.7.1926.

${ }^{658}$ Erdöl in Marokko, in: Petroleum 20 (1924) S. 1349f.; Eine Erdölraffinerie in Marokko, in: Petroleum 20 (1924) S. 103; FonTAINE, L'etrange aventure, S. 196-200; André NOUSCHI, La France et le pétrole. De 1924 à nos jours, Paris 2001, S. 81. 
ne Angaben zu den Zielen der Reise machen wollte. Er sagte nur, es habe sich um eine "streng vertrauliche Mission« gehandelt. Wäre sie rein humanitär ausgerichtet gewesen, hätte es keinen Grund gegeben, dies zu verschweigen $^{659}$. Gordon-Cannings politisches Engagement hatte ein Ziel - die Unabhängigkeit des Rifs, denn nur in einem souveränen Rifstaat wäre das ansonsten geltende marokkanische Bergbaugesetz aufgehoben worden. Er verband sein Interesse für islamische Fragen mit Geschäftlichem.

Die Mission ins Rif führte die Briten zunächst nach Snada. Dort trafen Gordon-Canning und Spencer Pryse mit Si Mohammed Azerkane und Si Mohammed Mohammedine Hitmi von der Rifregierung zusammen. Abdelkrim und sein Bruder Si M'hammed blieben in Ajdir, um Friedensvorschläge von Horacio Echevarrieta entgegenzunehmen, der gerade mit seiner Jacht in der Bucht von Alhucemas vor Anker lag ${ }^{600}$. Die vergeblichen Versuche der Vergangenheit, mit europäischen Regierungen zu verhandeln, hatten Hitmi und Azerkane skeptisch gemacht. Spencer Pryse notierte: "Sie kennen die Gefahren, die sich hinter der wirtschaftlichen Durchdringung verbergen, und sie sind sich bewußt, daß Politik im Frieden nichts anderes als die Weiterführung von Krieg mit subtileren Mitteln sein könnte ${ }^{661}$. Der deutsche Deserteur Josef Klems führte Gordon-Canning an vermeintliche Fundorte von Bodenschät$\mathrm{zen}^{662}$. Die Briten wurden aber bewacht und durften weder fotografieren noch Zeichnungen anfertigen ${ }^{63}$.

Als Gordon-Canning und Spencer Pryse das Rif verließen, hatte sich die Stimmung gewandelt, da sie den Eindruck erwecken konnten, daß Großbritannien hinter ihren Ambitionen stünde. Dabei ist nicht festzustellen, ob sie sich als Gesandte ihres Landes präsentiert hatten, oder ob die Rifregierung die Lage schlicht falsch einschätzte. Zeitgleiche Kontakte zum Tangerer »Times«Korrespondenten Walter Harris verfestigten jedenfalls bei Abdelkrim den Eindruck vermeintlich guter Beziehungen zu Großbritannien. Bald darauf kursierten in Marokko, Frankreich und Spanien Gerüchte, Abdelkrim werde von der britischen Regierung unterstützt ${ }^{664}$.

${ }^{659}$ Two Englishmen among the Riff Tribesmen, in: Manchester Guardian, 13.12.1924.

${ }^{600}$ Siehe S. $235 \mathrm{f}$.

$\$ 1$ SPENCER PRYSE, Through the Lines, S. 473.

${ }^{662}$ PA-AA R70870: Botschaft Paris an AA, 21.6.1926 mit beiliegendem Bericht "Affaire Klems«; SHAT 12J3797, 27: Vernehmung von Josef Klems vor dem 2. Kriegsgericht Meknes, 19.6.1927; CADN Maroc DAI 199: EMA, 2 bureau an RG Rabat, 6.7.1926 mit beiliegendem Bericht »Note sur les renseignements fournis par le légionnaire Klems« o.D. [1927].

${ }_{663}^{63}$ CADN Maroc DAI 188: Tabor de police $N^{\circ} 1$, Note, 3.12.1924.

PRO-FO 371, 11077, 39, 120: CG Tangier an FO, 29.1.1925; PRO-FO 371, 11083, 2646, 193: CG Tangier an FO, 12.3.1925; Walter B. HARRIS, The Rifi Revolt. Stories of British Support, in: Times, 31.1.1925; Political Notes, in: Times, 11.2.1925; MOWRER, The House of Europe, S. 477; PA-AA Paris 454a: Botschaft Madrid an AA, 18.2.1925. Siehe zu Harris S. 346-354. 
Außenminister Austen Chamberlain sah sich gezwungen, derartige Berichte im Zuge einer parlamentarischen Anfrage im britischen Unterhaus deutlich zu dementieren ${ }^{665}$. Im Außenministerium wurde die Lage in Marokko mit Besorgnis betrachtet. Chamberlain befürchtete ein Eingreifen Frankreichs, falls Spanien Marokko aufgeben würde. Die britische Luftwaffe sah die Gefahr, daß eine eventuelle Okkupation der spanischen Zone Marokkos durch Frankreich für Gibraltar und für die britische Mittelmeerschiffahrt eine erhöhte Gefährdung aus der Luft zur Folge haben könnte ${ }^{666}$. Ein Memorandum des Außenministeriums kam zum Schluß, daß Frankreich aufgrund der bestehenden internationalen Verträge rechtlich nicht daran gehindert werden konnte, im Fall der Fälle die »Ordnung« im Rif wiederherzustellen ${ }^{667}$. Umso wichtiger war es der britischen Regierung, daß die spanische Einflußzone erhalten blieb.

Gleich nach seiner Rückkehr aus dem Rif Anfang Dezember 1924 machte sich Gordon-Canning ans Werk, die Sache der Rifkabylen - und insgeheim seine Geschäftsinteressen - offensiv zu vertreten. Er erntete in der britischen Gesandtschaft Tanger Hohn und Spott mit seinem Vorschlag, im Rif eine kommerzielle Luftfahrtgesellschaft, die Großbritannien in einem eventuellen Krieg mit Frankreich gute Dienste leisten könne, zu errichten. Generalkonsul Robert Clive verdeutlichte ihm, daß die britische Regierung Abdelkrim keinerlei Ermutigung zukommen lassen werde ${ }^{668}$. Für seine Haltung erhielt Clive Lob aus London. Dort betrachtete man Gordon-Canning als gewissenlosen Gesellen, „der bereit ist, sein Land für einen Wirtschaftsvertrag zu verkaufen $\aleph^{669}$.

Abdelkrims Berater offerierte seinen Luffahrtplan auch der deutschen Botschaft in London. In seinem Schreiben drängte er die deutsche Regierung, die Unabhängigkeitsbestrebungen der Rifkabylen »um jeden Preis« gegen die französischen Invasionsziele zu unterstützen. Im Gegenzug würde der Rifstaat die "französische Aggression" in der Meerenge von Gibraltar zurückweisen und auch die Gelegenheit für die Errichtung einer Luftwaffenbasis bieten ${ }^{670}$. Seit seinem ersten Tangeraufenthalt hatte Gordon-Canning einen Kontakt zu den deutschen Diplomaten in London aufrechterhalten. Er berichtete von der Popularität Deutschlands in Tanger und auch von seiner Mission nach Ma-

${ }^{665}$ PRO-FO 371, 11077, 39, 133: Bericht »Parliamentary Question«, 16.2.1925; Britain and Abdul Krim, in: Times, 17.2.1925.

${ }^{666}$ PRO-CAB 4, 12, 554B: Committee of Imperial Defence, Bericht $» A i r$ Staff Note on the Situation in Moroccos, 30.12.1924. Vgl. PRO-CAB 4, 12, 566B: Committee of Imperial Defence, Bericht »Memorandum of the First Lord of the Admiralty «, 1.1.1925.

${ }^{667}$ PRO-FO 371, 10584, 783, 150: Bericht "Memorandum on the Effects of the Spanish Withdrawal in Morocco«, 10.12.1924.

${ }^{668}$ PRO-FO 371, 10584, 783, 180: CG Tangier an FO, 9.12.1924.

${ }^{669}$ PRO-FO 371, 10584, 783, 186: FO an CG Tangier, 23.12.1924.

${ }^{670}$ PA-AA Rom 748: Botschaft London an AA, 10.12.1924 mit dem beiliegenden Brief Robert Gordon-Canning an German Embassy of London, 1.12.1924. 
rokko. Er wollte helfen, den deutschen Einfluß in Nordafrika wieder zu erhöhen ${ }^{671}$. Zwar ist der Aktenbestand für das Marokko der 1920er Jahre recht dünn, aber nichts deutet darauf hin, daß Gordon-Cannings Angebot von der deutschen Regierung nur ansatzweise in Erwägung gezogen wurde ${ }^{672}$. Es galt der Leitsatz, größte Zurückhaltung in marokkanischen Angelegenheiten zu üben, solange Deutschen der Zutritt nach Tanger und nach Französisch-Marokko verwehrt blieb ${ }^{673}$. Der Hintergrund für Gordon-Cannings Engagement war, daß seine Germanophilie ähnlich stark ausgeprägt war wie seine Gallophobie. Diese Haltung sollte ihn später dazu bringen, der Kontaktmann der British Union of Fascists zu Hitler zu werden, und nach dem Ende des Zweiten Weltkrieges sogar so weit gehen, daß er aus den Beständen der verwaisten deutschen Botschaft Londons eine Hitlerbüste kaufte ${ }^{674}$.

Bald nach seiner Rückkehr nach London erhielt Gordon-Canning eine offizielle Stellungnahme von Si M'hammed, die dieser am 28. Januar 1925 in Chichaouen verfaßt hatte - einen Tag vor seinem Treffen mit dem amerikanischen Journalisten Vincent Sheean ${ }^{675}$. Der Bruder Abdelkrims hob hervor, daß die Rifregierung bewiesen habe, auf der Basis des Koran zur Verwaltung des Landes fähig zu sein, aber sie benötige dennoch wirtschaftliche und wissenschaftliche Hilfe aus Europa. Sie wolle mit ihren Nachbarn in Frieden leben und die Ideale des Völkerbundes vertreten, müsse aber dafür die anerkannte Entscheidungsfreiheit besitzen. Sobald der Krieg beendet sei, werde die Rifregierung mit der Entwicklung der Ressourcen des Landes - also vor allem der Bodenschätze - beginnen. Gordon-Canning ließ diese Erklärung unter anderem im "Manchester Guardian« und in der »Islamic Review» veröffentlichen $^{676}$. Er ließ sie auch dem Außenministerium zukommen und organisierte für den 2. März 1925 eine parlamentarische Anfrage hinsichtlich der Haltung der britischen Regierung. Doch Chamberlain beharrte auf der Ansicht, daß der Rifkrieg eine innere Angelegenheit Spaniens sei ${ }^{677}$.

${ }^{671}$ PA-AA R71126, K430427: Botschaft London an AA, 5.5.1924; PA-AA London 554: Botschaft London an AA, 1.5.1924; PA-AA R72043, L057670: Botschaft London an AA, 25.10.1924 mit dem beiliegenden Brief Robert Gordon-Canning an German Embassy of London, 15.10.1924.

${ }^{67}$ KUNZ, MÛ́LER, Giftgas, S. 102-104.

${ }^{673}$ PA-AA R71126, K430377: AA an Botschaften Paris, Rom, London, Madrid, 16.1.1924.

${ }^{674}$ BENEWICK, Political Violence, S. 120; GRIfFITHS, Patriotism, S. 27; SANCHEZ PEREZ, Abdelkrim, S. 153.

${ }^{675}$ Siehe S. 309.

${ }^{676}$ A Riff Manifesto. Aim an Autonomous Moslem State, in: Manchester Guardian, 12.2.1925; Spain and the Riffs, in: Islamic Review 13 (1925) S. 125-127, S. 126.

${ }^{677}$ PRO-FO 371, 11077, 39, 103: Robert Gordon-Canning an FO, 9.2.1925 mit der beigefügten Stellungnahme Si M'hammeds, 28.1.1925; PRO-FO 371, 11077, 39, 146: Bericht »Parliamentary Question«, 2.3.1925. 
In seiner Erklärung vom 28. Januar 1925 hatte Si M'hammed den Willen zu guten Beziehungen mit Frankreich und Französisch-Marokko bekundet. Robert Gordon-Canning unterstrich dies in einem Aufsatz für die Zeitschrift "Foreign Affairs«. Trotz seiner antifranzösischen Grundhaltung hatte er die Bestrebungen im Rif, gegen Französisch-Marokko militärisch vorzugehen, mit Befremden beobachtet. Gordon-Canning wollte Frankreich um jeden Preis aus dem Geschehen heraushalten. Dafür war ihm auch die Aufrechterhaltung der spanischen Einflußzone sunter der Oberhoheit des Königs von Spanien« recht, solange den Rifkabylen völlige Freiheit für politische und wirtschaftliche Regierungstätigkeiten gewährleistet würde ${ }^{678}$. Daß dies im Interesse Abdelkrims war, muß stark bezweifelt werden, was sogar die Tangerer Zeitung »Al-Moghreb al Aksa \& Tangier Gazette« konstatierte ${ }^{679}$. Gordon-Cannings Verhalten demonstriert die Abdelkrim oft unbekannten diplomatischen Alleingänge seiner europäischen Berater beispielhaft. Der Angriff der Rifkabylen auf Französisch-Marokko im April 1925 machte Gordon-Cannings /Schreibtisch-Diplomatie zunichte.

Unter den Intellektuellen Londons bestand zu dieser Zeit ein erhöhtes Interesse an internationaler Politik, um Solidarität mit unterdrückten Völkern zu demonstrieren. Zahlreiche Komitees, Vereinigungen und Gesellschaften, die zum Teil eng miteinander verwoben waren, wurden gegründet ${ }^{600}$. Seit 1924 beschäftigte sich Robert Gordon-Canning in London zusammen mit John Arnalls Freund Arthur Field, Ernest H. Griffin und Captain Lionel Henry Miles Mander intensiv mit den politischen Implikationen des Rifkrieges ${ }^{681}$. Mander hatte ein Leben als Schafshirte in Neuseeland, als Pilot und als Ballonfahrer hinter sich. Er war Mitglied der Royal Geographical Society und des Royal Colonial Institute. 1925 sollte er eine politische Analyse über Albanien (»Albania Today«) veröffentlichen. Seit 1920 widmete er sich einer Filmkarriere, die ihn in späteren Jahren bis nach Hollywood führte. Auch in einigen Hitchcockstreifen spielte er als »Miles Mander« zumeist den distinguierten ২Oxford-Briten ${ }^{682}$. Er engagierte sich ebenfalls publizistisch und forderte in der Riffrage - wie Gordon-Canning - die Zuständigkeit des Völkerbundes ein, zu dessen zentralen Aufgaben es seiner Ansicht nach gehörte, »die Rechte kleiner Nationen zu bewahren ${ }^{683}$.

${ }^{678}$ GoRdon-CANNING, The Riff, S. 210. Vgl. IORL, P\&J, 12, 226, 1625, 1924: Bericht »Indians, and Others, in England«, 13.3.1925.

${ }^{679}$ Spain and the Riffs, in: Al-Moghreb al Aksa \& Tangier Gazette, 7.3.1925.

${ }^{680}$ Charles KING, Queen of the Highlanders. Edith Durham in "The Land of the Living Past «, in: Times Literary Supplement, 4.8.2000. URL = http://members.nbci.com/_XMCM/ knigi_en/ed/e_durham.html [6.7.2001].

${ }^{681}$ PRO-FO 371, 11079, 39: New Scotland Yard an FO, 10.8.1925.

682 Who Was Who 4 (1952) S. 757f.; IORL, P\&J, 12, 230, 1671, 1924: A. Merry del Val an Lord Birkenhead, 18.3.1925.

${ }^{683}$ Lionel H. MANDER, Spain and the Rif (Leserbrief), in: Times, 24.6.1924. 
Field und Mander gehörten einer Vereinigung namens East-West Circle an, die sich als Vermittlungsinstanz für ein besseres Verständnis zwischen der westlichen Welt und dem arabisch-moslemischen Raum im Osten verstand ${ }^{684}$. Am 13. Oktober 1924 hielt der East-West Circle zusammen mit der AngloTurkish Society, deren Geschäftsführer Arthur Field war, im Londoner Hotel Anderton eine Versammlung ab. Mander hielt zum Thema "Situation in the Riff« einen Vortrag. Es wurde eine Resolution beschlossen, in der der Völkerbund aufgrund der veränderten Rahmenbedingungen seit dem Vertrag von Algeciras von 1906 und seit dem französisch-spanischen Protektoratsvertrag von 1912 aufgefordert wurde, eine Revision dieser Abmachungen herbeizuführen ${ }^{685}$.

Der East-West Circle betrachtete sich als ein überparteiliches Gesprächsforum. Ihm gehörten daher auch einige Kommunisten an. Der bekannteste von ihnen war der indische Parlamentsabgeordnete Shapurji Saklatvala. Er kannte die britischen Rifaktivisten John Arnall und Arthur Field von der Independent Labour Party, der Workers Welfare League of India und der Society for Studying Oriental Races her ${ }^{686}$. Ende 1924 wurde Saklatvala aufgrund seiner Anschauungen aus der Independent Labour Party ausgeschlossen. Dies führte dazu, daß er - obwohl gewählt - nicht als Präsident des East-West Circle agieren durfte, um potentielle Mitgliedskandidaten nicht abzuschrecken. Die Versammlungen des East-West Circle und die parlamentarische Anfrage von Saklatvala im Februar 1925, warum die britische Regierung humanitäre Hilfsmaßnahmen der British Red Crescent Society für die Rifkabylen nicht unterstützte, blieben die einzigen Aktionen britischer Kommunisten gegen den Rifkrieg $^{687}$.

Da die programmatische Ausrichtung des East-West Circle zu allgemein ausgerichtet war, kam die Idee auf, eine spezielle Vereinigung für die Unterstützung der Rifkabylen zu gründen. Ein halbes Jahr später wurde am 4. Juli 1925 auf Initiative von Arthur Field, Charles Foster Ryder, Cuthbert Dixon-Johnson und Robert Gordon-Canning das »Riff-Committee - For the

${ }^{684}$ IORL, P\&J, 12, 226, 1625, 1924: Bericht „East-West Circle: Extract from Report by New Scotland Yard $\ll, 23.2 .1927$.

${ }_{685}$ Anglo-Turkish Society and East-West Circle, in: Islamic Review 12 (1924) S. 413.

${ }^{686}$ SaKlatvalA, The Fifth Commandment, S. 44, S. 47, S. 77-80; Marc WadSWORTH, Comrade Sak. Shapurji Saklatvala MP. A Political Biography, Leeds 1998, S. 29; The RiffCommittee, in: The Patriot 10 (1926) S. 120f., S. 120.

${ }^{687}$ IORL, P\&J, 12, 226, 1625, 1924: Bericht »Extract from Report by New Scotland Yard: East-West Circle«, 11.3.1925; PRO-FO 371, 11081, 240, 6: Bericht »Parliamentary Question«, 12.2.1925; IORL, P\&J, 12, 226, 1625, 1924: Bericht »Indians, and Others, in England«, 13.3.1925; Medical Supplies for the Rifis, in: Times, 13.2.1925; Demandes d'intervention. Secours aux blessés du Riff, in: BISCR 56 (1925) S. 116; ABBASI, London Muslim League, S. 380. 
Recognition of Riff Independence« gegründet. Herbeigeführt werden sollte ein allgemeines "mitfühlendes Verständnis für den Kampf der Rifkabylen zur Aufrechterhaltung ihrer Unabhängigkeit ${ }^{688}$. Es handelte sich um eine Art ১PR-Agentur» für die politische Unterstützung der »Rif-Republik«. Die Mitglieder des Riff-Committees waren:

1. Ehrenamtlicher Geschäftsführer: Robert Gordon-Canning (1888-1960er).

2. Vorsitzender: Ernest Nathanial Bennett (1868-1947) war zunächst Biologe und Kriegsberichterstatter (Kreta 1897, Sudan 1898). 1911 bis 1912 schloß er sich der türkischen Armee an, um gegen die italienische Besetzung von Tripolis zu kämpfen. Er schrieb über seinen Einsatz das Buch »With the Turks in Tripoli« (1912). Bennett sowie Cuthbert Dixon-Johnson und Ernest H. Griffin von der British Red Crescent Society kannten sich seither. Bennett präsentierte sich dem britischen Außenministerium in der Folgezeit als fanatischer Streiter für türkische Belange ${ }^{689} .1906$ bis 1910 gehörte er als Liberaler dem britischen Unterhaus an. Seit seinem 1916 erfolgten Wechsel zur Labour Party kämpfte er vergeblich um den Wiedereinzug ins Parlament. Bennett engagierte sich in der Union of Democratic Control ${ }^{690}$. Spätestens seit 1919 hatte er Verbindungen zur Anglo-Ottoman Society und damit zu deren Geschäftsführer Arthur Field ${ }^{691}$. Bennett gehörte der Near and Middle East Association, die humanitäre Hilfslieferungen an das Rif zu organisieren versuchte, als Geschäftsführer und stellvertretender Vorsitzender $\mathrm{an}^{692}$. Im Vorfeld des Zweiten Weltkrieges sollte Bennett Mitglied des faschistischen Right Club und der Organisation Anglo-German Friendship werden ${ }^{693}$.

3. Stellvertretender Vorsitzender: Robert Bontine Cunninghame Graham, der schottische Laird of Gartmore (1852-1936), war der erste sozialistische Abgeordnete des britischen Unterhauses und wurde nach seiner politischen Karriere als Reiseschriftsteller bekannt. 1897 durchquerte er das marokkanische Atlasgebirge und verfaßte das Buch »Mogreb El-Acksa» (1898). Cunninghame Graham und der »Times«-Korrespondent von Tanger Walter Harris

${ }^{688}$ ADMAE Maroc 134, 13: Ambassade de Londres an MAE, 10.9.1925; ADMAE Maroc 135, 112: Bericht »Résumé du rapport lu par Field, membre du Comité du Rif, à la réunion de l'Hôtel Anderton«, 10.1.1926; PRO-FO 371, 11079, 39, 70: New Scotland Yard an FO, 10.8.1925; SLAVIN, Anticolonialism, S. 355; MADARIAGA, España y el Rif, S. 536; DUMAS, Abd-el-Krim, S. 51f.; ESPAÑA, La actuación, S. 295. Die bisherige Literatur erwähnt das »Riff-Committee« eher beiläufig und geht weder auf dessen Vorläufer noch auf dessen Mitglieder ein.

${ }_{689}^{6 R O-F O ~ 371, ~ 9176, ~ 10839, ~ 62: ~ M i n u t e, ~ 12.11 .1923 ; ~ P R O-F O ~ 371, ~ 10223, ~ 3484, ~ 265: ~ M i-~}$ nute, 23.4.1924.

${ }^{690}$ STENTON, LEES, Who's Who, Bd. 3, S. 28; Who Was Who 4 (1952) S. $88 \mathrm{f}$.

${ }^{691}$ PRO-FO 371, 11079, 39: New Scotland Yard an FO, 10.8.1925.

${ }^{692}$ PRO-FO 371, 6581, 13103, 8: Scotland House an FO, 26.11.1921; PRO-FO 371, 9882, 160, 229: Near and Middle East Association an FO, 4.3.1924.

${ }^{693}$ GRIFFITHS, Patriotism, S. 146-149, S. 185. 
waren enge Freunde ${ }^{694} .1906$ berichtete Cunninghame Graham für den »Glasgow Herald" von der Algeciras-Konferenz und sprach sich klar gegen eine Aufteilung Marokkos aus ${ }^{695}$. Er war neben turkophilen Briten wie Lord Lamington von der British Red Crescent Society, dem Romancier Marmaduke Pickthall, dem konservativen Parlamentsabgeordneten Aubrey Herbert oder Charles F. Ryder eines der Gründungsmitglieder der Anglo-Ottoman (AngloTurkish) Society (1913) ${ }^{696}$.

4. Stellvertretender Geschäftsführer: Arthur Field gehörte im Gründungsjahr der Independent Labour Party im Jahre 1893 deren National Administrative Council an ${ }^{697}$. Er hatte sich wie sein Freund Shapurji Saklatvala zunehmend dem Kommunismus genähert und war für sein hohes Engagement für Moslems in der antikolonialen Szene Londons bekannt ${ }^{698}$. Er war Mitglied der League of Justice for Asia and Africa und gehörte wie auch Arnold Lupton und John Arnall der Society for Studying Oriental Races an ${ }^{699}$. Seit der Gründung der Anglo-Ottoman Society im August 1913 war er ihr Generalsekretär $^{700}$. Zusammen mit John Amall, Shapurji Saklatvala und Charles F. Ryder

${ }^{644}$ STENTON, LeES, Who's Who, Bd. 2, S. 143; HoweLL, British Workers, S. 133, S. 288; VAIDON, Tangier, S. 139f.; Michael BRETT, Don Roberto and the Tourmaline Affair. British Filibusters in the Canaries and Southern Morocco 1875-1900, in: Victor MORALES LEZCANO (Hg.), Il Aula Canarias y el Noroeste de Africa, Las Palmas de Gran Canaria 1988, S. 413-421, S. 413f.; DeRS., On the Historical Links between Morocco and Europe, in: George Joffé (Hg.), Morocco and Europe, London 1989, S. 5-12, S. 11; Aimé F. TschIFFELY, Don Roberto. Being the Account of the Life and the Works of R.B. Cunninghame Graham 1852-1936, London 1937, S. 290-318; Alexander MAITLAND, Robert and Gabriela Cunninghame Graham, Edinburgh 1983, S. 129-147.

${ }^{695}$ Robert B. CUNNINGHAME GRAHAM, The Spaniards and the Riff (Leserbrief, '8.10.1925), in: Manchester Guardian, 9.10.1925.

${ }^{6 \%}$ FrEemANTLE, Loyal Enemy, S. 228; QURESHI, Khilafat Delegation, S. 15, S. 21, S. 37; Muhammad N. QURESHI, Pan-Islam in British Indian Politics. A Study of the Khilafat Movement 1918-1924, Leiden u.a. 1999 (Social, Economic, and Political Studies of the Middle East and Asia, 66), S. 116, S. 140, Anm. 307; The Anglo-Ottoman Society, in: Islamic Review 10 (1922) S. 452; CLARK, Marmaduke Pickthall, S. 27f.; Arthur FIELD, TurkoBritish Entente, in: The Asiatic Quarterly Review 2 (1913) S. 249-253.

${ }^{697}$ Erhard JÜRKE, Vision und Realpolitik. Die Britische Independent Labour Party im Lernprozess 1893-1914, Frankfurt a. M. 1988 (Moralische Ökonomie, 3), S. 531; HOWELL, British Workers, S. 296; Mike SQUIRES, Saklatvala. A Political Biography, London 1990, S. $15 f$., S. 68f., S. 159.

${ }^{698}$ FrEemANTLE, Loyal Enemy, S. 22; Our Activities, in: Islamic Review 10 (1922) S. 196f., S. 197; WAdSWORTH, Comrade Sak, S. 29, S. 105; SAKLATVALA, The Fifth Commandment, S. 44, S. 47, S. 77; PENNELL, A Country, S. 210.

${ }^{699}$ The Riff-Committee, in: The Patriot 10 (1926) S. 121.

${ }^{700}$ FreEMANTLE, Loyal Enemy, S. 228. 
gründete Field 1917 die Workers Welfare League of India (WWLI) zur Unterstützung der indischen Gewerkschaftsbewegung ${ }^{701}$. Im East-West Circle fungierte er als Geschäftsführer ${ }^{702}$.

5. Cuthbert Francis Dixon-Johnson gehörte einer Delegation der British Red Crescent Society an, die im Zuge der italienischen Besetzung von Tripolitanien (1911-1912) die türkische Armee humanitär versorgte ${ }^{703} .1914$ wurde er Direktor der East and West Association. 1916 verteilte er im Unterhaus ein 63seitiges Pamphlet, in dem das türkische Vorgehen in Armenien verteidigt und der dortige Völkermord in Abrede gestellt wurde. Nach einem kurzen Intermezzo als Straußenzüchter in Tunesien (1919) kehrte er nach London zurück. Er engagierte sich zudem in der Anglo-Turkish Society, im East-West Circle und in der Near and Middle East Association ${ }^{704}$.

6. Joseph Montague Kenworthy (1886-1953), ab 1935 Lord Strabolgi, zog nach einer Marinekarriere, die ihn bis zum stellvertretenden Stabschef in Gibraltar aufsteigen ließ, für die Liberal Party ins britische Parlament ein $(1919)^{705}$. Am 3. August 1922 ergriff er erstmals für die Rifkabylen Partei, als er während einer parlamentarischen Anfrage die Intervention des Völkerbundes anregte ${ }^{706}$. Am 1. Juli 1924 und am 19. Dezember 1924 erinnerte er an gleicher Stelle mit dem Hinweis, daß Rifkabylen während des Ersten Weltkrieges das von der Nachschubversorgung abgeschnittene Gibraltar mit Lebensmitteln versorgt hätten, an die besondere Verantwortung Großbritanniens $^{707}$.

${ }^{701}$ SaklatVala, The Fifth Commandment, S. 77, S. 79f.

${ }^{702}$ IORL, P\&J, 12, 226, 1625, 1924: Bericht »Extract from Report by New Scotland Yard: East-West Circle«, 31.12.1924.

${ }^{703}$ ABBASL, London Muslim League, S. 283f., S. 390; MUHAMMAD, Syed Ameer Ali, S. 143; Charles F. DIXON-JOHNSON, The British Red Crescent Society (Leserbrief, 20.12.1912), in: Times, 28.12.1912; ADMAE Maroc 133, 233: Consul de Glasgow an MAE, 23.2.1926.

${ }_{704}$ PRO-FO 371, 11079, 39, 70: New Scotland Yard an FO, 10.8.1925; IORL, P\&J, 12, 226, 1625, 1924: Bericht »Extract from Report by New Scotland Yard: East-West Circlek, 23.2.1927; Charles F. DxXoN-JOHNSON, The Turkish Crisis, in: Foreign Affairs 4 (19221923) S. 83.

${ }^{705}$ Who's Who 80 (1928) S. 1658; HILlS, Franco, S. 406; STENTON, LEES, Who's Who, Bd. 3, S. 195f.; Trevor WILSON, The Downfall of the Liberal Party 1914-1935, London 1968 , S. 220.

${ }^{706}$ PRO-FO 371, 8354, 4882, 120: Bericht »Parliamentary Question«, 3.8.1922; MADARIAGA, L'Espagne et le Rif, Bd. 2, S. $203 f$.

${ }^{707}$ PRO-FO 371, 10583, 783, 23: Bericht "Parliamentary Question«, 1.7.1924; Moroccan Situation. British Attitude, in: Times, 20.12.1924; PRO-FO 371, 10582, 17, 31: Bericht »Extract from the Parliamentary debates of 19th December«. Vgl. Joseph M. KENWORTHY, Moslems and the Moroccan War. France, Spain and the Riffs. Great Britain's Interest, in: The Referee, 15.5.1925. 
7. Herbert Bryan fungierte als Präsident der Sheep Workers Union ${ }^{708}$ und war der Vorgänger von John Arnall als Ortsgruppenchef der Nord-Londoner ILP. Zusammen mit Helena Swanwick befürwortete Bryan während des Ersten Weltkrieges eine enge Kooperation mit der pazifistischen Union of Democratic Control (UDC) ${ }^{709}$. Er war innerhalb der ILP ein enger Vertrauter von Arthur Field und Shapurji Saklatvala ${ }^{710}$. Über Field erhielt er Zugang zur Anglo-Turkish Society ${ }^{711}$.

8. Charles Foster Ryder aus Leeds war Mitbegründer der Anglo-Ottoman Society und der Workers Welfare League of India ${ }^{712}$. Während des Ersten Weltkrieges gab er mehrere Broschüren mit kritischen bis pazifistischen Aussagen über das Verhältnis des Christentums zum Krieg heraus ${ }^{713}$. Ryder war Mitinitiator der Gründung des Riff-Committees ${ }^{714}$.

9. Dr. Bertram William Sheldrake (1888-1947) konvertierte 1913 zum Islam und nahm den Namen Khalid an. Sheldrake war Mitbegründer der Londoner Pan-Islamic Society um Syed Ameer $\mathrm{Ali}^{715}$, Mitglied der Pariser Gruppierung Fraternité islamique ${ }^{716}$ und der British Muslim Society ${ }^{717}$ sowie ehrenamtlicher Präsident der Western Islamic Association ${ }^{718}$. Ebenso nahm er an Versammlungen des East-West Circles teil ${ }^{719}$. Sheldrake gehörte einer steigenden Anzahl britischer Moslems an - etwa 1000 im Jahre 1924 -, deren Hauptzentren Liverpool, London und Woking waren ${ }^{720}$. Sheldrake und Gordon-Canning kannten sich von der moslemischen Gemeinschaft in Woking her. In der Zeitschrift »Islamic Review« veröffentlichte Sheldrake zahlreiche Artikel, in denen er etwa die "Pflicht, den westlichen Völkern das Licht des

${ }^{708}$ ADMAE Maroc 133, 276: Bericht »Réunion du Comité du Riff du 17 février 1926 à l'Hôtel Anderton - Fleet Street«, 30.3.1926.

${ }^{709}$ SWARTZ, The Union of Democratic Control, S. 89-91, S. 99, S. 101.

${ }^{710}$ Saklatvala, The Fifth Commandment, S. 47, S. 77.

${ }^{711}$ PRO-FO 372, 2092, 1470, 143: Arthur Field an Prime Minister, 21.7.1924.

${ }^{712}$ Freemantle, Loyal Enemy, S. 228, S. 254, S. 258.

${ }^{713}$ Charles F. RYDER, The War and International Good Faith. On the Efforts Which Are Being Made for a Conference of the Neutral Powers, London 1914; DERS., The War and Christianity, Leds 1915; DERS., The Price of Victory, London 1916.

${ }^{71}$ ADMAE Maroc 135, 112: Bericht »Résumé du rapport lu par Field, membre du Comité du Riff, à la réunion de l'Hôtel Anderton«, 10.1.1926.

${ }^{715}$ Max EVEREST-PHILLIPS, The Suburban King of Tartary, in: Asian Affairs 21 (1990) S. 324-335, S. 324f.; Albert C. NIEMEuER, The Khilafat Movement in India 1919-1924, 's-Gravenhage 1972, S. 38; QURESHI, Pan-Islam, S. 50f.; DerS., Khilafat Delegation, S. $17 \mathrm{f}$.

${ }^{716}$ ADMAE Maroc 133, 276: Bericht »Réunion du Comité du Riff du 17 février 1926 a l'Hôtel Anderton - Fleet Streetu, 30.3.1926.

${ }^{717}$ The British Muslim Society, in: Islamic Review 10 (1922) S. $451 \mathrm{f}$.

${ }^{718}$ PRO-FO 371, 13871, 316, 207: Residency of Cairo an FO, 24.1.1929.

${ }^{79}$ PRO-FO 372, 2092, 1470, 143: Arthur Field an Prime Minister, 21.7.1924.

${ }^{720}$ Ali KöSE, Conversion to Islam. A Study of Native British Converts, London, New York 1996, S. 15; CLARK, Marmaduke Pickthall, S. 39, S. 41. 
Islam zu bringen ${ }^{721}$ propagierte oder die Hoffnung ausdrückte, daß der Islam eines Tages weltweit den Siegeszug halten werde ${ }^{722}$. Im August 1933 sollte er in der internationalen Presse Aufsehen erregen, als ihm eine aus Tataren bestehende Delegation mitteilte, daß er zu ihrem König gewählt worden sei. Sheldrake benannte das Land kurzerhand um und nannte sich nun "König Khalid von Islamestan«. Seine monarchistischen Träume platzten jedoch schon ein Jahr später ${ }^{723}$.

10. Prof. Henri Marcel Leon (1855-1932) konvertierte ebenso zum Islam und nannte sich seither Haroon Mustapha. Er gehörte als Vizepräsident der Anglo-Turkish Society sowie dem East-West Circle an. Er gehörte zu den führenden Vertretern der moslemischen Gemeinde von Woking ${ }^{724}$. Leon war in vielen Wissenschaften zu Hause und schrieb über die Geologie der Isle of Man, über türkische Dichter oder über Reptilien in Palästina ${ }^{725}$. Anfang 1926 gründete Leon in Schottland ein gesondertes Muslim Riff-Committee ${ }^{726}$.

11. Mary Edith Durham (1863-1944) unterbrach 1900 ihre durchaus erfolgreiche Malerinnenkarriere an der Royal Academy of Arts und unternahm als Mittel gegen ihre anhaltenden Depressionen eine Reise nach Albanien. Sie war fasziniert von Land und Leuten sowie vom albanischen Kampf um internationale Anerkennung eines eigenen Staates. Es folgten weitere Reisen ins Landesinnere, die Durham in ihrem Buch »High Albania« (1909) festhielt, das bis heute ein ethnologisches Standardwerk darstellt. In Albanien wurde sie hoch verehrt und wegen ihres Engagements für die Unabhängigkeit »Königin der Berge« genannt. Sie wurde Geschäftsführerin des Albanian Committees, des Albanian Relief Committees und der von Aubrey Herbert gegründeten Anglo-Albanian Society. 1920 wurde Albanien vom Völkerbund als Staat an-

${ }^{721}$ Khalid SHELDRAKE, Our Duty To-day, in: Islamic Review 9 (1921) S. 71-74, S. 73.

${ }^{72}$ DerS., The New Era in the West, in: Islamic Review 9 (1921) S. 322-326, S. 325. Vgl. auch Ders., The British Muslim Society. Public Meeting in the Mosque, Woking, in: Islamic Review and Muslim India 3 (1915) S. 4-7; DERS., Muhammad a True Man, in: Islamic Review 9 (1921) S. 197-200; DERS., People of the Book, in: Islamic Review 9 (1921) S. 252255; DERS., Islam and the Unity of Mankind, in: Islamic Review 9 (1921) S. 373-377; DERS., Practical Experience of Islam, in: Islamic Review 9 (1921) S. 420-423.

${ }^{723}$ EVEREST-PHILLIPS, The Suburban King, S. 325f.

${ }^{224}$ KöSE, Conversion to Islam, S. 15; CLARK, Marmaduke Pickthall, S. 40-42; IORL, P\&J, 12, 230, 1671, 1924: Bericht „Indians, and Others, in England«, 13.3.1925.

${ }_{725}$ Who's Who 78 (1926) S. 1720; Who Was Who 3 (1947) S. 802; QURESHI, Khilafat Delegation, S. 16; Henri M. LEON, The Geology of the Isle of Man, London 1915; DERS., Sheikh Haroun Abdullah, a Turkish Poet, and His Poetry, Blackburn 1916; DeRS., The Chelonia or "Shield Reptiles of Palestine«, London 1917; DERS., Influenza. Its History, Symptology and Treatment, London 1921.

${ }^{226}$ ADMAE Maroc 133, 219: Consulat de Glasgow an MAE, 18.2.1926; ADMAE Maroc 133, 192: Note, 8.2.1926. 
erkannt $^{727}$. Durham gehörte dem East-West Circle ${ }^{728}$ und der Union of Democratic Control (General Council) an. Von dort her kannte sie Ernest N. Bennett und Helena Swanwick ${ }^{729}$.

12. Helena Maria Swanwick (1864-1939) war ein führendes Mitglied der britischen Suffragettenbewegung, deren Zeitschrift »Common Cause« sie herausgab. Sie war Präsidentin der Women's International League for Peace and Freedom ${ }^{730}$. Neben ihrem Kampf für die Rechte der Frauen engagierte sich Swanwick in der Union of Democratic Control. Dort gehörte sie dem Exekutivkomitee an. Sie gab von 1924 bis 1928 die UDC-Zeitschrift »Foreign Affairs « heraus, in der von Mitgliedern des Riff-Committees Artikel veröffentlicht werden konnten. Mit der Independent Labour Party, über die sie Herbert Bryan kennenlernte, verbanden sie ihre pazifistischen und antimilitaristischen Ansichten ${ }^{731}$.

Weitere Mitglieder waren 13. S.M. Haffar aus Manchester, der auch der Near and Middle East Association angehörte ${ }^{732}$, 14. F.E. Edwards von der pazifistischen World Brotherhood Federation ${ }^{733}$, 15. F. de Vere Summers vom National Liberal Club und vom East-West Circle ${ }^{734}$, 16. G.K. Tiddemore, der ebenfalls Mitglied des East-West Circles war $^{735}$, 17. der Londoner Rechtsanwalt Ronald G. Armstrong, 18. der Maler und Geschäftspartner GordonCannings Gerald Spencer Pryse, 19. C.B. Wilson, 20. Christopher J. Searle,

${ }^{727}$ Who Was Who 4 (1952) S. 341; KNG, Queen of the Highlanders, 4.8.2000; Gary W. ShanAfelt, An English Lady in High Albania. Edith Durham and the Balkans, in: East European Quarterly 30 (1996) S. 283-300, S. 285-295; Johan HoDGSON, Edith Durham, Traveller and Publicist, in: John B. ALLCOCK, Antonia YOUNG (Hg.), Black Lambs and Grey Falcons. Women Travellers in the Balkans, Bradford 1991, S. 8-34; Margaret FITZHERBERT, The Man Who Was Greenmantle. A Biography of Aubrey Herbert, London 1983, S. 117; PRO-FO 371, 9642, 1166, 272: M. Edith Durham an FO, 6.2.1924; PRO-FO 371, 9642, 1166, 274: FO an M. Edith Durham, 12.2.1924.

${ }_{28}$ IORL, P\&J, 12, 226, 1625, 1924: Bericht "East-West Circle: Extract from Report by New Scotland Yard $\ll, 23.2 .1927$.

${ }_{729}$ Tenth Annual General Meeting of the U.D.C., in: Foreign Affairs 5 (1923-1924) S. 204.

${ }^{730}$ Beryl HASLAM, From Suffrage to Internationalism. The Political Evolution of Three British Feminists 1908-1939, New York u.a. 1999 (American University Studies, Ser. 9: History, 168), S. 3-11, S. 17-20, S. 43-46, S. 160f., S. 173; Gertrude C. BuSSEY, Margaret TMS, Women's International League for Peace and Freedom 1915-1965. A Record of Fifty Years' Work, London 1965, S. 40; Who Was Who 3 (1947) S. 1316.

${ }^{731}$ SwARTZ, The Union of Democratic Control, S. 58, S. 100f.; The Twenty-Third General Council Meeting of the U.D.C., in: Foreign Affairs 6 (1924-1925) S. 155.

${ }^{732}$ PRO-FO 371, 12302, 21, 7: Robert Gordon-Canning an Near and Middle East Association, 27.9.1926.

${ }_{733}$ PRO-FO 371, 11079, 39, 70: New Scotland Yard an FO, 10.8.1925.

${ }^{734}$ PRO-FO 372, 2092, 1470, 143: Arthur Field an Prime Minister, 21.7.1924; IORL, P\&J, 12, 230, 1671, 1924: Bericht "Indians, and Others, in England«, 13.3.1925.

${ }_{735}$ IORL, P\&J, 12, 226, 1625, 1924: Bericht »Extract from Report by New Scotland Yard: East-West Circle«, 17.12.1924. 
21. Mrs. Z. Charlton, 22. Thomas Linden, 23. Syed Haroun el Rashid Abd el Majid, 24. Lady Frederica »Freda« Pole, 25. Mrs. L. Crawfurd, 26. Captain Rudkin $^{736}$.

Die Mitgliedschaft eines weiteren Briten war ein Indiz dafür, daß auch Bergbauinteressen hinter dem Bestreben lagen, die Unabhängigkeit des Rifstaates zu erreichen, denn er hatte 1917 gemeinsam mit John Arnall eine Erkundungsmission ins Rif geplant ${ }^{737}$. 27. Bergbauingenieur Arnold Lupton (1846-1930) hatte 21 Jahre lang als Professor für Kohlebergbau am Yorkshire College der Victoria University in Leeds gelehrt. 1906 bis 1910 war er Parlamentsabgeordneter für die Liberal Party ${ }^{738}$. Wegen seines radikalen Antimilitarismus wurde er während des Ersten Weltkrieges zu sechs Monaten Haft verurteilt $^{739}$. Er war Mitglied der Society for Studying Oriental Races ${ }^{700}$.

Es handelte sich demnach um eine kleine Gruppierung von sicher 27 Personen, auch wenn Schätzungen vereinzelt die Zahl 100 erreichen $^{741}$. Der Kern des Riff-Committees war untereinander durch gemeinsame Mitgliedschaften in anderen Komitees, Zirkeln oder Parteien sehr gut bekannt. Die Gruppe bestand aus zum Teil prominenten Personen aus links-pazifistischen (v.a. Independent Labour Party, Union of Democratic Control) und pro-moslemischen Kreisen (v.a. Near and Middle East Association, Anglo-Turkish Society, EastWest Circle), denen in der Regel aus durchaus hehren und philanthropischen Motiven die Unabhängigkeit der »Rif-Republik« und das Selbstbestimmungsrecht der Rifkabylen am Herzen lag. Im Außenministerium machte sich Gerald Villiers über das Riff-Committee als »ein vortreffliches Beispiel für die angeborene Liebe einiger Engländer, sich in die Angelegenheiten anderer Leute einzumischen , lustig $^{742}$.

Am 30. Oktober 1925 wurde die erste öffentliche Versammlung des RiffCommittees in der Londoner Essex Hall abgehalten. Resolutionen über die Forderungen nach der Unabhängigkeit des Rifs, einem sofortigen Waffen-

${ }^{736}$ ADMAE Maroc 133, 276: Bericht wReunion du Comité du Riff du 17 février 1926 à l'Hótel Anderton - Fleet Street«, 30.3.1926; ADMAE Maroc 133, 253: Bericht »Déclarations du Capitaine Gordon-Canning au cours d'un déjeuner qui lui a été offert par le RiffCommittee le 20 février 1926«, 23.2.1926; ADMAE Maroc 133, 245: Bericht "Reunion tenue par le Riff-Committee le $1^{\text {er }}$ mars 1926«, 3.3.1926; The Riff-Committee and Captain Gordon-Canning, in: Foreign Affairs 7 (1925-1926) S. 305; ADMAE Maroc 133, 192: Note, 8.2.1926; TERRIER, Les »Frères de la côte« 1926, S. 39.

${ }^{737}$ Siehe S. 268f.

738 STENTON, LEES, Who's Who, Bd. 2, S. 225; WILSON, The Downfall, S. 32 u. S. 32 , Anm. 16; Who's Who 78 (1926) S. 1793; Who Was Who 3 (1947) S. 835.

${ }^{739}$ Andrew J. A. MORRIS, Radicalism against War 1906-1914. The Advocacy of Peace and Retrenchment, London 1972, S. 93.

${ }^{740}$ The Riff-Committee, in: The Patriot 10 (1926) S. 121.

${ }^{741}$ TERRIER, Les »Frères de la côte« 1926, S. 39; Abd-el-Krim Asks Status of Canada, in: New York Times, 23.12.1925.

${ }^{742}$ PRO-FO 371, 11907, 5, 109: Minute, 9.2.1926. 
stillstand, einem internationalen Schiedsspruch und der Entsendung von medizinischen Hilfsgütern wurden verabschiedet und von Arthur Field an die Kriegsparteien weitergegeben ${ }^{743}$. Das Abhalten von Versammlungen und die Verabschiedung von Resolutionen waren die Hauptaktivitäten des RiffCommittees ${ }^{744}$. Die Mitglieder suchten internationale Kontakte zu den amerikanischen Friends of the Riff oder zu Organisationen wie der Ligue internationale de la paix universelle, der Association de compréhension internationale oder der Union mondiale pour l'égalité des races ${ }^{75}$.

Ein Faltblatt mit dem Titel "The Proof of Riff Belligerency«, das mit Hilfe von Rechtsbeispielen nachweisen sollte, daß der Rifstaat eine kriegfuihrende Nation sei $^{\mathbf{7 4 6}}$, brachte die Diplomaten des britischen Außenministeriums ins Schwitzen. In einer Notiz hieß es: »Man muB in dieser Angelegenheit sehr vorsichtig sein, denn offensichtlich erfüllen die Rifkabylen die meisten Anforderungen für eine kriegführende Gemeinschaft ${ }^{747}$. Insgesamt gesehen war das Riff-Committee aber nicht viel mehr als ein Debattierklub von wohlwollenden Freizeitaktivisten, ohne dabei zu vergessen, daß seine Mitglieder zu den wenigen Europäern gehörten, die überhaupt den Rifkabylen helfen wollten. Allerdings standen hinter dem äußeren Schein der Humanität Gordon-Cannings und Arnold Luptons Wirtschaftsinteressen ${ }^{748}$.

Zwischen John Arnall und dem Riff-Committee besteht nicht nur durch seine Beziehung zu einigen Mitgliedern eine direkte Verbindungslinie, sondern auch aufgrund der von seinen Nachfolgern benutzten Schlagworte. Daß der Völkerbund die Riffrage entscheiden oder daß die Rifkabylen als Kriegführende anerkannt werden sollten, hatte Arnall schon 1921 und 1922 gefordert.

${ }^{743}$ SHAT 3H102: Ambassade de Londres an MG, EMA, 2 bureau, 31.10.1925; CADN Londres C258: The Riff Committee an French Embassy of London, 18.11.1925; Fair Play for the Riffi, in: Manchester Guardian, 23.10.1925 (Ankündigung der Versammlung des »RiffCommittees 1 ).

${ }^{74}$ ADMAE Maroc 133, 140: Bericht œComité du Riff«, 30.12.1925; PRO-FO 371, 12687, 11, 190: Ambassade de Londres an FO, 25.2.1927; ADMAE Maroc 135, 112: Bericht »R6sumé du rapport lu par Field, membre du Comité du Rif, à la réunion de l'Hôtel Anderton«, 10.1.1926; SHAT 3H102: EMA, $2^{c}$ bureau, Bericht "Renseignements sur le Riff Committee de Londres«, 10.2.1926; ADMAE Maroc 133, 253: Bericht "Déclarations du Capitaine Gordon-Canning au cours d'un dejeuner qui lui a été offert par le Riff-Committee le 20 février 1926«, 23.2.1926; ADMAE Maroc 133, 245: Bericht »Réunion tenue par le RiffCommittee le 1" mars 1926«, 3.3.1926; ADMAE Maroc 133, 276: Bericht »Reunion du Comité du Riff du 17 février 1926 à l'Hôtel Anderton - Fleet Street«, 30.3.1926.

${ }_{745}$ ADMAE Maroc 133, 212: Bericht »Comité du Riffu, 17.2.1926.

${ }^{746}$ PRO-FO 371, 11081, 240, 25: Robert Gordon-Canning an FO, 26.8.1925; PRO-FO 371, 11081, 240, 24: Minute, 31.8.1925; PRO-FO 371, 11081, 240, 33: Robert Gordon-Canning an FO, 7.9.1925; Arthur FIELD, Neutrality in Tangier, in: Foreign Affairs 7 (1925-1926) S. 84.

${ }^{747}$ PRO-FO 371, 11081, 240, 32: Minute, 10.9.1925.

${ }^{748}$ PRO-FO 371, 11917, 469, 6: Consul General of Rabat an FO, 13.1.1926. 
Er war also eine Art geistiger Vater des Riff-Committees. Wie Gordon-Canning hatte auch Arnall das Interesse an den Rif-Bodenschätzen zu seinem Engagement angetrieben.

Sowohl Frankreich - über die Vermittlung von »Times«-Korrespondent Walter Harris - als auch Spanien führten im Sommer 1925 gesonderte und fruchtlose Friedensverhandlungen mit Abdelkrim. Am 11. Juli 1925 vereinbarten französische und spanische Unterhändler dann eine gemeinsame Vorgehensweise. Der Bevölkerung des Rifs wurde in vagen Ausdrücken ein hohes $\mathrm{MaB}$ an administrativer, politischer und wirtschaftlicher Autonomie unter der Herrschaft des marokkanischen Sultans in Aussicht gestellt ${ }^{749}$. Allerdings wollten weder die Alliierten ihre Vorschläge Abdelkrim offiziell zukommen lassen, noch wollte dieser sie anfordern, obwohl er von ihnen Kenntnis hatte. Niemand wollte sein Gesicht verlieren ${ }^{750}$. Abdelkrim bestritt, jemals die JuliBedingungen erhalten zu haben ${ }^{751}$.

Robert Gordon-Canning, der über Gertrude Arnall ständig brieflich mit Abdelkrim in Kontakt stand, hatte längst eigene Friedensvorschläge ausgearbeitet. Als sie am 23. Juli 1925 im Pariser "Quotidien« veröffentlicht wurden, erregten sie großes Aufsehen, da die Zeitung als regierungsnah galt ${ }^{752}$. Zwei Faktoren blieben für Gordon-Canning und seine Bergbauinteressenten im Hintergrund von besonderer Bedeutung - die Anerkennung des Rifstaates durch den Völkerbund und insbesondere die wirtschaftliche Gestaltungsfreiheit Abdelkrims. Es sei, so Gordon-Canning, das Recht der Rifbevölkerung und ihres Anführers, frei über ihre wirtschaftliche Entwicklung zu bestimmen ${ }^{753}$.

Als Frankreichs Ministerpräsident Painlevé die französisch-spanischen Friedensbedingungen am 14. August 1925 veröffentlichen ließ, wies Gordon-Canning auf ihren dehnbaren Charakter hin, wobei er besonderen Wert auf die Frage legte, ob die marokkanischen Bergbaugesetze auch für das Rifgebiet Gültigkeit besitzen würden ${ }^{754}$. Frankreichs Angebot von wirtschaftlichen Freiheiten für das Rif innerhalb bestehender internationaler Verträge war für ihn nichts anderes als eine Fallgrube, denn so hätte der Sultan von Marokko die Verfügungsgewalt über die Erzreichtümer behalten. Gordon-Canning hielt je-

${ }^{749}$ PRO-FO 371, 11079, 39, 68: Embassy of Paris an FO, 10.8.1925.

${ }^{750}$ WOOLMAN, Rebels in the Rif, S. $180 \mathrm{f}$.

751 TNLA, Harris, BNS, 2: Abdelkrim an Walter Harris, 29.8.1925; Walter B. HARRIS, Spanish Landing Alhucemas, in: Times, 8.9.1925; DERS., Rifi Reports. Fighting Near Tetuan, in: Times, 9.9.1925.

752 Abd-el-Krim et la paix, in: Quotidien, 23.7.1925; Die Lage in Marokko, in: Zürcher Zeitung, 24.7.1925; AGERON, La presse parisienne, S. 16; OVED, La gauche française, Bd. 1, S. 218.

${ }^{753}$ Robert GORDON-CANNING, Riff Independence (Leserbrief, 26.7.1925), in: Manchester Guardian, 29.7.1925.

${ }^{754}$ DERS., The French Peace Terms to the Riff (Abdruck eines Leserbriefes aus der $»$ Westminster Gazette«, 18.8.1925), in: Al-Moghreb al Aksa \& Tangier Gazette, 5.9.1925. 
doch das Argument entgegen, daß der Sultan das Rif niemals erobert habe und dort nur als religiöses Oberhaupt anerkannt sei ${ }^{755}$. Von daher, so der Brite, seien die von Europäern oder die unter ihrer Anleitung gefertigten marokkanischen Bergbaugesetze auf das Rif nicht anwendbar ${ }^{756}$. Cuthbert Dixon-Johnson vom Riff-Committee pflichtete ihm in einem Leserbrief an den "Manchester Guardian« bei, daß die Rifkabylen - sund nicht der Sultan oder seine französischen und spanischen Herren« - von den Erlösen des Bergbaus profitieren sollten ${ }^{757}$.

Im Sommer 1925 erhielt Robert Gordon-Canning einen neuen Weggefährten, denn der Deutsche Karl Hermann Hackländer erschien wieder auf der Bildfläche. In einem Brief vom 7. April 1925 hatte Abdelkrim den Deutschen eingeladen, persönlich im Rif zu erscheinen, um eine leidige Angelegenheit zu bereinigen ${ }^{758}$. Seit über einem Jahr hatte Hackländer erhebliche Probleme mit der Deutschen Bank in Köln. Eine dort von ihm hinterlegte Kaution für den Gardiner-Vertrag vom 30. April 1923 in Höhe von 250000 Francs wurde gesperrt $^{759}$. Hackländer, der sich selbst in seinen Briefen ins Rif nur in aller Bescheidenheit »El Necesario« (der Notwendige) nannte, hatte sich daraufhin bei Abdelkrim beschwert und die Zusendung der originalen Garantieerklärungen von 1923 erbeten, um die Blockade seiner Guthaben aufzuheben ${ }^{760}$. Durch Abdelkrims Einladung faßte er neuen Mut. Im Juni 1925 knüpfte er Kontakt zu Robert Gordon-Canning ${ }^{761}$.

Seine Partnerschaft mit Charles Gardiner hatte Hackländer im Jahr zuvor beendet ${ }^{762}$. Verschiedentlich wurde auch Gordon-Canning direkt mit den Geschäften von Charles Gardiner in Verbindung gebracht ${ }^{763}$. Es gab aber wohl

${ }^{755}$ DERS., The Peace Terms Offered to the Riffs (Leserbrief, 6.10.1925), in: Manchester Guardian, 7.10.1925.

${ }^{756}$ DERS., Peace Terms for the Riff, in: Foreign Affairs 7 (1925-1926) S. $67 f$., S. 67.

${ }^{757}$ Charles F. DIXON-JOHNSON, Riff Independence (Leserbrief, 30.7.1925), in: Manchester Guardian, 1.8.1925.

${ }_{758}$ ADMAE Maroc 112, 275: Abdelkrim an Karl Hackländer, 7.4.1925. In der französischen Ausgabe der Erinnerungen Abdelkrims teilte dieser dem überraschten Journalisten RogerMathieu mit, Hackländer nicht zu kennen [ROGER-MATHIEU, Mémoires, S. 170f.]. In der deutschen Ausgabe findet man Hackländers Namen nur im Anhang [ABDELKRIM, Memoiren, S. 127-129].

${ }^{759}$ ADMAE Maroc 112, 279: Deutsche Bank Köln an Fa. Hackländer \& Co., 12.1.1924.

${ }^{760}$ ADMAE Maroc 112, 272: Karl Hackländer an Abdelkrim, 7.11.1924.

${ }^{761}$ PRO-FO 174, 305, 88: Bericht $»$ Reference Hacklander and Gordon-Canning« o.D. [Anfang 1926]; PRO-FO 371, 11907, 5, 113: Robert Gordon-Canning an FO, 2.2.1926; WOLF, Les secrets, S. 123; FONTAINE, L'étrange aventure, S. 86; GIORGI-MiGNOT, Les milieux, S. 84.

${ }^{762}$ HARRIS, Captain Canning and Abd-el-Krim, 30.1.1926.

${ }^{763}$ TERRIER, Les »Frères de la côte« 1925, S. 655; DERS., Les »Frères de la côte« 1926, S. 178; FONTAINE, L'étrange aventure, S. 85f.; CADN Tanger C37: Bericht »Note au sujet du Capitaine anglais Gordon-Canning et sur la mission qui lui est confiée par Abdelkrim«, 19.12.1925. 
eher ein Konkurrenzverhältnis. In Pressekonferenzen betonte Gordon-Canning, in keiner Beziehung zu Gardiners Geschäften gestanden zu haben ${ }^{764}$. Einige von Gardiners früheren Geschäftspartnern wie Thomas Perrott oder nun auch Karl Hermann Hackländer arbeiteten allerdings aus wirtschaftlichen Interessen mit Gordon-Canning zusammen. Die deutsche Botschaft in Paris berichtete, Hackländer gehöre wzu jener internationalen Bande, die die Rifleute beschützen, um das Rifgebiet auszubeuten ${ }^{765}$.

Der Deutsche entwickelte den nicht gerade neuen Plan, daß der Genfer Völkerbund die Schlüsselrolle für die Anerkennung der »Rif-Republik« - die Voraussetzung für die wirtschaftliche Selbstbestimmung der Rifkabylen - übernehmen sollte. Im Juli 1925 teilte er seinem britischen Partner Arthur John Barry das Grundkonzept mit. Über die French Iron Ore Company hatte Barry seit 1919 Interesse an bergbaulichen Aktivitäten in Spanisch-Marokko ${ }^{766}$. Er war Ingenieur und leitete die auf den Bau von Eisenbahnen spezialisierte Firma A.J. Barry \& Partners. Er hatte zahlreiche Brücken, Eisenbahnstrecken und Häfen in Großbritannien, Indien oder China konstruiert ${ }^{767}$.

Dieses Spezialwissen wollte Hackländer für seine Idee ausnutzen. Seiner Ansicht nach fehlte es in Nordafrika an Eisenbahnverbindungen. Der Plan sah vor, daß ein spanisch-französisches Konsortium eine Eisenbahnstrecke zwischen Tanger und Fes sowie von Melilla über Kiffane nach Taza bauen sollte, während der Bau der Linie Ceuta-Tetuan-Chichaouen-Fes einem spanischenglischen Konsortium zufallen sollte. Eine internationale Gesellschaft war, so der Plan, für die Errichtung der Linien Alhucemas-Ouergha-Fes und Ouergha-Ouezzane-Larache zuständig. Hackländer schlug weiter vor, daß Abdelkrim das für Frankreich wichtigere Moulouya-Tal gegen das Ouergha-Ouezzane-Tal eintauschen sollte. Spanien sollte Melilla und Ceuta behalten, die Festung in der Bucht von Alhucemas aber aufgeben sowie für den Handel mit den ebenfalls abzutretenden Städten Arzila, Larache und Tetuan Zugeständnisse erhalten. Die wirtschaftlichen Vorteile für alle beteiligten Seiten durch diese Verkehrserschließung eines unabhängigen Rifs lagen für Hackländer auf

764 Jacques LADREIT DE LACHARRIERE, Les amis d'Abd el Krim, in: Le Temps, 31.12.1925; GORDON-CANNING, The Riff, S. 209; ROGER-MATHIEU, Le capitaine Gordon-Canning, 22.12.1925; SHAT 3H102: EMA, $2^{e}$ bureau, Note, 11.1.1926.

${ }^{765}$ PA-AA R1 18401: Botschaft Paris an AA, 27.12.1925.

${ }^{766}$ PRO-FO 371, 3842, 20176: Embassy of Madrid an FO, 30.12.1919; ADMAE Maroc 133, 91: Sous-Direction d'Afrique, Note, 17.12.1925.

${ }_{767}$ Who Was Who 4 (1952) S. 66; Who's Who 80 (1928) S. 165; APP BA 1678: ML, Sareté générale, Bericht "Circulaire $N^{\circ} 226 \ll, 26.9 .1925$; Arthur J. BARRY, Railway Expansion in China and the Influence of Foreign Powers on its Development, London 1910. 
der Hand ${ }^{768}$. Das Ziel war, durch die wirtschaftliche Entwicklung des Landes die gesamte Region zu befrieden ${ }^{769}$. Hackländer wurde daraufhin von Abdelkrim zu seinem Wirtschaftsberater ernannt ${ }^{770}$.

Die Vision einer wafrikanischen Schweiz» wies eine deutliche Ähnlichkeit mit dem Mannesmann-Projekt von 1913, dem Echevarrieta-Plan von 1923 und dem Gardiner-Vertrag von 1923 auf. Die Friedensbedingungen Abdelkrims, die Gordon-Canning am 23. Juli 1925 im Pariser "Quotidien« und dann in der europäischen Presse veröffentlichen ließ, beruhten auf Hackländers Projektvorschlag ${ }^{71}$. Auch dieser Plan wurde nie verwirklicht. Eine von Hackländer und Arthur J. Barry vorgesehene Konferenz mit Vertretern Frankreichs, Großbritanniens und Spaniens kam nie zustande, da die Regierungen keinerlei Interesse zeigten ${ }^{772}$. Der Versuch des Deutschen, Gordon-Canning für dessen geplante nächste Rifreise einen Journalisten der »Kölner Zeitung« an die Seite zu geben, mißlang ebenso, da das Auswärtige Amt dringend davon abriet. Die deutsche Regierung wollte keinerlei Spannungen mit Frankreich riskieren ${ }^{773}$. Ein Fokker-Flugzeug sollte die Expedition ins Rif fliegen ${ }^{774}$.

Trotz der Mahnungen aus Berlin machten sich andere deutsche Korrespondenten auf den Weg nach Marokko, wie etwa Hans Theodor Joël (»Neue Zürcher Zeitung«, »Deutsche Allgemeine Zeitung", "Düsseldorfer Nachrichten«), Hellmuth Goldström (»Berliner Tageblatt «) ${ }^{775}$, Hans Felix Wolff (»Illustrirte Zeitung«, Weber-Verlag Leipzig) ${ }^{776}$ oder Bernd Terhorst (»Die Woche«) ${ }^{777}$.

${ }^{768}$ ADMAE Maroc 133, 24: Karl Hackländer an Arthur J. Barry, 11.7.1925. Vgl. Ein Geheimdokument über Marokko, in: Weser-Zeitung, 11.12.1925.

${ }^{769}$ Robert GORDON-CANNING, The Future of the Riff (Leserbrief, 31.8.1925), in: Manchester Guardian, 1.9.1925.

${ }^{770}$ ADMAE Maroc 133, 18: Karl Hackländer an Aimé Berthod, 17.10.1925.

${ }^{771}$ GORDON-CANNING, The Riff, 27.7.1925; Abd-el-Krim et la paix, in: Quotidien, 23.7.1925; Die Lage in Marokko, in: Neue Zürcher Zeitung, 24.7.1925; Abd el Krims Friedensbedingungen, in: Vossische Zeitung, 24.7.1925.

77 ADMAE Maroc 133, 14: Arthur J. Barry an Karl Hackländer, 11.8.1925; ADMAE Maroc 133, 150: Ambassade de Madrid an MAE, 30.12.1925; FonTAINE, Abd el-Krim, S. 84f.; DERS., L'étrange aventure, S. 96f.

${ }^{73}$ ADMAE Maroc 133, 10: Karl Hackländer an Robert Gordon-Canning, 13.8.1925; PA-AA R30190k: Vermerk, 15.7.1925.

${ }^{74}$ Siehe hierzu Kapitel 5, S. $201 \mathrm{f}$.

775 PA-AA R30190k: Generalkonsulat Neapel an AA, 13.8.1925 und 19.10.1925; PA-AA Madrid 136: Konsulat Tetuan an Botschaft Madrid, 21.9.1925.

${ }^{76}$ Hans F. WolfF, Mit der spanischen Flotte vor Kap Morro (In der Bucht von Alhucemas), in: Illustrirte Zeitung 165 (1925) S. 508-512; DERS., Bei den Spaniern in Marokko. Der Vorstoß zum Djebel Malmusi, in: Illustrirte Zeitung 165 (1925) S. 584f.; DERS., Bei den Spaniern in Marokko. Der Sektor von Ajdir, in: Illustrirte Zeitung 165 (1925) S. 694; DERS., Die Lage im Innern des Rifgebiets, in: Illustrirte Zeitung 165 (1925) S. 774-778; DERS., Das Gesicht des Rif, Berlin 1927, S. 10f., S. 98-110 (Augenzeugenberichte von der spanischen Landung in der Bucht von Alhucemas).

${ }^{m}$ Bernd TERHORST, Spaniens Kampf um Marokko, in: Die Woche 26 (1924) S. 10021006; DERS., Bei den Rifkabylen. Vom Schauplatz der Kämpfe in Spanisch-Marokko, in: 
Sie schlossen sich allesamt der spanischen Armee an und kamen mit den Rifkabylen nicht direkt in Berührung. Der in Deutschland geborene Lette Otto Zeltin, der 1924 mit einer Sahara-Durchquerung von Touggourt nach Timbuktu von sich reden gemacht hatte, wurde am 16. November 1925 von spanischen Soldaten angeschossen, als er von Tanger aus ins Rif eingeschleust werden sollte. Er hatte für den »Deutschen Pressekurier« ein Interview mit Abdelkrim führen wollen ${ }^{778}$. Erst nach mehrmonatiger Gefangenschaft wurde das Verfahren wegen Spionage gegen Zeltin eingestellt ${ }^{779}$. Die deutsche Presse bediente sich in der Regel der Meldungen internationaler Presseagenturen oder engagierte Marokkoexperten wie etwa den Nationalökonomen Paul Mohr (Gründer der Marokkanischen Gesellschaft 1902) oder den Orientalisten der Universität Leipzig Edgar Pröbster, die in Zeitschriftenartikeln ihrer Agitation gegen Frankreich freien Lauf ließen ${ }^{780}$.

Hackländers Reisepläne ins Rif lagen zunächst auf Eis, da er als einer der deutschen Delegierten vom 1. bis 7. September 1925 am 24. Weltfriedenskongreß in Paris teilnahm ${ }^{781}$. Der Rifkrieg, so berichtete ein Beobachter, »lag lähmend auf der Stimmung der Mehrzahl der französischen Delegierten und bewog viele Mitglieder deutscher Verbände zu taktvoller Zurückhaltung « ${ }^{782}$.

Die Woche 26 (1924) S. 1060-1062; DERS., Feuer am Rif. Zwei Jahre unter Rifkabylen, Berlin 1925. Terhorsts Titel sind zum Teil irreleitend, denn er gelangte nur bis an die Randgebiete des Rifs.

778 TERRIER, Les »Frères de la côte« 1925, S. 654; SHEEAN, Personal History, S. 136, S. 170; Otto ZELTIN, Der Tausend-Meilen-Ritt durch die Sahara. Auf nie betretenen Pfaden, Dresden 1927; PA-AA R72045, L058113: Dr. Julius Goldfeld an Hamburger Senatskommission für die Reichs- und Auswärtigen Angelegenheiten, 25.11.1925; PA-AA R72045, L058128: Otto Zeltin an Konsulat Tetuan, 21.11.1925; PA-AA R30190k: Botschaft Madrid an AA, 30.11.1925; PA-AA R72045, L058133: Deutscher Pressekurier an AA, 5.12.1925; CADN Tanger C39: Tabor de police $\mathrm{N}^{\circ}$ 1, Bulletin de renseignements, 23.11.1925.

${ }^{779}$ Spanish Keep Latvian in Jail without Trial, in: New York Times, 31.3.1926; PA-AA R72046, L058233: Gesandtschaft Riga an AA, 21.6.1926.

${ }^{780}$ Paul MOHR, Tragödie, 8.9.1925; DERS., Frankreichs wahre Marokkoziele, in: Tägliche Rundschau, 3.10.1925; DERS., Abd el-Krim und der Marokkofriede, in: Tägliche Rundschau, 15.4.1926; DERS., Frankreich und Marokko, Berlin 1926; Edgar PRÖBSTER, Vom marokkanischen Kriegsschauplatz, in: Deutsche Allgemeine Zeitung, 24.5.1925; DERS., Der Krieg im Rif, in: Deutsche Allgemeine Zeitung, 3.10.1925; DERS., Die Rifrepublik, in: Deutsche Allgemeine Zeitung, 22.10.1925; DERS., Spanische Marokkozone und die Politik der Westmächte, in: Der Deutsche Gedanke 2 (1925) S. 360-366; DERS., Das Rifproblem, in: Die Deutsche Nation 7 (1925) S. 401-406; DERS., Liquidation der Rifrepublik, in: Der Deutsche Gedanke 3 (1926) S. 922-929; DERS., Der Kampf um Marokko, in: Deutschlands Erneuerung 10 (1926) S. 170-178. Vgl. LANG, Die Darstellung Abd el-Krims, S. 66f.

${ }^{781}$ ADMAE Maroc 133, 156: Bericht »Reference Hacklaender and Gordon-Canning« o.D. [1926].

${ }_{782}$ Franz C. ENDRES, Die Pazifisten, in: Das Tagebuch 6 (1925) S. 1401-1403, S. 1401. 
In einer Resolution wurde lediglich beschlossen, eine Kommission beim internationalen Friedensbüro einzurichten, um »die Kolonialprobleme genau ins Auge zu fassen ${ }^{783}$.

Während der Konferenz kam es zum ersten persönlichen Treffen zwischen Hackländer und Gordon-Canning. Der Brite organisierte ein Gespräch mit dem französischen Delegierten der radikalen Partei, Aimé Berthod, einem Parteigenossen des Ministerpräsidenten Painlevé. Hackländer diskutierte mit ihm zwei Stunden über die Möglichkeiten eines Friedensschlusses mit Abdelkrim $^{784}$. Wenig später sandte er Berthod einen Brief, in dem er ausführte, daß die Zeit für eine »Entente« des Rifs mit Frankreich gekommen sei und daß der Völkerbund nun seine Theorien im Rif in die Praxis umsetzen könne. Hackländer führte aus, daß Abdelkrim und sein Bruder Si M'hammed, mit dem er 1923 ein ausgiebiges Gespräch über die Lage im Rif geführt habe, dazu bereit seien, denn: »Ihr Vater war Afrikaner, die Söhne aber sind Europäer « ${ }^{785}$.

Im November 1925 regte Hackländer in einem weiteren Brief an den zum stellvertretenden Staatssekretär beförderten Berthod an, den Geist von Locarno auf das Rif zu übertragen und eine Konferenz in Tanger einzuberufen. Hackländer bat Berthod auch darum, für ihn beim marokkanischen Sultan eine Spezialerlaubnis für den Aufenthalt in der internationalen Zone zu erwirken, damit er an Verhandlungen teilnehmen könne ${ }^{786}$. Der Hintergrund hierfür war, daß Abdelkrim Hackländer in einem Brief vom 15. Oktober 1925 gebeten hatte, nach Tanger zu kommen, um die Kommunikationswege zu verkürzen ${ }^{787}$. Gordon-Canning machte dem Deutschen jedoch klar, daß er wegen seiner Nationalität nicht nach Marokko fahren sollte ${ }^{788}$. Auch Hackländers Briefe an Aimé Berthod bewirkten für Abdelkrim nichts. Der Franzose trat zwar für eine Beendigung der Kämpfe in Marokko ein, aber selbst die Anerkennung einer Autonomie für das Rifgebiet betrachtete er als realitätsfern ${ }^{789}$.

${ }^{783}$ Dokumente der Friedensbewegung. Beschlüsse des 24. Weltfriedenskongresses, in: Die Friedenswarte 25 (1925) S. 316-319, S. 318. Vgl. Hans WeHBERG, Der XXIV. Weltfriedenskongreß zu Paris (1. bis 7. September 1925), in: Die Friedenswarte 25 (1925) S. 289-299, S. 297f.

${ }_{784}$ ADMAE Maroc 133, 156: Bericht »Reference Hacklaender and Gordon-Canning« o.D. [1926].

${ }^{785}$ Alle Zitate aus ADMAE Maroc 133, 18. Karl Hackländer an Aimé Berthod, 17.10.1925.

${ }^{786}$ ADMAE Maroc 133, 37: Karl Hackländer an Aimé Berthod, 2.11.1925.

${ }^{787}$ ADMAE Maroc 133, 40: Abdelkrim an Karl Hackländer, 15.10.1925; KHARCHICH, La France, S. 163.

${ }^{788}$ ADMAE Maroc 133, 156: Bericht »Reference Hacklaender and Gordon-Canning« o.D. [1926].

${ }^{789}$ A. BERTHOD, Vers la paix au Maroc, in: Petit Journal, 19.4.1926; ADMAE Maroc 135, 20: Bericht „Entretien avec M. Berthod, député du Jura, au sujet de la paix dans le Riff et de la formule d'autonomie envisagée en faveur des tribus Djebala et Riffaines«, 24.12.1925. 
Kurz darauf schaffte es Robert Gordon-Canning Ende Oktober 1925, über die Vermittlung des französischen Diplomaten Louis Malvy zu Ministerpräsident Paul Painlevé vorgelassen zu werden ${ }^{790}$. Es gibt unterschiedliche Versionen über das Ergebnis der Gespräche. Während Gordon-Canning beteuerte, von der französischen Regierung autorisiert worden zu sein, Abdelkrim die Friedensvorschläge vom Juli zur Kenntnis zu bringen ${ }^{791}$, behauptete Painlevé im nachhinein, jeden offiziellen Charakter einer Mission abgelehnt zu haben $^{792}$. Gordon-Canning erhielt auf jeden Fall einen Passierschein, um die französische Zone Marokkos in Richtung Rif durchqueren zu dürfen. Während er sich auf den Weg nach Marokko machte, befand sich der amerikanische Journalist Vincent Sheean mit Friedensvorschlägen Abdelkrims auf dem Weg nach Paris ${ }^{793}$. Gordon-Canning und seine Mitstreiter vom Riff-Committee wachten eifersüchtig auf ihr angebliches Monopol für Verhandlungen im Namen Abdelkrims und stritten Sheean jegliche Zuständigkeit $\mathrm{ab}^{794}$.

Sheean seinerseits hielt sich für den einzig wahren Rifrepräsentanten und spottete, daß man am Strand von Tanger nicht spazierengehen könne, ohne über freiwillige Botschafter Abdelkrims zu stolpern ${ }^{795}$. Sogar Charles Gardiner tauchte wieder in Tanger auf und bot Abdelkrim an, gegen die Zahlung von einer Million Peseten für Friedensverhandlungen zwischen Spanien und dem Rif zur Verfügung zu stehen ${ }^{796}$. Die »Tangier Gazette« wunderte sich über diesen Wettbewerb selbstsüchtiger Amateurdiplomaten, da niemand die Bereitschaft zeigte, einem anderen für das Erreichen des Ziels Frieden den Vortritt zu lassen ${ }^{797}$.

790 SUEIRO SEOANE, España, S. 303; Arthur FIELD, France and the Riff. Captain GordonCanning's Mission, in: Foreign Affairs 7 (1925-1926) S. 234f., S. 234; PRO-FO 371, 11917 , 469, 6: Consul General of Rabat an FO, 13.1.1926.

791 ADMAE Maroc 135, 35: Robert Gordon-Canning an Aristide Briand, 27.12.1925; CADN Tanger C40: Bericht »Renseignements donnés par Abdelkrim el Hadj Ali el Bokkoyi«, 5.3.1926; ADMAE Maroc 111, 1: Bericht »Renseignements donnés par El Hadj Hitmi«, 22.6.1926; CADN Madrid C263: Abdelkrim an Walter Harris, 27.1.1926; MELLOR, Morocco, S. 85 f.

72 AN 313 AP 223: Bericht „Comité central de la Ligue française pour la défense des droits de l'homme et du citoyen«, 3.5.1926.

${ }_{293}$ Siehe S. 314.

${ }^{794}$ Robert GORDON-CANNING, Correspondence (Leserbrief), in: Al-Moghreb al Aksa \& Tangier Gazette, 19.12.1925; Arthur FIELD, Terms from Abdel Krim (Abdruck eines Leserbriefes aus dem »Daily Express «, 25.11.1925), in: Al-Moghreb al Aksa \& Tangier Gazette, 12.12.1925.

795 SHEEAN, Condition for an Armistice, 5.12.1925.

${ }^{796}$ Le capitaine Gardiner qu'on l'appelait à Londres ll'ambassadeur du Riff, est signalé à Tanger, in: Journal, 9.11.1925; CADN Tanger C37: Bericht »Note au sujet du Capitaine anglais Gordon-Canning et sur la mission qui lui est confiée par Abdelkrim«, 19.12.1925; CADN Madrid C263: MAE an Ambassade de Madrid, 20.11.1925; PRO-FO 371, 11908, 5, 273: CG Tangier an FO, 25.3.1926.

${ }_{797}$ The Riff Question, in: Al-Moghreb al Aksa \& Tangier Gazette, 19.12.1925. 
Gordon-Canning hatte sich mittlerweile auf den Weg nach Marokko gemacht. In Rabat traf er am 13. November 1925 den erst einige Tage zuvor aus Algerien eingetroffenen neuen Generalresidenten des französischen Protektorats, Théodore Steeg - ein weiteres Indiz für einen offiziellen Charakter seiner Mission $^{798}$. Von dort aus brach er weiter zur Front auf und überquerte die französischen Linien. In Targuist wurde Gordon-Canning am 23. November 1925 von Abdelkrim und Si M'hammed empfangen ${ }^{799}$. Sie waren angesichts der für sie prekären militärischen Lage bereit, eine Autonomie zu akzeptieren, verlangten aber weiterhin das Recht auf eine eigene bewaffnete Streitmacht und forderten Tetuan, den Sitz des spanischen Hochkommissars, als Hauptstadt des zukünftigen autonomen Rifs ein. Die religiöse Hoheit des Sultans sollte anerkannt werden, aber die Rifregierung war nicht willens, von ihm bestätigte Bergbaurechte, die sich auf das Rif bezogen, zu akzeptieren ${ }^{800}$.

Am 9. Dezember 1925 kehrte Gordon-Canning nach Tanger zurück. Er hatte jedoch kein Schriftstück mit den Friedensvorschlägen Abdelkrims in der Hand, sondern nur ein von ihm selbst verfaßtes Memorandum, das die Ergebnisse seiner Unterredung zusammenfaßte. Dieses Memorandum übergab er den Generalkonsulaten Frankreichs und Spaniens. Er erbat eine rasche Antwort, da er schnell wieder ins Rif aufbrechen wollte ${ }^{801}$. Der britische Generalkonsul Robert Clive gab Gordon-Canning zu bedenken, daß derartige Vorschläge Abdelkrims unnütz seien, da die spanische Regierung über sie keinen Augenblick nachdenken werde. In seinem Bericht nach London bezeichnete er Gordon-Canning als »keinen sehr weisen Berater«, denn sein Enthusiasmus für ein unabhängiges Rif ermutige Abdelkrim nur, überzogene Forderungen zu stellen $^{802}$.

${ }^{798}$ ADMAE Maroc 135, 35: Robert Gordon-Canning an Aristide Briand, 27.12.1925; Peace in Morocco Now Declared Near, in: New York Times, 14.12.1925; Riff Peace Move Reported. Abdel's Emissary at Rabat, in: Manchester Guardian, 16.11.1925; Riff Peace Move. French Receive Abdel's British Envoy, in: Manchester Guardian, 14.12.1925; Peace Move in Riff War, in: Al-Moghreb al Aksa \& Tangier Gazette, 12.12.1925; Ein Friedensvermittler in Marokko, in: Kölnische Zeitung, 12.11.1925; Die fremden Helfer Abd-el-Krims, in: Berliner Tageblatt, 24.11.1925; FURNEAUX, Abdel Krim, S. 215.

${ }^{799}$ DUMAS, Abd-el-Krim, S. 52; TERRIER, Les »Frères de la côte» 1926, S. 38; L'émissaire d'Abd-el-Krim en France, in: L'Illustration 84 (1926) S. 25; MELLOR, Morocco, S. 86.

${ }^{800}$ PRO-FO 371, 11080, 39, 222: CG Tangier an FO, 10.12.1925 mit dem Bericht GordonCannings »Official Views of the Riff Government as given to me at Targuist NEAUX, Abdel Krim, S. 215-218; TERRIER, Les »Frères de la cóter 1925, S. 655.

${ }^{801}$ ADMAE Maroc 134, 49: CG Tanger an MAE, 12.12.1925; ADMAE Maroc 134, 63: CG Tanger an MAE, 13.12.1925; ADMAE Maroc 134, 83: CG Tanger an MAE, 17.12.1925; CADN Tanger C37: Tabor de police $N^{\circ} 1$, Renseignements, 11.12.1925; Tangier News, in: Al-Moghreb al Aksa \& Tangier Gazette, 12.12.1925; HARRIS, Abd-el-Krim's Offer to Treat, 18.12.1925; Abd-el-Krim Envoy Outline Terms, in: New York Times, 22.12.1925; Der Sendbote Abd el Krims, in: Kölnische Zeitung, 15.12.1925; Abd el Krims Friedensbote, in: Deutsche Allgemeine Zeitung, 19.12.1925.

${ }^{802}$ PRO-FO 371, 11080, 39, 222: CG Tangier an FO, 10.12.1925. 
Als Folge erhielt der Brite auch weder von der spanischen noch von der französischen Regierung eine Antwort. Also machte er sich nach Paris auf, wo er bei seiner Ankunft am 22. Dezember 1925 von einem Journalistenpulk empfangen wurde. Er gab eine Pressekonferenz nach der anderen, war Gast der Anglo-American Press Association und führte Gespräche mit Louis Malvy und Théodore Steeg, der zum Jahresende in die Heimat gefahren war ${ }^{803}$. Gordon-Canning war ein gefragter Mann. Aber er war erfolglos. Die spanische Zensur hatte bis zum 26. Dezember 1925 jeglichen Bericht über den britischen Gesandten untersagt, doch dann veröffentlichte die spanische Regierung zwei Kommuniqués, in denen sie Abdelkrim aufgrund seiner Niederlagen der letzten Monate vorwarf, nur Zeit gewinnen zu wollen. Sie lehnte Verhandlungen und ein Treffen mit Gordon-Canning ab. Da sein Memorandum nicht von Abdelkrim unterschrieben war, war es ein Leichtes, die dort genannten Bedingungen in Frage zu stellen ${ }^{804}$. In Frankreich hatte es am 22. November 1925 zudem einen Regierungswechsel gegeben. Der neue Ministerpräsident hieß Aristide Briand, der eine härtere Gangart gegenüber Abdelkrim propagierte, da er den Krieg für mittelfristig gewonnen erachtete. Er weigerte sich, Gordon-Canning zu empfangen ${ }^{805}$.

${ }^{803}$ ADMAE Maroc 135, 40: MI, Sûreté générale an MAE, 23.12.1925; PRO-FO 371, 11827, 27, 170: Sir Charles Mendl an William Tyrrell, 30.12.1925; Abd-el-Krim's Ouvertures for Peace, in: Times, 23.12.1925; French Losses in Morocco, in: Times, 24.12.1925; Peace Terms for Abdel Krim. Captain Canning Explains His Mission, in: Manchester Guardian, 24.12.1925; Abd-el-Krim Asks Status of Canada, in: New York Times, 23.12.1925; Un ambassadeur d'Abd-el-Krim à Paris, in: L'Dlustration 84 (1926) S. 20; Le capitaine GordonCanning a conféré avec M. Malvy, in: Matin, 24.12.1925; Les propositions d'Abd El Krim, in: Matin, 23.12.1925; M. Gordon-Canning arrive hier à Paris et nous parle de la mission dont l'a chargé Abd-el-Krim, in: Quotidien, 23.12.1925.

${ }^{804}$ Léon ROLLIN, L'Espagne au Maroc, in: Bulletin du Comité de l'Afrique française 36 (1926) S. 45-50, S. 47-49; TERRIER, Les »Frères de la côte« 1926, S. 43; ESPAÑA, La actuación, S. 292; More Riffs Submit, Returning to Homes, in: New York Times, 29.12.1925; PRO-FO 371, 11907, 5, 10: Embassy of Madrid an FO, 28.12.1925; PRO-FO 371, 1190, 5, 16: Embassy of Madrid an FO, 31.12.1925; PRO-FO 371, 11910, 76, 201: Embassy of Madrid an FO, 6.1.1926; CADN Madrid C263: Ambassade de Madrid an MAE, 31.12.1925.

${ }^{805}$ AGERON, La presse parisienne, S. 285; FURNEAUX, Abdel Krim, S. 219; SLAVIN, Anticolonialism, S. 355f.; LAURE, La victoire, S. 154f.; TERRIER, Les »Frères de la côte» 1926, S. 41f.; Les propositions de paix d'Abd el Krim, in: Temps, 21.12.1925; Réponse du Quai d'Orsay à M. Gordon-Canning, in: Temps, 1.1.1926; M. Briand refuse de recevoir l'envoyé d'Abd el Krim, in: Humanité, 22.12.1925; M. Gordon-Canning dit à >l'Humanité l'ardent désir de paix qui anime les Rifains, in: Humanité, 23.12.1925; M. Briand répond à M. Canning qu'il ne peut le recevoir, in: Humanité, 1.1.1926; Une lettre du Capitaine Gordon-Canning, in: Humanité, 6.1.1926; Briand Refuses Riff Peace Offer, in: New York Times, 31.12.1925; Correspondence between Captain Gordon-Canning and the Ministry of Foreign Affairs Paris, in: Al-Moghreb al Aksa \& Tangier Gazette, 16.1.1926; Captain Canning's Mission, in: Times, 29.12.1925; Briands Absage an Abd el Krim, in: Düsseldorfer Nachrichten, 2.1.1926; Der Brief des Hauptmanns Canning, in: Berliner Tageblatt, 31.12.1925. 
Nach seiner vergeblichen Friedensmission sank Gordon-Cannings Stern rapide. Im Dezember 1925 und noch Anfang 1926 in einem Brief an den französischen Ministerpräsidenten Aristide Briand hatte er die Öffentlichkeit glauben machen wollen, keinerlei Interesse an Bergbau-Konzessionen im Rif zu haben $^{806}$. Doch dann mußte Gordon-Canning gegenüber dem Tangerer »Times«Korrespondenten Walter B. Harris zugeben, daß sein Partner Karl Hackländer mit britischen und spanischen Interessenten über die Bildung eines Bergbausyndikats verhandelte. Sobald Frankreich und Spanien die Unabhängigkeit oder Autonomie des Rifs anerkennen würden, begänne seine Gruppe mit der Ausbeutung der Rifbodenschätze. Falls er Erfolg habe, werde er mehrere Jahre als Repräsentant dieser Gruppe und als Berater Abdelkrims im Rif arbeiten. Damit erschienen Gordon-Cannings vermeintlich hehre Absichten in einem völlig neuen Licht. Offensichtlich standen wirtschaftliche Interessen hinter seinen diplomatischen Initiativen. Harris gab seine Erkenntnisse an gute Bekannte in den französischen und britischen Konsulaten Tangers weiter ${ }^{807}$.

Die Neuigkeiten machten schnell die Runde. Gordon-Cannings Londoner Riff-Committee wurde daraufhin in der »Revue indigène« als »Riff Mining Committee $\ll$ verspottet ${ }^{808}$. Besonderen Ärger bekam Gordon-Canning wegen seiner Zusammenarbeit mit Karl Hackländer. Der Brite beteuerte nicht sehr glaubwürdig, daß Hackländer seine materiellen Interessen im Rif niemals habe erkennen lassen - wobei Gordon-Canning seine eigenen Pläne tunlichst verschwieg $^{809}$. Der Abbruch seines Kontaktes zu Hackländer kam zu spät ${ }^{810}$. Gordon-Cannings Reputation und seine Glaubwürdigkeit vor allem innerhalb der britischen Gemeinschaft Tangers waren verspielt ${ }^{811}$.

${ }^{806}$ ADMAE Maroc 135, 7: Embassy of Paris an MAE, 23.12.1925; ADMAE Maroc 135, 84: Robert Gordon-Canning an Aristide Briand, 1.1.1926; French Losses in Morocco, in: Times, 24.12.1925; Peace Terms for Abdel Krim. Captain Canning Explains his Mission, in: Manchester Guardian, 24.12.1925. Auch später beteuerte Gordon-Canning gegenüber dem britischen Autor Francis W. Mellor, sich niemals für Bergbau im Rif interessiert zu haben [MELLOR, Morocco, S. 85].

${ }^{807}$ CADN Tanger C40: Bericht »Note sur le rôle du Capitaine anglais Gordon-Canning dans les affaires riffaines $\lll$, 12.1.1926.

${ }_{808}$ Étienne MARSAN, L'ambassadeur d'Abd el Krim, in: Revue indigène 203-204 (1925) S. 236-239, S. 237.

${ }^{809}$ PRO-FO 371, 11907, 5, 113: Robert Gordon-Canning an FO, 2.2.1926.

110 ADMAE Maroc 135, 169: CG Tanger an MAE, 28.1.1926 mit dem beiliegenden Telegramm Robert Gordon-Canning an Karl Hackländer o.D. [Januar 1926]. Vgl. Robert GoRDON-CANNING, Correspondence (Leserbriefe), in: Al-Moghreb al Aksa \& Tangier Gazette, 30.1.1926 und 6.2.1926.

${ }^{811}$ Captain Gordon-Canning and the Riff-Committee, in: Al-Moghreb al Aksa \& Tangier Gazette, 30.1.1926; La presse de Tanger dévoile le rôle suspect du Capitaine Canning, in: Petit Parisien, 30.1.1926; HaRRIS, Captain Canning and Abd-el-Krim, 30.1.1926. 
Es kam zudem heraus, daß Abdelkrim von Gordon-Canning den Ratschlag erhalten hatte, die spanischen Truppen anzugreifen, um sie aus dem Land zu vertreiben. Hingegen sollten die französischen Truppen von Kämpfen verschont bleiben, da Frankreich eher zum Frieden bereit sei ${ }^{812}$. Generalkonsul Robert Clive beorderte Gordon-Canning daraufhin zu sich und beschrieb ihn im Anschluß als selbstgefalligen Egozentriker, der gerne Schicksal spielen wolle. Gordon-Canning meinte, daß nur spanischer Stolz den Frieden verhindere. Jeder könne sehen, daß ein Angriff Abdelkrims eine friedensfördernde Maßnahme sei, um Primo de Rivera zum Einlenken zu zwingen. Der Brite kokettierte damit, daß er es gelegentlich für ratsam gehalten habe, »Abdelkrim einen kleinen privaten Ratschlag gegeben zu haben, der den Franzosen oder Spaniern nicht geschmeckt haben könnte ${ }^{813}$. Um seine drohende Ausweisung aus Tanger, die Spanien und Frankreich vehement forderten, abzuwenden, wurde Gordon-Canning nahegelegt, die Stadt freiwillig zu verlassen ${ }^{814}$. Er befolgte den Rat am 4. Februar 1926 und kehrte über Gibraltar und Paris nach London zurück ${ }^{815}$.

$\mathrm{Da}$ sie sich von Gordon-Canning betrogen fühlten, traten Mary Edith Durham und Robert Cunninghame Graham, der die Affaire eigens in Tanger untersucht hatte ${ }^{816}$, aus dem Riff-Committee aus. Cunninghame Graham warf Gordon-Canning die Zusammenarbeit mit Karl Hackländer, das Redigieren von Friedensbedingungen nach eigenem Gutdünken und das Versäumnis, auch die spanische Regierung informiert zu haben, vor ${ }^{817}$. Zehn Mitglieder des RiffCommittees - der sharte Kern in Person von Lady Pole, Mrs. Z. Charlton, Mrs. M.A. Bryan, Charles Ryder, Arnold Lupton, R.G.A. Armstrong, Herbert

${ }^{812}$ PRO-FO 371, 11907, 5, 90: CG Tangier an FO, 8.1.1926; PRO-FO 371, 11907, 5, 56: CG Tangier an FO, 13.1.1926.

${ }^{813}$ PRO-FO 174, 305, 88: CG Tangier an FO, 25.1.1926.

${ }^{814}$ PRO-FO 174, 305, 88: FO an CG Tangier, 28.1.1926; PRO-FO 174, 305, 88: CG Tangier an FO, 29.1.1926; ADMAE Maroc 135, 71: CG Tanger an MAE, 29.1.1926; PRO-FO 174, 305, 88: CG Tangier an Robert Gordon-Canning, 2.2.1926; ADMAE Maroc 133, 253: Bericht "Déclarations du capitaine Gordon-Canning au cours d'un déjeuner qui lui a offert par le Riff-Committee le 20 février 1926«, 23.2.1926.

${ }_{815}$ ADMAE Maroc 135, 197: CG Tanger an MAE, 4.2.1926; ADMAE Maroc 135, 209 und 212: Berichte «Surveillance exercée à l'égard de Gordon-Canning«, 12.-16.2.1926; Walter B. HARRIS, Captain Canning, in: Times, 8.2.1926; Le capitaine Canning a quitte Tanger, in: Petit Parisien, 6.2.1926; Neutrality, in: Al-Moghreb al Aksa \& Tangier Gazette, 6.2.1926.

${ }^{816}$ ADMAE Maroc 133, 245: Bericht »Réunion tenue par le Riff-Committeek, 3.3.1926; CADN Tanger C40: Tabor de police $N^{\circ}$ 1, Information, 2.3.1926; ADMAE Maroc 133, 277: Tabor de police $\mathrm{N}^{\circ}$ 1, Information, 15.3.1926; ADMAE Maroc 133, 295: Note, 26.3.1926; PRO-FO 371, 11908, 5, 273: CG Tangier an FO, 25.3.1926; PRO-FO 371, 11920, 2328, 20: CG Tangier an FO, 15.3.1926; Tangier News, in: Al-Moghreb al Aksa \& Tangier Gazette, 6.3.1926.

${ }^{817}$ CADN Madrid C263: MAE an Ambassade de Madrid, 29.3.1926 mit dem beiliegenden Bericht »Note remise le 26 mars 1926 par l'ambassade d'Espagne«. 
Bryan, Khalid Sheldrake, Christopher Searle und Arthur Field - veröffentlichten allerdings in der Aprilausgabe der Zeitschrift »Foreign Affairs« eine Solidaritätsbekundung zu Gordon-Canning ${ }^{818}$.

Der Brite gab weiterhin nicht auf und plante bereits seine Rückkehr nach Marokko. Das britische Außenministerium warnte ihn, daß er im Hafen von Tanger nicht von Bord gelassen würde ${ }^{819}$. Daraufhin machte sich GordonCanning im April 1926 nach Paris auf, da er von bevorstehenden Verhandlungen zwischen den Kriegsparteien erfahren hatte. Zu seinen dortigen Freunden gehörte auch der französische Journalist Jacques Roger-Mathieu, der im August 1925 selbst im Rif gewesen war ${ }^{820}$. Gordon-Canning bemühte sich vergebens, im französischen Außenministerium Gehör zu finden ${ }^{821}$.

Seine Versuche, als Rif-Delegierter für die Friedensverhandlungen von Oujda (18. April bis 7. Mai 1926) anerkannt zu werden, wurden vereitelt ${ }^{822}$. Briefe, die Gordon-Canning Christopher Searle vom Riff-Committee mitgab, um sie den Rif-Gesandten in Oujda auszuhändigen, kamen nie an. Searle arbeitete für die spanische Botschaft in London, um die Sympathisantengruppe auszuspionieren $^{823}$. Gordon-Canning versuchte, die Konferenz von Oujda scheitern zu lassen, denn er erwartete, daß die französische Regierung wegen einer schweren Finanzkrise nicht mehr lange im Amt bleiben würde. Die von Frankreich und Spanien geforderte Anerkennung des marokkanischen Sultans durch Abdelkrim konnte nicht in seinem Interesse sein. Dies hätte die Akzeptanz des marokkanischen Bergbaugesetzes bedeutet. Über seine Tangerer Kontakte ließ er Abdelkrim mitteilen, er solle den Krieg fortsetzen und durchhalten ${ }^{824}$. Die Rifregierung gab sich weiter kämpferisch und beharrte in Interviews und während der Verhandlungen von Oujda auf ihrem alleinigen Recht, Bergbaurechte zu vergeben. Auf die Frage eines schwedischen Journalisten nach der Gültig-

${ }^{818}$ The Riff-Committee and Captain Gordon-Canning, in: Foreign Affairs 7 (1925-1926) S. 305. Vgl. auch FIELD, France and the Riff, S. 234f.; DERS., The Morocco War (Leserbrief, 3.3.1926), in: Manchester Guardian, 4.3.1926; TNLA, GGD, 1: Arthur Field an Editor of Times, 28.3.1926.

${ }^{819}$ PRO-FO 371, 11907, 5, 147: Robert Gordon-Canning an FO, 20.2.1926; PRO-FO 371, 11907, 5, 161: Robert Gordon-Canning an FO, 26.2.1926; PRO-FO 371, 11907, 5, 185: Robert Gordon-Canning an FO, 7.3.1926; PRO-FO 371, 11907, 5, 145: Minute, 22.2.1926; PRO-FO 371, 11907, 5, 184: Minute, 9.3.1926; PRO-FO 371, 11907, 5, 189: FO an Robert Gordon-Canning, 12.3.1926.

${ }^{800}$ CADN Madrid C263: MAE an Ambassade de Madrid, 29.3.1926.

${ }^{821}$ Riff Envoy Waits to Discuss Peace, in: New York Times, 4.4.1926.

${ }_{22}$ PRO-FO 371, 11908, 5, 13: Embassy of Paris an FO, 13.4.1926; ADMAE Maroc 135, 288: Gouverneur général de l'Algérie an MAE, 19.4.1926; ADMAE Maroc 135, 287: Général Simon, Oujda an Gouverneur général de l'Algérie, 16.4.1926.

${ }^{823}$ ADMAE Maroc 134, 23: MI, Cabinet an Préfet d'Oran, 15.4.1926; ADMAE Maroc 134, 32: Bericht $»$ Note au sujet de Searle, sujet anglais«, 22.4.1926; ADMAE Maroc 135, 286: Bericht »Surveillance exercée à l'égard de Gordon-Canning«, 15.4.1926.

${ }^{824}$ CADN Maroc DAI 198: Si Abdelkrim ben el Haj Ali Luh an Abdelkrim, 8.4.1926; CADN Madrid C261: Ambassade de Madrid an MAE, 21.4.1926. 
keit früherer Konzessionen antwortete Si Mohammed Boujibar, daß sie auf keinen Fall anerkannt würden ${ }^{825}$. Insgeheim jedoch verschickte Abdelkrim bereits Abschieds- und Dankesbriefe an seine Bergbau-Geschäftspartner und an seine europäischen Sympathisanten ${ }^{826}$.

Auch nach Abdelkrims Kapitulation gab Gordon-Canning seinen Einsatz für Moslems nicht auf. Er engagierte sich zunächst in Syrien, Ägypten und Palästina, ehe er sich dann der British Union of Fascists und dem Right Club anschloß. Die Mitgliedschaften brachten ihm während des Zweiten Weltkrieges einen Gefangnisaufenthalt ein ${ }^{827}$. Neben Gordon-Canning verfielen auch andere Unterstützer Abdelkrims faschistischem Gedankengut, wie etwa George Ward Price, Ernest N. Bennett oder Jacques Doriot.

\subsection{Abdelkrim und der »Times«-Korrespondent Walter Harris}

Ein weiterer britischer Berater Abdelkrims war der Tangerer »Times «-Korrespondent Walter Burton Harris. Seit er 1887 eine britische diplomatische Mission zum Sultanshof begleitet hatte, ließ Marokko ihn nicht mehr los. Seit 1894 sandte der Lebemann von seiner östlich von Tanger gelegenen Villa aus Artikel über Marokko zur "Times«-Redaktion nach London. Er avancierte zu einer legendären Figur in der Hafenstadt. Walter Harris und Robert Cunninghame Graham vom Londoner Riff-Committee kannten sich seither und waren sehr gute Freunde. Seine jahrzehntelangen Erfahrungen - zwischen 1901 und 1902 auch als Berater des marokkanischen Sultans Moulay Abdelaziz - und seine exzellenten Arabischkenntnisse machten Harris zu einem ausgewiesenen Kenner Marokkos ${ }^{828}$. Reisen hatten ihn in viele Landesteile geführt - aller-

${ }^{825}$ LANGLET, Life, 1.5.1926; PRO-FO 371, 11908, 5, 109: Consul General of Rabat an FO, 10.5.1926.

${ }^{826}$ TERRIER, Les »Frères de la côter 1926, S. 299.

${ }^{827}$ DERS., England and Egypt, in: Times, 4.5.1929; PRO-FO 371, 12302, 21, 7: Robert Gordon-Canning an The Near and Middle East Association, 27.9.1926; PRO-FO 371, 11909, 5, 105: Bericht »Activities of Capt. Gordon-Canning «, 18.10.1926; PRO-FO 371, 12380, 424, 117: The Residency of Cairo an FO, 27.3.1927; SHEEAN, Personal History, S. $411 \mathrm{f}$; GRIFFITHS, Patriotism, S. 26f., S. 273; Alfred W.B. SIMPSON, In the Highest Degree Odious. Detention without Trial in Wartime Britain, Oxford u.a. 1992, S. 139-142, S. 215, Anm. 106; Former Officer Detained, in: Times, 15.7.1940.

${ }^{828}$ JOFFÉ, Walter Harris, S. 250, S. 256; PORCH, The Conquest, S. 17; PARSONS, The Origins, S. 506, S. 637; LANDAU, Portrait, S. 149; DeSmOnd, Crisis and Conflict, S. 263; VAIDON, Tangier, S. 114, S. 140; GuLLEN, L'Allemagne, S. 620, S. 624, S. 671-673; BIDWELL, Morocco, S. 295; The History of the Times. The Twentieth Century Test 1884-1912, London 1947, S. 410; Edward GLEICHEN, France, Spain and the Rif. By Walter Harris (Rezension), in: Joumal of the Royal Institute of International Affairs 6 (1927) S. 260; PRO-FO 
dings nie ins Rif, dessen Verhältnisse er aus eigener Anschauung nicht kann$t^{829}$. Lange Zeit betrachtete sich Harris als nicht für den Rifkrieg zuständig. Er hielt ihn für eine spanische Angelegenheit und war der Meinung, sein Intimfeind Ernest de Caux, der »Times«-Korrespondent von Madrid, habe darüber zu berichten ${ }^{830}$.

Über Harris und die »Times« - die wichtigste Tageszeitung Großbritanniens - versuchte Abdelkrim, die britische Öffentlichkeit und die britische Regierung von seinen Zielen zu überzeugen. Sporadisch ließ Abdelkrim dem Briten bereits 1922 Briefe zukommen, in denen er Europäer einlud, das Rif zu besuchen $^{831}$, oder in denen er politische Erklärungen über den Willen der Rifkabylen zur Unabhängigkeit abgab ${ }^{832}$. Erst im Mai 1924 erneuerte er den Briefkontakt. Abdelkrim spielte Harris die ein Jahr alte Korrespondenz von 1923 zwischen seinem Außenminister Azerkane und dem spanischen Verhandlungsführer Don Diego Saavedra zu, um damit zu untermauern, daß die Erklärung Azerkanes vom 24. Juli 1923 noch immer Gültigkeit hatte. In einem Brief an seinen Chef Harold Williams machte sich Harris darüber lustig: «Abdelkrim über den Krieg und den Vertrag von Versailles - und über Moral im allgemeinen -, das ist wirklich amüsant ${ }^{833}$. Und er ging in einem »Times«Artikel noch weiter, indem er behauptete, die Rifkabylen seien "völlig unfähig, sich selbst zu regieren ${ }^{834}$.

Derartige Äußerungen entsprachen seiner Grundhaltung. Er war als frankophiler Bewunderer Lyauteys ein Befürworter des Imperialismus und des französischen >Schutzes` von Marokko ${ }^{835}$. Er behielt aber immer auch die britischen Interessen im Auge. Seine Landsleute warnte er vor Bergbauverträgen, da von Abdelkrim vergebene Konzessionen wertlos seien. An ihn weitergeleitete Informationen Abdelkrims über Schmuggelgeschäfte mit Engländern hielt Harris zurück, um sein Land vor einem Skandal zu bewahren - aber auch, weil er kurz zuvor genau das Gegenteil behauptet hatte ${ }^{836}$. Harris war ohnehin dafür

371, 11080, 39, 155: Embassy of Madrid an FO, 23.10 .1925 mit dem beigefügten Bericht von W.W.T. Torr "Interview with Mr. W.B. Harris, the `Times` Correspondent at Tangier«, 10.10.1925.

${ }^{829}$ PRO-FO 371, 7082, 8256, 170: John Amall an FO, 13.8.1921.

${ }^{830}$ TNLA, BNS, 1, Williams: Harold Williams an Walter Harris, 12.9.1924.

${ }^{831}$ TNLA, RD, 1, Deakin: Walter Harris an Ralph Deakin, 7.6.1922.

${ }^{832}$ HARRIS, Spain's Moroccan War, 30.5.1922.

${ }^{833}$ TNLA, BNS, 1, Williams: Walter Harris an Harold Williams, 19.5.1924.

${ }^{834}$ Walter B. HARRIS, Spain and the Riff. Two Unpublished Letters, in: Times, 9.6.1924. Vgl. TNLA, BNS, 1, Williams: Walter Harris an Harold Williams, 4.10.1924.

${ }^{835}$ FURNEAUX, Abdel Krim, S. 189; The History of the Times, S. 411.

${ }^{836}$ TNLA, BNS, 1, Williams: Walter Harris an Harold Williams, 18.9.1924; HARRIS, The Moroccan Campaign, 11.9.1924. 
berüchtigt, es in seinen Artikeln mit der Wahrheit nicht immer genau zu nehmen. Gerald Villiers vom britischen Außenministerium betrachtete ihn als notorischen Lügner ${ }^{837}$.

Am 22. September 1924 gab Harris dem Rifboten Si Mohammed ben Haj Hammouch einen Brief mit, in dem er Abdelkrim seine Dienste anbot. Falls Abdelkrim wolle, daß durch ausländische Unterstützung ein Friedensabkommen erreicht werden solle, müsse er eine realitätsnahe Politik verfolgen und übermäßige Ansprüche unterlassen, schrieb Harris. Er hielt es für möglich, daß das Rif im bisher dreigeteilten Marokko eine vierte Zone werden konnte, aber nur mit der Zustimmung aller am Algeciras-Vertrag beteiligten Nationen einschließlich Spanien ${ }^{838}$.

Abdelkrim zeigte sich interessiert. Ihm fehlte, nachdem er sich mit Charles Gardiner überworfen hatte, ein politischer Berater. Er hoffte, daß Harris für ihn als neues Sprachrohr vor allem in Richtung Großbritannien fungieren würde $^{839}$. Beide profitierten voneinander. Harris gelangte über Abdelkrim an Informationen, und Abdelkrim konnte über Harris seine Ansichten veröffentlichen oder ihn als Vermittler verwenden. Ein Brief von Si Mohammed Azerkane vom 1. Juni 1925 verdeutlicht, daß er davon ausging, Harris habe seine hohe Position in der englischen Regierung « inne ${ }^{840}$. Abdelkrim zufolge spielte sich der Brite ihm gegenüber wals Wortführer der öffentlichen Meinung Englands auf $^{841}$. Tatsächlich brüstete sich Harris gelegentlich in Tanger als Verkünder der offiziellen Sichtweise Großbritanniens, ohne daß er dazu ermächtigt worden wäre ${ }^{842}$.

Über Harris wurden in der Folgezeit Friedensvorstellungen zwischen Abdelkrim und Spaniens Vermittler Francisco Sostoa ausgetauscht. Die Tangerer Rifagenten Si Abdelkrim ben el Haj Ali Luh und Moulay Ali el Khamlichi schleusten Boten mit Informationen in die internationale Zone ${ }^{843}$. Über Walter Harris ließ Abdelkrim seine Ansichten über die Grenzvorfälle im Ouerghatal vor der französischen Zone Marokkos publizieren. Hier hatte es im Sommer 1924 zwischen frankreichtreuen Kabylen und Riftruppen bewaffnete Ausein-

${ }^{837}$ PRO-FO 371, 11082, 1724, 172: Minute, 4.3.1925. Vgl. PRO-FO 371, 4517, 218: CG Tangier an FO, 20.10.1920; VAIDON, Tangier, S. 118.

${ }^{838}$ CADN Tanger B30: RG Rabat an CG Tanger, 3.10.1924 mit einer übersetzten Kopie des Briefes Walter Harris an Abdelkrim, 22.9.1924.

${ }_{839}$ JOFFÉ, Walter Harris, S. 261. Über seine Dienste für Abdelkrim verliert Harris in seinem Buch »France, Spain and the Rif« (1927) kein Wort. Abdelkrim stellte in seinen »Memoiren« klar: »Harris war mir Berater« [ABDELKRM, Memoiren, S. 106].

${ }^{840}$ TNLA, Harris, BNS, 2: Si Mohammed Azerkane an Walter Harris, 1.6.1926.

841 ABDELKRIM, Memoiren, S. 106.

${ }^{842}$ CADN Madrid C259: MAE an Ambassade de Madrid, 17.10.1924; CADN Tanger B30: MAE an CG Tanger, 17.10.1924.

${ }^{843}$ TNLA, BNS, 1, Williams: Walter Harris an Harold Williams, 18.9.1924; PRO-FO 371, 10582, 101, 159: CG Tangier an FO, 24.11.1924. 
andersetzungen gegeben, woraufhin französische Truppen den Fluß überschritten hatten. Abdelkrim führte aus, daß die Rifregierung die Aufsplitterung Marokkos in Protektorate nie anerkannt und deren Grenzen nie akzeptiert habe. Die Riftruppen hätten die Ouergha-Region in Abdelkrims Herrschaftsbereich eingegliedert. Er betrachte die Besetzung des Tales durch französische Truppen daher als Invasion in Rif-Territorium und als unfreundlichen $\mathrm{Akt}^{844}$. Generalresident Lyautey hingegen bezeichnete Abdelkrim nach dem OuerghaKonflikt in einem Interview mit Walter Harris als »eine deutliche Gefahr für alle Mächte, die in islamischen Ländern Interessen verfolgen « ${ }^{845}$.

Die fast zeitgleichen Veröffentlichungen waren eine Art Vorläufer für Harris' Vermittlungsversuche zwischen der Rifregierung und Frankreich im Sommer 1925. Seit den ersten etwas engeren Kontakten vom Vorjahr hatte sich das Verhältnis zu Abdelkrim intensiviert. Angesichts der für Frankreich problematischen militärischen Situation im Sommer 1925 versuchte Generalresident Lyautey, sich die guten Beziehungen von Harris zu Abdelkrim zunutze zu machen. Anfang Juni 1925 bat er den britischen Journalisten, sich als Mittelsmann für Verhandlungen zur Verfügung zu stellen ${ }^{846}$. Für Harris war klar, daß der Bergbau im Rif der Hauptgrund für Abdelkrims Gesprächsbereitschaft $\operatorname{war}^{847}$.

Zeitgleich verliefen ähnliche und unabhängig verlaufende Bestrebungen Spaniens über den Vermittler Horacio Echevarrieta. Zu dieser Zeit steckte die französisch-spanische Allianz noch in den Anfängen. Harris' Dienste für Abdelkrim vollzogen sich ebenso zu parallelen und gesonderten Aktionen des Rif-Beraters Robert Gordon-Canning. Eine von Abdelkrim am 8. Juni 1925 verfaßte Grundsatzerklärung in Bezug auf den Willen der Rifkabylen, weiterhin unabhängig zu leben, publizierte die "Times» mit Harris' Hilfe am 19. Juni $1925^{848}$.

Lyauteys Angebot für Abdelkrim lautete: 1. Verzicht auf die von den Rifkabylen eroberten Gebiete nördlich der Linie, die französische Truppen 1924 gehalten hatten, 2. Anerkennung der Souveränität des Sultans im Rif, 3. Garantie "eines hohen Grades an Unabhängigkeit ${ }^{849}$. Lyautey vermied demnach das Zugeständnis einer Anerkennung der absoluten Unabhängigkeit des Rifs - ein Punkt, der für ihn nie in Frage gekommen wäre. Er schlug zudem für zukünftige Friedensverhandlungen eine Vermittlerrolle Großbritanniens oder der

\footnotetext{
244 Walter B. HARRIS, France and Morocco. Abdel Krim's Claims, in: Times, 11.11.1924.

${ }^{\text {945 }}$ DERS., France and Morocco. Marshall Lyautey's Warning, in: Times, 10.11.1924.

${ }^{846}$ PRO-FO 371, 11080, 186, 103: CG Tangier an FO, 14.6.1925.

${ }^{847}$ TNLA, BNS, 1, Williams: Walter Harris an Harold Williams, 22.6.1925.

${ }^{848}$ Walter B. HARRIS, Rif Coast Fortified. Warning to Merchantmen, in: Times, 19.6.1925; PRO-FO 371, 11080, 186, 124: CG Tangier an FO, 22.6.1925 mit dem beigefügten Brief Abdelkrim an Walter Harris, 8.6.1925.

${ }^{249}$ PRO-FO 371, 11079, 39, 68: Embassy of Paris an FO, 10.8.1925.
} 
USA vor. Es handelte sich um eine Hinhaltetaktik ${ }^{850}$. Am 15. Juni 1925 empfing Harris einen Rifboten und telegrafierte nach London, daß Abdelkrim zu Friedensgesprächen bereit sei und dringend die Unterstützung der britischen Regierung erbitte ${ }^{851}$. Gerald Villiers von der Afrika-Abteilung des Außenministeriums schloß dies unter allen Umständen aus. In einem internen Memorandum erklärte er die Gründe, denn zum einen war seiner Ansicht nach die öffentliche Meinung nicht bereit, »ein einziges britisches Leben oder einen einzigen britischen Schilling in Marokko zu riskieren«, und zum anderen sah er die Gefahr, daß ein britisches Engagement in Marokko Auswirkungen auf Indien hätte entfalten können ${ }^{852}$.

Im Gegensatz zum Vorjahr änderte Harris seine Einschätzung von der Regierungsfähigkeit Abdelkrims gewaltig. Nun hielt er ihn in seinen Artikeln für »einen sehr bemerkenswerten Mann von großem Organisationsgeschick und großen politischen Fähigkeiten«, der mehr Kompetenz aufbringe, das Rif zu regieren, als jeder Europäer ${ }^{853}$, oder er pries Abdelkrim als »Verkörperung des nationalen Geistes« und als Personifizierung seines Landes ${ }^{854}$. Sein Chef $\mathrm{Ha}-$ rold Williams war von Harris' Enthusiasmus weniger angetan. Er sah nach Absprache mit der britischen Regierung die Gefahr, durch die Veröffentlichung von Briefen Abdelkrims den Anschein einer Sympathie Großbritanniens für das Rif zu erwecken bzw. das Verhältnis zu Frankreich zu trüben ${ }^{855}$. Harris bedauerte diese Haltung der Londoner Redaktion, da seiner Ansicht nach nur mit Hilfe der britischen Regierung der Friedensprozeß in Gang gesetzt werden konnte ${ }^{856}$.

Abdelkrim lud den Briten zu einem persönlichen Gespräch ins Rif ein. Zu dieser Zeit hielten sich dort auch der amerikanische Journalist Larry Rue und der italienische Reporter Mirko Ardemagni, die Abdelkrim ebenfalls für seine Ziele einspannen wollte, auf ${ }^{857}$. Dem 58 jährigen Harris war die Reise zu Lande oder per Schiff jedoch zu gefährlich. Er versuchte, Abdelkrim die Schuld

${ }^{850}$ PRO-FO 371, 11080, 186, 89: CG Tangier an FO, 9.6.1925.

${ }^{851}$ TNLA, Harris, BNS, 2: Walter Harris an Times, 16.6.1925.

${ }_{852}$ PRO-FO 371, 11077, 39, 89: Bericht »Memorandum Morocco: Proposals of the FrancoSpanish Conference at Madrid«, 30.6.1925.

${ }^{853}$ HARRIS, The Warfare, 10.6.1925.

${ }^{854}$ DERS., Moroccan Issue. Basis for Peace Negotiations. Rifi Nationalism, in: Times, 16.6.1925.

${ }^{855}$ TNLA, BNS, 1, Williams: Harold Williams an Walter Harris, 17.6.1925; JOFFE, Walter Harris, S. 262.

${ }^{856}$ TNLA, GGD, 1: Walter Harris an George Dawson, 18.6.1925.

${ }^{857}$ TNLA, Harris, BNS, 3. Walter Harris an Times, 16.6.1925; CADN Maroc DAI 192: CG

Tanger an RG Rabat, 16.6.1925. Siehe S. 310f. 
für die nicht geglückte Vermittlung Großbritanniens zuzuschieben, indem er ihn schriftlich aufforderte, deutlich mehr Friedenssignale zu senden und das Blutvergießen zu stoppen ${ }^{858}$.

Das Mißtrauen Abdelkrims, von Frankreich verraten zu werden, war sehr groß. Harris' Vorschlag, für die Dauer von Verhandlungen eine neutrale Zone zwischen den kämpfenden Truppen einzurichten, wurde von ihm abgewie$\operatorname{sen}^{859}$. Am 28. Juni 1925 empfing Abdelkrim jedoch als ersten - und einzigen - französischen Funktionär seit Beginn des Rifkrieges den Kontrollbeamten von Taourirt Léon Gabrielli. Abdelkrim beteuerte, mit Frankreich in Frieden leben zu wollen, und nannte als Voraussetzung für jede weitere Diskussion die Anerkennung der Unabhängigkeit des Rifstaates. Damit behartte er auf einem Punkt, der für Frankreich nicht diskutabel war ${ }^{860}$.

Nach diesem ersten direkten Kontaktversuch und nach dem Madrider Abkommen zwischen Frankreich und Spanien über ein gemeinsames Vorgehen in Marokko ließ Lyautey Walter Harris am 20. Juli 1925 telegrafisch mitteilen, daß seine Dienste nicht mehr benötigt würden ${ }^{861}$. Abdelkrim jedoch wollte weiter über den Briten verhandeln, da er ihn immer noch als Mittelsmann zur britischen Regierung betrachtete. In deren Vermittlung sah er die einzige Möglichkeit für Frieden ${ }^{862}$. Harris teilte Abdelkrim brieflich und per Feldtelefon vom äußersten Rand der Tangerzone aus mit, daß eine britische Einmischung sehr unwahrscheinlich sei ${ }^{863}$. Gleichzeitig veröffentlichte er Abdelkrims Angebot sofortiger Friedensgespräche, sofern die Unabhängigkeit des Rifstaates und der Verhandlungsort Tanger anerkannt würden ${ }^{864}$. Parallel erschienen jedoch - mit völlig anderen Schwerpunkten - die von Robert Gordon-Canning redigierten Vorschläge Abdelkrims im Pariser "Quotidien«, was zur allgemeinen Verwirrung über die tatsächlichen Ziele des Rifemirs beitrug $^{865}$.

Ende Juli 1925 erhielt der nach Tetuan gebetene Rifgesandte Si Mohammed ben Haj Hammouch alias El Christo sogar noch zusätzliche, nicht mit Frankreich abgesprochene Friedensvorstellungen Primo de Riveras. Die wichtigsten

${ }^{858}$ PRO-FO 371, 11080, 186, 124: CG Tangier an FO, 22.6.1925 mit dem beigefügten Brief Walter Harris an Abdelkrim, 19.6.1925.

${ }^{859}$ TNLA, Harris, BNS, 3: Walter Harris an Times, 23.6.1925.

${ }^{860}$ GABRIELLI, Abd-el-Krim, S. 81-91, S. 94; JACQUES, L'aventure riffaine, S. 229-238; BolCHUT, Campagne, S. 309.

${ }^{861}$ PRO-FO 371, 11079, 39, 89: CG Tangier an FO, 20.8.1925.

${ }^{862}$ PRO-FO 371, 11079, 39, 184: Bericht $»$ Report on a Visit of a Messenger from Abdel Krim to W.B. Harris«, 24.7.1925.

${ }^{863}$ PRO-FO 371, 11079, 39, 4: Bericht $» N o t e:$ Very confidential«, 25.7.1925; PRO-FO 371, 11079, 39, 170: CG Tangier an FO, 26.7.1925.

${ }^{864}$ Walter B. HARRIS, Abd-el-Krim's Reply to Peace Offer. Independence Claim, in: Times, 27.7.1925.

${ }^{865}$ Siehe S. 334, S. 337. 
Punkte betrafen die lokale Autonomie des Rifs, Abdelkrims Anerkennung des marokkanischen Sultans und Spaniens Rückzug nach einer begrenzten Zeit ${ }^{866}$. Nachdem der französische Ministerpräsident Paul Painlevé die französischspanischen Julivorschläge mit ihrem Angebot einer politischen, wirtschaftlichen und administrativen Autonomie am 14. August 1925 veröffentlicht hatte, wurde der Druck auf Abdelkrim größer. Harris riet ihm, diese Bedingungen anzunehmen ${ }^{867}$. Doch als der »Matin«-Korrespondent Jacques Roger-Mathieu Ende August ins Rif reiste, bestanden seine Gesprächspartner Si Mohammed Mohammedine Hitmi und Si M'hammed weiter darauf, daß die Voraussetzung für den Beginn von Friedensgesprächen die Anerkennung der Unabhängigkeit sei $^{868}$. Abdelkrim verfolgte seinen Kurs weiter. Es war allerdings schon zu spät, als ein Rifbote am 6. September 1925 über Tanger nach Tetuan reisen wollte, um mit Primo de Rivera doch noch über die spanischen Vorschläge zu verhandeln ${ }^{869}$. Die spanische Landung in der Bucht von Alhucemas begann zwei Tage danach.

Ein Gespräch mit Major Torr - dem britischen Militärattaché in Madrid - gegen Ende September 1925 bestärkte Walter Harris in seiner spanienkritischen Grundhaltung. Torr hatte erzählt, daß König Alfonso XIII. ihm Fotos von geköpften Rifsoldaten gezeigt habe. Von 140 während der Kämpfe bei Alhucemas gefangengenommenen Rifkabylen seien nur noch 15 am Leben. Der Rest sei, als Offiziere weggeschaut hätten, enthauptet worden ${ }^{870}$. Der empörte Harris forderte die "Times« auf, seinen Artikel über die Vorkommnisse zu veröffentlichen. Ein großes Foto, das Soldaten der spanischen Fremdenlegion und eine Krankenschwester des Roten Kreuzes zeige, liege vor ihm, schrieb Harris. Die Legionäre hielten fünf Köpfe von Rifkabylen in die Kamera. »Im Namen der christlichen Zivilisation« verlangte Harris von der »Times«, beim spanischen Botschafter in London vorstellig zu werden ${ }^{871}$. Die $»$ Times «-Redaktion versuchte jedoch, Harris zurückzuhalten, denn wegen kritischer Artikel drohte ihrem Madrider Korrespondenten Ernest de Caux zu dieser Zeit die Ausweisung aus Spanien. Dies sollte unter allen Umständen verhindert wer-

${ }^{866}$ PRO-FO 371, 11079, 39, 87: CG Tangier an FO, 7.8.1925; PRO-FO 371, 11079, 39, 68: Embassy of Paris an FO, 10.8.1925; Walter B. HARRIS, Abd-el-Krim and the Spanish Envoys at Tetuan, in: Times, 30.7.1925; DERS., Abd-el-Krim and Spain. Envoys at Tetuan, in: Times, 3.8.1925; Ders., Rifi Envoys and Peace Terms. Report to Abd-el-Krim, in: Times, 4.8.1925; DERS., Abd-el-Krim and the Peace Terms, in: Times, 7.8.1925; Les affaires marocaines, in: L'Illustration 83 (1925) S. 126f., S. 126.

${ }^{867}$ TNLA, Harris, BNS, 2: Walter Harris an Abdelkrim, 18.8.1925. Vgl. TNLA, BNS, 1, Williams: Walter Harris an Harold Williams, 19.8.1925.

${ }^{368}$ Jacques ROGER-MATHIEU, Le »Matin« chez Abd el Krim. Un important entretien avec le frère d'Abd el Krim et son premier ministre, in: Matin, 3.9.1925.

${ }^{869}$ PRO-FO 371, 11079, 39, 115: CG Tangier an FO, 6.9.1925.

${ }^{870}$ TNLA, BNS, 1, Williams: Walter Harris an Harold Williams, 30.9.1925. Siehe auch Kapitel 3, S. 57.

${ }^{871}$ TNLA, Harris, BNS, 3: Walter Harris - Editor of Times, 4.10.1925. 
den. Eine Kampagne in der "Times« gegen spanische Greueltaten in Marokko hätte der spanischen Regierung, so fürchtete Williams, nur eine passende $\mathrm{Ge}-$ legenheit geliefert ${ }^{872}$. Harris mußte sich der Selbstzensur seines Blattes fügen.

Als ihm General Primo de Rivera am 9. November 1925 während eines persönlichen Gespräches in Tetuan versicherte, daß Derartiges nicht mehr vorkommen werde, und ihm anbot, künftig zu Besprechungen eingeladen zu werden, war Harris schnell besänftigt. Um sich diese Chance nicht entgehen zu lassen, drängte er die "Times« nun, die Sache nicht hochzuspielen. Rivera bat den Briten auch, sich für eine neue Gesprächsinitiative Spaniens als Vermittler zur Verfügung zu stellen. Harris hatte den Eindruck, daß sein Gesprächspartner nichts von der zeitgleichen Mission Robert Gordon-Cannings, die mit Billigung der französischen Regierung erfolgte, wußte ${ }^{873}$. In seinem Brief an Abdelkrim vom 11. November 1925 verschärfte Harris seinen Ton. Er hatte eingesehen, daß er sich mit seinen Tätigkeiten verzettelt hatte: »Es scheint, daß ich im Rif als französischer Agent angesehen werde, und in den französischen und spanischen Protektoratszonen hält man mich für einen Rifagenten«. Nun wies er Abdelkrim auf seine Neutralität als Engländer hin. Er zeigte sich überzeugt, daß die Angebote der französischen und spanischen Regierung eine großzügige Grundlage für Friedensverhandlungen darstellten, bot aber nur für den Fall seine Hilfe an, daß der Krieg ein Ende fände ${ }^{874}$.

Abdelkrim reagierte auf das Angebot vorerst nicht, da er sich Hoffnungen machte, daß Robert Gordon-Cannings Friedensmission Ende 1925 Erfolg haben würde. Erst nach dessen Scheitern sandte er Harris am 27. Januar 1926 eine eindringliche Erklärung zu. Er hob nicht nur das Recht der Rifkabylen auf eine eigene Regierung und auf Selbstverteidigung gegen äußere Invasoren hervor, sondern auch seine weiterbestehende Bereitschaft zu Friedensverhandlungen ${ }^{875}$. Ähnlich äußerte sich Abdelkrim Mitte Februar 1926 gegenüber dem schwedischen Journalisten Hans Langlet ${ }^{876}$ sowie gegenüber dem französischen Reporter Auguste Montagne im darauffolgenden März ${ }^{877}$.

${ }^{872}$ TNLA, BNS, 1, Williams: Harold Williams an Walter Harris, 21.10.1925.

${ }^{873}$ PRO-FO 371, 11076, 18: Walter Harris an CG Tangier, 14.11.1925.

874 TNLA, Harris, BNS, 2: Walter Harris an Abdelkrim, 11.11.1925.

${ }^{875}$ Walter B. HARRIS, The Rif Case. A Letter from Abd-el-Krim, in: Times, 17.3.1926. Vgl. DERS., Rifi Appeals to the British. Krim's European Advisers, in: Times, 27.5.1926; ToYNBEE, The Islamic World, S. 581f.

${ }^{876}$ LANGLET, Abdel Krim's Views, 29.4.1926; DERS., Life, 1.5.1926; DERS., How the Riffis Fight, 4.5.1926.

${ }^{87}$ Abd-el-Krim Tells of Hope for Peace, in: New York Times, 25.4.1926; Le chef riffain précise les responsabilités de la guerre actuelle et affirme une fois de plus sa volonté de paix, in: Humanite, 17.3.1926; Les prisonniers français au Maroc, in: L'Blustration 84 (1926) S. 334. 
Die Signale wurden in Frankreich registriert. Eine Finanzkrise, der Drusenaufstand in Syrien und zunehmend kritische Stimmen in der Presse über den Sinn des Krieges bewogen die französische Regierung, zusammen mit Spanien eine Konferenz in Oujda zu arrangieren. Während Frankreich und Spanien die Verhandlungen als Gelegenheit für Abdelkrim betrachteten, ehrenvoll und unbesiegt den Rifkrieg zu beenden, hoffte dieser, die Alliierten zu spalten, um möglichst mit Frankreich einen Separatfrieden abzuschließen ${ }^{87}$. Der Rifbevölkerung ließ Abdelkrim im Vorfeld mitteilen, daß er zudem die Unterstützung Großbritanniens, Italiens und der USA hinter sich habe ${ }^{879}$. Walter Harris ärgerte sich in der »Times« darüber, daß die Gerüchte einer britischen Hilfe bei den Rifkabylen nur falsche Hoffnungen wecken würden - wobei er seinen eigenen Beitrag dazu tunlichst aussparte ${ }^{880}$. Vor Beginn der Verhandlungen in Oujda am 18. April 1926 versuchte er den Rifdelegierten Si Mohammed Azerkane davon zu überzeugen, da $B$ nicht mit einer Intervention Großbritanniens gerechnet werden könne ${ }^{881}$.

Die Konferenz wurde am 7. Mai 1926 ergebnislos abgebrochen. Die Lage im Rif war katastrophal. Es herrschten Hunger und Krankheiten. Viele Verbündete Abdelkrims legten die Waffen nieder. Kurz vor dem militärischen Zusammenbruch versandte Abdelkrim am 22. Mai 1926 Briefe an Théodore Steeg und den spanischen Oberkommandierenden General José Sanjurjo, in denen er neue Verhandlungen und die Einstellung der Feindseligkeiten erbat. Doch Spanien bestand auf seiner Unterwerfung ${ }^{822}$. Am 24. Mai 1926 erschien ein Bote Abdelkrims in der »Villa Harris«, um den britischen Journalisten nochmals zu fragen, ob Abdelkrim mit der Hilfe Großbritanniens oder einer anderen Macht rechnen könne. Harris verfaßte auf Arabisch eine negative Antwort. Der Bote verließ Harris am Abend des 25. Mai 1926 und erreichte Bougabech kurz nach Mitternacht, von wo er Abdelkrim den Brief per Feldtelefon vorlesen konnte ${ }^{883}$. Einen Tag später kapitulierte der Emir des Rifs.

\footnotetext{
${ }^{878}$ FLEMING, Primo de Rivera and Spain's Moroccan Problem, S. $92 \mathrm{f}$.

${ }^{879}$ PENNELL, A Country, S. $212 \mathrm{f}$.

${ }^{880}$ Walter B. HARRIS, Moroccan War. Abd-el-Krim's Plans, in: Times, 29.3.1926. Vgl. FURNEAUX, Abdel Krim, S. 85.

${ }^{881}$ HARRIS, France, S. 290f,; JOFFÉ, Walter Harris, S. 261.

${ }^{882}$ PARENT, Au Riff, S. 83, S. 96-106; ABDELKRIM, Memoiren, S. 119-121; CADN Madrid C261: MAE an Ambassade de Madrid, 24.5.1926; PRO-FO 371, 11908, 5, 124: Embassy of Madrid an FO, 24.5.1926.

${ }^{883}$ CADN Madrid C261: MAE an Ambassade de Madrid, 2.6.1926; CADN Tanger C40: CG Tanger, Renseignements, 27.5.1926.
} 